TITLE:

\title{
Ecosystem size predicts the probability of speciation in migratory freshwater fish
}

\section{$\operatorname{AUTHOR}(S)$ :}

Yamasaki, Yo Y.; Takeshima, Hirohiko; Kano, Yuichi; Oseko, Naoharu; Suzuki, Toshiyuki; Nishida, Mutsumi; Watanabe, Katsutoshi

\section{CITATION:}

Yamasaki, Yo Y.... [et al]. Ecosystem size predicts the probability of speciation in migratory freshwater fish. Molecular Ecology 2020, 29(16): 3071-3084

\section{ISSUE DATE:}

2020-08

URL:

http://hdl.handle.net/2433/250818

\section{RIGHT:}

This is the peer reviewed version of the following article: Yamasaki YY, Takeshima H, Kano Y, et al. Ecosystem size predicts the probability of speciation in migratory freshwater fish. Mol Ecol. 2020, which has been published in final form at https://doi.org/10.1111/mec.15415. This article may be used for non-commercial purposes in accordance with Wiley Terms and Conditions for Use of Self-Archived Versions.; The full-text file will be made open to the public on 19 April 2021 in accordance with publisher's 'Terms and Conditions for Self-Archiving'. This is not the published version. Please cite only the published version.; この論文は出版社版でありません。引用の際には出版社版をご確認ご利用くだ さい。 
1 Title: Ecosystem size predicts the probability of speciation in migratory freshwater fish

2

3 Short title: Ecosystem size predicts speciation

4

6

7

8 Author affiliations:

$9{ }^{1}$ Graduate School of Science, Kyoto University, Kitashirakawa-oiwake-cho, Sakyo, Kyoto 10 606-8502, Japan

$11{ }^{2}$ Ecological Genetics Laboratory, Department of Genomics and Evolutionary Biology,

12 National Institute of Genetics, Yata 1111, Mishima, Shizuoka, 411-8540, Japan

$13{ }^{3}$ Research Institute for Humanity and Nature, 457-4 Motoyama, Kamigamo, Kita, Kyoto 14 603-8047, Japan

${ }^{4}$ Department of Marine Biology, Tokai University, Shimizu 3-20-2, Shizuoka 424-0902,

16 Japan

$17{ }^{5}$ Graduate education and research training program in Decision Science for a Sustainable

18 Society, Kyushu University, 744, Motooka, Nishi, Fukuoka 819-0395, Japan

19 63-18-5-203, Nagata Ginowan, Okinawa 901-2212, Japan

$20{ }^{7}$ Kawanishi-midoridai Senior High School, 1-8 Kouyoudai, Kawanishi, Hyogo 666-0115, 21 Japan

$22{ }^{8}$ University of the Ryukyus, 1 Senbaru, Nishihara-cho, Nakagami-gun, Okinawa 903-0213, 23 Japan

$25 *$ Corresponding authors:

26 Yo Y. Yamasaki: yo.yamasaki@terra.zool.kyoto-u.ac.jp

27 Katsutoshi Watanabe: watanak@terra.zool.kyoto-u.ac.jp 


\section{ABSTRACT}

29 Predicting speciation is a fundamental goal of research in evolutionary ecology. The 30 probability of speciation is often positively correlated with ecosystem size. Although the 31 mechanisms driving this correlation are generally difficult to identify, a shared geographic and 32 ecological context provides a suitable condition to study the mechanisms that promote 33 speciation in large ecosystems by reducing the number of factors to be considered. Here, we 34 determined the correlation between speciation and ecosystem size, and discussed the underlying mechanisms of this relationship, using a probable parallel ecotype formation for freshwater fish. Our population genetic analysis revealed that speciation of the landlocked goby, Rhinogobius sp. YB, of the Ryukyu Archipelago, Japan, from its migratory ancestor, $R$. brunneus, occurred in parallel across five islands. Logistic regression analysis showed that speciation probability could be predicted using island size. The results suggest that ecosystem size predicts the occurrence of adaptation and reproductive isolation, likely through its association with three possible factors: divergent selection strength, population persistence, and occurrence probability of habitat separation.

\section{Key words}

45 ecological speciation, parallel evolution, island biogeography, approximate Bayesian 


\section{1 | INTRODUCTION}

49

Understanding the patterns and mechanisms of speciation is the fundamental goal of evolutionary ecology (Coyne \& Orr, 2004; Reznick \& Ricklefs, 2009). As macroevolutionary patterns of speciation, such as differences in diversification rate among lineages or regions, are caused by the accumulation of individual speciation events, the patterns are expected to be strongly influenced by speciation mechanisms (i.e., evolution of reproductive isolation). However, the relationships between macropatterns and the underlying mechanisms are not well understood, because they are usually investigated separately (Rosenblum et al., 2012; Cutter \& Gray, 2016; Rabosky, 2016; but see Rabosky \& Matute, 2013). Explicit consideration of the speciation mechanism would be helpful for obtaining a causal explanation of how macroevolutionary patterns of speciation have been generated (Harvey et al., 2017; Kisel et al., 2012).

Ecosystem size, often represented by habitat area, has long been considered as one of the best predictors for variation in species richness (MacArthur \& Wilson, 1967). Recent studies on species-area relationships also recognize "in situ speciation" as an important factor, in addition to immigration and extinction rates (Losos \& Parent, 2009; Losos \& Schluter, 2000; Wagner, Harmon, \& Seehausen, 2014; Weigelt, Steinbauer, Cabral, \& Kreft, 2016). The positive correlation between ecosystem size and speciation rate is supported by several empirical (Kisel \& Barraclough, 2010; Parent \& Crespi, 2006) and theoretical (Gavrilets \& Vose, 2005; Rosindell \& Phillimore, 2011) studies.

Several hypotheses have been proposed that explain how speciation rate, or speciation probability, is affected by ecosystem size through speciation processes. For example, the opportunity for geographical isolation, which impedes gene flow, is likely to increase in larger areas (Kisel \& Barraclough, 2010; Losos \& Schluter, 2000). As larger areas contain heterogeneous environments, this phenomenon might also promote diversification to new environments following speciation (Parent \& Crespi, 2006). Moreover, larger areas allow larger population sizes and longer persistence of newly emerged species (Kisel, McInnes, Toomey, \& Orme, 2011). However, these hypotheses have been rarely tested empirically, because studies have usually assessed speciation by considering various mechanisms simultaneously. Thus, it is difficult to evaluate the influence of different factors on the speciation process. This problem could be addressed by targeting a group with parallel 
diversification under the same mechanism (Lucek, Kristjánsson, Skúlason, \& Seehausen, 2016; Vamosi, 2003). However, when using such an approach, it is important to first obtain evidence of repeated evolution under the same mechanism as the focal system.

Due to clear boundaries and replications, freshwater invasion by migratory fish in island habitats is a suitable case for testing the relationship between ecosystem size and occurrence of speciation. The East Asian goby, genus Rhinogobius, is one such fish group, in which the amphidromous (migratory) species $R$. brunneus might have repeatedly produced strictly freshwater populations (Rhinogobius sp. YB sensu Akihito, Sakamoto, Ikeda, \& Aizawa, 2013) in the Ryukyu Archipelago of Japan (Kano, Nishida, \& Nakajima, 2012; Nishida, 2001; Ohara, Takagi, Hashimoto, Miyazaki, \& Hirashima, 2008). However, the number of times and geographical scales (i.e., islands, rivers, etc.) of the origin of the freshwater form of this goby have not yet been elucidated. Furthermore, the extent and factors of reproductive isolation between the amphidromous and freshwater forms have not been investigated.

We propose that the freshwater colonization of the goby in the Ryukyu Archipelago is a good model system for testing the correlation between ecosystem size and speciation probability for the following reasons. First, the ancestral amphidromous populations might have shared common evolutionary potential, because of possible gene flow through the sea during the larval period. Second, ecosystem age is similar among islands. According to geographical data, most islands in the Ryukyu Archipelago formed nearly simultaneously $\sim 1.5$ million years ago by the opening of straits between the islands (Osozawa et al., 2012). Third, ecological conditions are probably similar among the islands, because almost no freshwater

100 fish species, except those of Rhinogobius, occur in the upper reaches of the rivers in the 101 Ryukyu Archipelago (Kano et al., 2012; Yoshigou, 2014), resulting in few competitors and 102 predators, which are important components of ecological opportunity (Wellborn \& 103 Langerhans, 2014; Yoder et al., 2010).

104 Using the simple system of Rhinogobius gobies, we primarily aimed to clarify whether the 105 speciation probability of the freshwater form can be explained by ecosystem size. We first 106 confirmed the existence of genetic isolation between the amphidromous and freshwater forms inhabiting the same islands or rivers. Next, we estimated where and how many times the freshwater forms originated, based on statistically explicit tests among demographic models that hypothesized parallel or single origin scenarios. We then examined whether speciation 
110 probability could be predicted by ecosystem size. The correlation between independent

111 origins of the freshwater form inferred from demographic modelling and ecosystem size (e.g.,

112 island area) was tested statistically (see Figure 1, concept diagram representing our approach).

113 On the basis of these results, we discuss the mechanisms producing the relationships between

114 ecosystem size and the speciation process in this system.

\section{$115 \quad 2 \mid$ MATERIALS AND METHODS}

\section{$116 \quad 2.1 \mid$ Study system}

117 The freshwater resident form derived from the amphidromous species Rhinogobius brunneus

118 is recognized as an independent species but has not yet been described because of taxonomic

119 confusion. Previous studies (e.g., Akihito et al., 2013) tentatively used the name

120 "Rhinogobius sp. YB" for this freshwater form. However, until its evolutionary status is

121 clarified, we will use the code "FF" (freshwater form) for Rhinogobius sp. YB and "AF"

122 (amphidromous form) for R. brunneus based on their life history modes.

123 The FF completes its life in freshwater; conversely, AF larvae hatch in rivers and immediately

124 drift down to the sea and return to rivers after 2-3 months (Mizuno, 2001). The eggs and

125 larvae of FF are larger than those of AF (Supporting Information methods and results S1).

126 These traits are assumed to be an adaptation to the river environment, where small food items

127 (i.e., plankton) are scarce and higher level of swimming ability in river currents is needed

128 (Hirashima \& Tachihara, 2000; Nishida, 2001; Shinomiya, Sasabe, Sakurai, \& Kishino, 2005;

129 Yamasaki, Nishida, Suzuki, Mukai, \& Watanabe, 2015).

130 Although the distribution of the two species sometimes overlapped in a single river, their

131 distributions were generally different. AF mainly lived in the middle to lower reaches of

132 rivers. In fact, AF populations are found only in rivers shorter than $18 \mathrm{~km}$ in the central

133 Honshu region of Japan (Tamada, 2005). The larvae of AF must rapidly reach the sea to avoid

134 starvation because of the scarcity of small food in rivers (Iguchi \& Mizuno, 1999; Moriyama,

135 Yanagisawa, Mizuno, \& Omori, 1998). Thus, they might not be able to reproduce effectively

136 in areas far from the sea (Iguchi \& Mizuno, 1999). By contrast, FF mainly live in the upper

137 reaches of rivers, and are often found in the upper areas of waterfalls where no other fish

138 species are distributed (Kano et al., 2012). 


\section{2 | Sampling}

140 Samples were collected on seven islands where populations of FF have been recorded

141 previously (locality code 2. Amami-Ohshima Is., 4. Tokunoshima Is., 5. Okinoerabujima Is.,

142 6. Okinawajima Is., and 7. Kumejima Is. in Middle Ryukyu; 8. Ishigakijima Is. and 9.

143 Iriomotejima Is. in South Ryukyu; Table S1; Figure 2; Ohara et al., 2008; Yoshigo, 2014). In

144 addition, AF specimens were collected from three other islands (Figure 2). The specimens

145 were identified by body colour patterns when fresh (Kano et al., 2012; Suzuki, Shibukawa,

146 Yano, \& Senou, 2004). Identification based on body colour was in agreement with the results

147 of the genetic analysis, but some samples were difficult to identify or showed inconsistent

148 genetic characteristics. When genetic data suggested that the focal specimens were not judged

149 as hybrids based on the criteria described below and that incorrect identification based on

150 morphology in the field was likely (see the next section and Supporting methods and results

$151 \mathrm{~S} 1$ ), these samples were removed from all subsequent analyses. If a sample was judged to be a

152 hybrid, we tentatively named it based on morphology. As a result, $842 \mathrm{FF}$ and $578 \mathrm{AF}$

153 specimens from 52 points in 42 river systems were included in the analysis. Both forms were

154 collected from nine river systems; they were sympatrically collected at seven points.

\section{$155 \quad 2.3 \mid$ Genetic data and population structure}

156 Genetic data of Rhinogobius specimens were obtained by genotyping 20 nuclear

157 microsatellite loci (Table S2; Ohara, Takahashi, \& Takagi, 2004). Methods for molecular

158 experiments and genotyping are described in the Supporting methods and results S1.

159 Genotype data were deposited in Dryad (https://doi.org/10.5061/dryad.mpg4f4quh). To assess

160 the genetic features of the respective populations, we calculated the expected and observed

161 heterozygosity $\left(H_{\mathrm{E}}\right.$ and $H_{\mathrm{O}}$, respectively) and allelic richness $(R s)$ for the respective

162 populations. Pairwise $F_{\mathrm{ST}}$ and Jost's $D$ were also calculated. We conducted analysis of

163 molecular variance (AMOVA; Excoffier, Smouse, \& Quattro, 1992) separately for AF and FF,

164 to assess hierarchical genetic differentiation. To visualize relatedness among populations, we

165 constructed a neighbour-joining tree among populations based on Nei's $D a$ distance (Nei,

166 Tajima, \& Tateno, 1983) using poptree2 (Takezaki, Nei, \& Tamura, 2010). The credibility of each clade was evaluated using 1,000 bootstrap resamplings. 
168 To infer the existence and extent of gene flow and genetic isolation, we analysed the genetic

169 structure of the population using structure version 2.3.4 (Lawson, van Dorp, \& Falush, 2018;

170 Pritchard, Stephen, \& Donnelly, 2000). We prepared two data sets: one for both FF and AF

171 populations from each island, and another for only AF populations from all islands. Evanno's

$172 \Delta K$ (Earl \& von Holdt, 2012; Evanno, Regnaut, \& Goudet, 2005) was used as a reference for

$173 K$ value selection. Hybrid individuals were evaluated using $q$ values; we arbitrarily judged

174 specimens as hybrids (or individuals with hybrid origin) in cases where minor genetic

175 components accounted for $10 \%$ or more of the aggregate (Vähä \& Primmer, 2006). Detailed

176 methods are provided in the Supporting methods and results S1.

\subsection{Testing the parallel formation of FF by ABC}

178 Before testing the relationship between ecosystem size and speciation probability, we needed

179 to infer the islands where speciation of FF occurred. To examine the single or parallel origins

180 of FF statistically, we conducted a demographic model selection under the Approximate

181 Bayesian Computation (ABC) framework (Beaumont, 2010). We briefly describe the

182 procedures of model construction and model selection in this section (for details, see

183 Supporting methods and results S1).

184 Our general model construction strategies for ABC analysis were as follows. First, we

185 generated separate models using three geographical scales (i.e. within-islands, regional

186 [Middle and South Ryukyu], and archipelago scales) and examined FF origins in each

187 geographical scale to reduce the number of models and populations examined in a single

188 analysis. Second, we examined both models with and without gene flow between AF and FF

189 populations. This is because a simulation study suggests that gene flow could alter apparent

190 phylogenetic relationships among populations when simple genetic distance was used (Bierne,

191 Gagnaire, \& David, 2013). Demographic model comparisons that consider gene flow can

192 overcome this problem (Butlin et al., 2014).

193 In the within-islands analyses, we mainly examined two questions: whether FF had single or

194 parallel origin, and whether gene flow between AF and FF existed on each island. We

195 hypothesized several plausible divergence orders between populations based on the result of

196 structure analysis, phylogeny and geographical locations for respective islands. Thereafter, we

197 compared the models with single/parallel origins and with/without gene flow. Analyses were 
198 conducted for the five islands where FF is distributed in multiple rivers (i.e., Amami-Oshima

199 Is., Tokunoshima Is., Okinawajima Is., Kumejima Is. and Iriomotejima Is.). We selected three

200 (or two) river populations for each island to reduce the model complexities. Criteria for

201 population selection are described in the Supporting methods and results S1. The constructed

202 models (a total of 34 models) are described in Figure S1a-e. Summary statistics are given in

203 Table S3.

204 For the among-islands within-region analyses, we constructed several plausible models

205 separately for the regions of Tokunoshima Is. and Okinoerabujima Is., Middle Ryukyu, and

206 South Ryukyu. Five to 10 models were constructed on the basis of the phylogenetic tree and

207 geographical distance between islands. Finally, in the between-region analyses, we compared

20810 models generated from the results of the previous analyses. All constructed models are

209 described in the Supporting methods and results S1 and Figure S1f-I. Scripts that describe the

210 models have been deposited in Dryad (https://doi.org/10.5061/dryad.mpg4f4qvh).

211 For model selection, we chose the model that had the highest posterior probability in the

212 respective analyses. To evaluate the accuracy of model selection, we calculated a

213 misclassification rate (i.e., the rate at which the focal model was selected despite the other

214 model being true [type 2 error rate]).

\section{$215 \quad 2.5 \mid$ Correlation between ecosystem size and speciation probability}

216 We first identified the islands on which the speciation of FF occurred based on the results of

217 structure (genetic isolation) and ABC model selection (independent origin). The relationship

218 between ecosystem size and speciation was analysed for the Middle and South Ryukyu

219 islands. This is because these islands are assumed to be similar in age, were never connected

220 to the continent after separation, and were not catastrophically affected by volcanic activity

221 (Osozawa et al., 2012; Supporting methods and results S1). We acquired distribution

222 information of the two forms from published literature (Yoshigou, 2014) and our own field

223 survey, and we only chose the islands where either or both forms were distributed. This is

224 because we assumed that speciation was not likely to have occurred on the island where either

225 of these species is not currently distributed. We coded the occurrence of speciation in each

226 island as follows: 1 for the island where speciation occurred, and 0 for the island where

227 speciation did not occur. As a proxy of ecosystem size, we used island area $\left(\mathrm{km}^{2}\right.$; data from 
228 the Geospatial Information Authority of Japan), maximum catchment area $\left(\mathrm{km}^{2}\right)$, maximum

229 river length $(\mathrm{m})$ or the maximum number of waterfalls on each island (Supporting methods

230 and results $\mathrm{S} 1)$.

231 We performed one-parameter logistic regression analysis in the generalized linear model

232 framework with binomial error structure for the response variable (speciation: 1, presence; 0 ,

233 absence) using the glm package of $\mathrm{r}$ version 3.1.1 (R Core Team, 2014). Due to a strong

234 positive correlation between the four variables (Pearson's correlation coefficient, 0.592-0.993,

235 Supporting methods and results S1), we primarily used island area as the explanatory variable

236 for the main result. Explanatory variables, except the number of waterfalls, were

$237 \log _{10}$-transformed. To test the significance of explanatory variables, we conducted a

238 likelihood ratio test using 10,000 rounds of parametric bootstrap sampling with a constant

239 model as a null model that assumes no relationship between ecosystem variables and

240 speciation probability. We calculated McFadden's pseudo $R^{2}$.

241 Furthermore, to examine the effect of the ecosystem size parameters other than island size

242 (i.e., maximum catchment area, river length and number of waterfalls), we constructed

243 another generalized linear model for speciation probability. We used the residuals from a

244 regression between island size and each of the other ecosystem size parameters, together with

245 the island size and their interaction, as explanatory variables. Stepwise model selections by

246 Akaike information criterion (AIC) scores were conducted using the step function on $\mathrm{r}$.

$247 \quad 3 \mid$ RESULTS

$248 \quad 3.1 \mid$ Basic summary statistics

249 Heterozygosity and allelic richness were generally higher in the AF populations than in the

250 FF populations (Table S1, Figure S2a, b). The AF populations showed relatively little

251 pairwise genetic differentiation within islands and among islands within regions (Tables S4-

252 S6, Figure S2c, d). In comparison, the genetic differentiation of AF populations between

253 regions was large (Tables S4-S6, Figure S2c, d). The FF populations often showed large

254 genetic differentiation within islands and among islands within regions, as well as among

255 regions (Tables S4-S6, Figure S2c, d). 
257 In the AF data set, Evanno's $\Delta K$ showed the maximum value at $K=2$; the populations in

258 North plus Middle Ryukyu and South Ryukyu were clearly separated. In the data set for each

259 island, including $\mathrm{FF}$ and $\mathrm{AF}$ populations, $\Delta K$ had a maximum value at $K=2$ for all islands,

260 except one (Amami-Oshima Is.). The two genetic clusters corresponded to the two forms,

261 except on Okinawajima Is. (see below; Figure 3; Figure S3).

262 Suspected hybrid individuals were rare (2.0\% of the total individuals). No suspected hybrid

263 individuals were detected from five of the seven sympatric collection points. Several

264 suspected hybrid individuals were detected in $11 \mathrm{FF}$ and AF populations. Among these, all FF

265 individuals that were identified based on morphology in the FFOK-4-1 and FFOK-4-2

266 populations (Okinawajima Is.; Figures 2 and 3; Figure S3) exhibited the genetic features of

$267 \mathrm{AF}$ as the dominant component.

\subsection{Genetic relationships among populations}

269 The neighbour-joining tree showed two divergent groups separated by the Kerama Gap in all

270 of the FF and AF populations (bootstrap value, 97\%; Figure 4). Each group included both

271 forms, which we present as Group 1 (Honshu, North Ryukyu and Middle Ryukyu) and Group

272 (South Ryukyu), hereafter. In both groups, FF populations

273 on each island formed a monophyletic group (bootstrap value, 91\%-100\%), except those on

274 two islands in Group 1 (Amami-Oshima Is., 67\%; Okinawajima Is., 33\%). In addition, FF

275 populations on different islands (Tokunoshima Is. and Okinoerabujima Is.) formed a

276 monophyletic group (89\%). The AF populations within each group were closely related to

277 each other, and the populations of each island in Group 1 tended to form a monophyletic

278 group.

\subsection{Test for multiple origins of FF}

280 In the within-island-scale analysis, the single origin model of FF was selected for all islands

281 (Table 1 and Table S7; Figure 4 and Figure S4). Models including gene flow among all or

282 partial populations of the two forms showed higher posterior probability than those not

283 considering gene flow (Table 1 and Table S7; Figure 4 and Figure S4). 
284 At the among-island scale, Group 1 in Middle Ryukyu and Group 2 in South Ryukyu were analysed separately. For Group 1, we first examined the single origin of FF in the adjoining islands, Tokunoshima Is. and Okinoerabujima Is., which was suggested by the phylogenetic analysis. $\mathrm{ABC}$ analysis supported their single origin (Table 1 and Table S7), and thus only FF on Tokunoshima Is. was used for subsequent analyses. The model selection for Group 1 strongly supported the four independent origins of FF (Table 1; Table S7). The model with gene flow between the two forms provided a higher Bayes factor (BF) than the model not considering gene flow (Table S7). In Group 2, the single origin of FF of Iriomotejima Is. and

292 Ishigakijima Is. was supported (Table 1; Table S7). The model including gene flow between

293 the AF and FF populations was better supported than that not considering gene flow (Table

294 S7).

295 For the between-region scale, the neighbour-joining tree for populations suggested

296 independent origins of FF in Groups 1 and 2. However, no conclusion could be drawn at this

297 scale from ABC, because no single model was successfully selected, probably because of

298 insufficient data (Table 1; Table S7).

\section{5 $\mid$ Correlation between speciation probability and ecosystem size}

300 We confirmed the occurrence of AF or FF populations on 18 islands from the published

301 literature and our field survey (Table S8). As we could not specify the islands where unique

302 speciation occurred, we tested 20 alternative scenarios that hypothesized that speciation

303 occurred in different combinations of the candidate islands (see Supporting methods and

304 results $\mathrm{S} 1$, and Table S9 for details).

305 For all four data sets in the scenario of independent origins between the regions, speciation

306 probability was significantly explained by island area (Table 2 and Table S9; Figure 5 and S5).

307 The relationship was also significant for 12 of the 16 data sets in the nonindependent scenario

308 (Table S9). Almost identical results were obtained for maximum catchment area and river

309 length (Table 2 and Table S9; Figure S5). Furthermore, two of the four data sets for the

310 independent origin scenario and five of the 16 data sets for the nonindependent scenario

311 showed significant relationships between the number of waterfalls and speciation (Table 2

312 and Table S9). Model selection by AIC scores showed that the best model included no 
313 variables, except for island area, as the predictors for speciation probability in most data sets

314 when the variables were controlled by island area (Table S9).

\section{$315 \quad 4 \mid$ DISCUSSION}

316 Our results revealed that FF repeatedly evolved from AF in the Ryukyu Archipelago, and that

317 the occurrence of FF was highly correlated with island size. These results suggest that the

318 speciation of FF was promoted in larger ecosystems. In the following sections, we discuss the

319 mechanisms of speciation and the causes of correlation between ecosystem size and

320 speciation of FF.

\section{1 $\mid$ Reproductive isolation between the two forms and its evolution}

322 Genetic isolation between the two forms was suggested, even at sympatric sites (Figure 3 and

323 Figure $\mathrm{S} 3$ ); the results support that $\mathrm{FF}$ and $\mathrm{AF}$ are reproductively isolated. This genetic

324 isolation between AF and FF cannot be explained by isolation by distance (IBD), because

325 geographically isolated FF populations in different river systems showed closer relationships

326 than FF and AF in the same river. This relationship was consistent in the respective islands.

327 Some behavioural mechanisms might be responsible for this reproductive isolation, as

328 reported for other species pairs of Rhinogobius (Mizuno, 1987), which share common

329 reproductive features with intersexual behavioural interactions (Takahashi \& Kohda, 2004).

330 Differences in the breeding season might also contribute to their current reproductive isolation

331 (AF, January to May; FF, March to June; Hirashima, 2016; Katoh, 1996; Tachihara, 2009).

332 Although the presence of pre- and post-zygotic isolations has not been tested for our studied

333 pair of species and their position along a speciation continuum (Nosil, 2012) is not clear,

334 genetic isolation, as well as distinct life history divergence, support that FF populations

335 should be treated as different biological species from AF populations.

336 Although AF and FF currently exhibit genetic isolation, our ABC analysis suggested that

337 reproductive isolation between these two ecologically divergent forms evolved under the

338 existence of gene flow. This result suggests that the evolution of reproductive isolation was

339 not caused simply by allopatry and mutation-order mechanisms but by divergent ecological

340 adaptation between the AF and FF populations (Seehausen \& Wagner, 2014). 
341 What is the factor that led to the evolution of their reproductive isolation? Previous studies

342 have focused on the differences in food size for larvae between seas and rivers (Nishida,

343 2001). AF larvae generally feed on small food items available in seas. If larvae cannot reach

344 the sea rapidly, large larvae might be favoured by directional selection in rivers (Closs, Hicks,

345 \& Jellyman, 2013; Kishi, 1979; Kondo, Maeda, Hirashima, \& Tachihara, 2013; Mizuno,

346 1963). A mathematical model has shown that speciation could occur due to differences in

347 favourable egg and larval size between the upper and lower reaches (Omori et al., 2012). Such

348 empirical and theoretical evidence suggests that the primary factor in the evolution of

349 reproductive isolation is divergent selection between the optimal combinations of the

350 within-rivers distribution and larval size.

351 The role of barriers in a river should also be emphasized, because they might promote adaptation to freshwater habitats through reduced gene flow and the invasion of predators and competitors. During repeated sea-level fluctuations during the Pleistocene, steep marine terraces of limestone or coral reef developed in the coastal areas of the Ryukyu Archipelago (Machida, Ota, Kawana, Moriwaki, \& Nagaoka, 2001). Such terraces would form many waterfalls near river mouths. Nishida (2001) and Kano et al. (2012) hypothesized an important role of waterfall formation in the landlocking process of FF. The relationship between such barriers and divergent selection should be further investigated to understand the early processes of landlocking.

360 Despite the existence of current reproductive isolation, suspected hybrid individuals were

361 occasionally detected. Some hybridization might be explained by artificial disturbances in the

362 distribution and migration schemes of AF. Six of the 11 populations containing suspected

363 hybrids were collected from the waters above artificial dams; they included FFOK-4-1 and

364 FFOK-4-2 populations of FF, which primarily exhibited genetic features of AF. Artificial

365 dams would promote hybridization in the following process.

366 Artificial dams have promoted the establishment of a landlocked AF population (Tachihara,

367 2009), because there are small food items in reservoirs that the larvae of AF and hybrids

368 would be able to use. This would induce a sympatric distribution of the two forms and

369 facilitate the survival of hybrids in the upper reaches of the dam. These cases might be 370 examples of human-mediated reverse speciation (Grabenstein \& Taylor, 2017; Taylor et al., 371 2006). 


\section{2 $\mid$ Multiple origins of FF}

373 The AF and FF populations showed large divergence between the North/Middle Ryukyu

374 (Group 1) and South Ryukyu (Group 2). The AF populations were closely related among 375 islands within each region (Figures 3 and 4), suggesting that gene flow by larval drifting is

376 effective at the regional scale, but is prevented between regions by the Kerama Gap.

377 A series of $\mathrm{ABC}$ analyses supported the parallel derivation of FF populations on respective 378 islands. The estimated number of times speciation occurred was four or five. The uncertainty

379 in the number is attributed to the unresolved relationship among the FF populations across the

380 Middle and South Ryukyus, which could not be resolved by ABC analysis, probably owing to

381 the limitation of microsatellite markers, such as allele size homoplasy. However, the

382 following reasons support that the FF populations originated independently in each region;

383 that is, FF originated five times. First, the independent origins of FF populations among

384 islands within regions were supported (Table 1; Figure 4). Second, the simple tree analysis

385 supported the dichotomous relationship of the populations between the North/Middle and

386 South Ryukyus. Third, the two regions are separated by a deep strait, the Kerama Gap, which

387 is considered to have not emerged above water since the Ryukyu Archipelago separated from

388 the continent (Osozawa et al., 2012). This geographical barrier has also been noted for many

389 other terrestrial animals, such as amphibians and reptiles (Matsui, Ito, et al., 2005; Matsui,

390 Shimada, et al., 2005; Ota, 1998; Tominaga, Matsui, Eto, \& Ota, 2015).

391 Our results suggest that the multiple origins of FF were an example of parallel speciation,

392 which is the phenomenon whereby reproductive isolation repeatedly evolves under the same

393 mechanism (Schluter \& Nagel, 1995). Nosil (2012) proposed four criteria to distinguish

394 parallel speciation: nonmonophyletic pattern of an ecotype; nonmonophyly of ecologically

395 similar forms representing multiple origins, rather than the effect of gene flow or incomplete

396 lineage sorting; positive correlation between reproductive isolation and ecological divergence;

397 and the genetic basis of reproductive isolation. The ABC analysis, as well as the egg and

398 larval size difference between FF and AF, indicated that our study system satisfies the former

399 two criteria. In addition, the latter two criteria were probably satisfied because of the clear

400 differences in life history and reproductive traits between the two forms (Yamasaki et al.,

401 2015), although they need to be confirmed by conducting mate choice and common garden

402 experiments in the future. 


\subsection{Correlation of ecosystem size and speciation probability}

404 Our logistic regression analysis showed that speciation probability was significantly

405 explained by island size, river length and catchment area in most of the data sets under the

406 various analysis conditions. This result suggests that some mechanisms promoting the

407 speciation process tend to be more effective in larger ecosystems. As the number of waterfalls

408 also explained speciation probability in some data sets, it also partly supported that waterfalls

409 promote speciation in the goby.

410 Why is the speciation probability of FF positively correlated with ecosystem size? To answer

411 this question, understanding the relationships between ecosystem size and the following three

412 components related to the mechanism of speciation is necessary: (a) establishment of

413 reproductive isolation, (b) persistence of diverged populations and (c) enhancement of the

414 former two components by population separation (Allmon, 1992; Mayer, 1963).

415 First, the establishment of reproductive isolation would be promoted in larger ecosystems,

416 because the strength of divergent selection is expected to be positively correlated with

417 ecosystem size. Divergent selection between flowing and staying larvae would become

418 stronger in longer rivers (i.e., larger ecosystems), as the spawning sites of AF are restricted

419 within a certain distance from the sea owing to the mortality of drifting larvae (see above;

420 Moriyama et al., 1998; Omori et al., 2012). Furthermore, divergent selection might have been

421 stronger during glacial periods, when sea level was lower, and hence rivers became longer

422 (Kondo et al., 2013). Therefore, the landscape in the period of low sea level might have

423 affected patterns of speciation. However, unfortunately, we could not test the correlation

424 between speciation probability and island size at the low sea level, represented by the Last

425 Glacial Maximum (i.e., when sea level was $-122 \mathrm{~m}$ ), because the 18 islands investigated were

426 estimated to have been merged into eight, and the statistical power was too low to detect the

427 correlation (data not shown). Although the correlation between the strength of divergent

428 selection and river length should be tested in the future, larger ecosystems might enhance

429 reproductive isolation via divergent selection, when the extent of the focal environmental

430 gradient is positively related to ecosystem size. This relationship might generally lead to the

431 development of a correlation between speciation probability and ecosystem size in other

432 systems as well. 
433 Second, the amount of available space might increase with ecosystem size, which could result

434 in the greater persistence of freshwater-adapted populations through an increase in population

435 size. In longer rivers, the freshwater population could use larger areas in the upper reaches of

436 the rivers, because the optimal distance between the spawning area and sea for AF does not

437 increase with river length. A larger population size might reduce the risk of demographic

438 extinction. In addition, extinction risk due to fusion with the amphidromous population might

439 be alleviated in the larger freshwater populations. Furthermore, the reinforcement of

440 reproductive isolation might be more effectively developed when the population sizes of the

441 two secondarily contacted species are similar (Liou \& Price, 1994). A larger population size is

442 also beneficial for retaining adaptive alleles (Gavrilets \& Vose, 2005) and reducing

443 maladaptive gene flow (Hanski, Mononen, \& Ovaskainen, 2011).

444 Third, the probability of habitat separation between rivers and seas might be positively

445 correlated with ecosystem size, promoting the previously described two processes during

446 speciation. Correlation between the number of waterfalls and river length suggests the more

447 frequent emergence of barriers to migration in longer rivers. Furthermore, greater river length

448 might hinder migration to the upper reaches. Such habitat separation in longer rivers might be

449 important for population divergence, because the separation would reduce gene flow between

450 FF and AF populations, and would impede the entrance of other predatory and competitive

451 fishes in the upper reaches.

\section{5 - CONCLUSIONS}

453 We have confirmed that speciation probability is explained by ecosystem size in our goby

454 system. This result suggests positive correlations between ecosystem size and several

455 components of the speciation process, including the strength of divergent selection,

456 population persistence and population separation frequency. These correlations could promote

457 the establishment of reproductive isolation and the persistence of new populations, although

458 further explicit tests for these relationships are necessary. These correlations could also be

459 important for understanding species diversification mechanisms at the phylogenetic level.

460 Simple systems, such as our parallel species pairs, could contribute to the development of

461 theories that link the mechanisms of each speciation to macroevolutionary patterns of

462 speciation. 
464 ACKNOWLEDGMENTS

465 We thank K. Nakao for collecting samples; S. Matsuzaki, N. Muto, S. Chiba, K. Nakayama

466 and S. Hirase for helping with the molecular experiment; and A. Iwata, M. Hoso, T. Fujisawa,

467 J. Kitano and members of Laboratory of Animal Ecology of Kyoto University for providing

468 valuable comments. We thank C. Riginos and three anonymous reviewers for providing

469 helpful comments. Computations were partially performed on the NIG supercomputer at

470 ROIS National Institute of Genetics. This study was partially supported by the Sasakawa

471 Scientific Grant (No. 27-507) and JSPS KAKENHI (Nos. 26250044, 16J08762, 17H03720).

\section{AUTHOR CONTRIBUTIONS}

473 Y.Y.Y., M.N. and K.W. planned the project. Y.Y.Y., Y.K., N.O. and T.S. performed field

474 surveys. Y.Y.Y. and H.T. conducted molecular experiments. Y.Y.Y. conducted population

475 genetic and statistical analysis. Y.Y.Y. and K.W. wrote the first draft manuscript, and all

476 authors contributed to the improvement of the manuscript.

\section{DATA AVAILABILITY STATEMENT}

478 The microsatellite genotype data and scripts of $\mathrm{ABC}$ analysis have been deposited in Dryad 479 (https://doi.org/10.5061/dryad.mpg4f 4qvh). NGS data for developing microsatellite makers 480 have been de- posited in DDBJ (accession no. DRA006388).

ORCID

Yo Y. Yamasaki https://orcid.org/0000-0002-7495-2712

484

Katsutoshi Watanabe https://orcid.org/0000-0003-2244-2902

\section{REFERENCES}


487 Akihito, Sakamoto, K., Ikeda, Y., \& Aizawa, M. (2013). Gobioidei. In T. Nakabo (Ed.),

488 Fishes of Japan with pictorial keys to species, 3rd ed. (pp. 1374-1608). Tokyo, Japan: Tokai 489 University Press. (in Japanese).

490 Allmon, W. D. (1992). A causal analysis of stages in allopatric speciation. Oxford Surveys in

491 Evolutionary Biology, 8, 219-257.

492 Beaumont, M. A. (2010). Approximate Bayesian computation in evolution and ecology.

493 Annual Review of Ecology, Evolution, and Systematics, 41, 379-406.

494 https://doi.org/10.1146/annurev-ecolsys-102209-144621

495 Bierne, N., Gagnaire, P. A., \& David, P. (2013). The geography of introgression in a patchy 496 environment and the thorn in the side of ecological speciation. Current Zoology, 59, 72-86.

497 https://doi.org/10.1093/czoolo/59.1.72

498 Butlin, R. K., Saura, M., Charrier, G., Jackson, B., Andŕe, C., Caballero, A., ... Rolán-Alvarez, 499 E. (2014). Adaptation and reproductive isolation in the face of gene flow. Evolution, 68, 935500 949. https://doi. org/10.1111/evo.12329

501 Closs, G. P., Hicks, A. S., \& Jellyman, P. G. (2013). Life histories of closely related 502 amphidromous and non-migratory fish species: A trade-off between egg size and fecundity. 503 Freshwater Biology, 58, 1162-1177. https://doi.org/10.1111/fwb.12116

504 Coyne, J. A., \& Orr, H. A. (2004). Speciation. Sunderland, MA: Sinauer Associates.

505 Cutter, A. D., \& Gray, J. C. (2016). Ephemeral ecological speciation and the latitudinal 506 biodiversity gradient. Evolution, 70, 2171-2185. https://doi.org/10.1111/evo.13030

507 Earl, D. A., \& vonHoldt, B. M. (2012). STRUCTURE HARVESTER: A website and program 508 for visualizing STRUCTURE output and implementing the Evanno method. Conservation 509 Genetics Resources, 4, 359-361. https://doi.org/10.1007/s12686-011-9548-7

510 Evanno, G., Regnaut, S., \& Goudet, J. (2005). Detecting the number of clusters of individuals 511 using the software STRUCTURE: A simulation study. Molecular Ecology, 14, 2611-2620.

512 https://doi. org/10.1111/j.1365-294X.2005.02553.x 
513 Excoffier, L., Smouse, P. E., \& Quattro, J. M. (1992). Analysis of molecular variance inferred

514 from metric distances among DNA haplotypes: application to human mitochondrial DNA

515 restriction data. Genetics, 131, 479-491.

516 Gavrilets, S., \& Vose, A. (2005). Dynamic patterns of adaptive radiation.

517 Proceedings of the National Academy of Sciences of the United States of America, 102,

518 18040-18045. https://doi.org/10.1073/pnas.05063 30102

519 Grabenstein, K. C., \& Taylor, S. A. (2017). Breaking barriers: Causes, consequences, and 520 experimental utility of human-mediated hybridization. Trends in Ecology \& Evolution, 33, 521 198-212. https://doi. org/10.1016/j.tree.2017.12.008

522 Hanski, I., Mononen, T., \& Ovaskainen, O. (2011). Eco-evolutionary metapopulation

523 dynamics and the spatial scale of adaptation. American Naturalist, 177, 29-43.

524 https://doi.org/10.1086/657625

525 Harvey, M. G., Seeholzer, G. F., Smith, B. T., Rabosky, D. L., Cuervo, A. M., \& Brumfield, 526 R. T. (2017). Positive association between population genetic differentiation and speciation 527 rates in New World birds. Proceedings of the National Academy of Sciences of the United 528 States of America, 114, 6328-6333. https://doi.org/10.1073/pnas.0506330102

529 Hirashima, K. (2016). Variety of life history and strategy of Rhinogobius fishes. Aquabiology, $53038,363-369$. (in Japanese with English abstract). Hirashima, K., \& Tachihara, K. (2000).

531 Embryonic development and morphological changes in larvae and juveniles of two 532 land-locked gobies, Rhinogobius spp. (Gobiidae), on Okinawa Island. Japanese Journal of 533 Ichthyology, 47, 29-41. (in Japanese with English abstract). https://

534 doi.org/10.11369/jji1950.47.29

535 Iguchi, K., \& Mizuno, N. (1999). Early starvation limits survival in amphidromous fishes. 536 Journal of Fish Biology, 54, 705-712. https://doi.org/10.1111/j.1095-8649.1999.tb02027.x

537 Kano, Y., Nishida, S., \& Nakajima, J. (2012). Waterfalls drive parallel evolution in a 538 freshwater goby. Ecology and Evolution, 2, 1805-1817. https://doi.org/10.1002/ece3.295 
539 Katoh, M. (1996). Seasonal variation in gonadal activity of females among four species of

540 freshwater gobies in the Rhinogobius brunneus species complex in Okinawa, Japan.

541 Ichthyological Research, 43, 169-174.

542 Kisel, Y., \& Barraclough, T. G. (2010). Speciation has a spatial scale that depends on levels

543 of gene flow. American Naturalist, 175, 316-334. https://doi.org/10.1086/650369

544 Kisel, Y., McInnes, L., Toomey, N. H., \& Orme, C. D. L. (2011). How diversification rates 545 and diversity limits combine to create large-scale species-area relationships. Philosophical

546 Transactions of the Royal Society B, 366, 2514-2525. https://doi.org/10.1098/ rstb.2011.0022

547 Kisel, Y., Moreno-Letelier, A. C., Bogarín, D., Powell, M. P., Chase, M. W., \& Barraclough, 548 T. G. (2012). Testing the link between population genetic differentiation and clade

549 diversification in Costa Rican orchids. Evolution, 66, 3035-3052. https://doi.

$550 \quad$ org $/ 10.1111 / \mathrm{j} .1558-5646.2012 .01663 . \mathrm{x}$

551 Kishi, Y. (1979). A geographical model of disruptive selection on offspring size and a

552 possible case of speciation in freshwater gobies characterized by egg-size difference.

553 Researches on Population Ecology, 20, 211-215.

554 Kondo, M., Maeda, K., Hirashima, K., \& Tachihara, K. (2013). Comparative larval

555 development of three amphidromous Rhinogobius species, making reference to their habitat

556 preferences and migration biology. Marine and Freshwater Research, 64, 249-266.

557 https://doi. org/10.1071/MF12234

558 Lawson, D. J., van Dorp, L., \& Falush, D. (2018). A tutorial on how not to over-interpret

559 STRUCTURE and ADMIXTURE bar plots. Nature Communications, 9, 3258.

560 https://doi.org/10.1038/s41467-018-05257-7

561 Liou, L., \& Price, T. D. (1994). Speciation by reinforcement of premating isolation. Evolution, $56248,1451-1459$.

563 Losos, J. B., \& Parent, C. E. (2009). The speciation-area relationship. In J. B. Losos, \& R. E.

564 Ricklefs (Eds.), The theory of island biogeography revisited (pp. 415-438). Princeton, NJ, 565 USA: Princeton University Press. 
566 Losos, J. B., \& Schluter, D. (2000). Analysis of an evolutionary species-area relationship.

567 Nature, 408, 847-850. https://doi. org/10.1038/35048558

568 Lucek, K., Kristjánsson, B. K., Skúlason, S., \& Seehausen, O. (2016). Ecosystem size

569 matters: The dimensionality of intralacustrine diversification in Icelandic stickleback is

570 predicted by lake size. Ecology and Evolution, 6, 5256-5272. https://doi.org/10.1002/

$571 \quad$ ece3.2239

572 MacArthur, R. H., \& Wilson, E. O. (1967). The theory of island biogeography. Princeton, NJ:

573 Princeton University Press.

574 Machida, H., Ota, Y., Kawana, T., Moriwaki, H., \& Nagaoka, N. (2001). Regional

575 geomorphology of the Japanese Islands, vol. 7 Kyushu and Southern Islands. Tokyo, Japan:

576 University of Tokyo Press. (in Japanese).

577 Matsui, M., Ito, H., Shimada, T., Ota, H., Saidapur, S. K., Khonsue, W., ... Wu, G.-F. (2005).

578 Taxonomic relationships within the pan-oriental narrow-mouth toad Microhyla ornata as

579 revealed by mtDNA analysis (Amphibia, Anura, Microhylidae). Zoological Science, 22, 489-

580 495. https://doi.org/10.2108/zsj.22.489

581 Matsui, M., Shimada, T., Ota, H., \& Tanaka-Ueno, T. (2005). Multiple invasions of the

582 Ryukyu Archipelago by Oriental frogs of the subgenus Odorrana with phylogenetic

583 reassessment of the related subgenera of the genus Rana. Molecular Phylogenetics and

584 Evolution, 37, 733-742. https://doi.org/10.1016/j.ympev.2005.04.030

585 Mayer, E. (1963). Animal species and evolution. Cambridge, MA, USA: Belknap Press.

586 Mizuno, N. (1963). Distribution of Cottus japonicus Okada (Cottidae) and Tukugobius

587 flumineus Mizuno (Gobiidae), with special references to their peculiarities in both the

588 land-locking and the speciation from amphidromous to ancestors. Bulletin of Osaka Gakugei

589 University, 11, 129-161. (in Japanese with English abstract).

590 Mizuno, N. (1987). Yoshinobori rui (genus Rhinogobius). In N. Mizuno, \& A. Goto (Eds.),

591 Nihon no tansuigyo - sono bunpu, hen'i, shubunka wo megutte (Freshwater fishes in Japan-

592 Distribution, variation, and speciation) (pp. 179-188). Tokyo, Japan: Tokai University Press. 593 (in Japanese). 
594 Mizuno, N. (2001). Rhinogobius. In H. Kawanabe, N. Mizuno, \& K. Hosoya (Eds.),

595 Freshwater fishes of Japan, 3rd ed. (p. 584) Tokyo, Japan: Yama-Kei Publishers. (in 596 Japanese).

597 Moriyama, A., Yanagisawa, Y., Mizuno, N., \& Omori, K. (1998). Starvation of drifting goby 598 larvae due to retention of free embryos in upstream reaches. Environmental Biology of Fishes, 599 52, 321-329. https://doi. org/10.1023/A:1007333302864

600 Nei, M., Tajima, F., \& Tateno, Y. (1983). Accuracy of estimated phylogenetic trees from 601 molecular data. Journal of Molecular Evolution, 19, 153-170.

602 Nishida, M. (2001). Dairanka eno purosesu: Yoshinobori rui (The process toward large egg

603 forms: Rhinogobius. In A. Goto, \& K. Iguchi (Eds.), Suisei doubutsu no ran-saizu:

604 Seikatsushi no hen'i, shubunka no seibutsugaku (Evolutionary biology of egg size in aquatic 605 animals) (pp. 149-170). Tokyo, Japan: Kaiyusha. (in Japanese).

606 Nosil, P. (2012). Ecological speciation. Oxford, UK: Oxford University Press.

607 Ohara, K., Takagi, M., Hashimoto, M., Miyazaki, K., \& Hirashima, K. (2008). DNA markers 608 indicate low genetic diversity and high genetic divergence in the landlocked freshwater goby, 609 Rhinogobius sp. YB, in the Ryukyu Archipelago, Japan. Zoological Science, 25, 391-400. 610 https://doi.org/10.2108/zsj.25.391

611 Ohara, K., Takahashi, D., \& Takagi, M. (2004). Isolation of microsatellite loci in the 612 freshwater goby, Rhinogobius sp. (Gobiidae). Molecular Ecology Notes, 4, 449-451. 613 https://doi. org/10.1111/j.1471-8286.2004.00677.x

614 Omori, K., Ohnishi, H., Hamaoka, H., Kunihiro, T., Ito, S., Kuwae, M., ... Iguchi, K. (2012). 615 Speciation of fluvial forms from amphidromous forms of migratory populations. Ecological 616 Modelling, 243, 89-94. https://doi.org/10.1016/j.ecolmodel.2012.06.006

617 Osozawa, S., Shinjo, R., Armid, A., Watanabe, Y., Horiguchi, T., \& Wakabayashi, J. (2012). 618 Palaeogeographic reconstruction of the 1.55 Ma synchronous isolation of the Ryukyu Islands, 619 Japan, and Taiwan and inflow of the Kuroshio warm current. International Geology Review, $620 \quad 54,1369-1388$. https://doi.org/10.1080/00206814.2011.639954 
621 Ota, H. (1998). Geographic patterns of endemism and speciation in amphibians and reptiles of 622 the Ryukyu Archipelago, Japan, with special reference to their paleogeographical implications. 623 Researches on Population Ecology, 40, 189-204. https://doi.org/10.1007/BF02763404

624 Parent, C. E., \& Crespi, B. J. (2006). Sequential colonization and diversification of Galapágos 625 endemic land snail genus Bulimulus (Gastropoda, Stylommatophora). Evolution, 60, 2311626 2328. https:// doi.org/10.1111/j.0014-3820.2006.tb01867.x

627 Pritchard, J. K., Stephen, M., \& Donnelly, P. (2000). Inference of population genetic structure 628 using multilocus genotype data. Genetics, 155, 945-959.

629 R Core Team (2014). R: A language and environment for statistical computing. Vienna, 630 Austria: R Foundation for Statistical Computing. http:// www.R-priject.org/

631 Rabosky, D. L. (2016). Reproductive isolation and the causes of speciation rate variation in 632 nature. Biological Journal of the Linnean Society, 118, 13-25.

633 https://doi.org/10.1111/bij.12703

634 Rabosky, D. L., \& Matute, D. R. (2013). Macroevolutionary speciation rates are decoupled 635 from the evolution of intrinsic reproductive isolation in Drosophila and birds. Proceedings of 636 the National Academy of Sciences of the United States of America, 110, 15354-15359. https:// 637 doi.org/10.1073/pnas.1305529110

638 Reznick, D. N., \& Ricklefs, R. E. (2009). Darwin's bridge between microevolution and 639 macroevolution. Nature, 457, 837-842. https://doi. org/10.1038/nature07894

640 Rosenblum, E. B., Sarver, B. A. J., Brown, J. W., Des Roches, S., Hardwick, K. M., Hether, T. 641 D., ... Harmon, L. J. (2012). Goldilocks meets Santa Rosalia: An ephemeral speciation model 642 explains patterns of diversification across time scales. Evolutionary Biology, 39, 255-261. 643 https:// doi.org/10.1007/s11692-012-9171-x

644 Rosindell, J., \& Phillimore, A. B. (2011). A unified model of island biogeography sheds light 645 on the zone of radiation. Ecology Letters, 14, 552-560.

646 https://doi.org/10.1111/j.1461-0248.2011.01617.x 
647 Schluter, D., \& Nagel, L. M. (1995). Parallel speciation by natural selection. American

$648 \quad$ Naturalist, 146, 292-301.

649 Seehausen, O., \& Wagner, C. E. (2014). Speciation in freshwater fishes. Annual Review of 650 Ecology, Evolution, and Systematics, 45, 621-651.

651 https://doi.org/10.1146/annurev-ecolsys-120213-091818

652 Shinomiya, A., Sasabe, K., Sakurai, M., \& Kishino, T. (2005). Morphological characters of 653 newly hatched larvae and their habitat selection of a fluviatile goby, Rhinogobius sp. YB in 654 the upper stream of Sumiyo River, Amami-oshima Island, Japan. Japanese Journal of 655 Ichthyology, 52, 1-8. (in Japanese with English abstract). https://doi.org/10.11369 $656 \quad / j j i 1950.52 .1$

657 Suzuki, T., Shibukawa, K., Yano, K., \& Senou, H. (2004). A photographic giude to the 658 gobioid fishes in Japan. Tokyo, Japan: Heibonsha. (in Japanese).

659 Tachihara, K. (2009). Two landlocked Rhinogobius species in the Ryukyu Archipelago: 660 Conservation and the future of gobies endemic to isolated rivers. Japanese Journal of 661 Ichthyology, 56, 70-74. (in Japanese). https://doi.org/10.11369/jji.56.70

662 Takahashi, D., \& Kohda, M. (2004). Courtship in fast water currents by a male stream goby 663 (Rhinogobius brunneus) communicates the parental quality honestiy. Behavioral Ecology and 664 Sociobiology, 55, 431-438. https://doi.org/10.1007/s00265-003-0693-1

665 Takezaki, N., Nei, M., \& Tamura, K. (2010). POPTREE2: Software for constructing 666 population trees from allele frequency data and computing other population atatistics with 667 Windows interface. Molecular Biology and Evolution, 27, 747-752.

668 https://doi.org/10.1093/molbev/ msp312

669 Tamada, K. (2005). Clutch and egg size in Rhinogobius sp. DA inhabiting small rivers.

670 Japanese Journal of Ichthyology, 52, 17-20. (in Japanese with English abstract).

671 https://doi.org/10.11369/jji1950.52.17

672 Taylor, E. B., Boughman, J. W., Groenenboom, M., Sniatynski, M., Schluter, D., \& Gow, J. L. 673 (2006). Speciation in reverse: Morphological and genetic evidence of the collapse of a 
674 three-spined stickleback (Gasterosteus aculeatus) species pair. Molecular Ecology, 15, 343675 355. https://doi.org/10.1111/j.1365-294X.2005.02794.X

676 Tominaga, A., Matsui, M., Eto, K., \& Ota, H. (2015). Phylogeny and differentiation of 677 wide-ranging Ryukyu Kajika frog Buergeria japonica (Amphibia: Rhacophoridae):

678 Geographic genetic pattern not simply explained by vicariance through strait formation. 679 Zoological Science, 32, 240-247. https://doi.org/10.2108/zs140227

680 Vähä, J.-P., \& Primmer, C. R. (2005). Efficiency of model-based Bayesian methods for 681 detecting hybrid individuals under different hybridization scenarios and with different 682 numbers of loci. Molecular Ecology, 15, 63-72.

683 https://doi.org/10.1111/j.1365-294X.2005.02773.x

684 Vamosi, S. M. (2003). The presence of other fish species affects speciation in threespine 685 sticklebacks. Evolutionary Ecology Research, 5, 717-730.

686 Wagner, C. E., Harmon, L. J., \& Seehausen, O. (2014). Cichlid species- area relationships are 687 shaped by adaptive radiations that scale with area. Ecology Letters, 17, 583-592.

688 https://doi.org/10.1111/ ele. 12260

689 Weigelt, P., Steinbauer, M. J., Cabral, J. S., \& Kreft, H. (2016). Late Quaternary climate 690 change shapes island biodiversity. Nature, 532, 99-102. https://doi.org/10.1038/nature17443

691 Wellborn, G. A., \& Langerhans, R. B. (2014). Ecological opportunity and the adaptive 692 diversification of lineages. Ecology and Evolution, 5, 176- 195.

693 https://doi.org/10.1002/ece3.1347

694 Yamasaki, Y. Y., Nishida, M., Suzuki, T., Mukai, T., \& Watanabe, K. (2015). Phylogeny, 695 hybridization, and life history evolution of Rhinogobius gobies in Japan, inferred from 696 multiple nuclear gene sequences. Molecular Phylogenetics and Evolution, 90, 20-33.

697 https://doi. org/10.1016/j.ympev.2015.04.012

698 Yoder, J. B., Clancey, E., Des roches, S., Eastman, J. M., Gentry, L., Godsoe, W., ... Harmon, 699 L. J. (2010). Ecological opportunity and the origin of adaptive radiations. Journal of 700 Evolutionary Biology, 23, 1581-1596. https://doi.org/10.1111/j.1420-9101.2010.02029.x 
701 Yoshigou, H. (2014). Annotated checklist and bibliographic records of inland water fishes of

702 the Ryukyu Archipelago, Japan. Fauna Ryukyana, 9, 1-153. (in Japanese with English

703 abstract). 
705 TABLE 1 Results of model selection by ABC analysis

\begin{tabular}{|c|c|c|c|c|c|c|c|}
\hline Tested geographic scale & $\begin{array}{c}\text { Origins of freshwater form in the best } \\
\text { model }\end{array}$ & Gene flow & $\begin{array}{l}\text { Posterior } \\
\text { probability of } \\
\text { the best model }\end{array}$ & $\begin{array}{l}\text { Bayes factors of the best } \\
\text { model against all models }\end{array}$ & $\begin{array}{l}\text { Bayes factosr of the } \\
\text { best model against } \\
\text { another origin models }\end{array}$ & $\begin{array}{l}\text { Type } 2 \text { error } \\
\text { rate (all } \\
\text { models) }\end{array}$ & $\begin{array}{c}\text { Type } 2 \\
\text { error rate } \\
\text { (against } \\
\text { another } \\
\text { origin } \\
\text { models) }\end{array}$ \\
\hline \multicolumn{8}{|l|}{ Within-islands } \\
\hline Amami-Oshima Is. & Single origin & Partial & 0.5087 & $1.668-37.70$ & $12.04-37.70$ & $0.05-0.17$ & $0.09-0.12$ \\
\hline Tokunoshima Is. & Single origin & All & 0.3128 & $1.355-2069$ & $133.5-2069$ & $0.02-0.11$ & $0.05-0.07$ \\
\hline Okinawajima Is. & Single origin & All & 0.6357 & $1.754-4300$ & $544.4-4300$ & $0-0.04$ & 0 \\
\hline Kumejima Is. & Single origin & Partial & 0.3254 & $1.047-18735$ & 4368- 18735 & $0.02-0.17$ & $0.02-0.09$ \\
\hline Iriomotejima Is. & Single origin & Partial & 0.4544 & $1.321-309807$ & $3247-309807$ & $0.01-0.15$ & $0.01-0.15$ \\
\hline \multicolumn{8}{|l|}{ Among-islands within-regions } \\
\hline Middle Ryukyu & Originated in respective islands & All & 0.4471 & $1.090-519.2$ & $23.97-24.37$ & $0-0.35$ & 0 \\
\hline South Ryukyu & Single origin & All & 0.8949 & $13.63-191.0$ & $36.98-191.0$ & $0-0.08$ & $0-0.08$ \\
\hline $\begin{array}{l}\text { Tokunoshima Is. - } \\
\text { Okinoerabujima Is. }\end{array}$ & Single origin & All & 0.7461 & $4.680-122.6$ & $9.419-122.6$ & $0.06-0.1$ & $0.06-0.1$ \\
\hline \multicolumn{8}{|l|}{ Among-regions } \\
\hline Middle Ryukyu - South Ryukyu & Robust result could not obtain. & - & - & - & - & - & - \\
\hline
\end{tabular}


709 TABLE 2 Results of the logistic regression analysis

\begin{tabular}{|l|l|c|c|c|}
\hline Explanatory variable & \multicolumn{1}{|c|}{ Data Set } & $P$ value & $\begin{array}{c}\text { Difference of } \\
\text { deviance }\end{array}$ & $R^{2}$ \\
\hline Island Area & Larger island & 0.0016 & 12.265 & 0.577 \\
\hline Catchment Area & Smaller island & 0.0061 & 8.650 & 0.407 \\
\hline & Larger island & 0.0026 & 12.055 & 0.567 \\
\hline River Length & Smaller island & 0.0187 & 6.923 & 0.325 \\
\hline & Larger island & 0.0038 & 11.699 & 0.550 \\
\hline No. Waterfalls & Smaller island & 0.0172 & 7.028 & 0.330 \\
\hline & Larger island & 0.0013 & 13.712 & 0.645 \\
\hline & Smaller island & 0.3277 & 1.407 & 0.066 \\
\hline
\end{tabular}

711 Note: The results presented in this table are based on the assumption that the freshwater form

712 (FF) has five independent origins. The data set column indicates the assumption of the islands

713 where speciation occurred. Our ABC analysis indicated that FF in Tokunoshima Is. and

714 Okinoerabujima Is., and Ishigakijima Is. and Iriomotejima Is. shared their origins. "Larger

715 island" in the data set column assumed that the speciation of FF occurred in the larger island

716 (i.e., Tokunoshima Is. and Iriomotejima Is.), whereas "smaller island" assumed that speciation

717 occurred in the smaller island (i.e., Okinoerabujima Is. and Ishigakijima Is.). The $p$ values for

718 all combinations are presented in Table S9. 


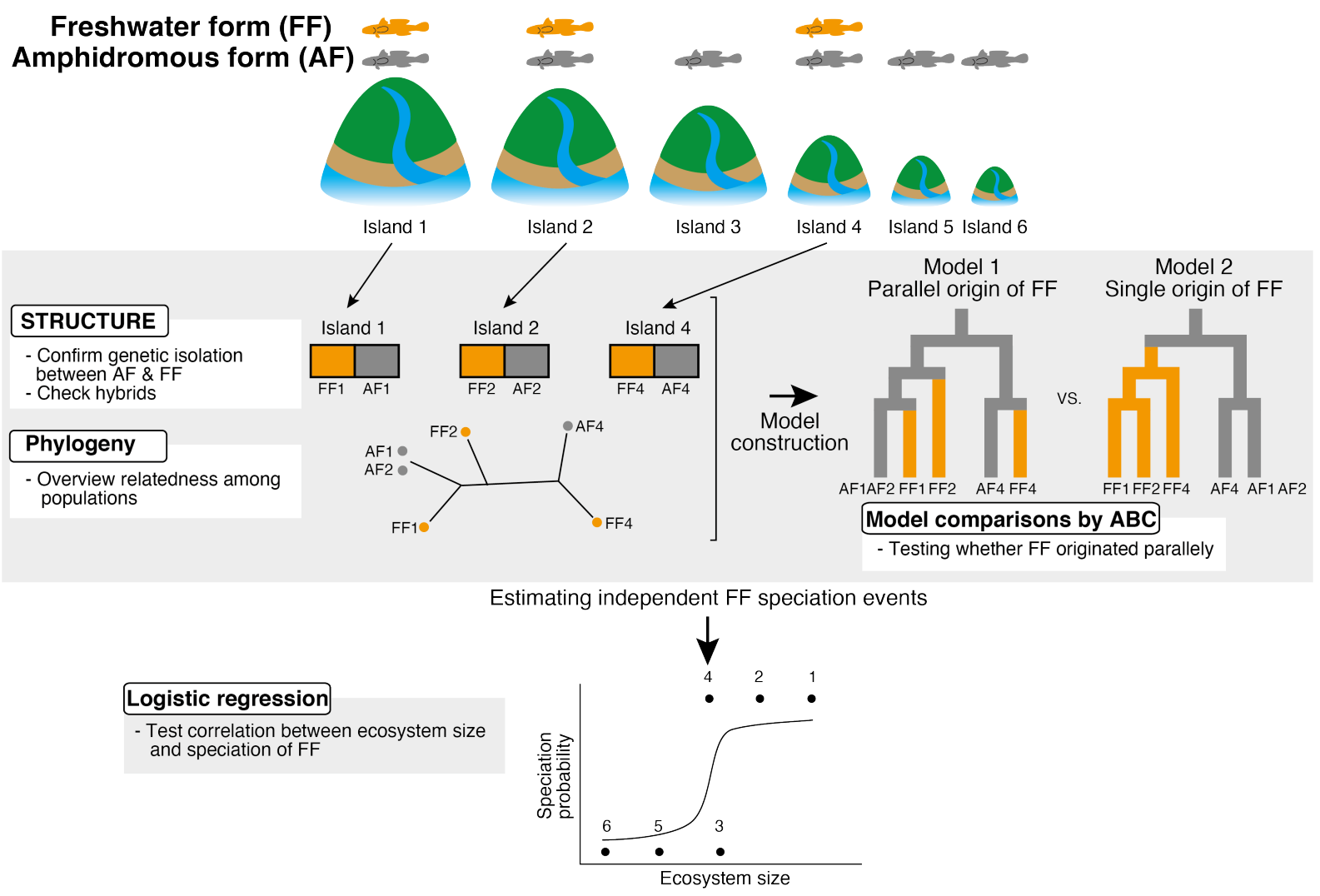

722 F I G U R E 1 Concept diagram of this study based on a hypothetical example. Our final goal 723 was to determine whether ecosystem

724 size explains the occurrence of speciation of the freshwater form (FF). To explain the study 725 workflow, we postulate six islands with the amphidromous form (AF). FF was distributed in 726 three islands among them. Four main analyses were conducted in this study. First, we 727 confirmed genetic isolation between AF and FF by structure analysis for each island. Second, 728 we estimated phylogenetic relationships among populations. Third, we tested independent 729 speciation of FF by demographic comparison based on $\mathrm{ABC}$ analysis. The phylogenetic tree 730 and geographical locations were used to construct demographic models. The occurrence of 731 speciation in focal islands was identified by these three analyses. Finally, we tested the 732 correlation between ecosystem size and occurrence of speciation by logistic regression 733 analysis. 

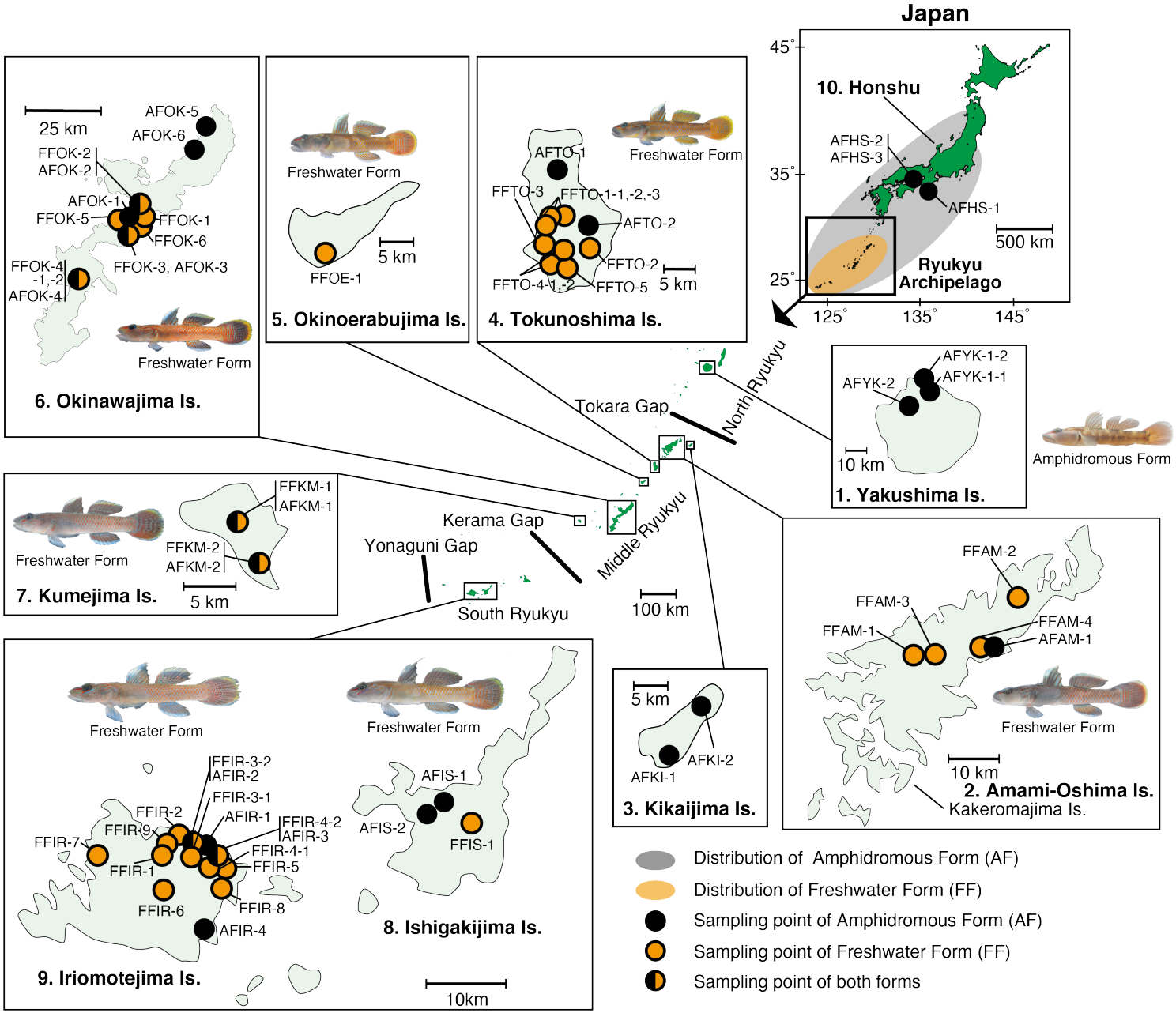

\section{FIGURE 2}

736 Samplingpointsinthisstudy.Themapintheupperrightboxindicatesdistributionrangesoftheamphid

737 romousform(AF;grey) and the freshwater form (FF; orange) in Japan as a whole. The central

738 map is the whole area of the Ryukyu Archipelago. Black and orange circles indicate the

739 points from where AF and FF were collected, respectively. Sympatrically collected points are

740 indicated by both colours. 
3. Kikaijima Is. \& 2. Amami-Oshima Is. $k=3$

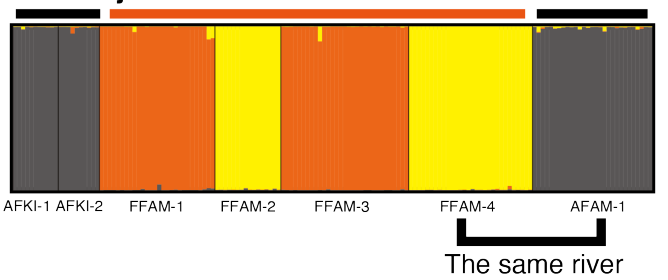

5. Okinoerabujima Is. $K=2$

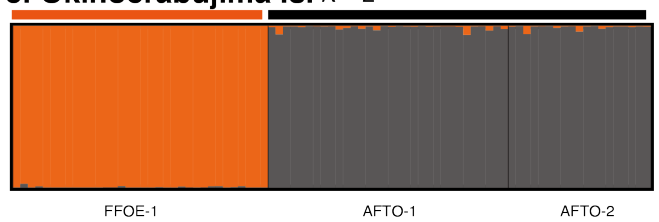

7. Kumejima Is. $K=2$

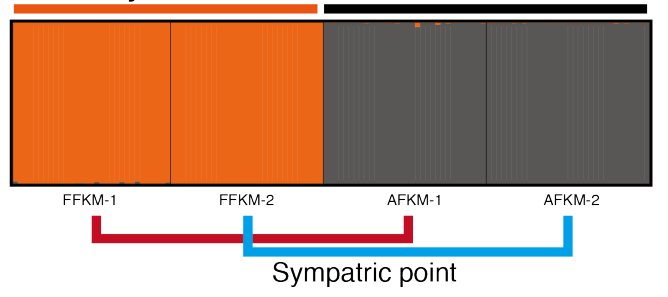

9. Iriomotejima Is. $k=2$

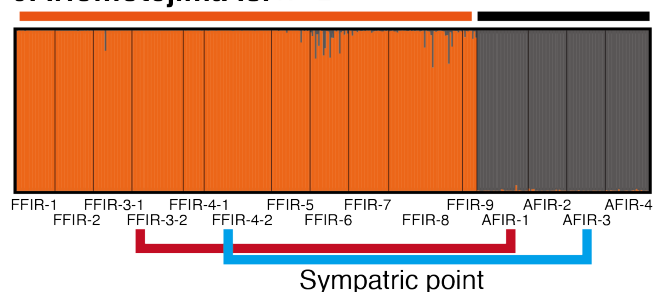

4. Tokunoshima Is. $K=2$

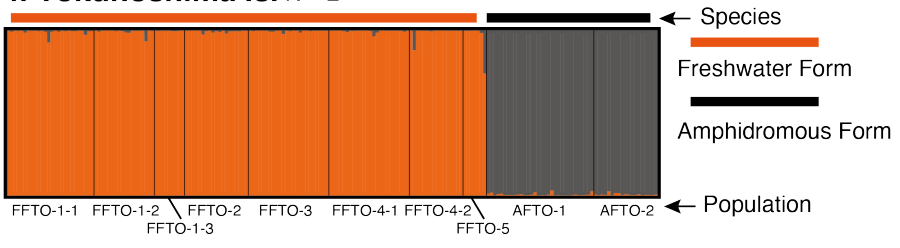

6. Okinawajima Is. $K=2$

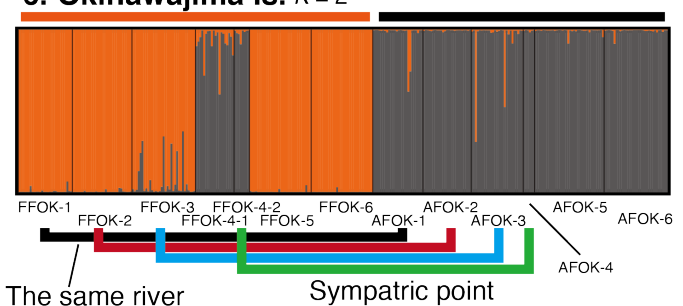

8. Ishigakijima Is. $k=2$

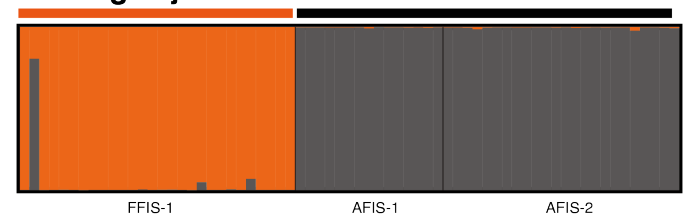

Amphidromous Form only $k=2$

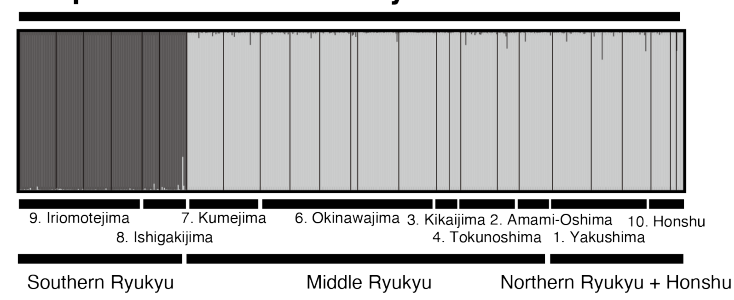

742 F I G U R E 3 Results of genetic clustering analysis performed in structure (Amami-Oshima

743 Is., $K=3$; others, $K=2$ ). Sampling points are indicated by black vertical bars in the

744 respective bar plots. Horizontal bars at the top of the plot indicate morphological

745 identification of respective specimens. Sympatric points are indicated by an additional

746 annotation. The specimens morphologically identified as the freshwater form (FF) are

747 presented in orange and yellow colours, whereas those identified as the amphidromous form

748 (AF) are presented in grey. 
(a)

(b)

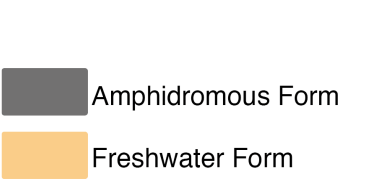

\section{$(2)^{2}$}

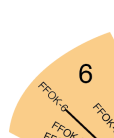

1,10

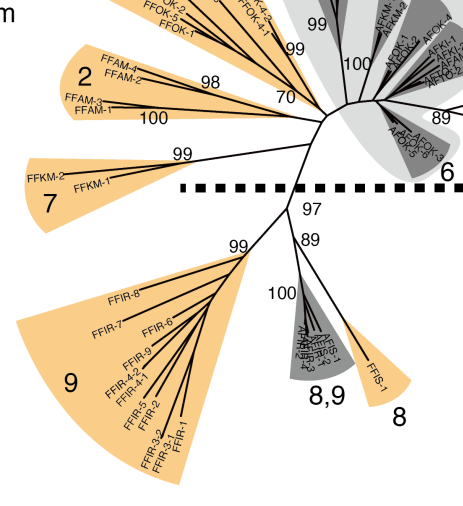

Within Island

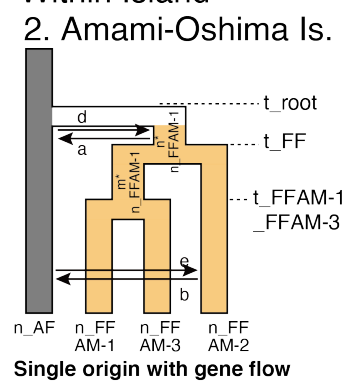

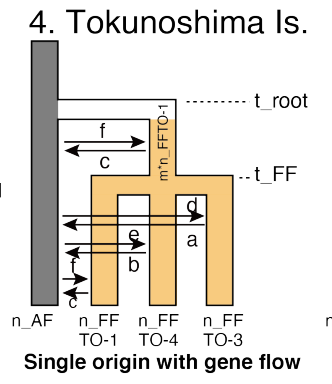

6. Okinawajima Is.

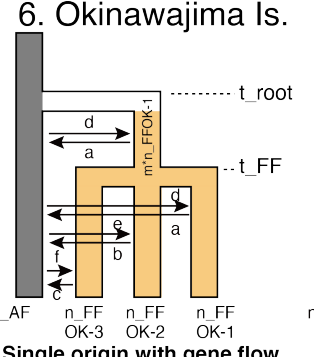

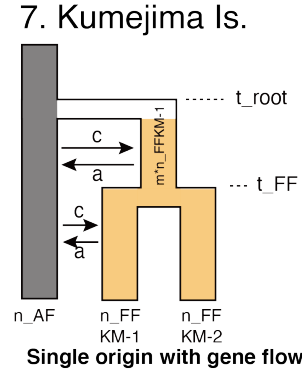

9. Iriomotejima Is.

Between Island

Middle Ryukyu (Group 1)

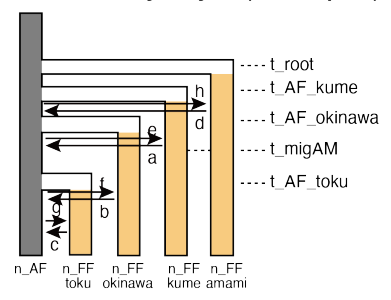

Parallel origin with gene flow

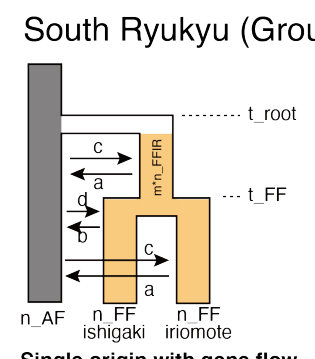

Single origin with gene flow

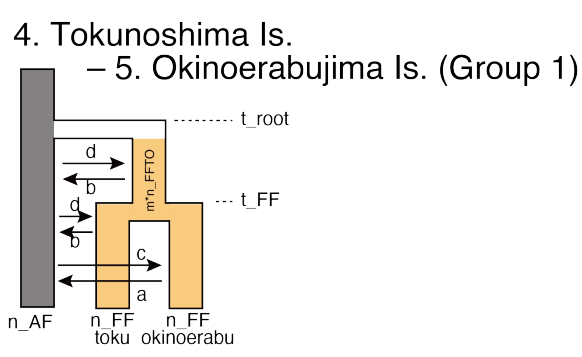

Single origin with gene flow

750 F I G U R E 4 Population relationships and evolutionary scenarios of the amphidromous

751 form (AF) and the freshwater form (FF). (a) Neighbour-joining tree based on Nei's $D a$

752 distance of 20 microsatellites. Numbers on tree nodes indicate bootstrap values. Only

753 bootstrap values $>70 \%$ are indicated. Island numbers are indicated at tips. (b) The models

754 selected by ABC analysis. AF and FF are represented by black and orange colours,

755 respectively. Arrows between populations indicate gene flow. Only representative populations

756 were used for ABC analysis to reduce the amount of calculation (see Materials and methods

757 and Supporting methods and results S1). 
A

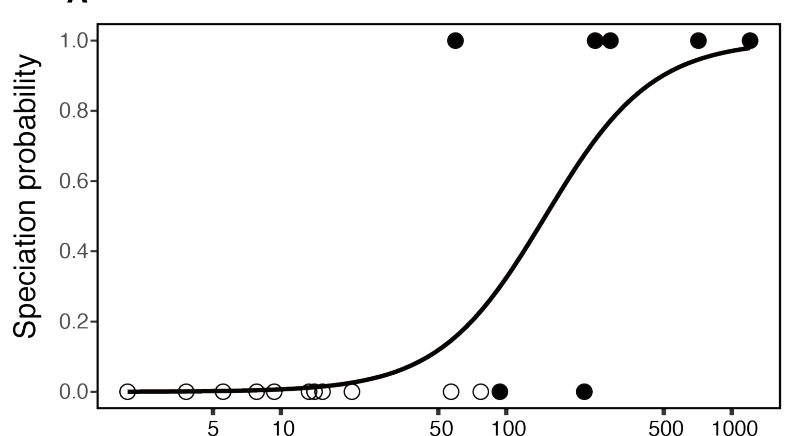

B

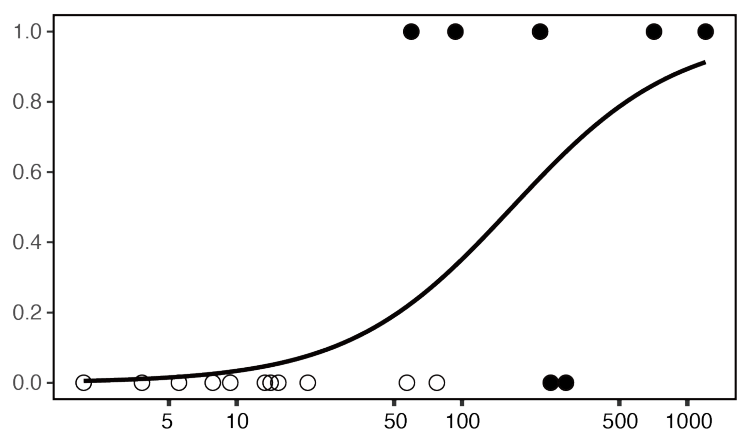

Island area $\left(\mathrm{km}^{2}\right)$

759 F I G U R E 5 Results of logistic regression analysis between island size and speciation

760 probability. Islands with the freshwater form (FF) are represented by filled circles, whereas

761 those without FF are represented by open circles. Filled circles plotted on the $x$-axis

762 (speciation probability $=0$ ) are for the islands with FF that was assumed to be of

763 nonindependent origin. Our ABC analysis indicated that FF in Tokunoshima Is. and

764 Okinoerabujima Is., and Ishigakijima Is. and Iriomotejima Is. shared their origins. (a)

765 Speciation of FF is assumed to have occurred in the larger islands (Tokunoshima Is. and

766 Iriomotejima Is.). (b) Speciation is assumed to have occurred in the smaller islands

767 (Okinoerabujima Is. and Ishigakijima Is.). 
1 Supplemental methods and results S1: Complete version of Materials and Methods

\section{2 and Results}

4 Materials and Methods

$5 \quad 1$. Study system

$6 \quad 1.1$ Study species

7 The genus Rhinogobius (Gobiidae) is the most speciose group of gobies occurring

8 in freshwater. This group contains more than 85 species in East and Southeast Asia, and

918 species in Japan (Oijen et al., 2011; Yamasaki et al., 2015). The freshwater resident

10 form derived from the amphidromous species $R$. brunneus is recognized as an

11 independent species but has not been described to date because of taxonomic confusion.

12 Previous studies (e.g., Akihito et al., 2013) tentatively used the name "Rhinogobius sp.

13 YB" for this freshwater form. However, until its evolutionary status is clarified, we will

14 use the code 'FF' (freshwater form) for Rhinogobius sp. YB and 'AF' (amphidromous

15 form) for R. brunneus based on their life history modes.

16 The FF completes its life in freshwater; conversely, AF larvae hatch in rivers and

17 immediately drift down to the sea and return to rivers after 2-3 months (Mizuno, 2001).

18 The eggs and larvae of FF are larger than those of AF. The sizes of eggs and hatched

19 larvae of respective forms and islands have already reported by some studies. As

20 follows, the both egg and larval sizes are greater in FF than in AF. The mean and

21 standard deviation of egg size of FF varies across islands; namely, long axis 3.07 and

$22 \quad 3.36 \mathrm{~mm}$, short axis 1.55 and $1.52 \mathrm{~mm}$ on Amami-Oshima Island (Kon et al., 2003);

23 long axis $5.06 \pm 0.39 \mathrm{~mm}$, short axis $1.77 \pm 0.10 \mathrm{~mm}$ on Amami-Oshima Is. (Shinomiya

24 et al., 2005); long axis 3.4 and $4.4 \mathrm{~mm}$, short axis 1.4 and $1.7 \mathrm{~mm}$ on Tokunoshima

25 Island (measured from the Figure 2 of Oshiro, 1981), long axis $4.3 \pm 0.2 \mathrm{~mm}$, short axis

$261.4 \pm 0.1 \mathrm{~mm}$ on Okinawajima Island (Hirashima \& Tachihara, 2000); long axis $5.4 \mathrm{~mm}$,

27 short axis $1.7 \mathrm{~mm}$ on Ishigakijima Island (measured from the Figure 2 of Oshiro, 1981).

28 We also measured the egg size of FF spawned in a tank by one individual collected

29 from Shirase River on Kumejima Island (long axis $3.52 \pm 0.24 \mathrm{~mm}$, short axis $1.31 \pm$

$300.07 \mathrm{~mm}, \mathrm{n}=26$ ). The mean and standard deviation of egg size of AF was recorded on

31 Okinawajima Island; namely, long axis $2.8 \pm 0.1 \mathrm{~mm}$, short axis $0.9 \pm 0.04 \mathrm{~mm}$ (Kondo

32 et al., 2013). The mean and standard deviation for notochord length of hatched larvae of

33 FF varies across islands; namely, 5.0 mm on Amami-Oshima Is. (Kon et al., 2013); 
$34 \quad 5.96-6.60 \mathrm{~mm}$ on Amami-Oshima Is. (Shinomiya et al., 2004); $5.3 \mathrm{~mm}$ on Okinawajima

35 Is. (Hirashima \& Tachihara 2000). The mean and standard deviation in notochord length

36 of hatched larvae of AF on Okinawajima Is. was $3.7 \pm 0.2 \mathrm{~mm}$ (Kondo et al., 2013);

$373.59 \pm 0.087 \mathrm{~mm}$ on Shikoku Island in the Japanese archipelago (Moriyama et al., 1998).

38 Fluvial species of this genus tend to produce larger eggs and larvae (Yamasaki et al.,

39 2015). Such traits are considered to be an adaptation to river environments, where small

40 food items (i.e., plankton) are scarce and higher level of swimming ability in river

41 current is needed during the larval period (Nishida, 2001; Shinomiya et al., 2005;

42 Hirashima \& Tachihara, 2000; Yamasaki et al., 2015).

43 Although the distribution of the two species sometimes overlapped in a single river,

44 the tendencies of their distributions were different. AF mainly lived in the middle to

45 lower reaches of rivers. In fact, AF populations are actually only found in rivers shorter

46 than $18 \mathrm{~km}$ in the central Honshu region of Japan (Tamada, 2005). The larvae of AF

47 must rapidly reach the sea to avoid starvation because of the scarcity of small food in

48 rivers (Moriyama, Yanagisawa, Mizuno, \& Omori, 1998; Iguchi \& Mizuno, 1999).

49 Thus, they might not be able to reproduce effectively in areas far from the sea (Iguchi \&

50 Mizuno, 1999). On the other hand, FF mainly live in the upper reaches of rivers, and are

51 often found in the upper areas of waterfalls where no other fishes are distributed (Kano

52 et al., 2012).

\subsection{Study area}

The Ryukyu Archipelago is a series of islands located in the southwestern part of Japan (Figure 2). The islands separated simultaneously from the continent about 1.5 million years ago (Osozawa et al., 2012). Three deep straits (Tokara Gap, Kerama Gap, and Yonaguni Gap) divide this archipelago into three regions: North Ryukyu, Middle Ryukyu, and South Ryukyu. These gaps act as biogeographic barriers for terrestrial organisms (Ota 1998). On the islands of North Ryukyu, the biota was destroyed by

61 pyroclastic flow 7300 years ago (Machida et al., 2001). AF is distributed in all three

62 regions, as well as mainland Japan, whereas FF is only distributed in Middle and South

63 Ryukyu (Yoshigou, 2014). In the Ryukyu Archipelago, primary freshwater fishes are

64 almost absent, and most fishes are diadromous. Therefore, fish assemblages in

65 freshwater areas are simple and similar among islands (Yoshigou, 2014). 
68 All animal experiments followed the rules, regulations, and guidelines relating to animal

69 experimentation of Kyoto University. Sampling of FF and AF was conducted from June

702012 to March 2015 on seven islands where former populations have been recorded

71 previously (Locality code 2. Amami-Oshima Is., 4. Tokunoshima Is., 5. Okinoerabujima

72 Is., 6. Okinawajima Is., and 7. Kumejima Is. in Middle Ryukyu; 8. Ishigakijima Is. and

73 9. Iriomotejima Is. in South Ryukyu; Figure 2; Table S1; Ohara et al. 2008; Yoshigo,

74 2014). In addition, AF specimens were collected from Kikaijima Is. (Locality code 3) in Middle Ryukyu, Yakushima Is. (1) in North Ryukyu, and mainland Japan (10). The specimens were identified by body colour patterns under fresh conditions (Suzuki et al., 2004; Kano et al., 2012). Identification based on body colour was validated by the results of the genetic analysis; however, some samples were difficult to identify or showed inconsistent genetic characteristics $3.2 \%$ of specimens in total, including potential hybrids). When genetic data suggested the focal specimens were not judged as hybrids based on the criteria described below and that wrong identification based on morphology in the field was likely, these samples were removed from further analysis. In the case that a sample was judged to be a hybrid (see 4.2), we tentatively named it based on the morphology. It should be noted that we found that morphologically identified FFOK-4-1 and FFOK-4-2 populations of FF largely reflected the genetic features of AF (Figure 3 and Supporting Information Figure S3). We judged them as hybrid populations and did not remove any specimens from the analysis even if they were not judged as hybrid (see Discussion). Specimens were anesthetized with iced water or 2-phenoxy-ethanol, and then a fin was clipped and preserved in $99 \%$ ethanol. Most specimens were fixed in $10 \%$ formalin or $99 \%$ ethanol. As a result, $842 \mathrm{FF}$ and 578 AF specimens from 52 points in 42 river systems were included in the population genetic analysis. The average numbers of localities and specimens per island were 5.2 and 142, respectively. Both forms were collected from nine river systems; they were sympatrically collected at seven points.

\section{Molecular experiment}

\subsection{Microsatellite marker development}

We developed new microsatellite markers following the methods of Takeshima et al. 
100 (2017). Total genomic DNA was extracted from one AF specimen collected from 101 DAIR-4 in Iriomotejima Island by using a Genomic DNA Purification Kit (Promega, 102 Madison, Wisconsin, USA). We concentrated CA repeat regions by using the target 103 capture method and sequenced them using the Roche 454 GS Junior system (Accession 104 No. DRA006388). Primers and multiplex systems were designed using QDD ver. 2 105 (Meglecz et al., 2010) and Multiplex Manager v. 1.2 (Holleley \& Geerts 2009), 106 respectively. One out of four universal tail sequences was added to each forward primer for fluorescent labelling during PCR (Blacket et al., 2012).

\subsection{DNA extraction, PCR, and genotyping}

110 Total genomic DNA was extracted from the fin clip by using the Genomic DNA

111 Purification Kit. Before PCR amplification, a droplet of $1.25 \mu \mathrm{L}$ extracted DNA was

112 placed on a 96 well plate and dried. Total 21 microsatellite markers (18 originally

113 developed loci and three loci reported by Ohara et al. (2004)) were analyzed. We

114 developed four multiplex sets and simultaneously amplified 4-10 loci (Table S2). For

115 the markers that were developed, the final concentration of each forward and reverse

116 primer was 1 and $2 \mu \mathrm{M}$, respectively. The $1 \mu \mathrm{M}$ tailed fluorescent primer for each

117 forward primer was also added to the multiplex reaction mixture. For the three loci

118 reported by Ohara et al. (2004), 5'-fluorescent-labelled forward primers were used, and

119 the final concentration of each forward and reverse primers was adjusted to $1 \mu \mathrm{M}$. PCR

120 amplification was performed in a $4 \mu \mathrm{L}$ volume containing $2.43 \mu \mathrm{L}$ of ultrapure water,

$1210.066 \mu \mathrm{L}$ of primer mix, and $1.5 \mu \mathrm{L}$ of Type-IT Microsatellite PCR Kit (Qiagen, Hilden,

122 Germany) with the dried DNA. The PCR settings for the originally developed markers

123 included a first step of denaturation at $95^{\circ} \mathrm{C}$ for $5 \mathrm{~min}$, followed by 35 cycles of the

124 second step (denaturation: $94^{\circ} \mathrm{C}, 30 \mathrm{~s}$; annealing: $63^{\circ} \mathrm{C}, 90 \mathrm{~s}$; and extension: $72^{\circ} \mathrm{C}, 75 \mathrm{~s}$ ),

125 and the final extension at $72{ }^{\circ} \mathrm{C}$ for $30 \mathrm{~min}$. For the PCR for the loci of Ohara et al.

126 (2004), the second step was changed as follows: 28 cycles of denaturation at $94^{\circ} \mathrm{C}$ for

$12730 \mathrm{~s}$; annealing at $53^{\circ} \mathrm{C}$ for $90 \mathrm{~s}$; and extension at $72^{\circ} \mathrm{C}$ for $60 \mathrm{~s}$. We directly added 10

$128 \mu \mathrm{L}$ HiDi Formamide (Thermo Fisher Scientific, Waltham, MA, USA) and $0.2 \mu \mathrm{L}$ of

129 GeneScan 500Liz dye Size Standard or GeneScan 400HD Rox dye Size Standard

130 (Thermo Fisher Scientific) for the respective PCR products. Next, we subjected the

131 products to heat shock treatment $\left(95^{\circ} \mathrm{C}, 5 \mathrm{~min} ; 0^{\circ} \mathrm{C}, 5 \mathrm{~min}\right)$. The peak size data were

132 acquired using ABI 3130xl sequencer (Applied Biosystems, Foster City, CA, USA) and 
133 were analyzed using GeneMapper v.4.0 (Applied Biosystems). The acquired allele size

134 data were transformed for integral number by using tandem v.1.09 (Matschiner \&

135 Salzburger 2009).

136 We genotyped a total of 21 microsatellite loci for population genetic analyses

137 (Table S2). Null alleles were checked using software Micro-checker ver.2.2.3 (van

138 Oosterhout et al., 2004) under 100\% interval condition for the 25 populations of $R$.

139 brunneus, which were assumed to not be affected by the bottleneck effect. Null alleles

140 were detected in several $R$. brunneus populations. We excluded locus br_b_04 from the

141 analysis because null alleles were detected at this locus in both North Ryukyu and

142 Middle Ryukyu populations. Null alleles in other loci occurred sporadically; hence, we

143 used the other 20 loci for the following analysis to avoid reduction of information.

144 Linkage disequilibrium among loci was tested using 10,000 times of permutation

145 implemented in Arlequin ver.3.5 (Excoffier \& Lischer 2010), and Bonferroni collection

146 was applied to $P$-values to avoid type I errors. No significant linkage disequilibrium

147 between loci was detected (adjusted $P \geq 0.05$ ). The final genotype data were deposited

148 in dryad (doi: 10.5061/dryad.mpg4f4qvh).

\section{Data analysis}

\section{$151 \quad$ 4.1 Calculation of summary statistics and estimation of phylogenetic trees}

152 We calculated the expected and observed heterozygosity ( $\mathrm{He}$ and $\mathrm{Ho}$, respectively), the

153 effective number of alleles $(A e)$ for the respective populations, and population-pairwise

$154 \quad F_{\mathrm{ST}}$ and Jost's $D$ by using GenoDive $2.0 \mathrm{~b} 27$ (Meirmans \& van Tienderen 2004). We

155 also calculated allelic richness $(R s)$ of the respective populations by using FSTAT

156 v2.9.3.2 (Goudet 1995). Phylogenetic relationships among populations were estimated

157 based on Nei's Da distance by using the neighbor-joining method implemented in

158 Poptree2 (Takezaki et al., 2010). The credibility of each clade was evaluated using

1591,000 bootstrap resamplings. To assess hierarchical genetic differentiation, we

160 conducted AMOVA (Excoffier, Smouse, \& Quattro, 1992) implemented in GenoDive

161 separately for AF and FF. The number of hierarchies to be tested was five. However,

162 AMOVA could include only four hierarchies in one analysis. To deal with this problem,

163 we conducted AMOVA separately in two geographic scales. In the among-islands

164 within-regions scale, we set following four hierarchies: within-individuals,

165 among-individuals, among-rivers, and among-islands. This analysis was separately 
166 conducted for Middle Ryukyu and South Ryukyu. In the among-regions scale, we set

167 the following four hierarchies: within-individuals, among-individuals, among-islands,

168 and among-regions. $F_{\mathrm{ST}-a n a l o g}$ distance was applied. Significance was tested using 999

169 permutations.

170

\subsection{STRUCTURE analysis}

172 To infer the existence and extent of gene flow and genetic isolation, we analyzed

173 the genetic structure of the population using STRUCTURE v.2.3.4 (Pritchard, Stephen,

174 \& Donnelly, 2000; Lawson, van Dorp, \& Falush, 2018). We prepared two datasets: one

175 for both FF and AF populations from each island, and another for only AF populations

176 from all islands. Because AF was not found on Okinoerabujima Is., the FF on the island

177 were analyzed along with the AF from the nearest island, Tokunoshima Is. Admixture

178 model with correlated allele frequencies was assumed. Markov Chain Monte Carlo was

179 performed with 100,000 generations for burn-in and final 1,000,000 generations. Ten

180 independent runs for each $K$ from 1 to 10 were evaluated. After a run finished, we

181 calculated Evanno's $\Delta K$ by using STRUCTURE Harvester (Evanno, Regnaut, \& Goudet,

182 2005; Earl \& von Holdt, 2012) was used for a reference for $K$ value selection. Hybrid

183 individuals were evaluated using $q$-values; we arbitrarily judged specimens as hybrids

184 (or individuals with hybrid origin) in cases where minor genetic components accounted

185 for $10 \%$ or more of the aggregate (Vähä \& Primmer 2006).

186

$187 \quad 4.3$ Testing parallel speciation of FF by using ABC

188 To statistically examine the single or parallel origins of FF, and to estimate which FF

189 populations shared their origins we conducted a demographic model selection under the

190 approximate Bayesian computation (ABC framework, Beaumont, 2010; Bertorelle et

191 al., 2010) implemented in ABCtoolbox v.1 (Wegmann et al.,. 2010) and R package 'abc'

192 v.2.1 (Csilléry et al., 2012). Coalescent simulation was conducted using fastsimcoal2

193 v.2.5.2.1.1 (Excoffier \& Foll 2011; Excoffier et al., 2013). Summary statistics were

194 calculated using arlsumstat v.3.5 for each simulation (Excoffier \& Lischer 2010).

\subsubsection{Prior distribution, summary statistics, and simulation}

198 analyses. When the range of the prior distribution of a parameter was across the digits, 
199 the value was $\log _{10}$ transformed. A uniform distribution for each parameter was assumed.

200 We set a larger prior range for population size of AF $\left(10^{2}-10^{5.3}\right)$ than for FF $\left(10^{2}-10^{4.7}\right)$.

201 The prior distribution of coalescent time (generation) was set to $10^{3}-10^{6.2}$, considering

202 that the Ryukyu Archipelago had separated from the continents 1.5 million years ago,

203 and the generation time of the Rhinogobius species was one to two years (Yamasaki,

204 personal observation). The prior distribution of the migration rate was set to $10^{-9}-10^{-3}$.

205 In the case that the models of two or more populations were merged, the ancestral

206 population size was set to the range of 0.5 to 2 times of either of the derived populations.

207 We applied a generalized stepwise mutation model for microsatellite evolution. Our data

208 did not match the simulated data produced using the models under a previously reported

209 average mutation rate of microsatellites in fish (common carp: $5.56 \times$

$21010^{-4}$ /locus/generation, 95\% interval, $1.52 \times 10^{-4}-1.63 \times 10^{-3}$, Yue et al., 2007) from

211 principal component analysis (PCA) (see 4.3.3). Simulated data under several average

212 mutation rates were tested, and then the value of $1.0 \times 10^{-4}$ was selected, under which

213 the generated data matched the acquired data. The prior distribution of the mutation rate

214 for each locus was set to a Gamma distribution. The maximum difference of repeat

215 number of alleles of each microsatellite in coalescent simulations was set to 45.

216 To capture information regarding population size and differentiation, we selected

217 summary statistics listed in Table S3. Detailed formulae of respective summary statistics

218 are described in the Arlequin 3.5 manual (Excoffier \& Lischer 2010). A total of 46 to

219132 summary statistics for each analysis were used according to the number of the

220 analyzed populations. We performed $1.0 \times 10^{6}$ simulations for each demographic model.

\subsubsection{General strategy for the construction of demographic models}

Our general model construction strategies for ABC analysis were as follows. First, we generated separate models using three geographic scales, i.e. within-islands, regional (Middle and South Ryukyu), and archipelago scales, and examined FF origins in each geographic scale to reduce the number of models and populations examined in a single analysis. Second, we examined both models with and without gene flow between AF and FF populations. This is because a simulation study suggests that gene flow could alter apparent phylogenetic relationships among populations when simple genetic distance was used (Bierne, Gagnaire, \& David, 2013). Demographic model comparisons that consider gene flow can overcome this problem (Butlin et al., 2014). 
In the within-islands analyses, we mainly examined two questions: whether FF had single or parallel origin, and whether gene flow between AF and FF existed on each island. We hypothesized several plausible divergence orders between populations based on the result of STRUCTURE analysis, phylogeny, and geographic locations for respective islands. Thereafter, we compared the models with single/parallel origins and with/without gene flow. Analyses were conducted for the five islands where FF is distributed in multiple rivers (i.e., Amami-Oshima Is., Tokunoshima Is., Okinawajima Is., Kumejima Is., and Iriomotejima Is.). Ishigakijima Is. and Okinoerabujima Is. were not included in the analyses because the FF population was only found in one river system on each island. We selected three (or two) river populations for each island to reduce the model complexities and calculation loading. FF specimens from a single river system were merged to increase calculation accuracy. Populations were selected by the following criteria to extract information of population history as much as possible; geographically distant river systems, to avoid bias from shared population history among geographically nearby populations; and lower rates of missing data. The constructed models (a total of 34 models) are described in Supporting Information Figure S1A-E.

For the among-islands within-region analyses, we constructed several plausible models separately for the regions of Tokunoshima Is. and Okinoerabujima Is., Middle Ryukyu, and South Ryukyu. Five to ten models were constructed on the basis of the phylogenetic tree and geographic distance between islands. Gene flow settings followed the results of within-islands scale analysis. For each island, we selected only one FF population whose population size was the largest, as judged from $\mathrm{He}$ values. Finally, in the between-region analyses, we compared ten models generated from the results of the previous analyses. All constructed models are described in Figure S1F-I. Scripts that described models were deposited in Dryad (doi: 10.5061/dryad.mpg4f4qvh).

\subsubsection{Prior check}

We performed PCA by using gfitpca function implemented in $a b c$ package to check the validity of the prior distribution. We confirmed that the observed summary statistics included of the $90 \%$ envelope of each simulation result (data not shown).

\subsubsection{Posterior probabilities of models}


The posterior probability of each model based on the observed value was estimated using the neuralnet method, which is a non-linear regression method involving neural networks. We used postpr function implemented in the $a b c$ package. The regression step was performed using 30 neural networks and 10 hidden layer units. Five hidden layer units were set in the analysis of the archipelago scale, because an error occurred when 10 hidden layers were set. We used $1 \%$ of simulations with summary statistic values closest to the observed ones (tolerance rate $=1 \%$ ). We conducted 10 calculations for each model selection by changing the tolerance rates from $0.1 \%$ to $1.0 \%$ with increments of $0.1 \%$ to evaluate the robustness of the results by using a tolerance rate of $1 \%$.

\subsubsection{Confidence in model selection}

To evaluate the accuracy of the model selection, we calculated the misclassification rate by using function cv4postpr implemented in $a b c$ package. We randomly generated 100 pseudo-observed data sets (pods) of each model from the prior distribution and performed model selection for the respective pods with $10^{5}$ simulations for each model. Model selection was performed using neuralnet method under 10 neural networks and 10 hidden layer units. Five hidden layer units were set in the analysis at the archipelago scale as in the calculation of posterior probabilities. Type 1 and type 2 errors were evaluated for each model: type 1 error rate is the probability that the other model was selected despite the focal model being true, and type 2 error rate is the probability that the focal model was selected despite the other model being true. For evaluating the accuracy of the model selection results, the type 2 error rate should be carefully considered (Cornuet et al., 2010; Lombert et al., 2014).

\subsubsection{Estimating posterior distributions of parameters}

We calculated the posterior distribution of each parameter under the selected model by using function $a b c$ implemented in the $a b c$ package. We retained $1 \%$ of simulations close to the observed summary statistics, and we performed regression analysis by using the neuralnet method under 30 neural networks and five hidden layer units. Parameters of population size and event time were log transformed before regression analysis.

\subsubsection{Posterior predictive check}


We checked whether the selected model could produce the observed value under the posterior distribution. We generated 1000 simulations under the posterior distribution of the selected model and calculated summary statistics. In addition to the originally used summary statistics, the following summary statistics were also calculated: the mean allelic range over loci for each population (R_pop) and its standard deviation (Rsd_pop), the mean allelic range over loci and populations (MEAN_R) and its standard deviation (MEAN_Rsd), and the mean total allelic range over loci and populations (TOT_R), and $F_{I S}$ (FIS). Next, PCA using function gfitpca implemented in $a b c$ package was performed to check whether the observed summary statistics were included in the range of summary statistics generated from the posterior distribution.

\section{Correlation between island size and speciation probability}

310 We first identified the islands on which the speciation of FF occurred based on the

311 results of STRUCTURE (genetic isolation) and ABC model selection (independent

312 origin). The relationship between ecosystem size and speciation was analyzed for the

313 Middle and South Ryukyu Islands between the Tokara Gap and Yonaguni Gap. This

314 analysis was conducted because these islands are assumed to be similar in age, were

315 never connected to any continent after separation, and were not catastrophically affected

316 by volcanic activity (Osozawa et al., 2012). We acquired distribution information for the

317 two forms from published literature (Yoshigou 2014) and our own field survey, and we

318 only chose the islands where either or both forms were distributed. This is because we

319 assumed that speciation was not likely to have occurred on the island where either of

320 these species is not currently distributed. We coded the occurrence of speciation in each

321 island as follows: 1 for the island where speciation occurred; 0 for the island where

322 speciation did not occur. As a proxy of ecosystem size, we used island area $\left(\mathrm{km}^{2}\right.$; data

323 obtained from Geospatial Information Authority of Japan), the maximum catchment

324 area $\left(\mathrm{km}^{2}\right)$, the maximum river length $(\mathrm{m})$, or the maximum number of waterfalls in

325 each island. The data on rivers on the islands where FF is distributed were only obtained

326 for rivers with FF. The latter three parameters were calculated using the $10 \mathrm{~m}$ mesh

327 digital elevation model (Geographic Information Authority of Japan) by using

328 ArcGIS10.3 (ESRI Japan, Tokyo). Because of strong positive correlations among the

329 four variables (Pearson's correlation coefficient: island size and catchment area, 0.959;

330 island size and river length, 0.951; catchment area and river length, 0.993; island size 
331 and number of waterfalls, 0.592; catchment area and number of waterfalls, 0.865; river

332 length and number of waterfalls, 0.865), we primarily used island area as the

333 explanatory variable.

334 We performed one-parameter logistic regression analysis in the generalized linear

335 model framework with binomial error structure for the response variable (speciation: 1,

336 presence; 0, absence) using glm package of R v. 3.1.1 (R Core Team, 2014).

337 Explanatory variables, except the number of waterfalls, were $\log _{10}$ transformed. To test 338 the significance of explanatory variables, we conducted a likelihood ratio test using 33910,000 rounds of parametric bootstrap sampling by using a constant model as the null

340 model that assumes no relationship between ecosystem variables and speciation

341 probability. We calculated McFadden's pseudo $R^{2}$ by using the following formula: $r^{2}=1$

$342-(\mathrm{SSE} / \mathrm{SST})$. In this formula, SSE and SST refer to the deviances of the focal and null 343 models, respectively.

344 Furthermore, to examine the effect of the ecosystem size parameters other than 345 island size (i.e., maximum catchment area, river length, and number of waterfalls), we 346 constructed another generalized linear model for speciation probability. We used the 347 residuals from a regression between island size and each of the other ecosystem-size 348 parameters, together with the island size and their interaction, as explanatory variables. 349 Stepwise model selections by AIC scores were conducted using step function on R.

\section{Results}

\section{1. Basic summary statistics}

354 Heterozygosity and allelic richness were generally higher in the AF populations than in 355 the FF ones, possibly suggesting a larger current or historical population size in the 356 former (AF: He, 0.296-0.554 and $R s, 1.94-3.65$; FF: He, 0.070-0.390 and Rs, 1.21357 3.08; Supporting Information Table S1, Figure S2A, B). The AF populations showed 358 relatively little pairwise genetic differentiation within-islands $\left(F_{\mathrm{ST}}=-0.008-0.145\right.$; 359 Jost's $D=-0.009-0.102$; Supporting Information Tables S4, 5, Figure S2C, D). In the

360 case of the among-islands within-regions scale, pairwise genetic differentiation was 361 moderate $\left(F_{\mathrm{ST}}, 0.022-0.168\right.$; Jost's $\left.D, 0.025-0.219\right)$. AMOVA showed significant 362 differentiation in the among-rivers hierarchy in both Middle Ryukyu and South Ryukyu, 363 and in the among-islands hierarchy in Middle Ryukyu (Supporting Information Table 
364 S6). Most of the variation was explained by within-individuals hierarchy. Compared

365 with this, the genetic differentiation of $\mathrm{AF}$ populations between regions was large $\left(F_{\mathrm{ST}}\right.$,

$366 \quad 0.110-0.456$; Jost's $D, 0.124-0.613)$. AMOVA showed significant differentiation in both

367 among-islands and among-regions hierarchies (Supporting Information Table S6).

368 Variations were mainly explained by within-individuals, among-islands, and

369 among-regions hierarchies. The FF populations often showed large genetic

370 differentiation within-islands ( $F_{\mathrm{ST}}, 0.003-0.804$; Jost's $D, 0.001-0.529$; Supporting

371 Information Tables S4, 5, Figure S2C, D) and among-islands within-regions $\left(F_{\mathrm{ST}}\right.$,

$3720.312-0.859$; Jost's $D, 0.146-0.778)$, as well as among-regions ( $F_{\mathrm{ST}}, 0.507-0.914$;

373 Jost's $D, 0.580-0.890)$. AMOVA for FF showed significant genetic differentiation in the

374 hierarchies of among-individuals, among-rivers, among-islands, and among-regions,

375 except among-islands in South Ryukyu (Supporting Information Table S6). In the

376 among-islands within-regions scale analysis, genetic variation was mainly explained by within-individuals, among-rivers, and among-islands hierarchies.

378

\section{Genetic isolation and hybrids}

380 In the AF dataset, Evanno's $\Delta K$ showed the maximum value at $K=2$; the populations in North plus Middle Ryukyu and South Ryukyu were clearly separated. In the dataset for each island, including $\mathrm{FF}$ and AF populations, $\Delta K$ had the maximum value at $K=2$ for all islands, except one (Amami-Oshima Is.). The two genetic clusters corresponded to the two forms, except on Okinawajima Is. (see below; Figure 3 and Supporting Information Figure S3). $\Delta K$ on Amami-Oshima Is. showed the maximum value at $K=3$, in which FF was further divided into two clusters. Suspected hybrid individuals ( $q$-value, $\geq 10 \%)$ were rare ( $2.0 \%$ of total individuals). No suspected hybrid individuals were detected from five of the seven sympatric collection points. Several suspected hybrid individuals were detected in $11 \mathrm{FF}$ and $\mathrm{AF}$ populations, including two FF populations on Tokunoshima Is. (FFTO-4-2, FFTO-5), three FF on Okinawajima Is. (FFOK-3, FFOK-4-1, and FFOK-4-2), one FF on Ishigakijima Is. (FFIS-1), three FF on Iriomotejima Is. (FFIR-3-1, FFIR-6, and FFIR-8), and two AF on Okinawajima Is.

393 (AFOK-1, AFOK-3). Among these, all FF individuals that were identified based on

394 morphology in the FFOK-4-1 and FFOK-4-2 populations (Okinawajima Is.; see Figures

395 2, 3 and Supporting Information Figure S3) exhibited the genetic features of AF as the dominant component. Except for these two populations, the proportion of suspected 
397 hybrid individuals ranged from $3.6 \%$ to $21.2 \%$ of individuals in a population. Potential

398 hybrids found in the FF populations contained $10.1 \%-80.5 \%$ of the AF component,

399 whereas those of the AF populations contained $25.6 \%-69.0 \%$ of the FF component.

400

401

\section{Genetic relationships among populations}

402 The neighbor-joining tree showed two divergent groups separated by the Kerama

403 Gap in all of the FF and AF populations (bootstrap value, 97\%; Figure 4). Each group

404 included both forms, which we present as Group 1 (Honshu, North Ryukyu, and Middle Ryukyu) and Group 2 (South Ryukyu), hereafter.

406 In both groups, FF populations on each island formed a monophyletic group

407 (bootstrap value, 89\%-100\%), except those on two islands in Group 1 (Amami-Oshima

408 Is., 67\%; Okinawajima Is., 33\%). In addition, FF populations on different islands

409 (Tokunoshimajima Is. and Okinoerabujima Is.) formed a monophyletic group (89\%).

410 The AF populations within each group were closely related to each other, and the

411 populations of each island in Group 1 tended to form a monophyletic group.

\section{Test for multiple origins of FF}

415 In the within-island scale analysis, the single origin model of FF was selected for all

416 islands (Table 1 and Supporting Information Table S7; Figure 4 and Supporting

417 Information Figure S4). Models including gene flow among all or partial populations of

418 the two forms showed higher posterior probability than those not considering gene flow

419 (Table 1 and Supporting Information Table S7; Figure 4 and Supporting Information

420 Figure S4). Type 2 error rates for the selected single origin model against alternative

421 parallel origin models were generally low (Table 1 and Supporting Information Table

422 S7; Figure 4 and S4).

423 At the among-island scale, Group 1 in Middle Ryukyu and Group 2 in South

424 Ryukyu were analyzed separately. For Group 1, we first examined the single origin of

425 FF in the adjoining islands, Tokunoshima Is. and Okinoerabujima Is., which was

426 suggested by the phylogenetic analysis. $\mathrm{ABC}$ analysis supported their single origin

427 (posterior probability (PP), 0.746; Bayes factor (BF), 9.42-122.57; Type 2 error rate,

$428 \quad 0.06-0.1$; BFs and Type 2 error rates are of the selected model against parallel origin

429 models; Table 1 and Supporting Information Table S7; Figure S4); thus, only FF on 
430 Tokunoshima Is. was used for subsequent analyses. The model selection for Group 1

431 strongly supported the four independent origins of FF (PP, 0.447; BF, 23.97-519.23;

432 Type 2 error rate, 0 ; BFs and Type 2 error rates are of the selected model against the

433 other non-four origin models; Tables 1 and S7; Figure S4). The model with gene flow

434 between the two forms obtained higher BF than the model not considering gene flow

435 (BF, 4.72; Type 2 error rate, 0.125). In Group 2, the single origin of FF of Iriomotejima

436 Is. and Ishigakijima Is. was supported (PP, 0.895; BF, 36.98-191.0; Type 2 error rate, 0

$437 \quad 0.08$; BFs and Type 2 error rates are of the selected model against parallel origin models

438 Tables 1 and S7; Figure S4). The model including gene flow between the AF and FF

439 populations was better supported than that not considering gene flow (BF, 13.63; Type 2

440 error rate, 0.06$)$.

441 For the between-region scale, the neighbor-joining tree for populations suggested

442 independent origins of FF in Groups 1 and 2. However, we could not obtain a

443 conclusion at this scale from ABC, because no single model was successfully selected,

444 probably because of insufficient data (PP, 0.0024-0.14; Table S7; Figure S4).

445

4465 Correlation between speciation probability and ecosystem size

447 We confirmed the occurrence of AF or FF populations on 18 islands from the published

448 literature and our field survey (Supporting Information Table S8). As we could not

449 conclude from the ABC analysis whether the FF population originated independently

450 between Groups 1 and 2, we analyzed independent and non-independent scenarios

451 between the Middle and South Ryukyus. In addition, because the single origin of FF

452 was supported for Tokunoshima Is. and Okinoerabujima Is. populations, as well as for

453 Ishigakijima Is. and Iriomotejima Is. populations, we could not conclude which island

454 FF originated in. We developed four datasets for the independent scenario between

455 Groups 1 and 2 with all possible combinations of islands in which speciation would

456 have occurred independently: dataset 1, speciation in Tokunoshima Is. and Iriomotejima

457 Is.; dataset 2, in Tokunoshima Is. and Ishigakijima Is.; dataset 3, Okinoerabujima Is. and

458 Iriomotejima Is.; and dataset 4, Okinoerabujima Is. and Ishigakijima Is. We also

459 developed 16 datasets for the non-independent scenario (Supporting Information Table 460 S9).

461 For all four datasets in the scenario of independent origins between the regions,

462 speciation probability was significantly explained by island area $(P=0.0016-0.0061$, 
463 difference of deviance $=8.650-12.265, r^{2}=0.407-0.577$; Table 2 and Supporting

464 Information Table S9; Figure 5 and S5). The relationship was also significant for 12 of

465 the 16 datasets in the non-independent scenario (Supporting Information Table S9).

466 Almost identical results were obtained for the maximum catchment area and river

467 length (Table 2 and Supporting Information Table S9). Furthermore, two of the four

468 datasets for the independent origin scenario and five of the 16 datasets for the

469 non-independent scenario, showed significant relationships between the number of

470 waterfalls and speciation (Table 2 and Supporting Information Table S9). Model

471 selection by AIC scores showed that the best model included no variables, except for

island area, as the predictors for speciation probability in most datasets when the

473 variables were controlled by the island area (Supporting Information Table S9).

\section{References}

Akihito, Sakamoto, K., Ikeda, Y., \& Aizawa, M. (2013). Gobioidei. In T. Nakabo (Ed.), Fishes of Japan with Pictorial Keys to Species (Third ed.). (pp. 1374-1608). Tokyo, Japan: Tokai University Press. (in Japanese).

Beaumont, M. A. (2010). Approximate Bayesian computation in evolution and ecology. Annual Review of Ecology, Evolution, and Systematics, 41, 379-406. https://doi.org/10.1146/annurev-ecolsys-102209-144621

Bertorelle, G., Benazzo, A., \& Mona, S. (2010). ABC as a flexible framework to estimate demography over space and time: some cons, many pros. Molecular Ecology, 19, 2609-2625. https://doi.org/10.1111/j.1365-294X.2010.04690.x

Blacket, M. J., Robin, C., Good, R. T., Lee, S. F., \& Miller, A. D. (2012). Universal primers for fluorescent labelling of PCR fragments-an efficient and cost-effective approach to genotyping by fluorescence. Molecular Ecology Resources, 12, 456463. https://doi.org/10.1111/j.1755-0998.2011.03104.x

Cornuet, J.-M., Ravigné, V., \& Estoup, A. (2010). Inference on population history and model checking using DNA sequence and microsatellite data with the software DIYABC (v1.0). BMC Bioinformatics, 11, 401. https://doi.org/10.1186/1471-2105-11-401 
494

495

496

497

498

499

500

501

502

503

504

505

506

507

508

509

510

511

512

513

514

515

516

517

518

519

520

521

522

523

524

525

526

Csilléry, K., François, O., \& Blum, M. G. B. (2012). abc: an R package for approximate Bayesian computation (ABC). Methods in Ecology and Evolution, 3, 475-479. https://doi.org/10.1111/j.2041-210X.2011.00179.x

Earl, D. A., \& vonHoldt, B. M, (2012). STRUCTURE HARVESTER: a website and program for visualizing STRUCTURE output and implementing the Evanno method. Conservation Genetics Resources, 4, 359-361. https://doi.org/10.1007/s12686-011-9548-7

Evanno, G., Regnaut, S., \& Goudet, J. (2005). Detecting the number of clusters of individuals using the software STRUCTURE: a simluation study. Molecular Ecology, 14, 2611-2620. https://doi.org/10.1111/j.1365-294X.2005.02553.x

Excoffier, L., \& Lischer, H. E. L. (2010). Arlequin suite ver 3.5: a new series of programs to perform population genetics analyses under Linux and Windows. Molecular Ecology Resources, 10, 564-567. https://doi.org/10.1111/j.1755-0998.2010.02847.x

Excoffier, L., \& Foll, M. (2011). fastsimcoal: a continuous-time coalescent simulator of genomic diversity under arbitrarily complex evolutionary scenarios. Bioinformatics, 27, 1332-1334. https://doi.org/10.1093/bioinformatics/btr124

Excoffier, L., Dupanloup, I., Huerta-SÃ nchez, E., Sousa, V. C., \& Foll, M. (2013). Robust Demographic Inference from Genomic and SNP Data. PLoS Genetics, 9, e1003905-17. https://doi.org/10.1371/journal.pgen.1003905

Goudet, J. (1995). Fstat version 1.2: a computation program to calculate Fstatistics. Journal of Heredity, 86, 485-486. https://doi.org/10.1093/oxfordjournals.jhered.a111627

Hirashima, K., \& Tachihara, K. (2000). Embryonic development and morphological changes in larvae and juveniles of two land-locked gobies, Rhinogobius spp.

(Gobiidae), on Okinawa Island. Japanese Journal of Ichthyology, 47, 29-41 (in Japanese with English abstract). https://doi.org/10.11369/jji1950.47.29

Holleley, C., \& Geerts, P. (2009). Multiplex Manager 1.0: a cross-platform computer program that plans and optimizes multiplex PCR. Biotechniques, 46, 511-517. https://doi.org/10.2144/000113156

Iguchi, K., \& Mizuno, N. (1999). Early starvation limits survival in amphidromous fishes. Journal of Fish Biology, 54, 705-712. https://doi.org/10.1111/j.1095-8649.1999.tb02027.x 
527 Kano, Y., Nishida, S., \& Nakajima, J. (2012). Waterfalls drive parallel evolution in a

528

529

530

531

532

533

534

535

536

537

538

539

540

541

542

543

544

545

546

547

548

549

550

551

552

553

554

555

556

557 freshwater goby. Ecology and Evolution, 2, 1805-1817. https://doi.org/10.1002/ece3.295

Kon, T., \& Yoshino, T. (2003). Coloration and ontogenetic features of fluviatile species of Rhinogobius (Gobioidei: Gobiidae in Amami-oshima Island, Ryukyu Islands, Japan. Ichthyological Research, 50, 109-116. https://doi.org/10.1007/s10228-002-0145-3

Kondo, M., Maeda, K., Hirashima, K., \& Tachihara, K. (2013). Comparative larval development of three amphidromous Rhinogobius species, making reference to their habitat preferences and migration biology. Marine and Freshwater Research, 64, 249-266. https://doi.org/10.1071/MF12234

Lombert, E., Guillemaud, T., Lundgren, J., Koch, R., Facon, B., Grez, A., ...Estoup, A. (2014). Complementarity of statistical treatments to reconstruct worldwide routes of invasion: the case of the Asian ladybird Harmonia axyridis. Molecular Ecology, 23, 5979-5997. https://doi.org/10.1111/mec.12989

Machida, H., Ota, Y., Kawana, T., Moriwaki, H., \& Nagaoka, N. (2001). Regional Geomorphology of the Japanese Island vol. 7 Kyushu and Southern Islands. Tokyo, Japan: University of Tokyo Press. (in Japanese)

Matschiner, M., \& Salzburger, W. (2009). TANDEM: integrating automated allele binning into genetics and genomics workflows. Bioinformatics 25:1982-1983. https://doi.org/10.1093/bioinformatics/btp303

Meglecz, E., Costedoat, C., Dubut, V., Gilles, A., Malausa, T., Pech, N., \& Martin, J. F. (2010). QDD: a user-friendly program to select microsatellite markers and design primers from large sequencing projects. Bioinformatics, 26, 403-404. https://doi.org/10.1093/bioinformatics/btp670

Meirmans, P. G., \& van Tienderen, P. H. (2004). genotype and genodive: two programs for the analysis of genetic diversity of asexual organisms. Molecular Ecology Notes, 4, 792-794. https://doi.org/10.1111/j.1471-8286.2004.00770.x

Mizuno, N. (2001). Rhinogobius. In H. Kawanabe, N. Mizuno, \& K. Hosoya (Eds.), Freshwater fishes of Japan (Third ed.). (p. 584) Tokyo, Japan: Yama-Kei Publishers (in Japanese). 
558 Moriyama, A., Yanagisawa, Y., Mizuno, N., \& Omori, K. (1998). Starvation of drifting

559

560

561

562

563

564

565

566

567

568

569

570

571

572

573

574

575

576

577

578

579

580

581

582

583

584

585

586

587

588

589

590 goby larvae due to retention of free embryos in upstream reaches. Environmental Biology of Fishes, 52, 321-329. https://doi.org/10.1023/A:1007333302864

Ohara, K., Takahashi, D., \& Takagi, M. (2004). Isolation of microsatellite loci in the freshwater goby, Rhinogobius sp. (Gobiidae). Molecular Ecology Notes, 4, 449451. https://doi.org/10.1111/j.1471-8286.2004.00677.x

Oijen, M. J. P., Suzuki, T., \& Chen, I. S. (2011). On the earliest published species of Rhinogobius. With a redescription of Gobius brunneus Temminck and Schlegel, 1845. Journal of the National Taiwan Museum, 64, 1-17.

Omori, K., Ohnishi, H., Hamaoka, H., Kunihiro, T., Ito, S., Kuwae, M., ... Iguchi K. (2012). Speciation of fluvial forms from amphidromous forms of migratory populations. Ecological Modelling, 243, 89-94.

https://doi.org/10.1016/j.ecolmodel.2012.06.006

Oshiro, N. (1981). Ryukyu rettousan Yoshinobori no yomoyamabanashi (Some topics about Rhinogobius fishes in Ryukyu Island). Tansuigyo, 7, 14-18 (in Japanese).

Osozawa, S., Shinjo, R., \& Armid, A. (2012). Palaeogeographic reconstruction of the 1.55 Ma synchronous isolation of the Ryukyu Islands, Japan, and Taiwan and inflow of the Kuroshio warm current. International Geology Review, 54, 13691388. https://doi.org/10.1080/00206814.2011.639954

Ota, H. (1998). Geographic patterns of endemism and speciation in amphibians and reptiles of the Ryukyu Archipelago, Japan, with special reference to their paleogeographical implications. Researches on Population Ecology, 40, 189-204. https://doi.org/10.1007/BF02763404

Pritchard, J. K., Stephen, M., \& Donnelly, P. (2000). Inference of population genetic structure using multilocus genotype data. Genetics, 155, 945-959.

Shinomiya, A., Sasabe, K., Sakurai, M., \& Kishino, T. (2005). Morphological characters of newly hatched larvae and their habitat selection of a fluviatile goby, Rhinogobius sp. YB in the upper stream of Sumiyo River, Amami-oshima Island, Japan. Japanese Journal of Ichthyology, 52, 1-8 (in Japanese with English abstract). https://doi.org/10.11369/jji1950.52.1

Suzuki, T., Shibukawa, K., Yano, K., \& Senou, H. (2004). A photographic giude to the gobioid fishes in Japan. Tokyo, Japan: Heibonsha (in Japanese).

Takeshima, H., Muto, N., Sakai, Y., Ishiguro, N., Iguchi, K., Ishikawa, S., \& Nishida, M. 
(2017). Rapid and effective isolation of candidate sequences for development of microsatellite markers in 30 fish species by using kit-based target capture and multiplexed parallel sequencing. Conservation Genetics Resources, 9, 479-490. https://doi.org/10.1007/s12686-017-0730-4

Takezaki, N., Nei, M., \& Tamura, K. (2010). POPTREE2: Software for constructing population trees from allele frequency data and computing other population atatistics with Windows interface. Molecular Biology and Evolution, 27, 747-752. https://doi.org/10.1093/molbev/msp312

Tamada, K. (2005). Clutch and egg size in Rhinogobius sp. DA inhabiting small rivers. Japanese Journal of Ichthyology, 52, 17-20 (in Japanese with English abstract). https://doi.org/10.11369/jji1950.52.17

Vähä, J.-P., \& Primmer, C. R. (2005). Efficiency of model-based Bayesian methods for detecting hybrid individuals under different hybridization scenarios and with different numbers of loci. Molecular Ecology, 15, 63-72. https://doi.org/10.1111/j.1365-294X.2005.02773.x

van Oosterhout, C., Hutchinson, W. F., Willis, D. P. M., \& Shipley. P. (2004). MICROCHECKER; software for identifying and correcting genotyping errors in microsatellite data. Molecular Ecology Notes, 4, 535-538. https://doi.org/10.1111/j.1471-8286.2004.00684.x

Wegmann, D., Leuenberger, C., Neuenschwander, S., \& Excoffier, L. (2010). ABCtoolbox: a versatile toolkit for approximate Bayesian computations. BMC Bioinformatics, 11, 116. https://doi.org/10.1186/1471-2105-11-116

Yamasaki, Y. Y., Nishida, M., Suzuki, T., Mukai, T., \& Watanabe, K. (2015). Phylogeny, hybridization, and life history evolution of Rhinogobius gobies in Japan, inferred from multiple nuclear gene sequences. Molecular Phylogenetics and Evolution, 90, 20-33. https://doi.org/10.1016/j.ympev.2015.04.012

Yoshigou, H. (2014). Annotated checklist and bibliographic records of inland water fishes of the Ryukyu Archipelago, Japan. Fauna Ryukyana, 9, 1-153. http://w3.u-ryukyu.ac.jp/naruse/lab/Fauna_Ryukyuana.html

Yue, G. H., David, L., \& Orban, L. (2007). Mutation rate and pattern of microsatellites in common carp (Cyprinus carpio L.). Genetica, 129, 329-331 https://doi.org/10.1007/s10709-006-0003-8 


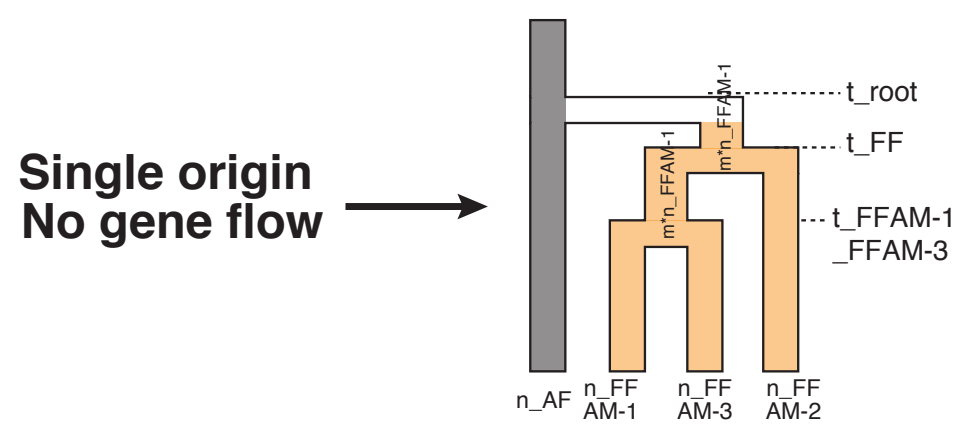

Model 3 (close relationship of FFAM-1\&-3)

\section{Single origin} Gene flow

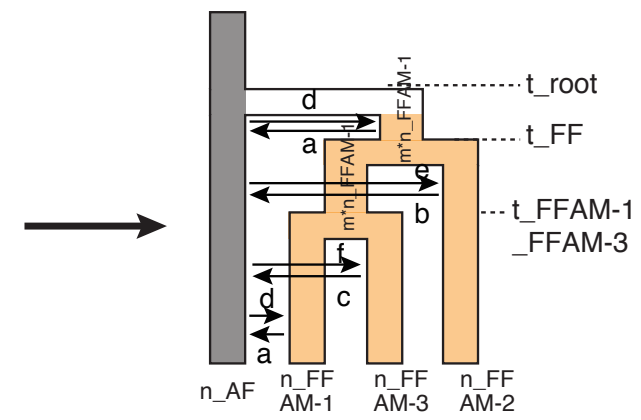

Model 4 (close relationship of FFAM-1\&-3)

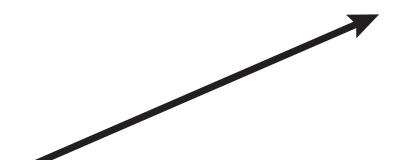

Different gene flow patterns

\section{Parallel origin No gene flow}

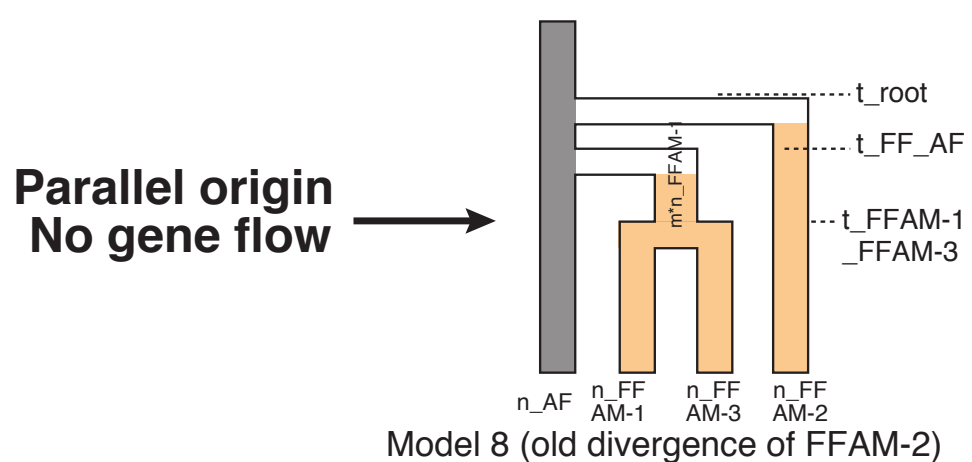

Model 8 (old divergence of FFAM-2)
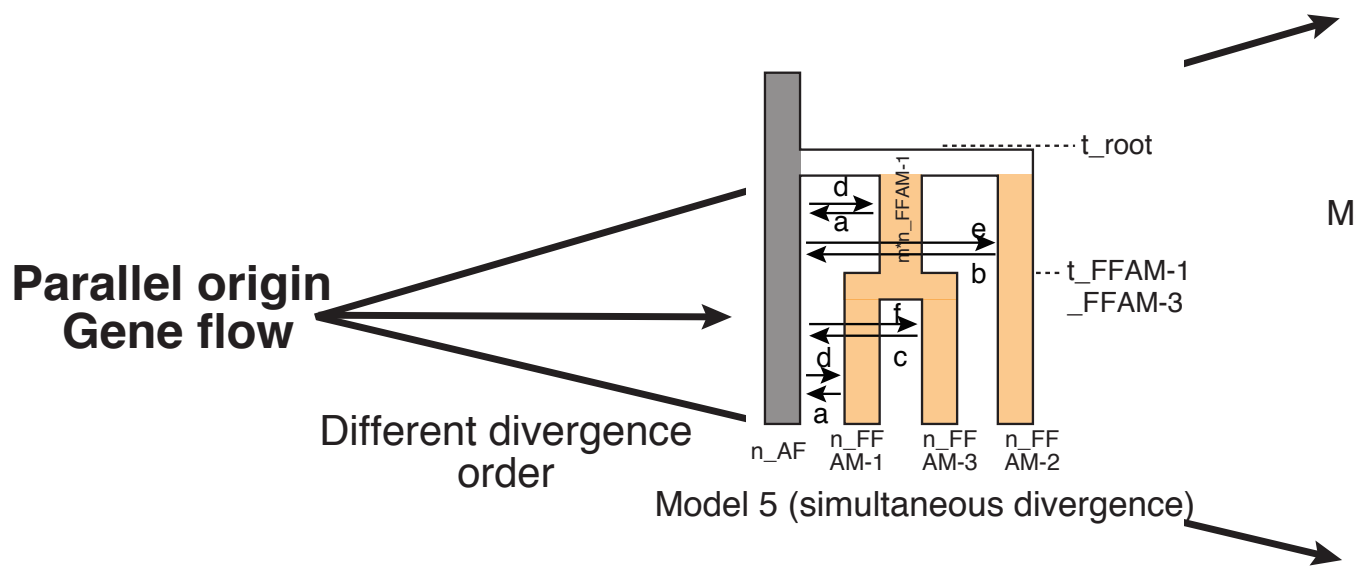

Model 1 (recent divergence of FFAM-2)

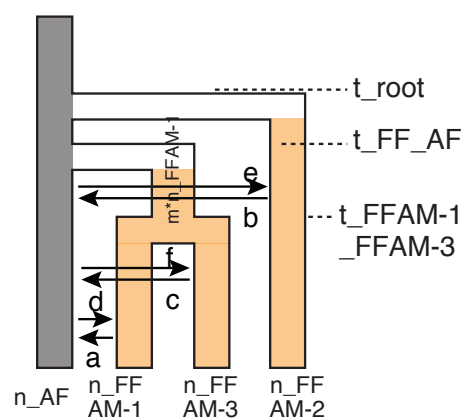

Model 2 (old divergence of FFAM-2)

Figure S1 Tested demographic models and their relationships. 

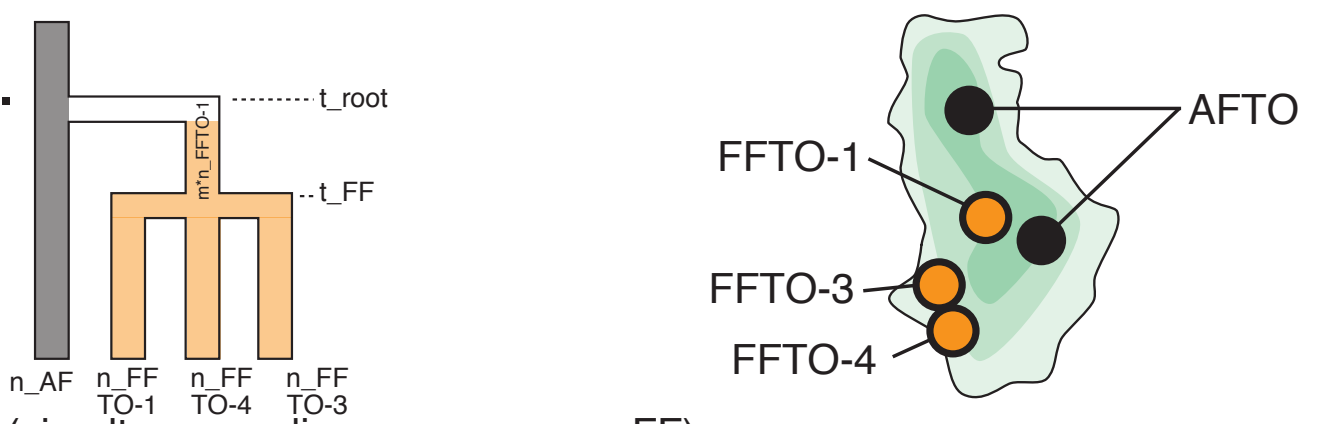

Single origin

Model 5 (simultaneous divergence among FF) No gene flow

Different divergence order

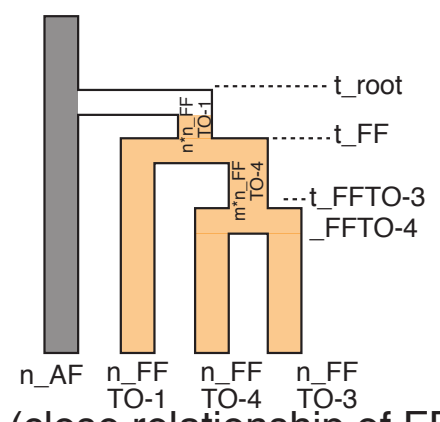

Model 6 (close relationship of FFTO-3\&-4)

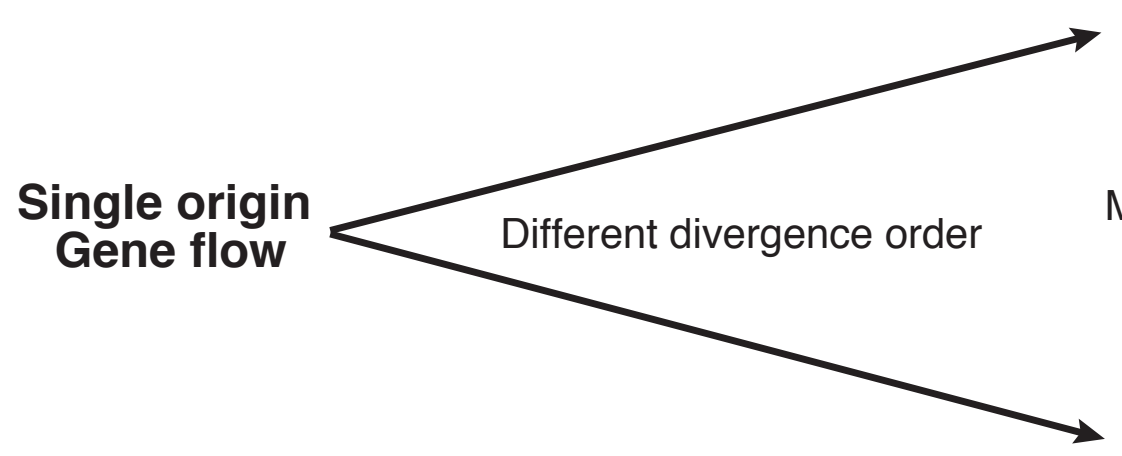

Parallel origin No gene flow

Model 1 (simultaneous divergence among FF)
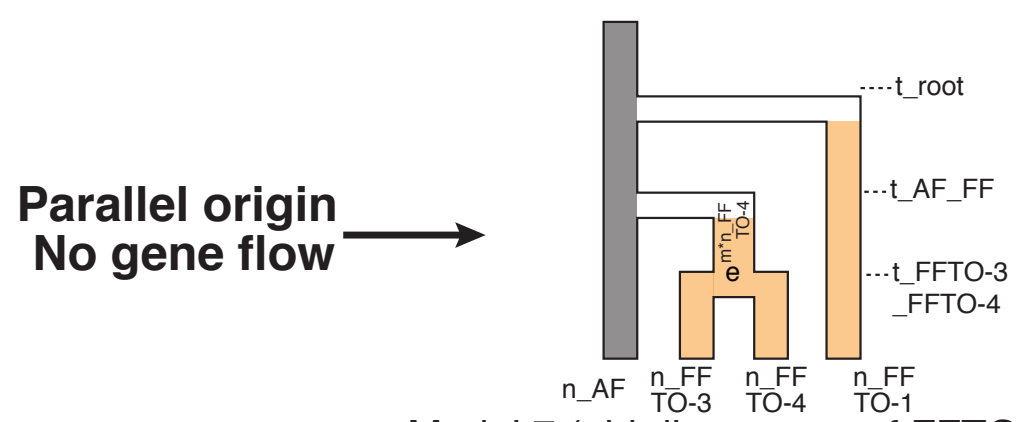

Model 7 (old divergence of FFTO-1)

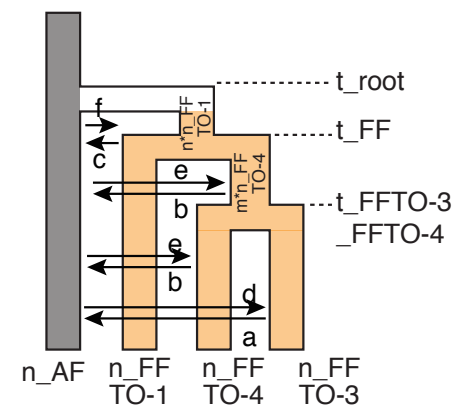

Model 3 (close relationship of FFTO-3\&-4)

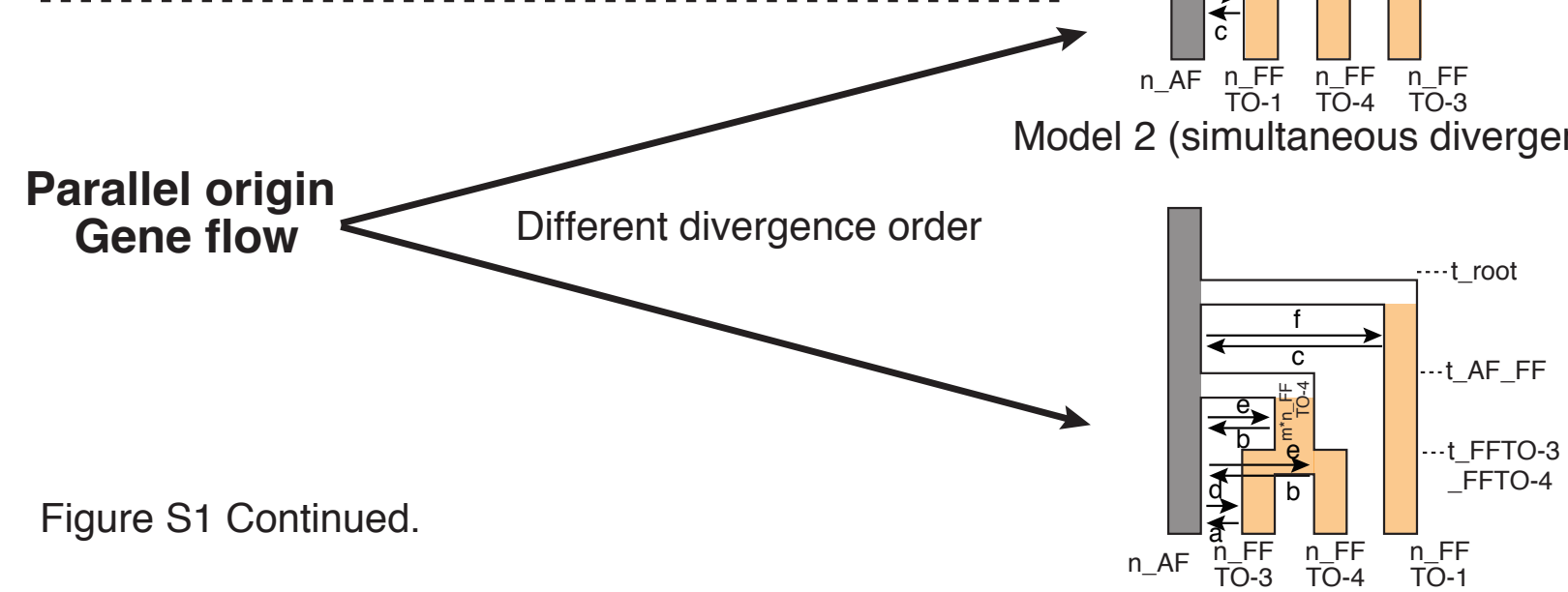

Figure S1 Continued.

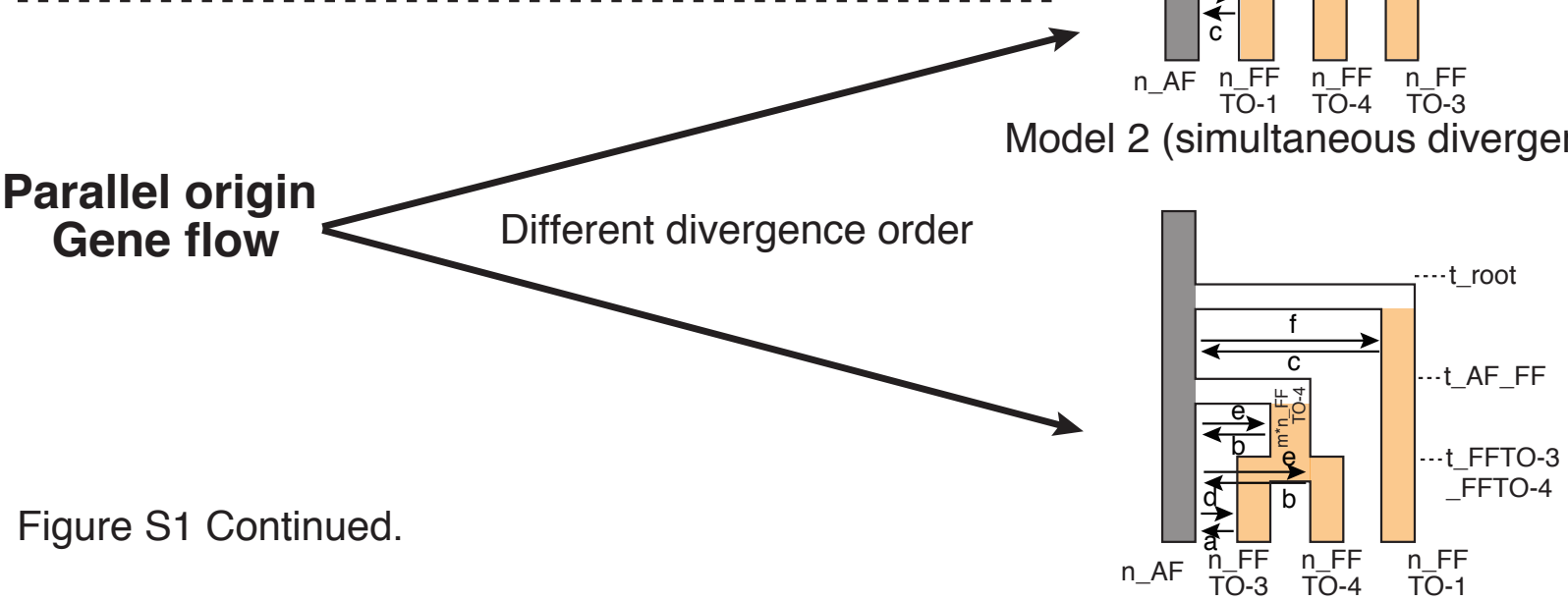

Model 4 (old divergence of FFTO-1) 
6. Okinawajima Is.

Single origin No gene flow

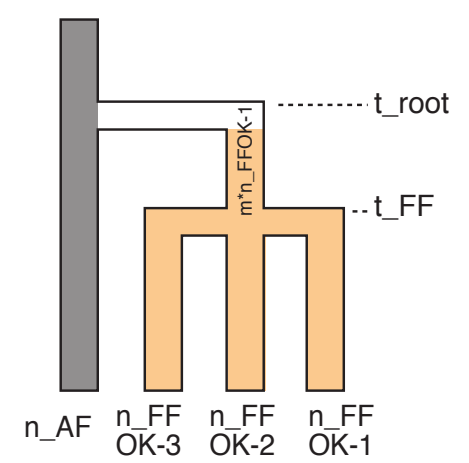

Model 5 (simultaneous divergence among FF)
Single origin

\section{Gene flow}

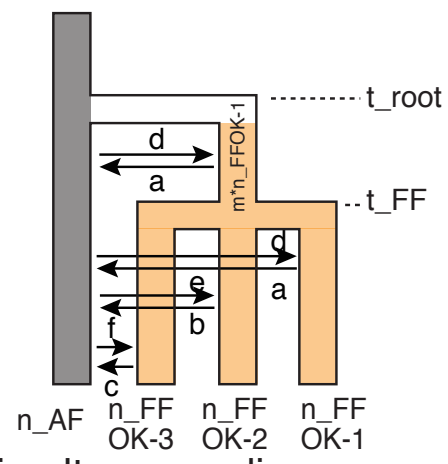

Model 1 (simultaneous divergence among FF)

\section{Parallel origin} No gene flow

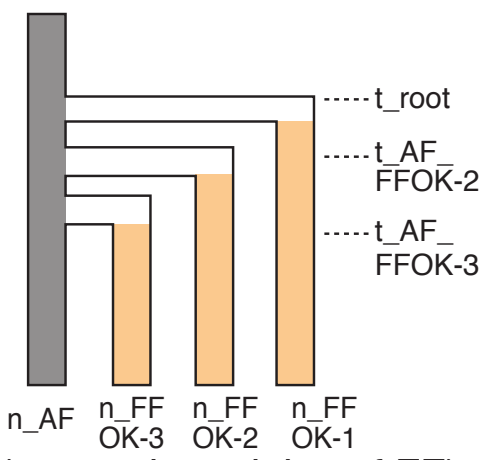

Model 3 (respective origins of FF)

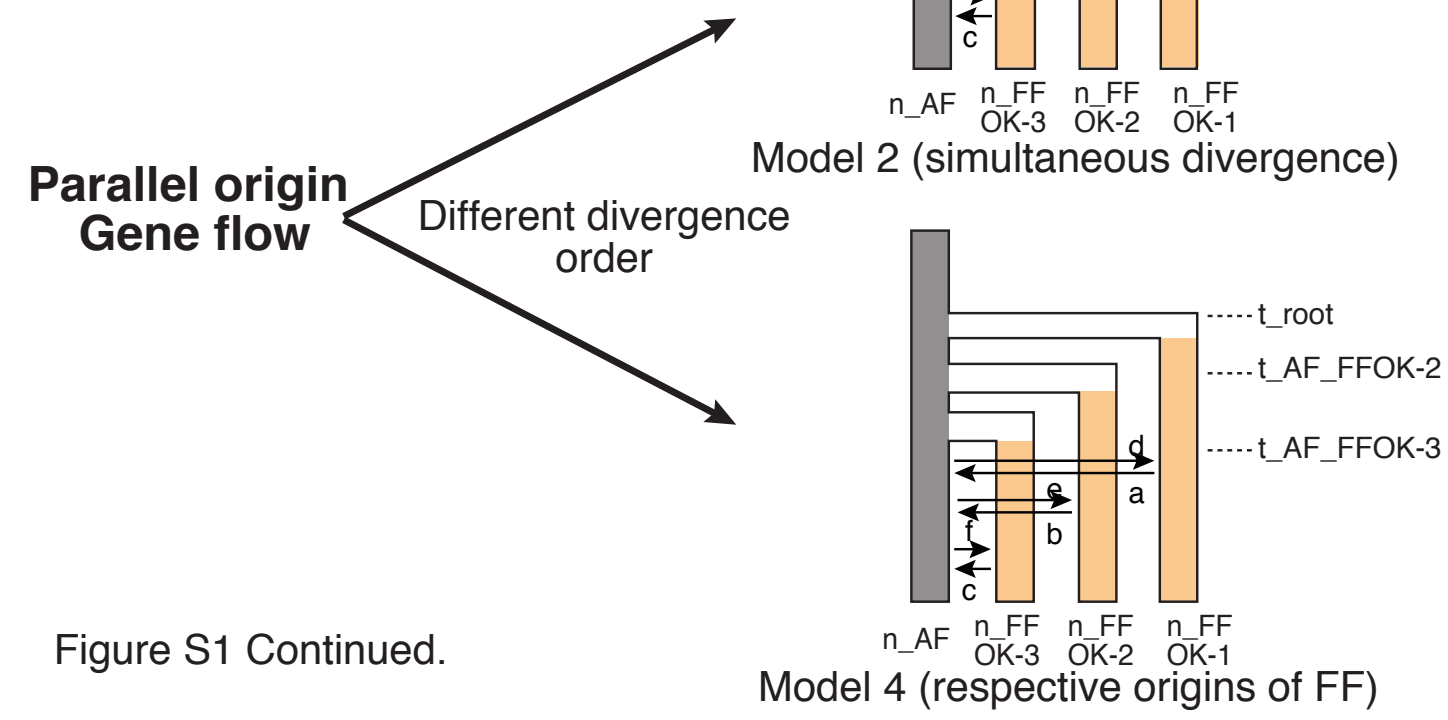




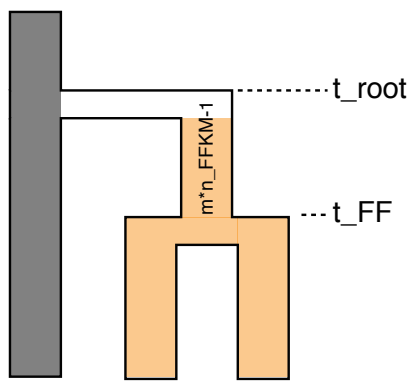

n_AFKM n_FFKM-1 n_FFKM-2

Model 4 (single origin, no gene flow)
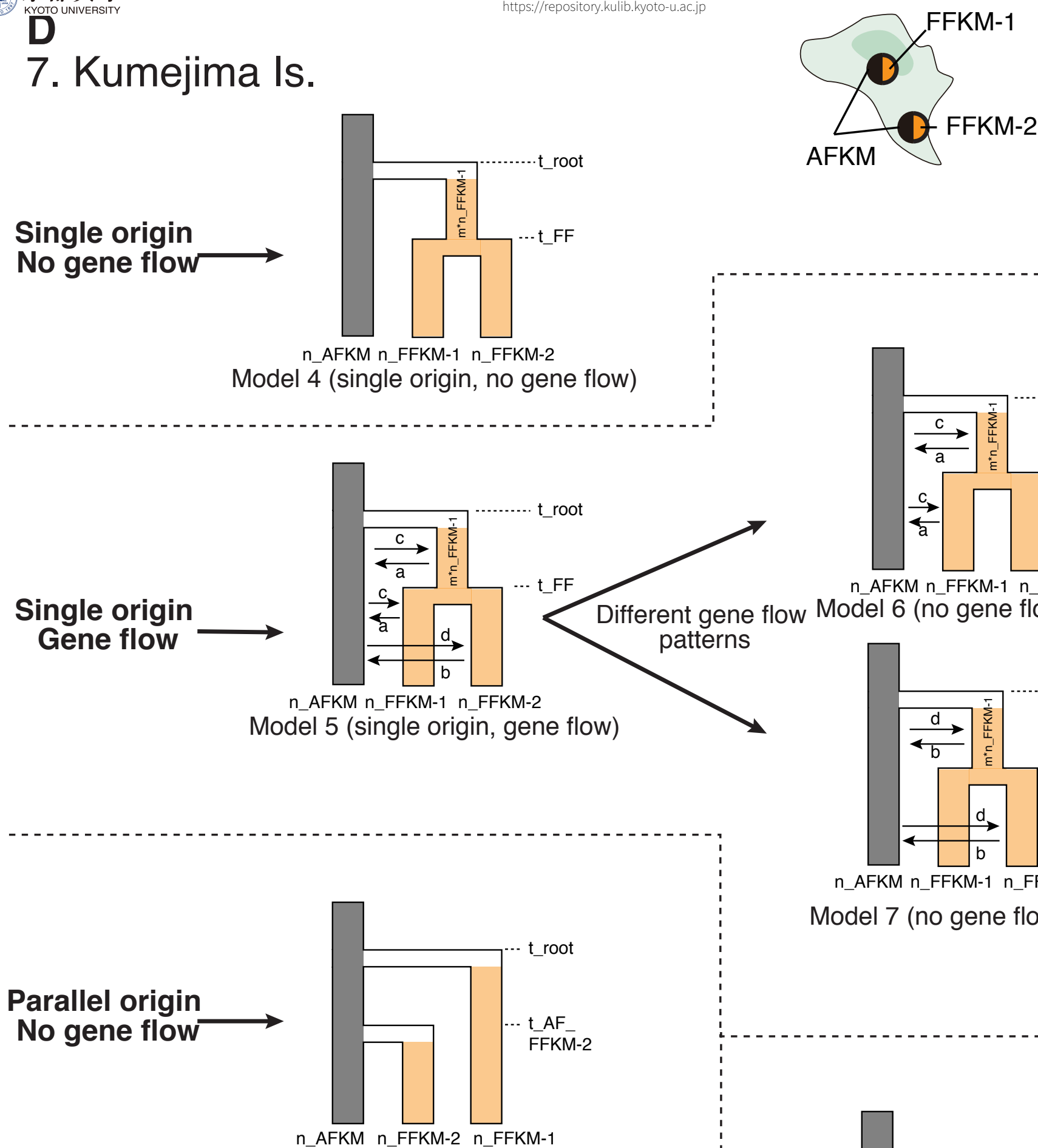

Model 8 (old divergence of FFKM-1)

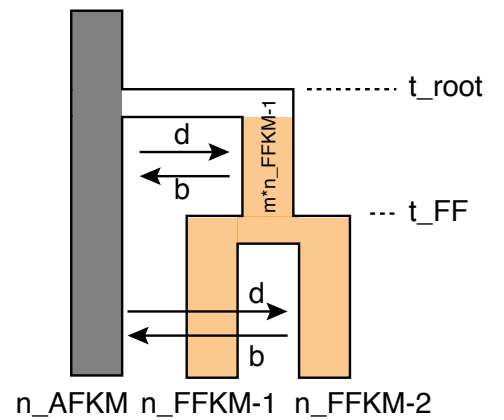

Model 7 (no gene flow for FFKM-1)

n_AFKM n_FFKM-1 n_FFKM-2

Different gene flow Model 6 (no gene flow for FFKM-2) patterns

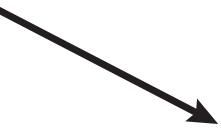

Parallel origin No gene flow 
Single origin No gene flow

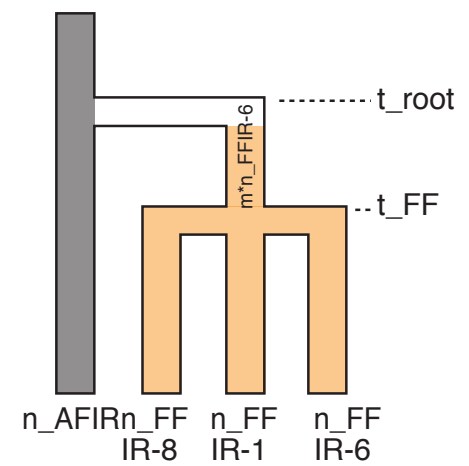

Model 1 (simultaneous divergence among FF)

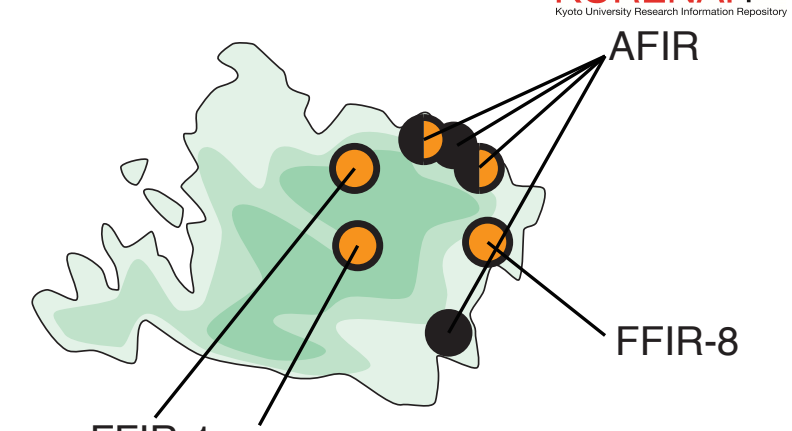

FFIR-1 FFIR-6
Single origin Gene flow

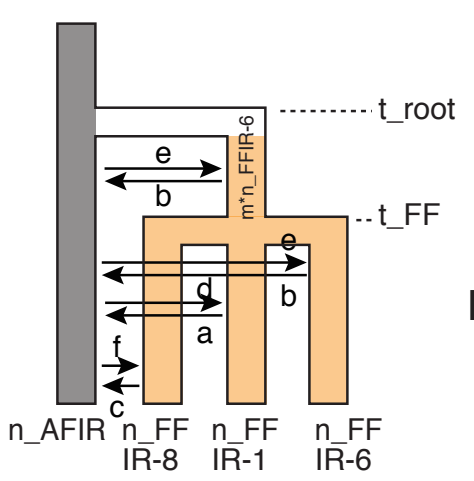

Model 3 (simultaneous divergence among FF)

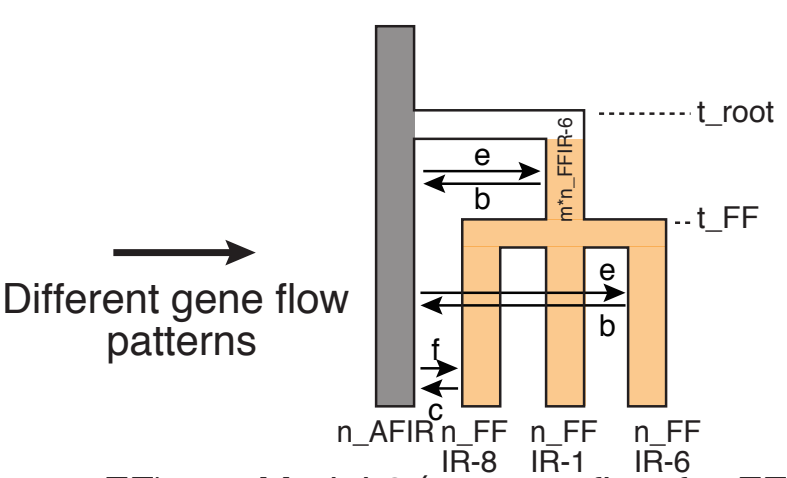

Model 6 (no gene flow for FFIR-1)
Parallel origin No gene flow

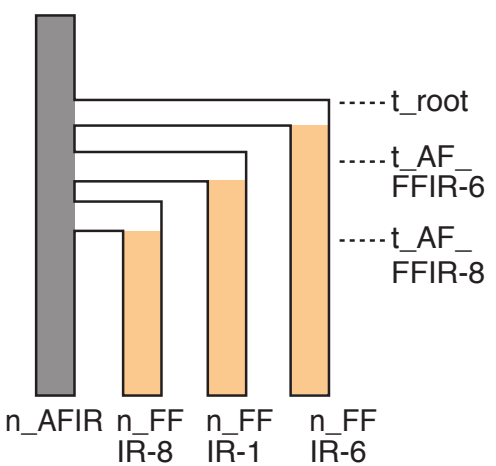

Model 2 (respective origins of FF)

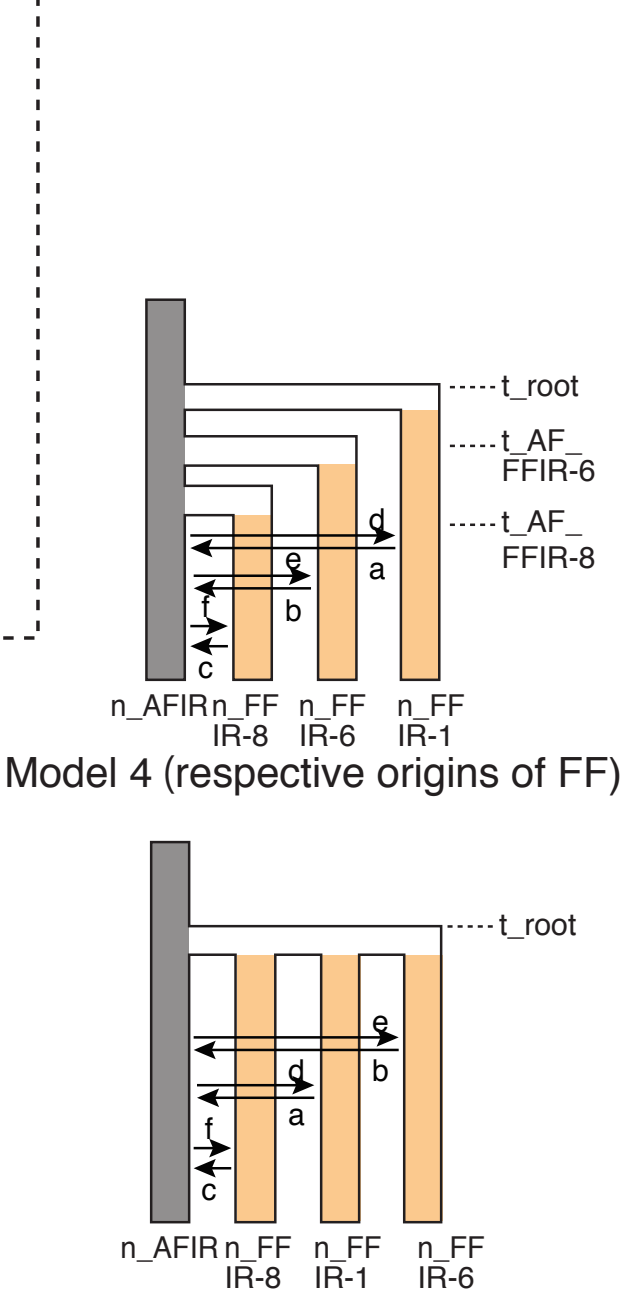

Model 4 (respective origins of FF)

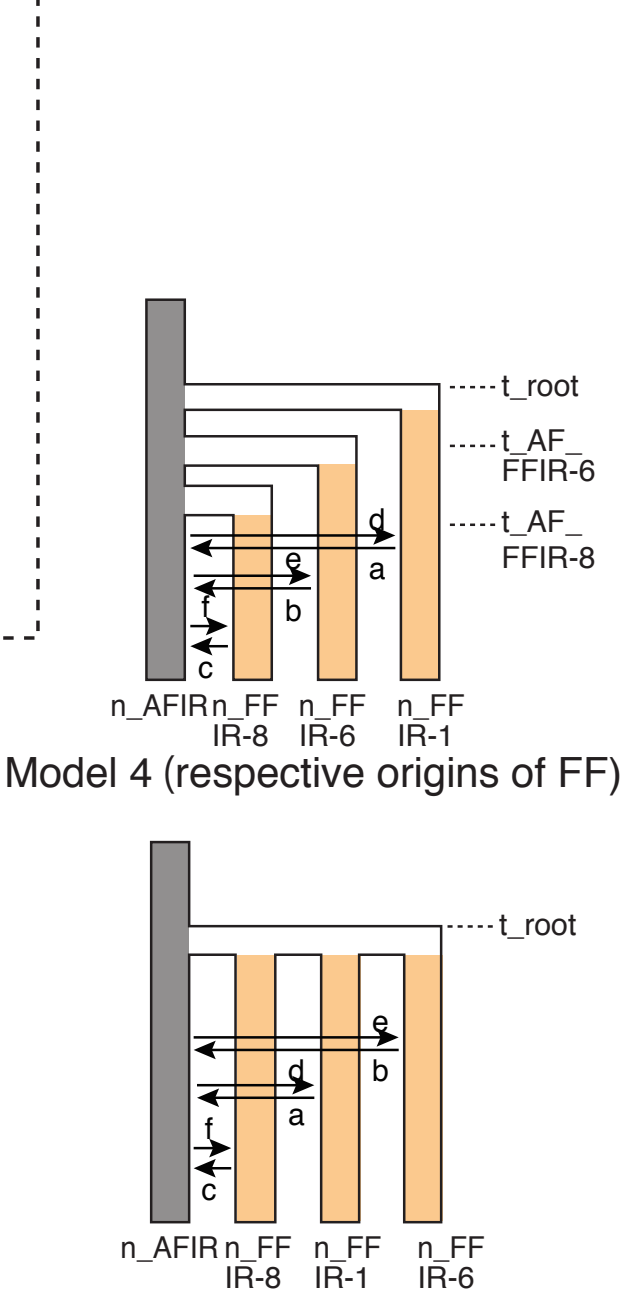

Model 5 (simultaneous divergence)

Figure S1 Continued.

\section{Gene flow}

Different divergence order

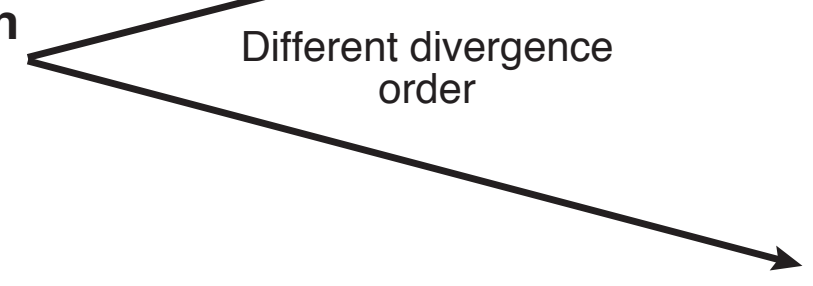




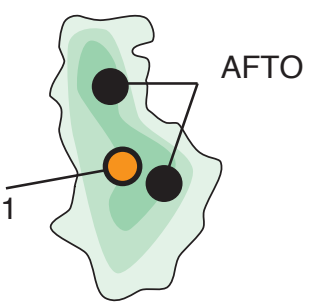

4. Tokunoshima Is.
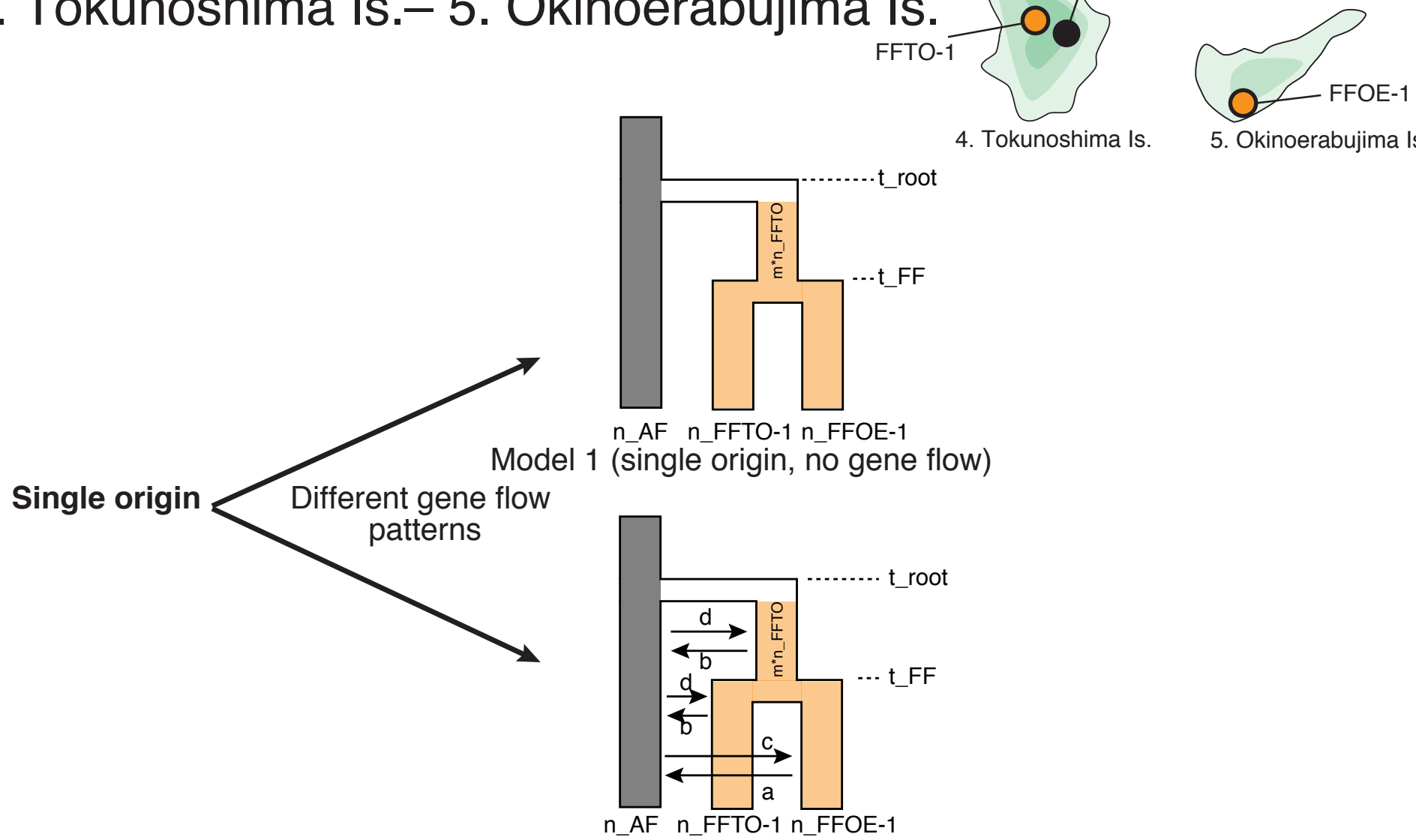

Model 2 (single origin, gene flow)

\section{Parallel origin}
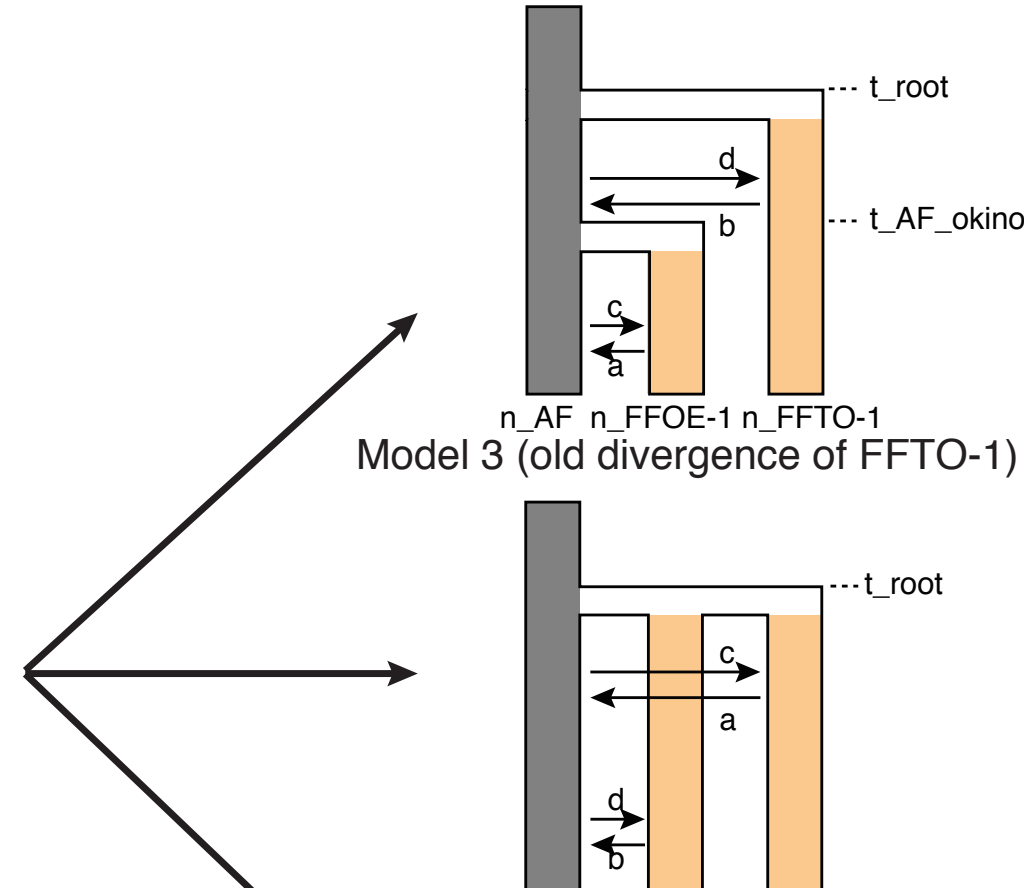

Model 3 (old divergence of FFTO-1)

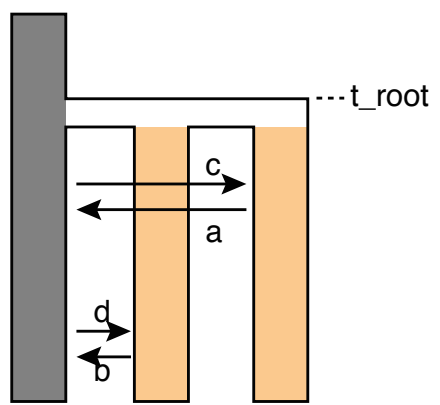

n AF n FFTO- 1 n FFOE- 1

Different divergence order

Figure S1 Continued.

Model 4 (simültaneous divergence)

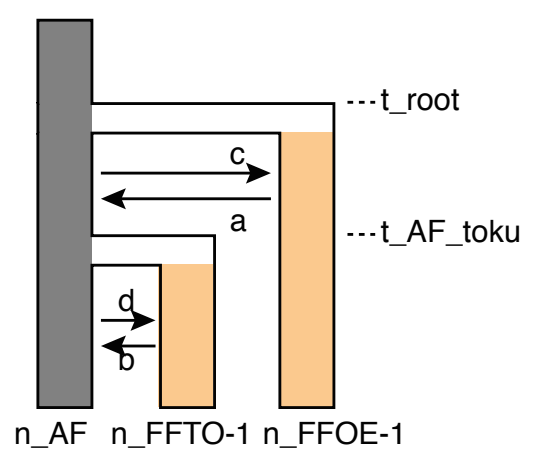




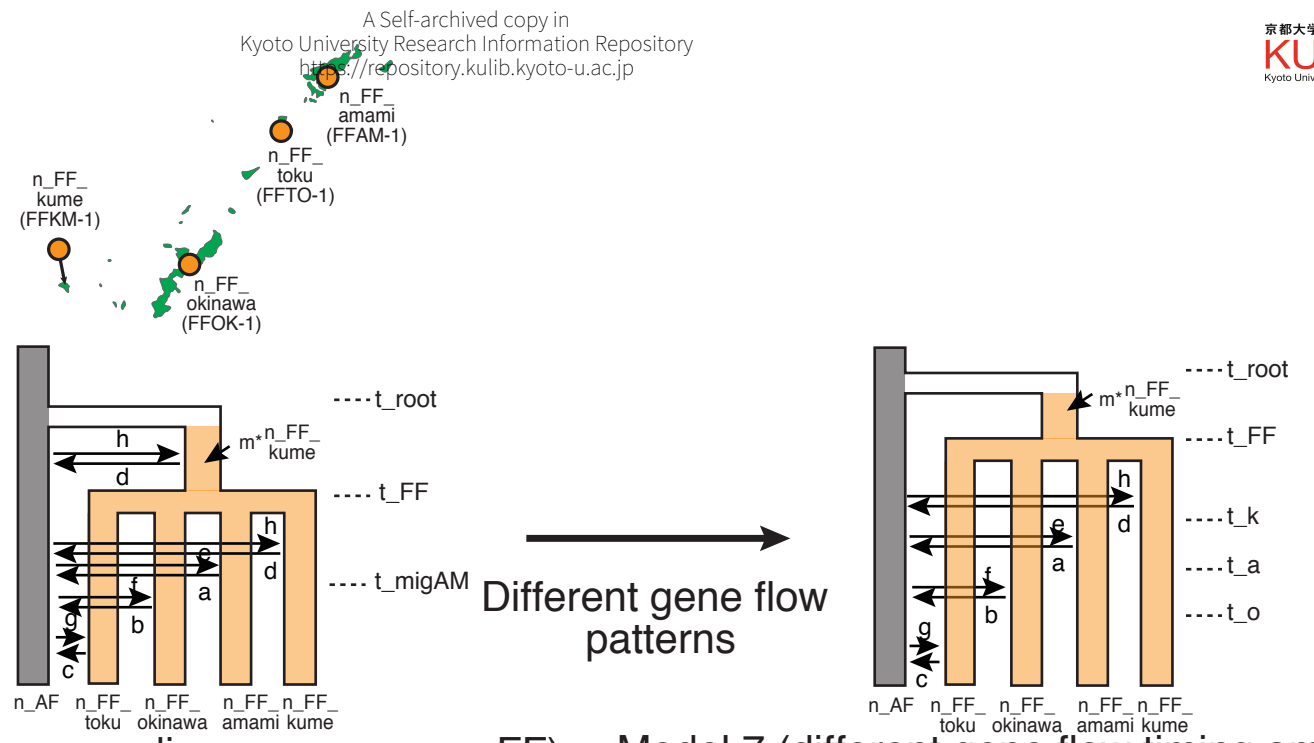

Model 3 (simultaneous divergence among FF) Model 7 (different gene flow timing among FF)

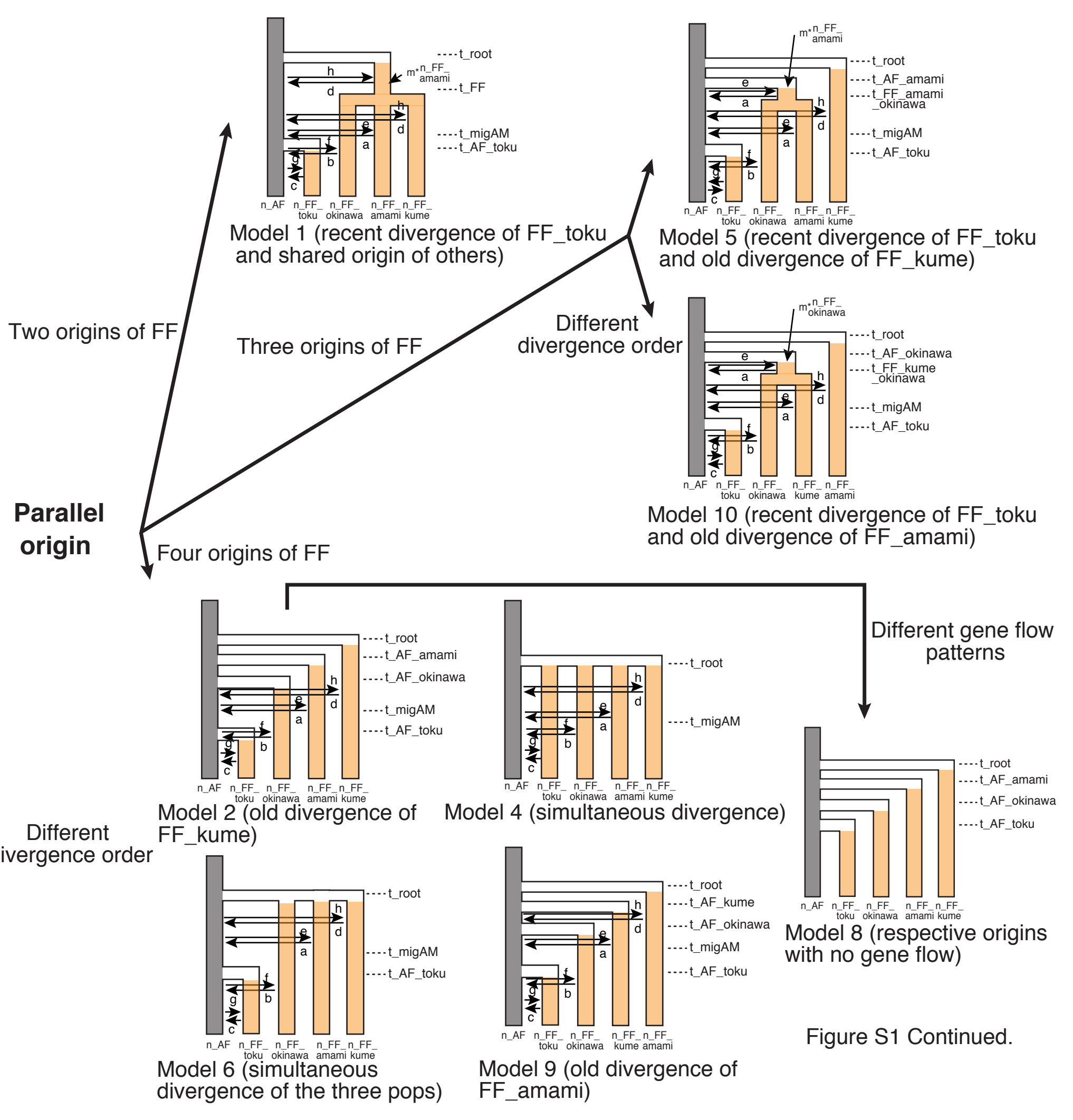




\section{South Ryukyu}
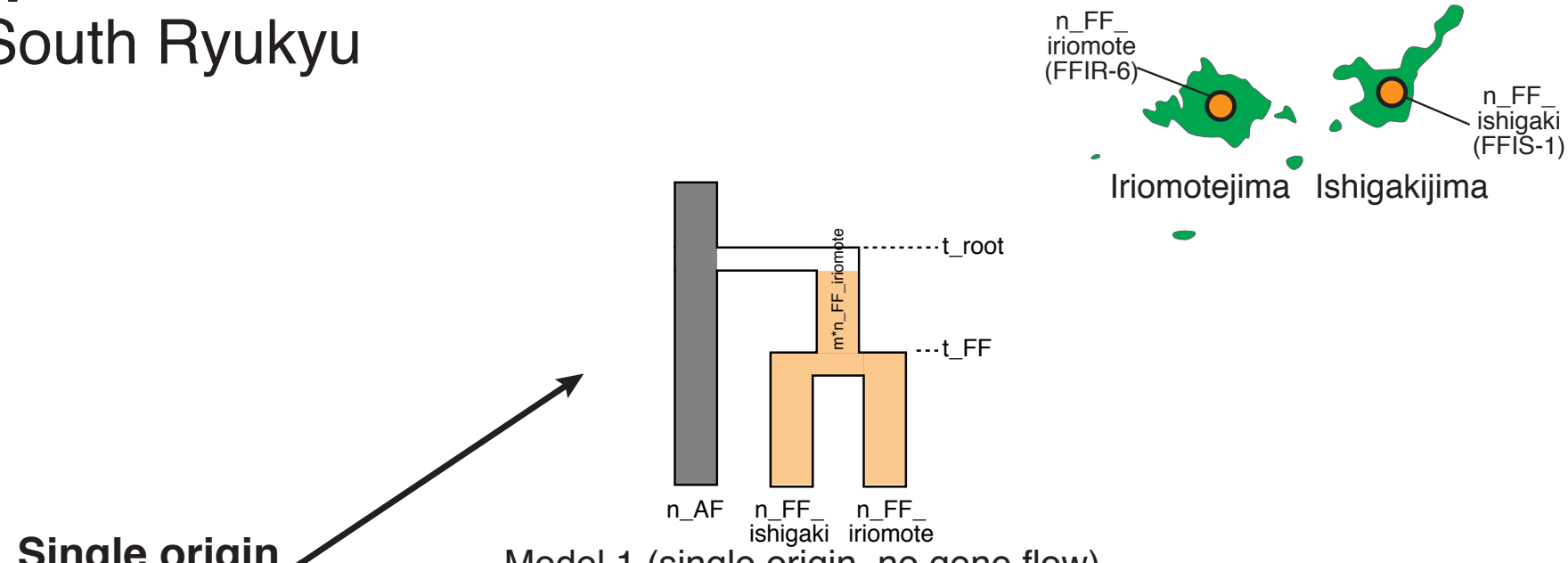

Iriomotejima Ishigakijima

Single origin

Model 1 (single origin, no gene flow)
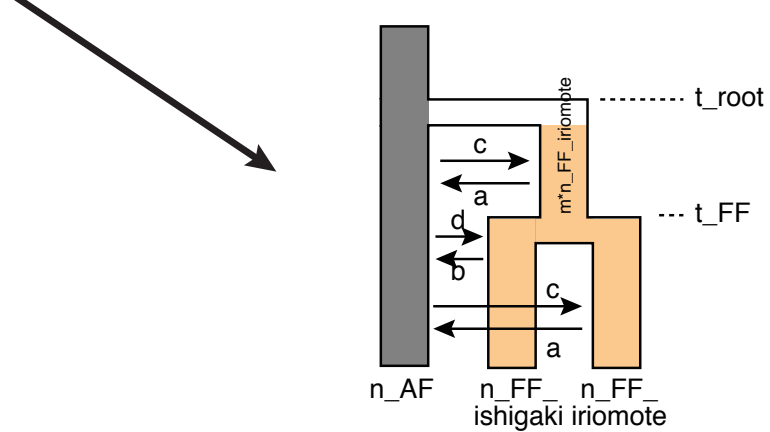

Model 5 (single origin, gene flow)

Figure S1 Continued.

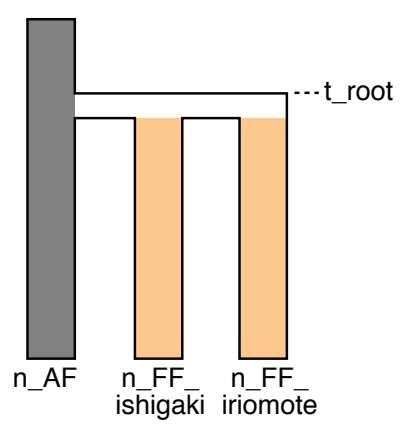

Model 2 (simultaneous divergence among FF, no gene flow)

Parallel origin
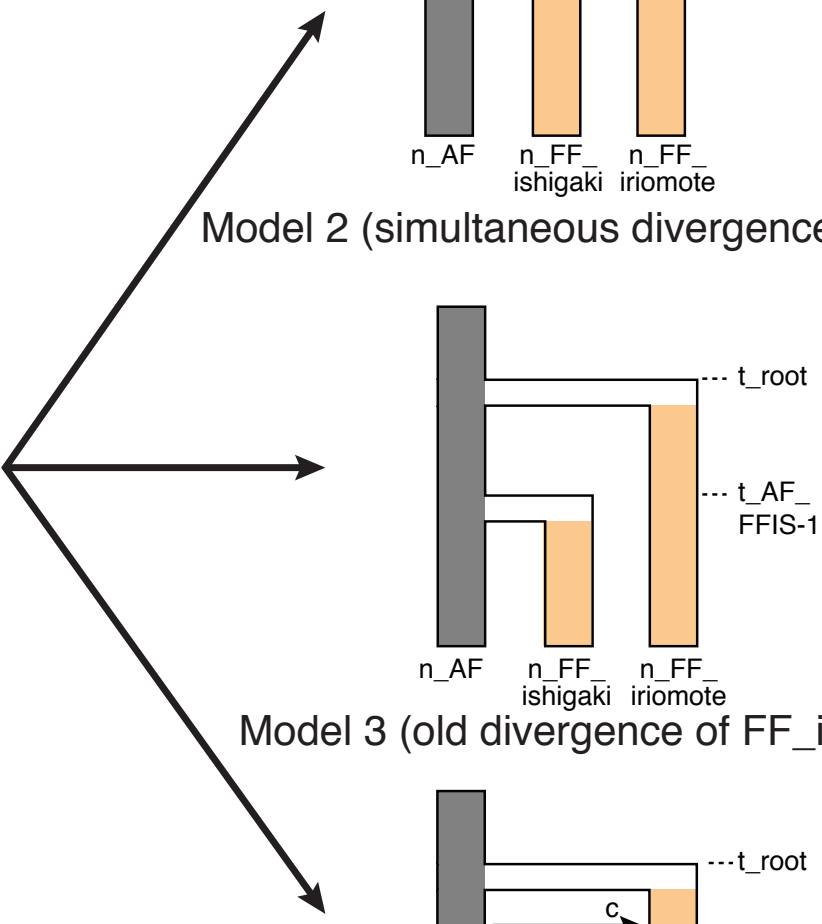

Model 3 (old divergence of FF_iriomote, no gene flow)

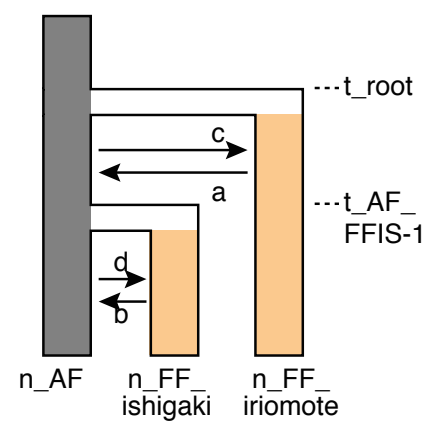

Model 4 (old divergence of FF_iriomote, gene flow) 

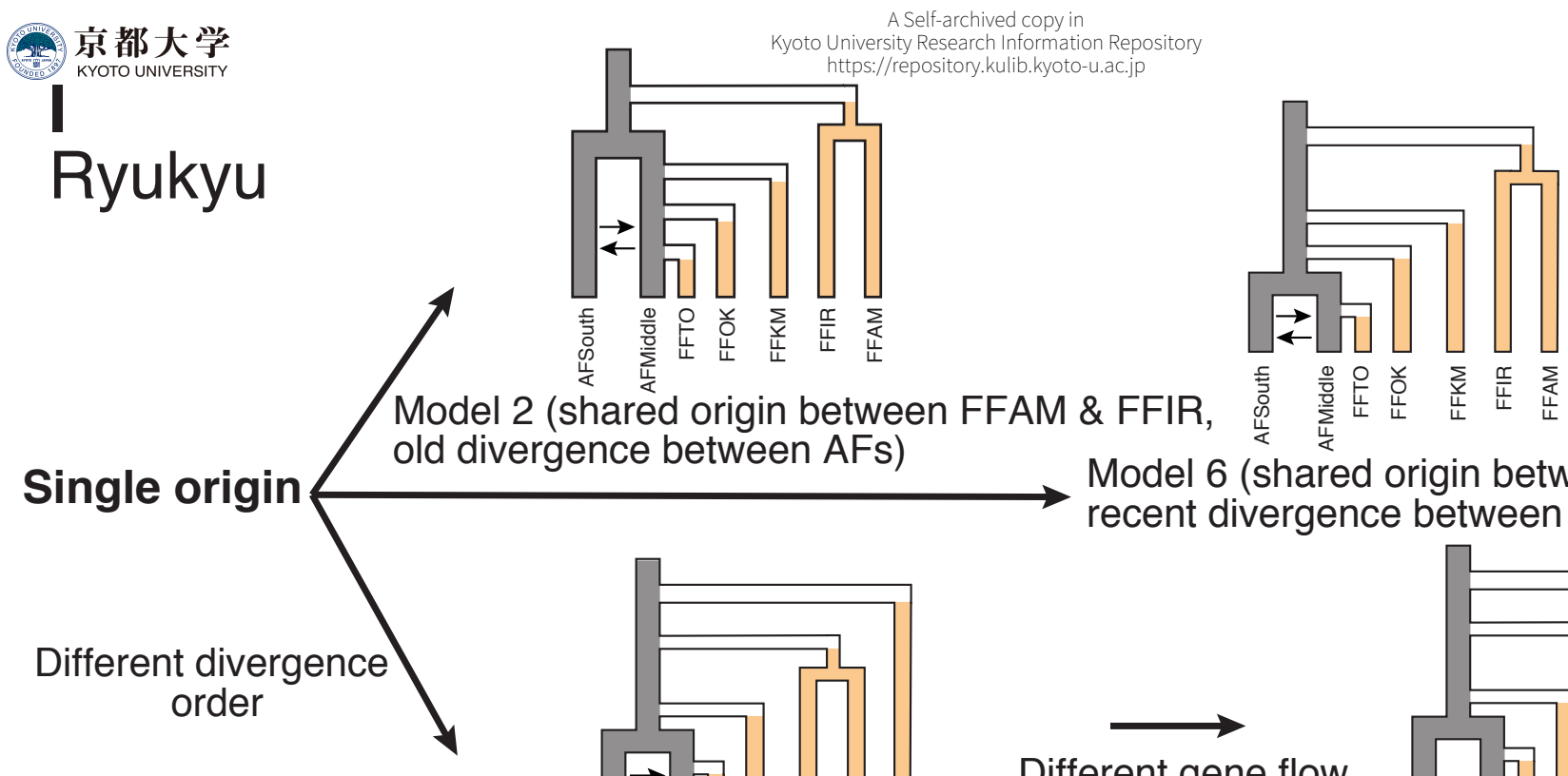

Model 6 (shared origin between FFAM \& FFIR, recent divergence between AFs)
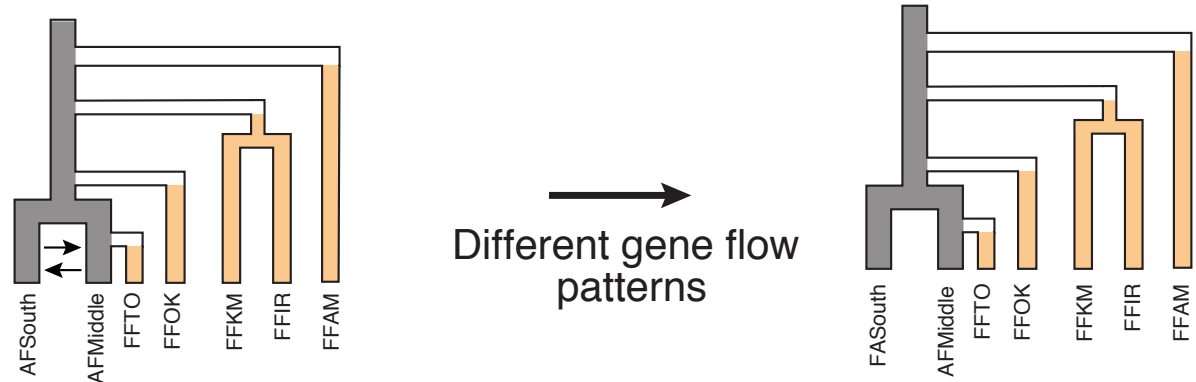

Model 7 (shared origin between FFKM \& FFIR, Model 10 (no gene flow between AFs) recent divergence between AFs)

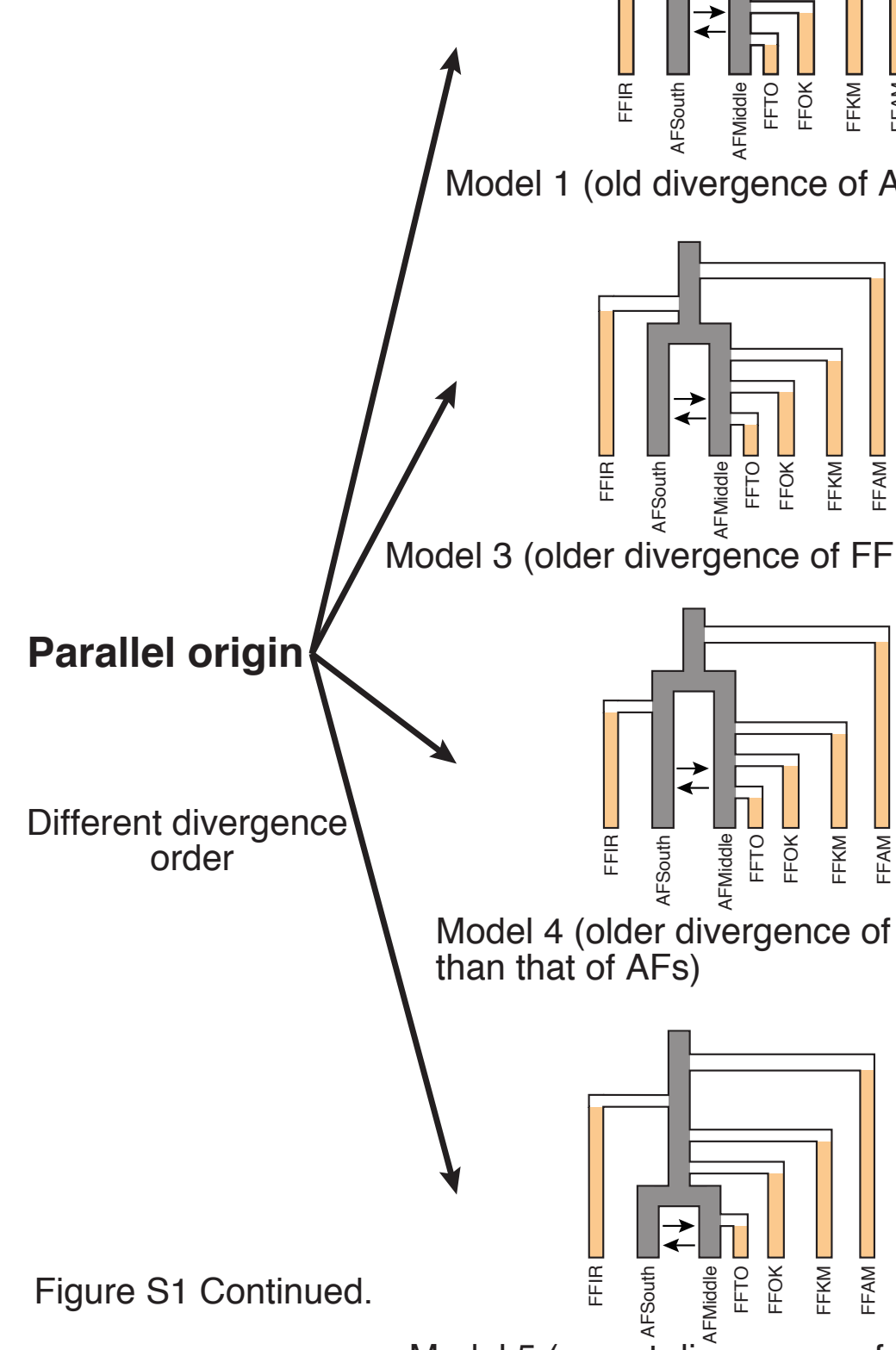

Model 5 (recent divergence of AFs)

Model 4 (older divergence of FFAM than that of AFs)

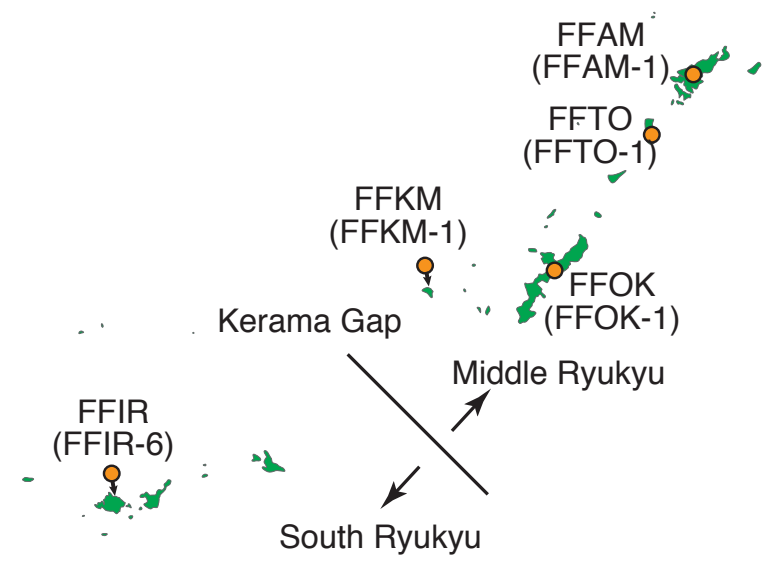

Different gene flow patterns

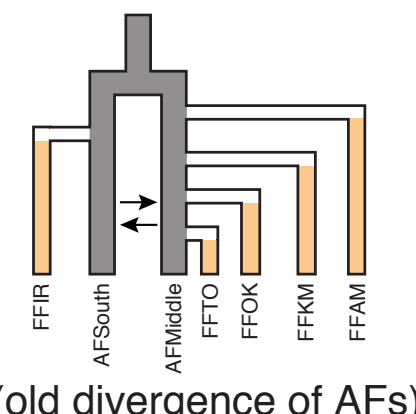

IR \& FFAM than that of AFs)

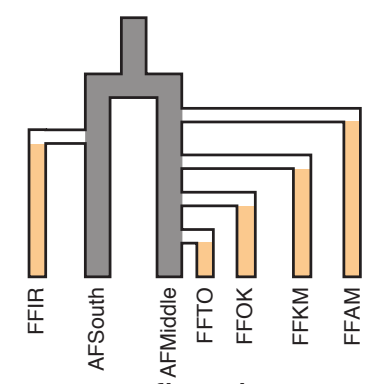

Model 8 (no gene flow between AFs)
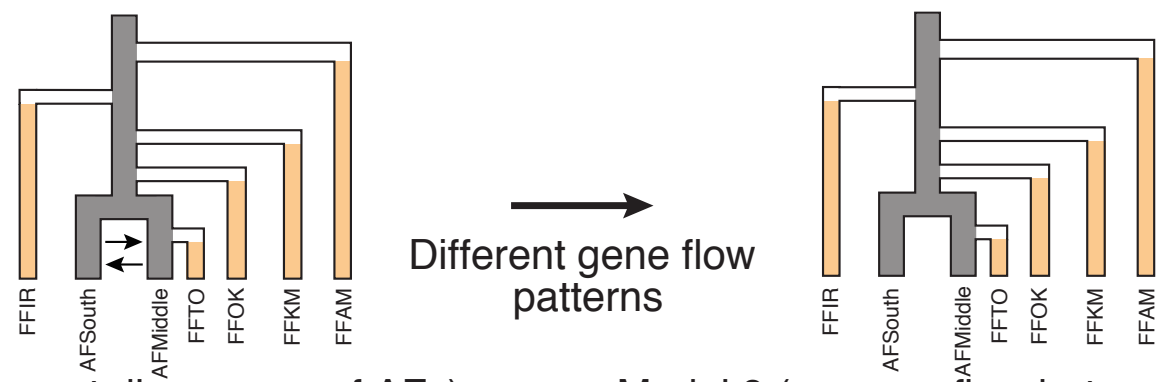

Model 9 (no gene flow between AFs) 
A

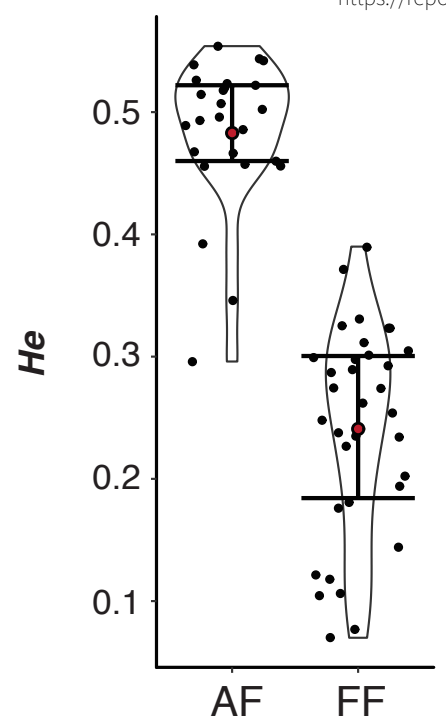

B

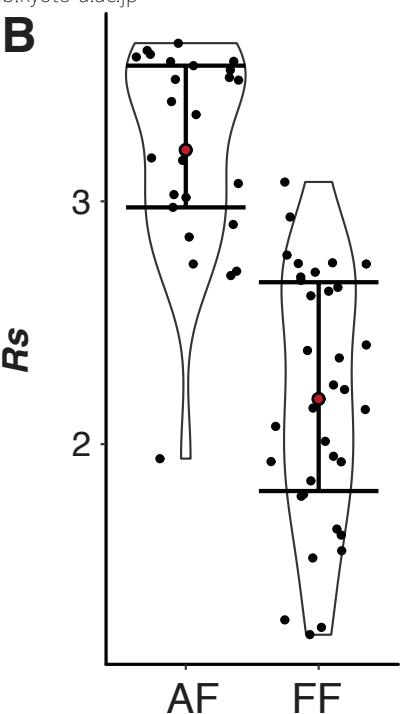

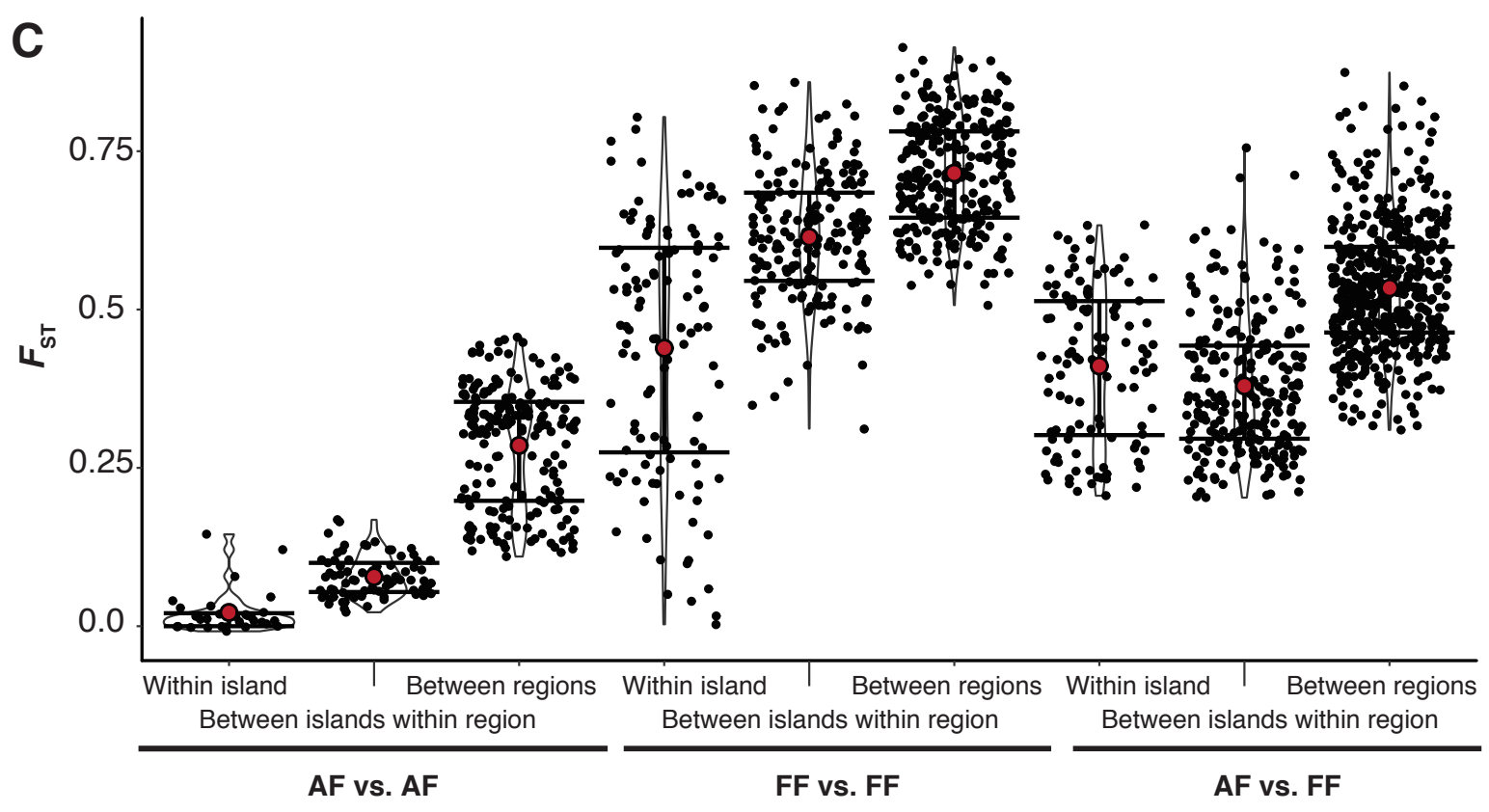

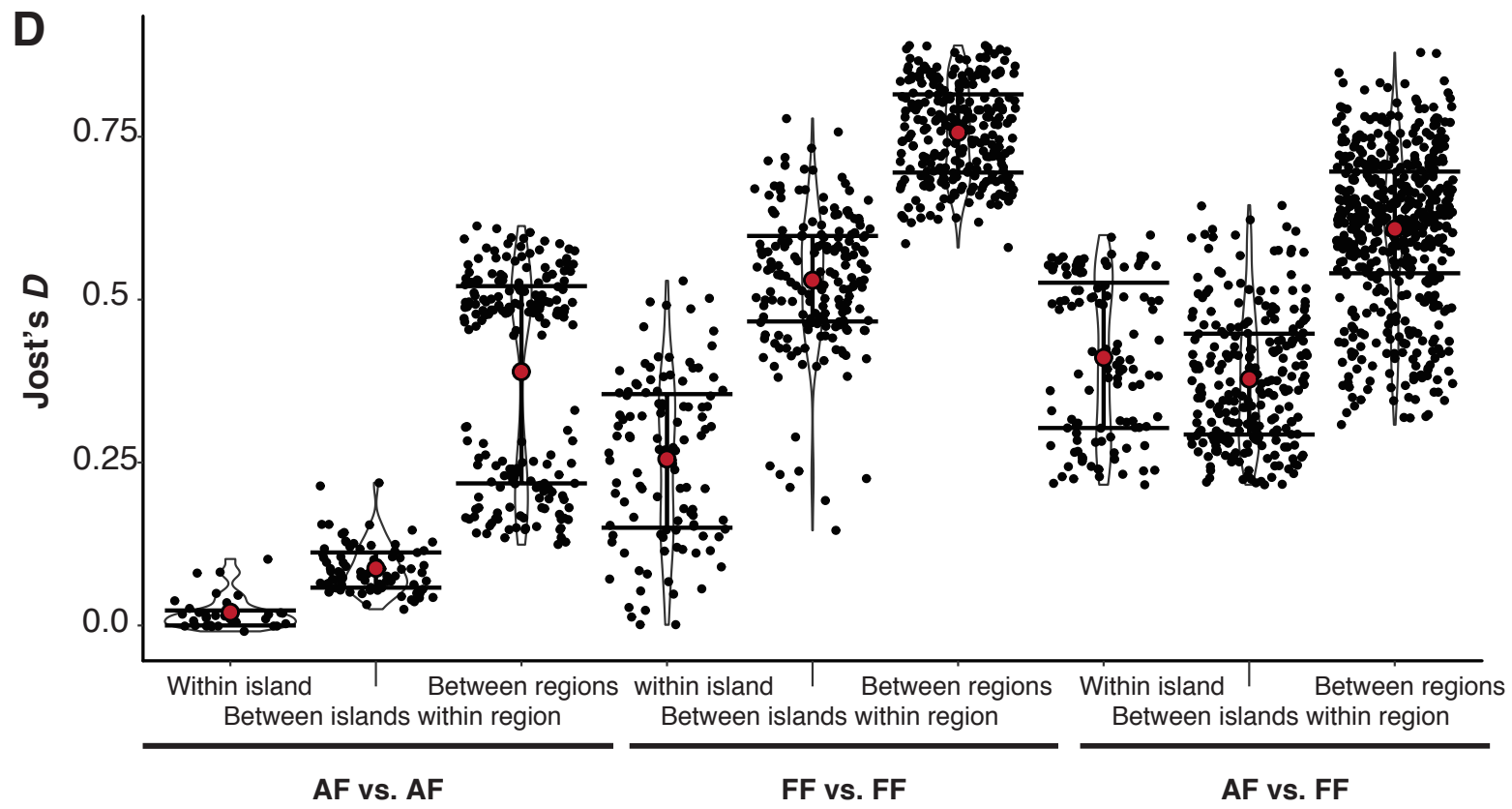

Figure S2 Distributions of summary statistics for genetic diversities within and between populations of the Rhinogobius species. Red dots and error bars indicate mean values and intermedian quantiles ranges, respectively. Genetic diversity values of populations were measured by expected heterozygosity $(\mathrm{He}, \mathrm{A})$ and allelic richness $(R s, \mathrm{~B})$. Pairwise population differences were measured by $F_{\mathrm{ST}}(\mathrm{C})$ and Jost's $D(\mathrm{D})$. 
2. Amami-Oshima Is. \& 3. Kikaijima Is.
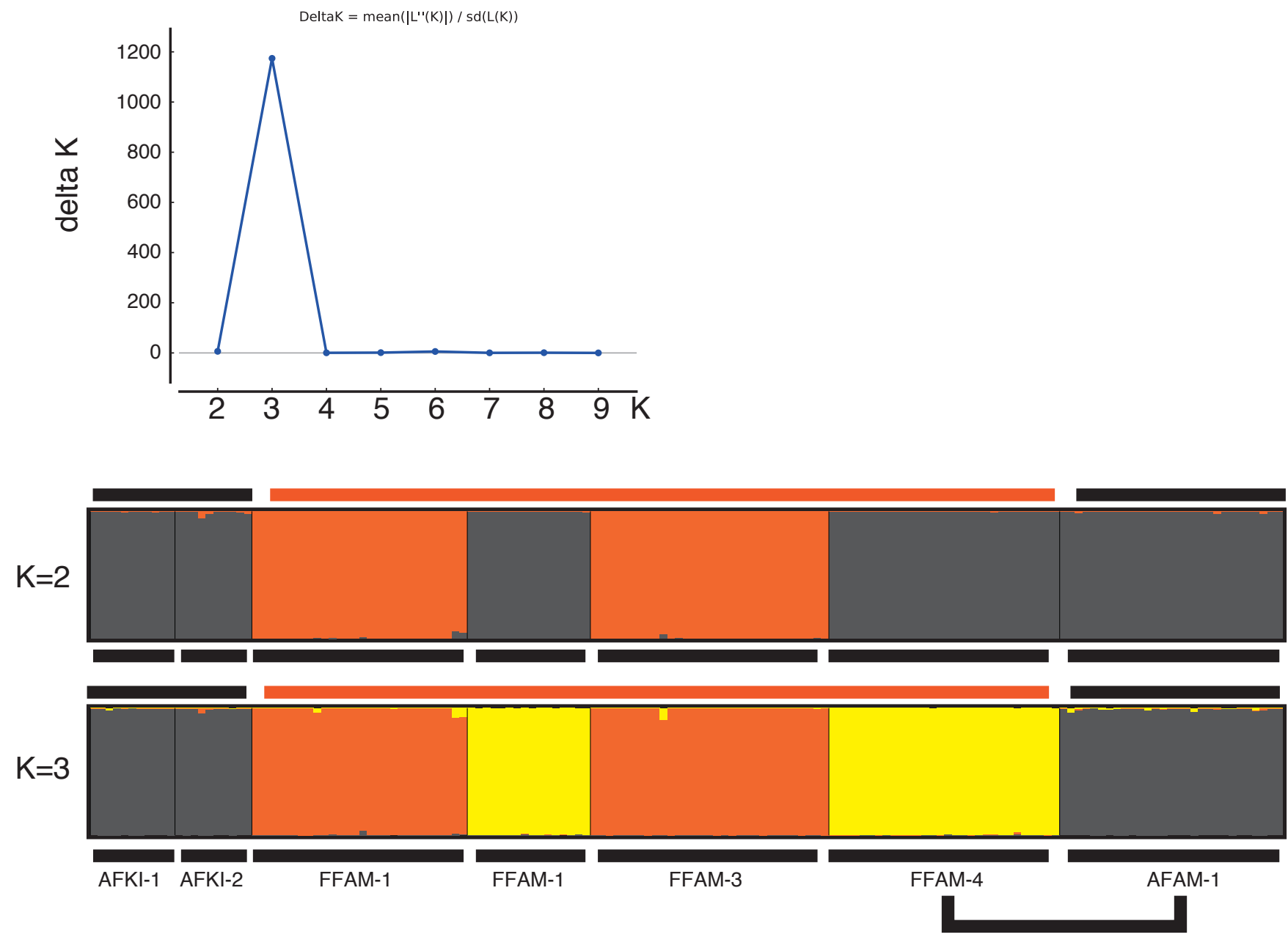

$\leftarrow$ Species

Freshwater Form Amphidromous

Amphidromous Form

$\leftarrow$ Population

The same river
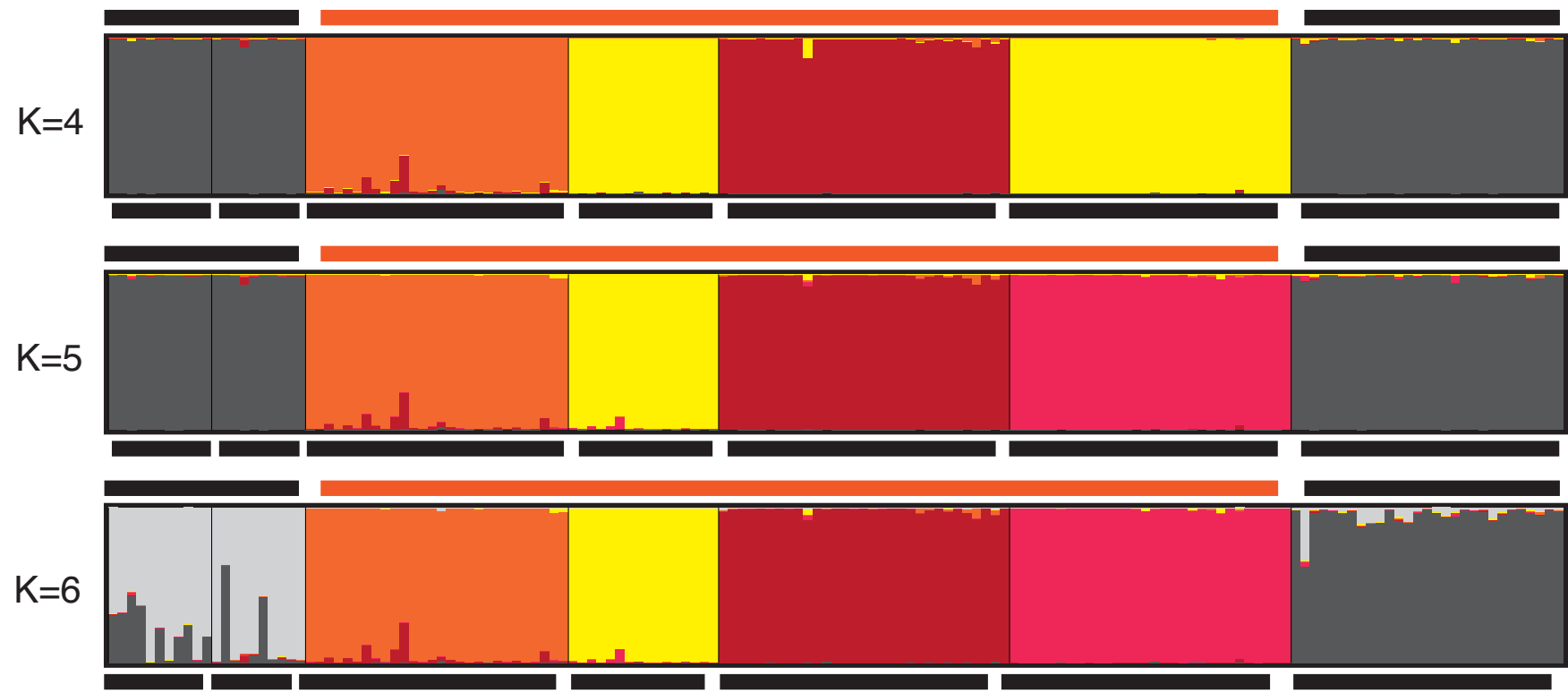

Figure S3 Results of STRUCTURE analysis for each island and AF. Sympatric points are indicated by additional annotation. Dominant genetic features in AF identified by morphology are shown in grey, whereas those in FF are shown in the other colours. Graphs of $\Delta \mathrm{K}$ are also shown. 
4. Tokunoshima Is.
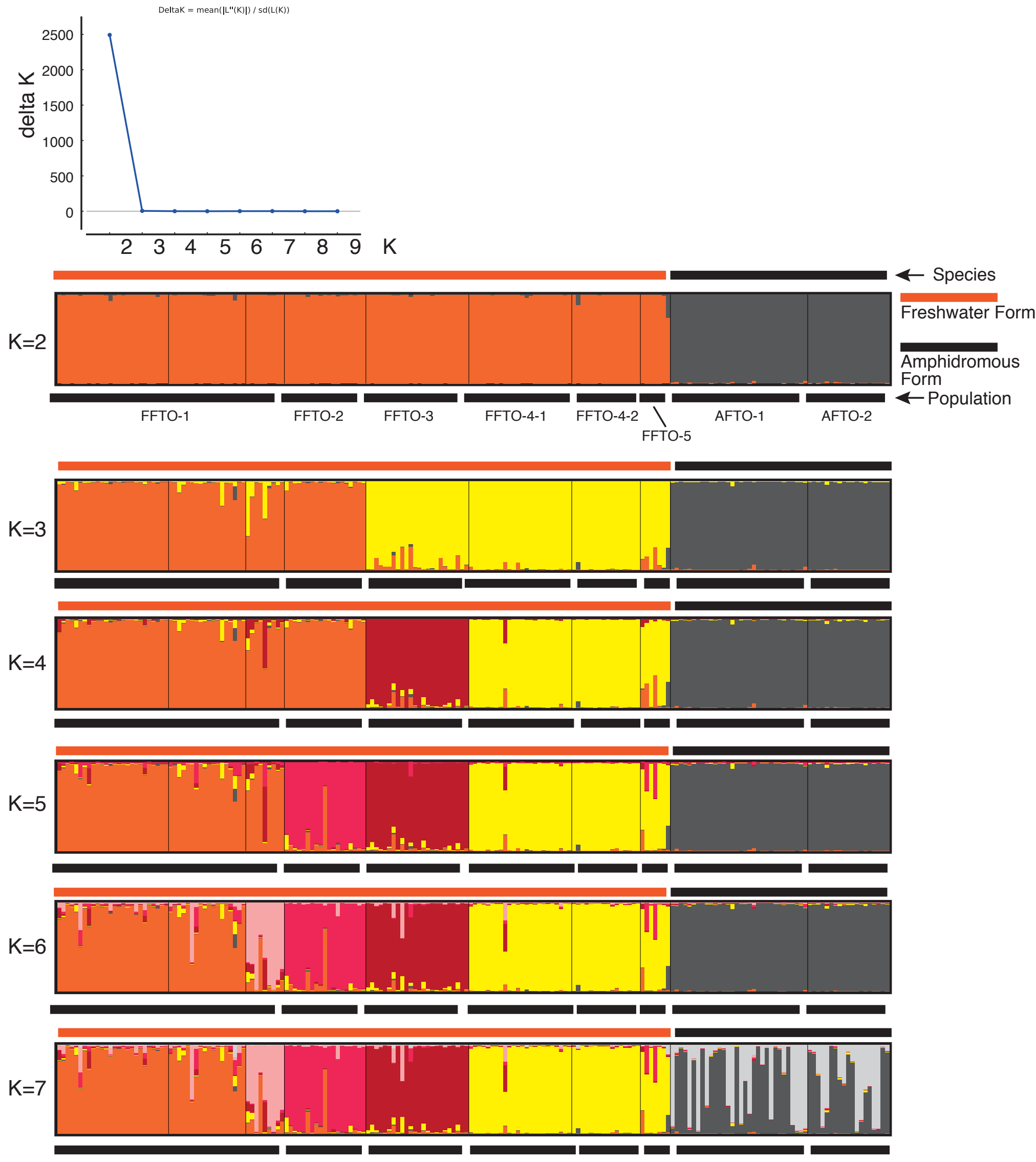

Figure S3 Continued. 
C

5. Okinoerabujima Is. (but specimens of $R$. brunneus collected in Tokunoshima Is. were used)
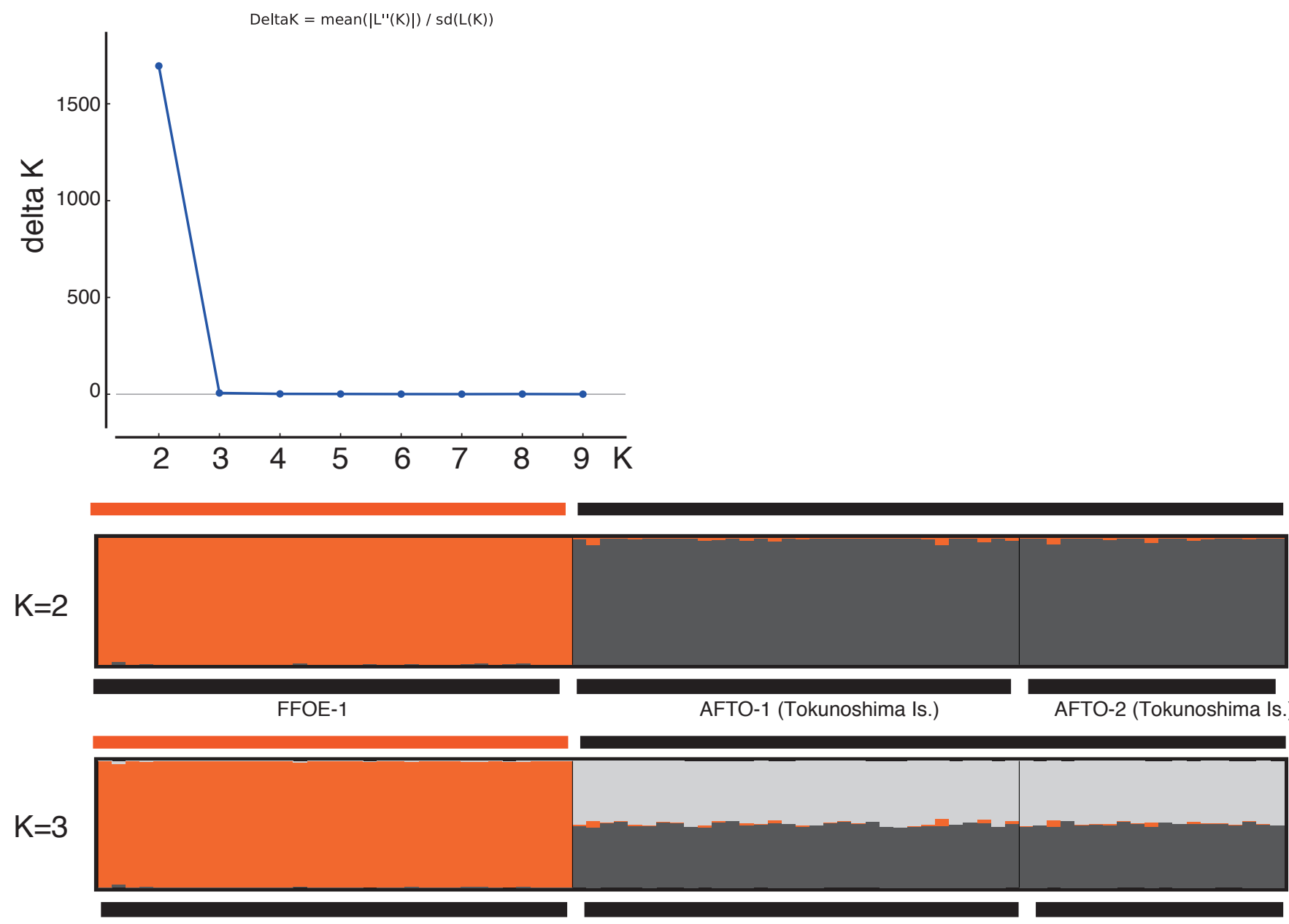

Figure S3 Continued. 
D

6. Okinawajima Is.
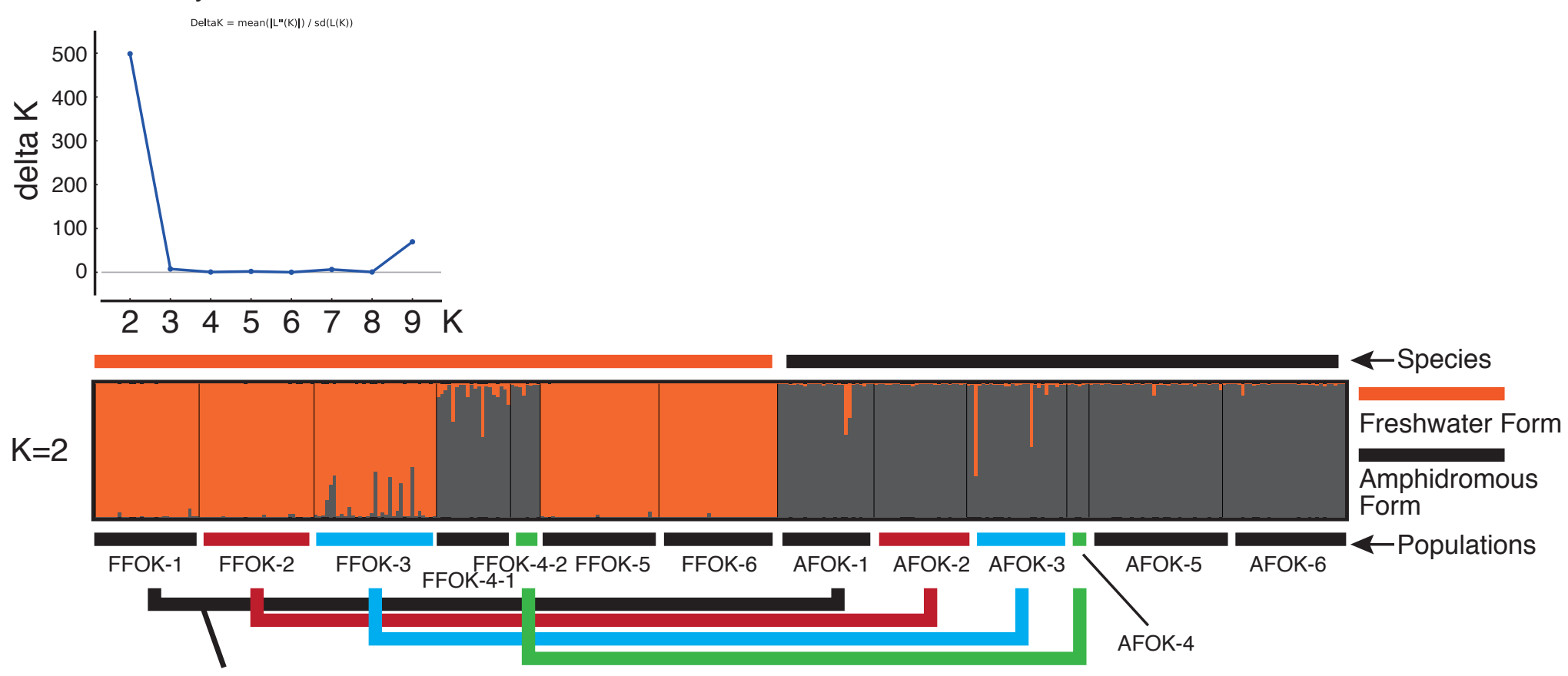

The same river

Sympatric point
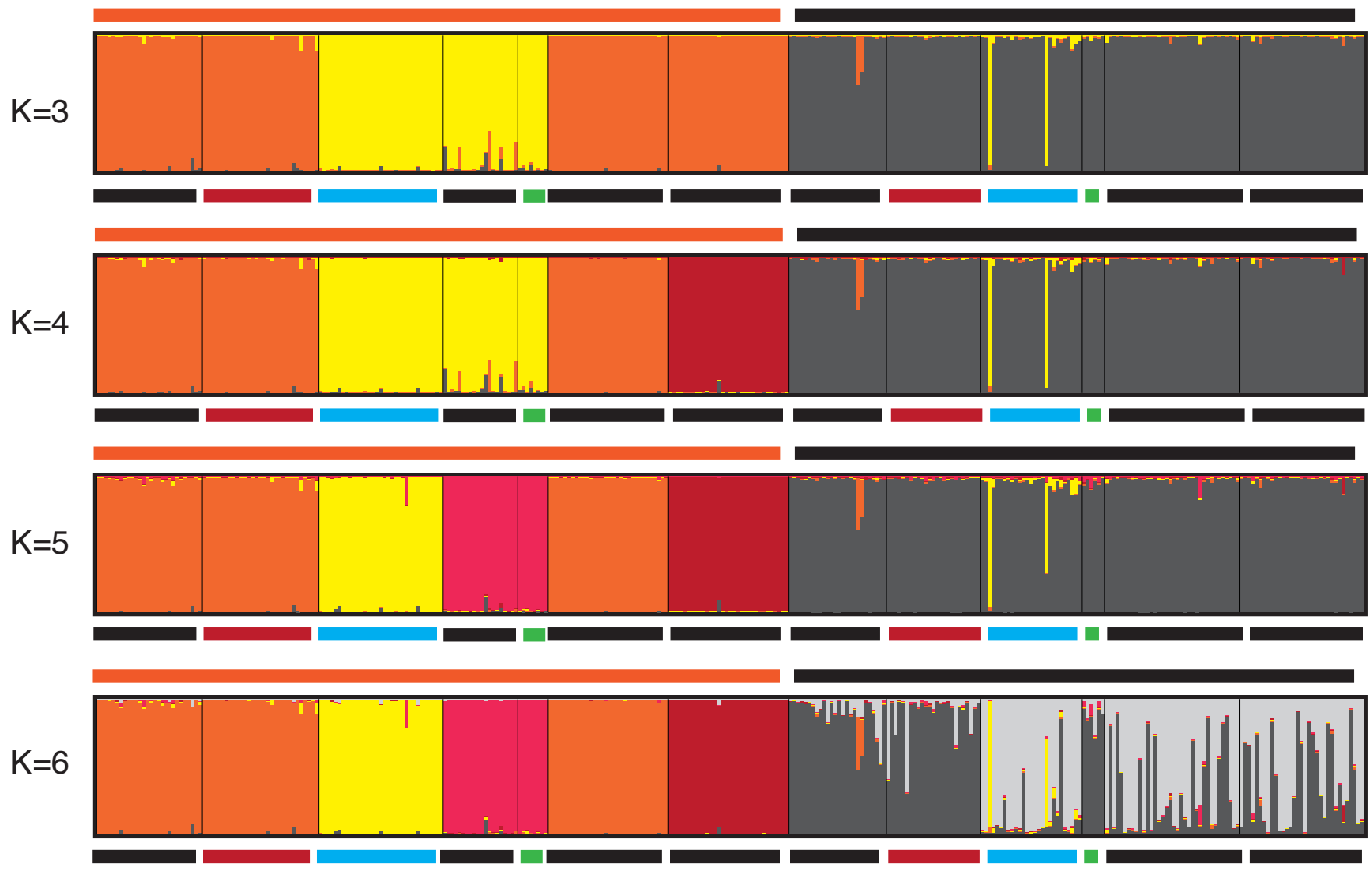

Figure S3 Continued. 
E

7. Kumejima Is.
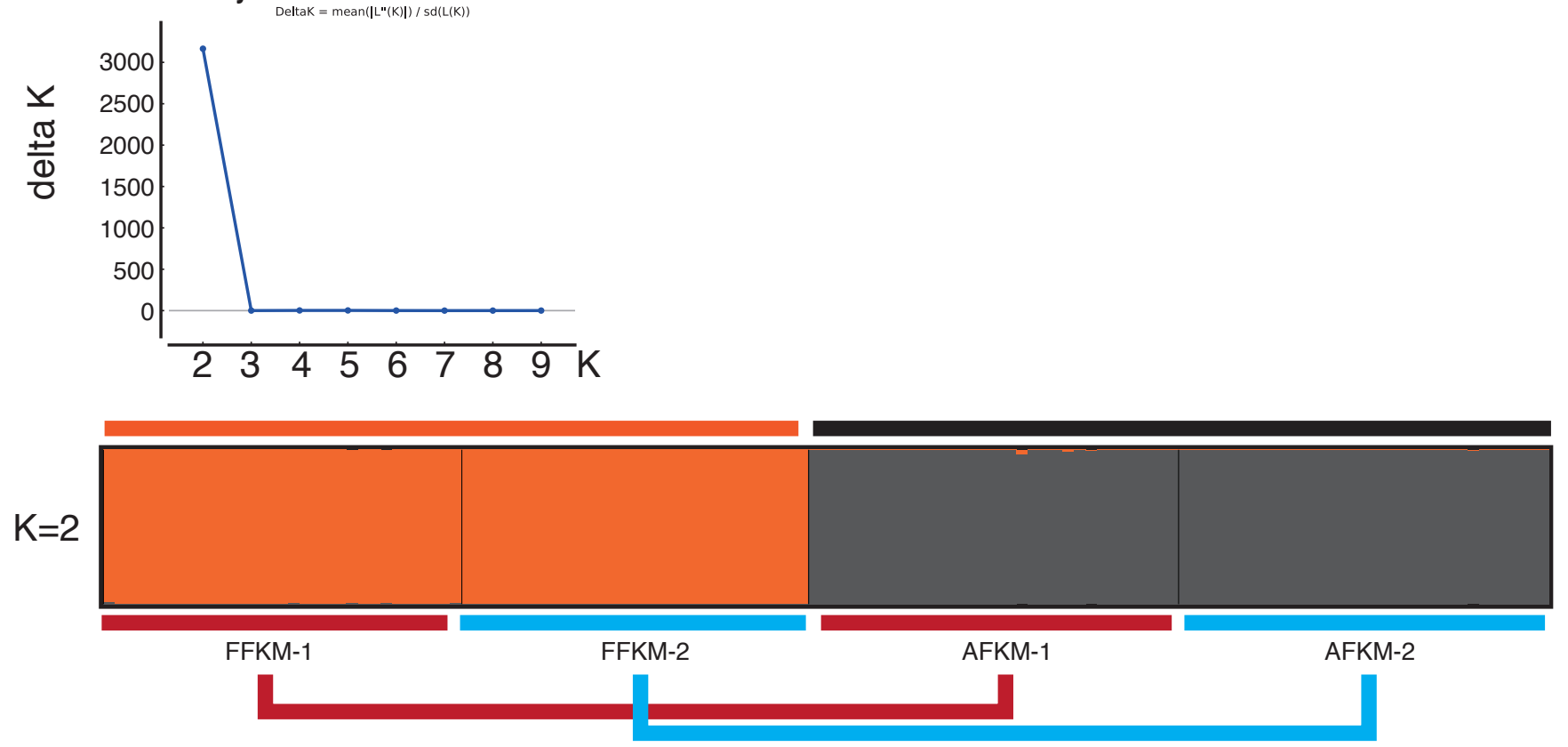

$\leftarrow$ Species

Freshwater Form

Sympatric point

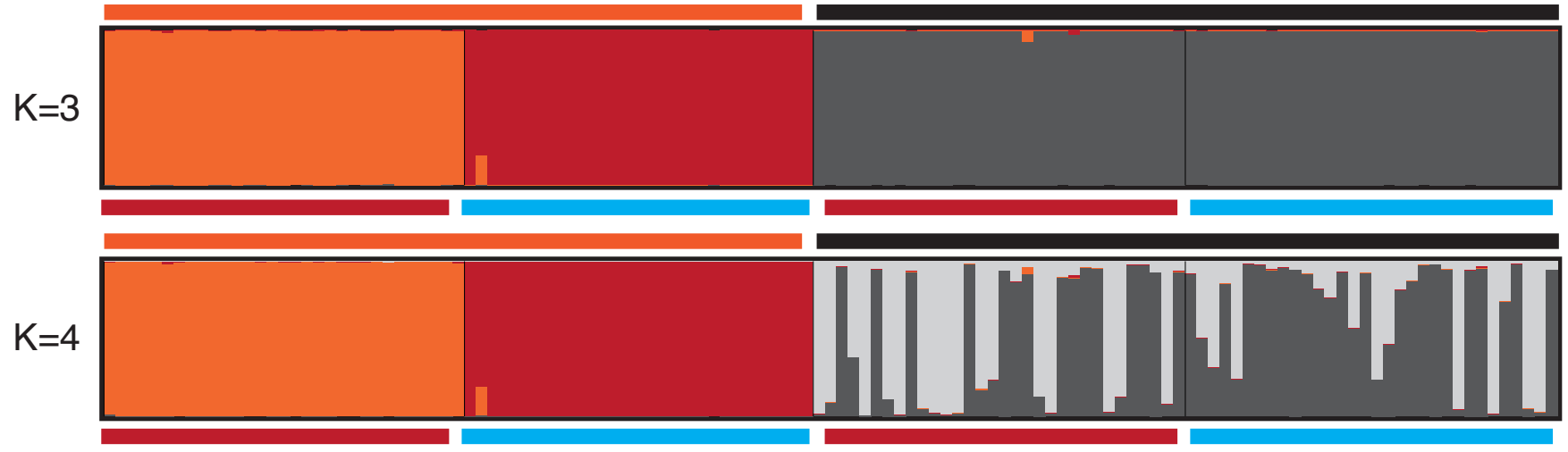

Figure S3 Continued.

Amphidromous Form ¿Population 


\section{F}

8. Ishigakijima Is.

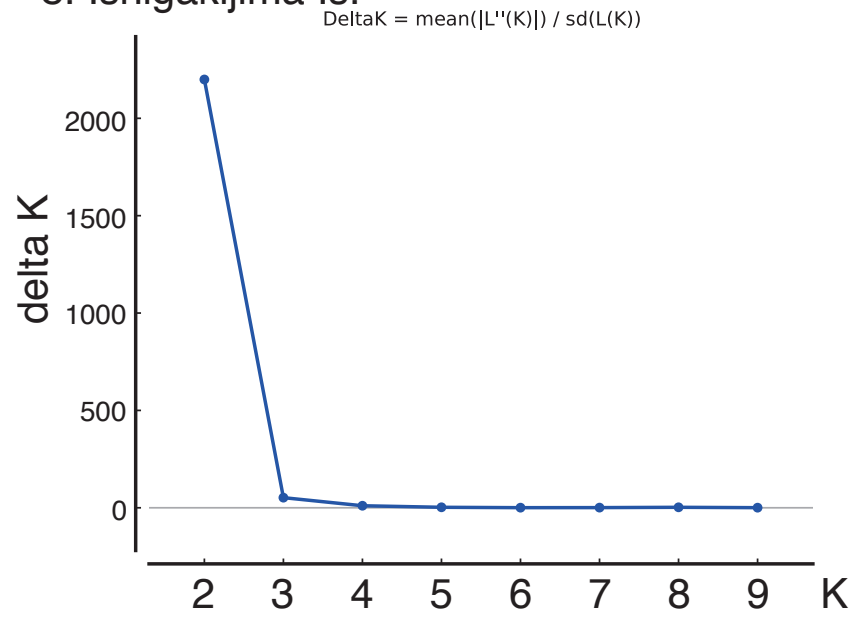

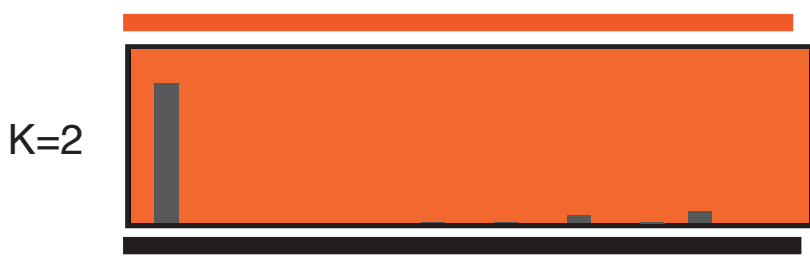

FFIS-1

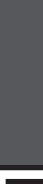

AFIS-1

AFIS-2

$\leftarrow$ Species

Freshwater Form

Amphidromous

Form

«Population

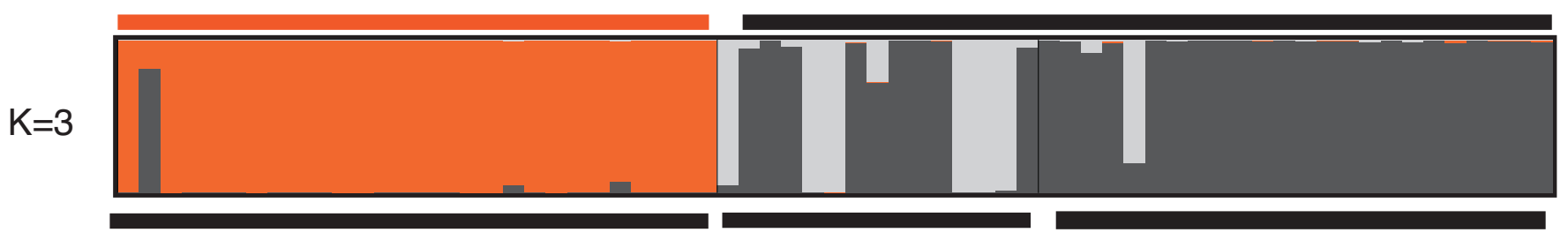

Figure S3 Continued. 
9. Iriomotejima Is.
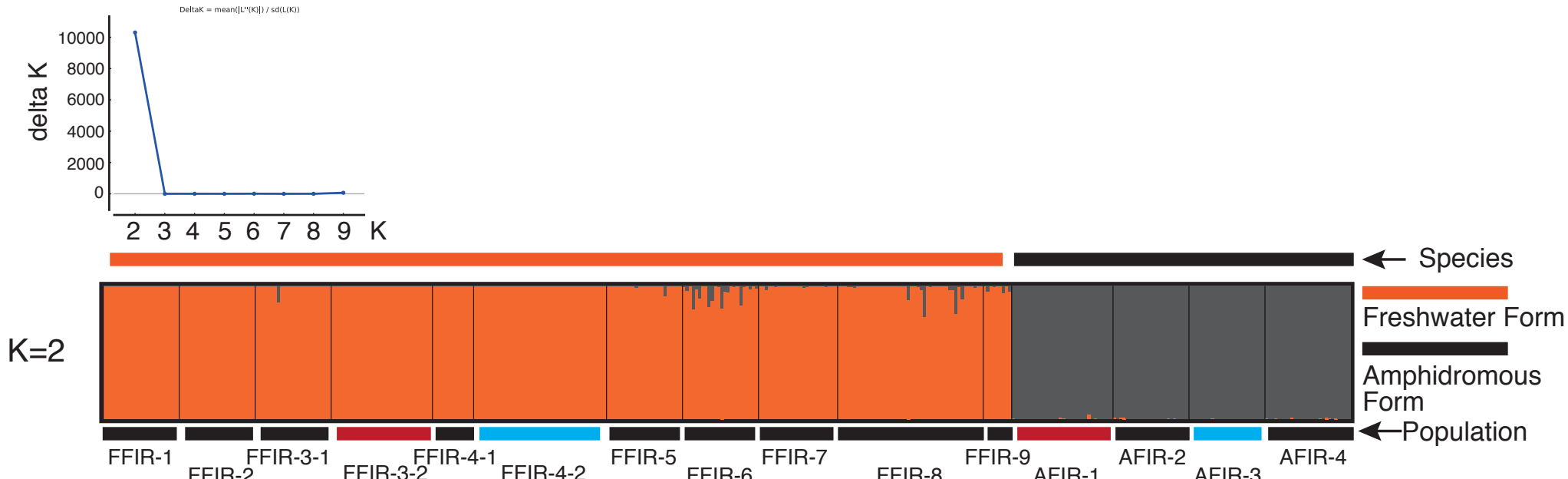

Sympatric point

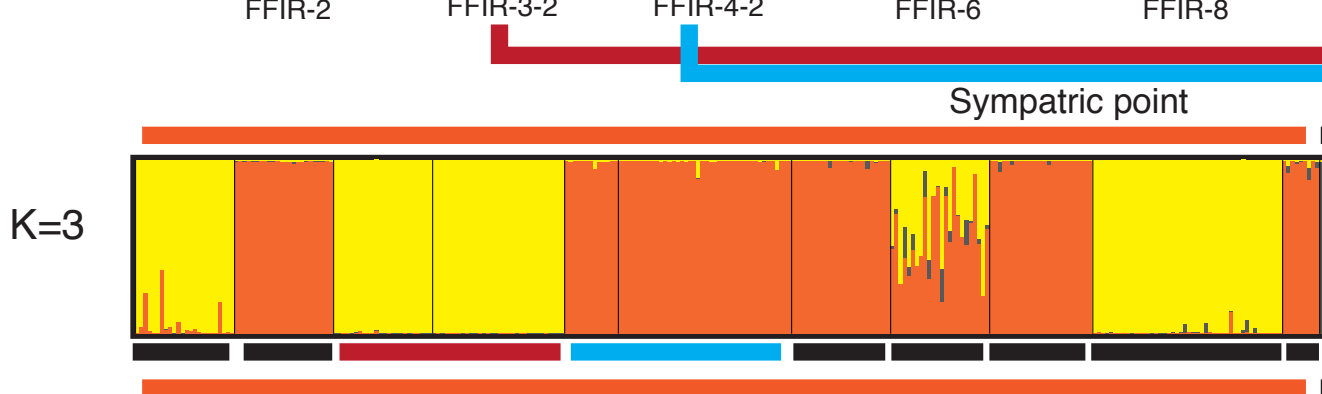
-
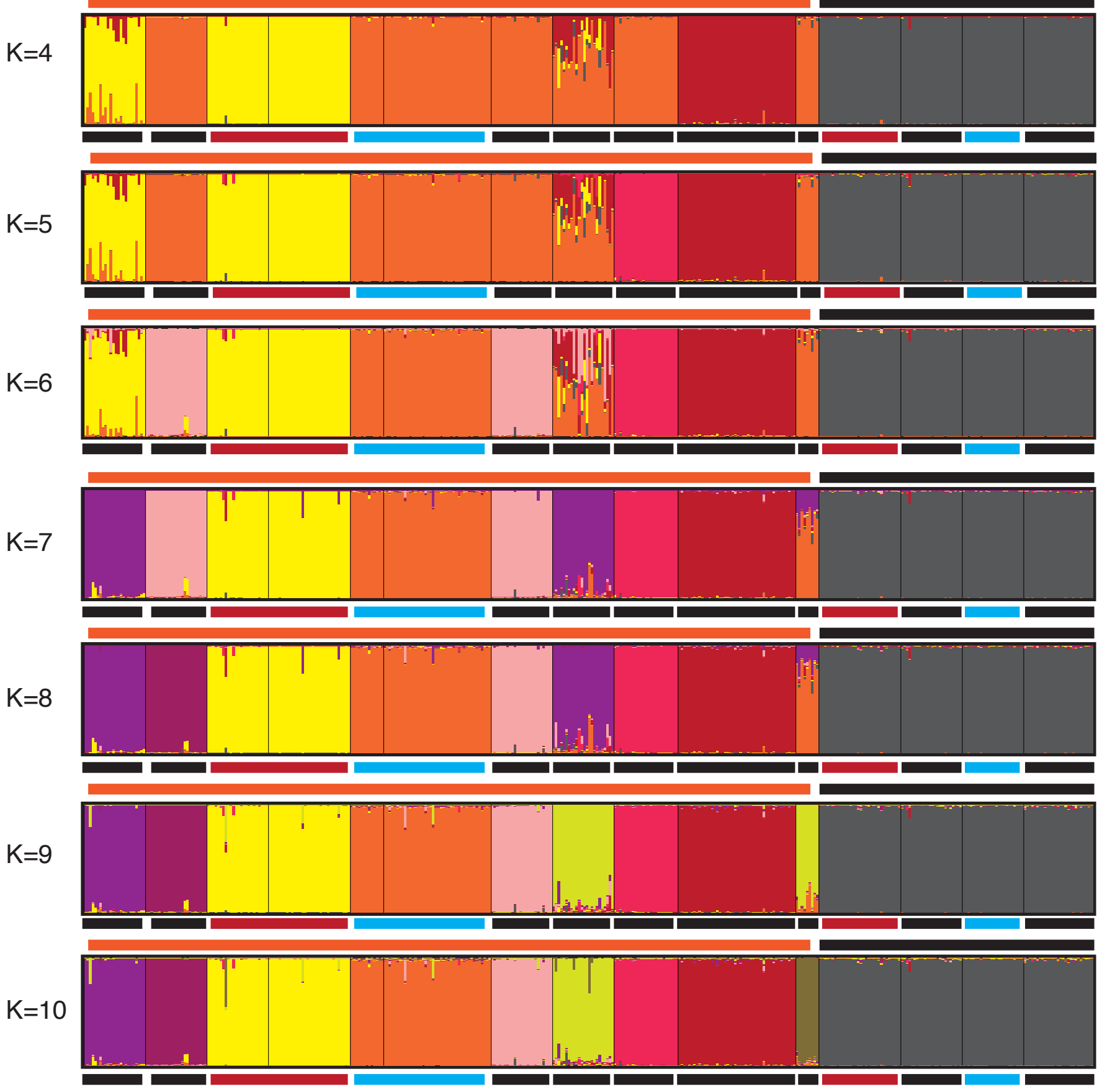

Figure S3 Continued. 


\section{Rhinogobius brunneus}

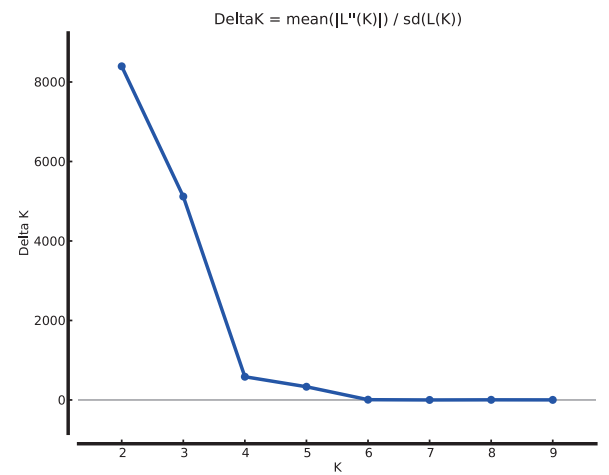

R. brunneusu only $\mathrm{K}=2$
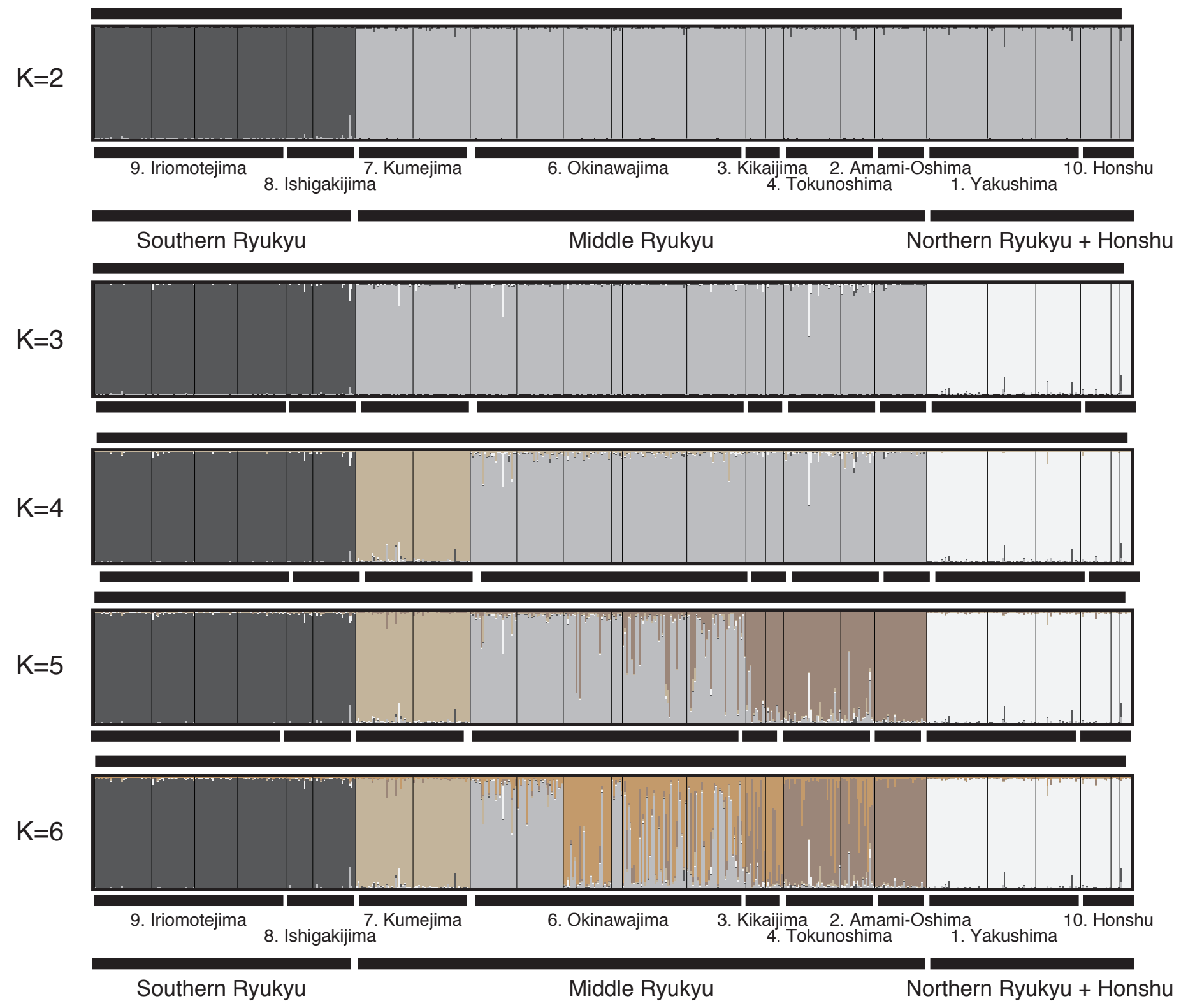

Fig. S3 Continued. 


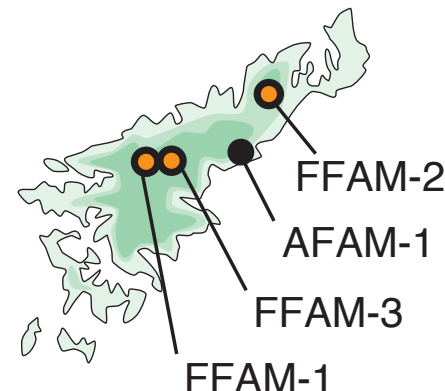

FFAM-1

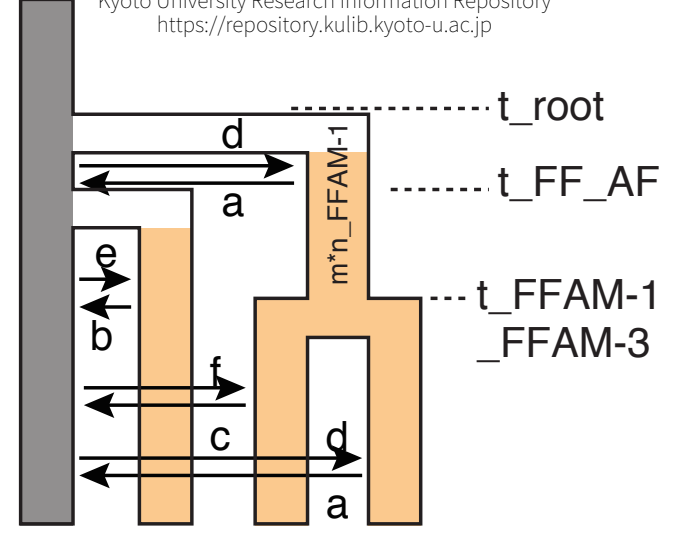

n_AF $\begin{array}{ccc}n \_F F & n \_F F & n \_F F \\ A \bar{M}-2 & A \bar{M}-3 & A \bar{M}-1\end{array}$

Model 1 (parallel origin, gene flow)

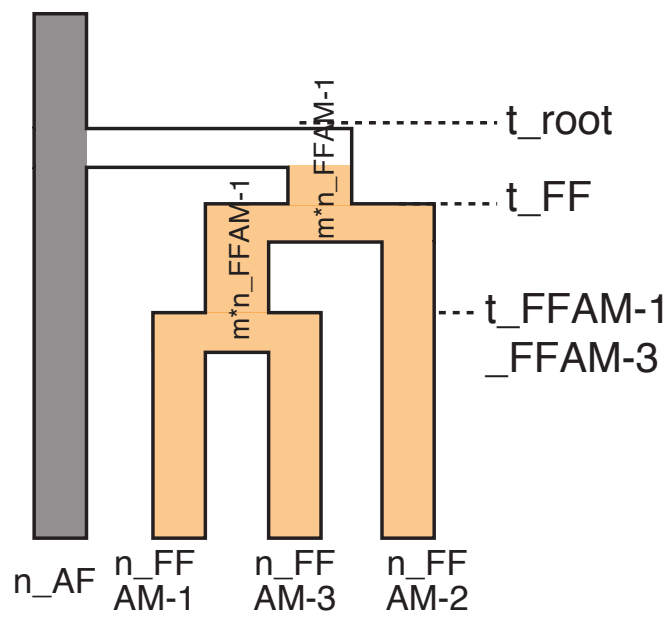

n_AF AM -1 A $\bar{M}-3$ A $\bar{M}-2$

Model 3 (single origin, no gene flow)

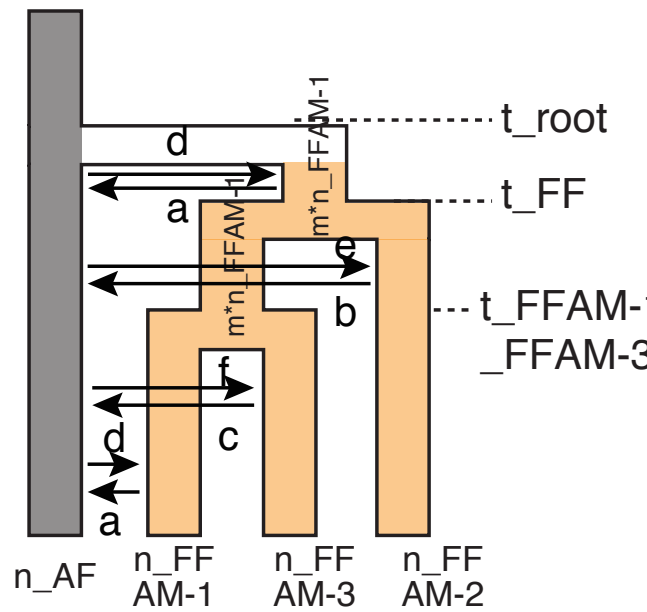

Model 4 (single origin, gene flow)

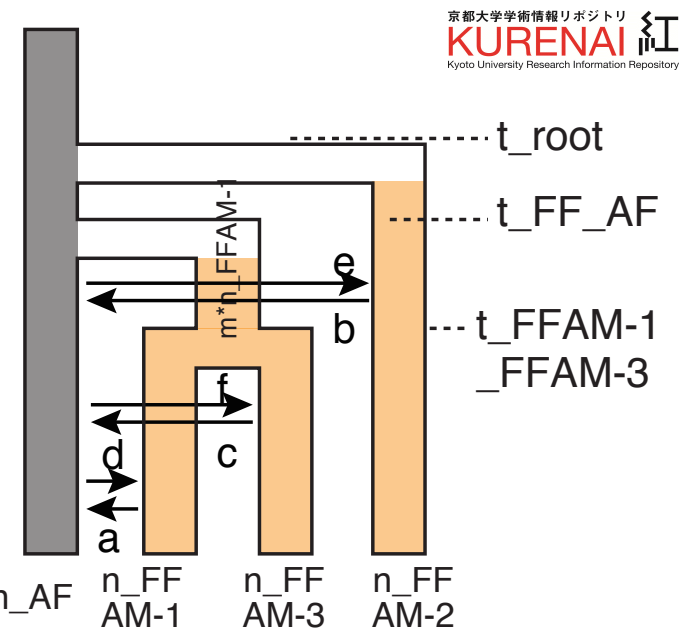

Model 2 (parallel origin, gene flow)

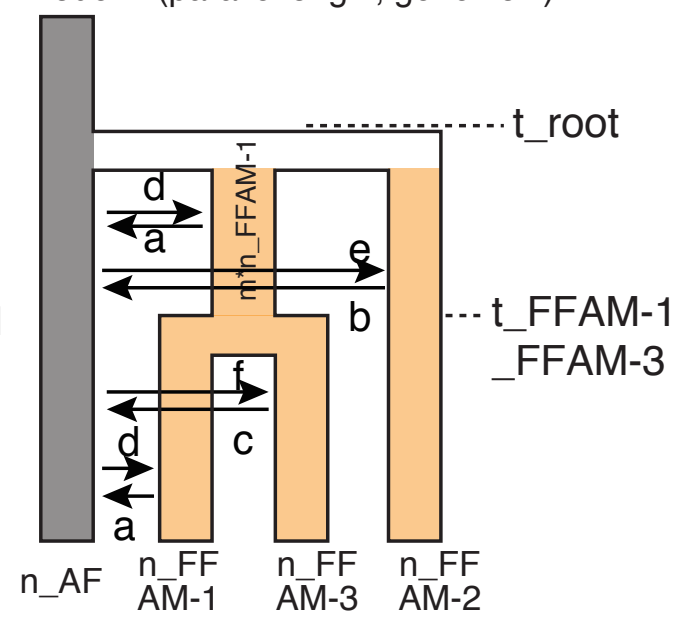

Model 5 (parallel origin, gene flow)

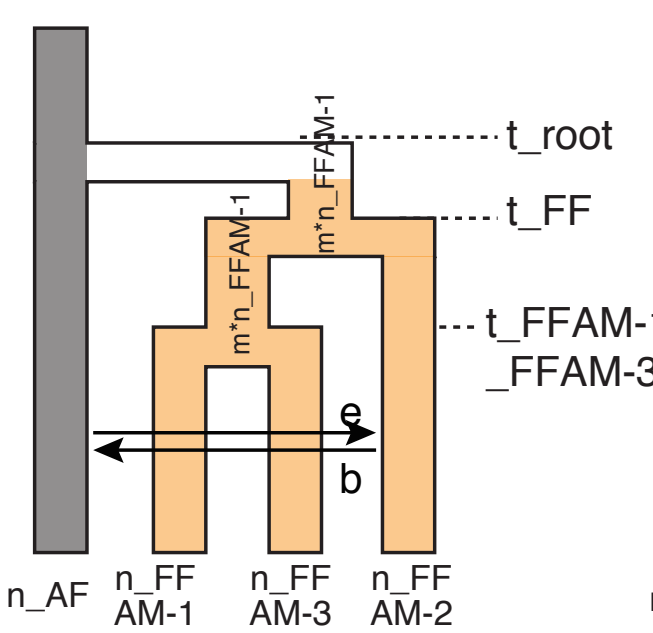

Model 7 (single origin, gene flow) Model 8 (parallel origin, no gene flow)

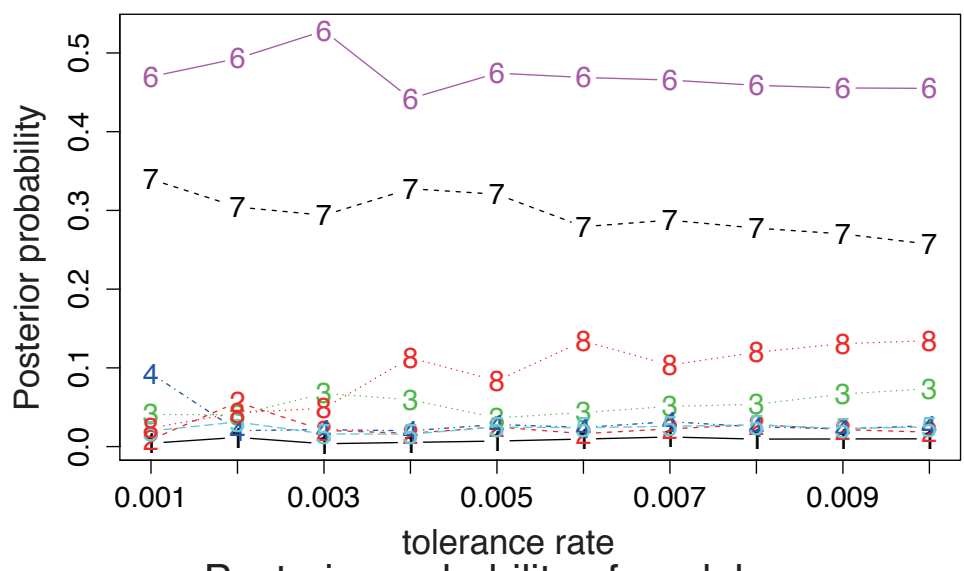

Posterior probability of models

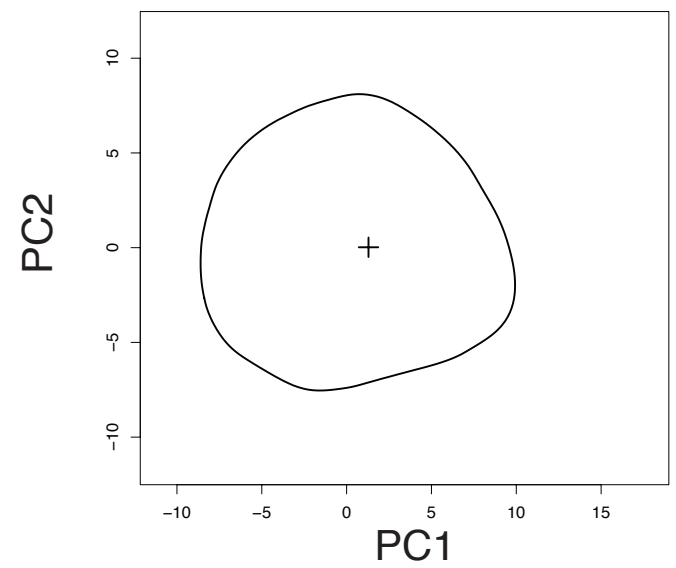

Posterior predictive check PCA

Figure S4 Tested demographic models and results of ABC model selection. Result of posterior predictive check conducted using principal component analysis for the selected model is also shown. Amphidromous and fluvial forms are indicated by black and orange, respectively. Arrows between populations indicate gene flow. The model that was selected is enclosed in a red square. 
4. Tokunoshima Is.

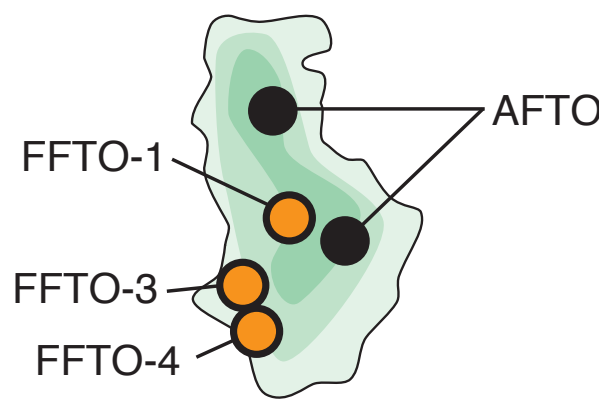

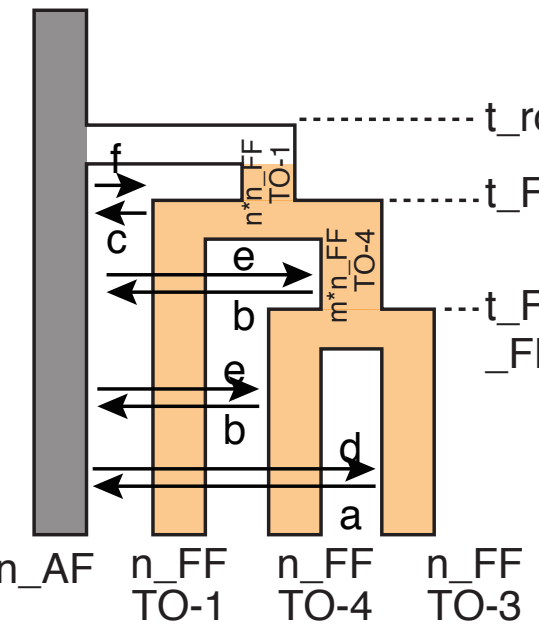

Model 3 (single origin, gene flow)
Model 1 (single origin, gene flow)
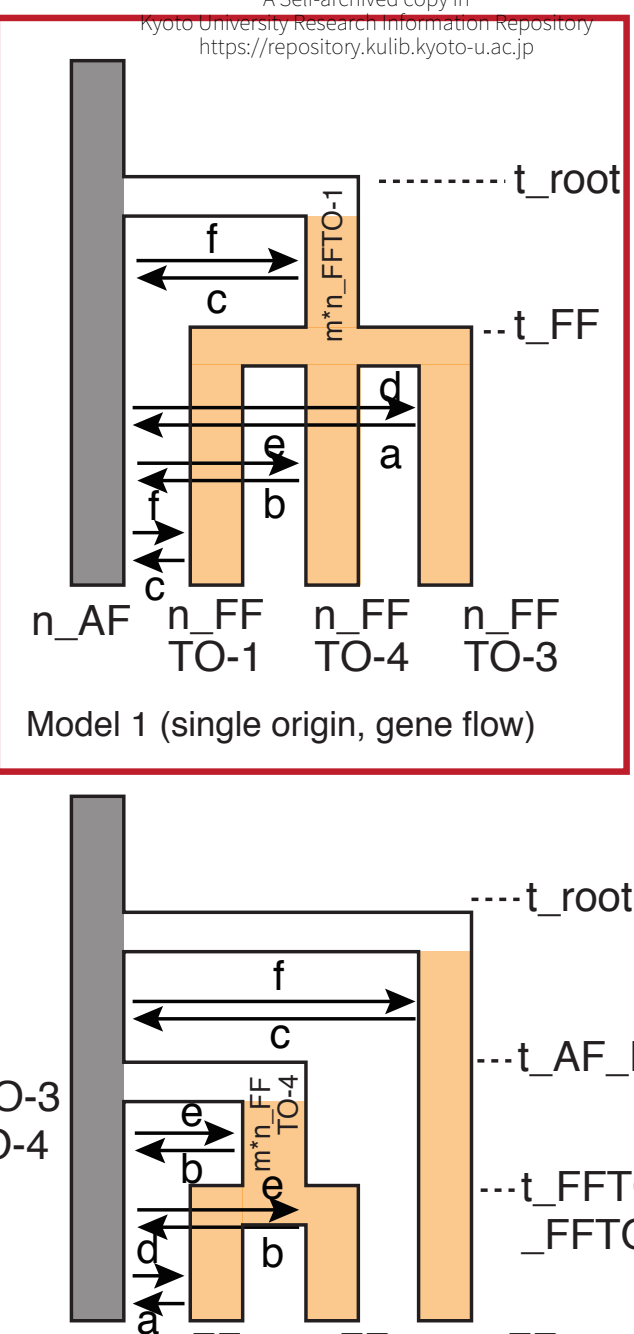

n AF

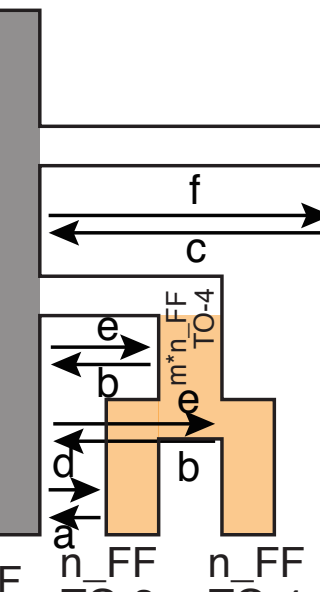

TO-3 TO-4

Model 4 (parallel origin, gene flow)

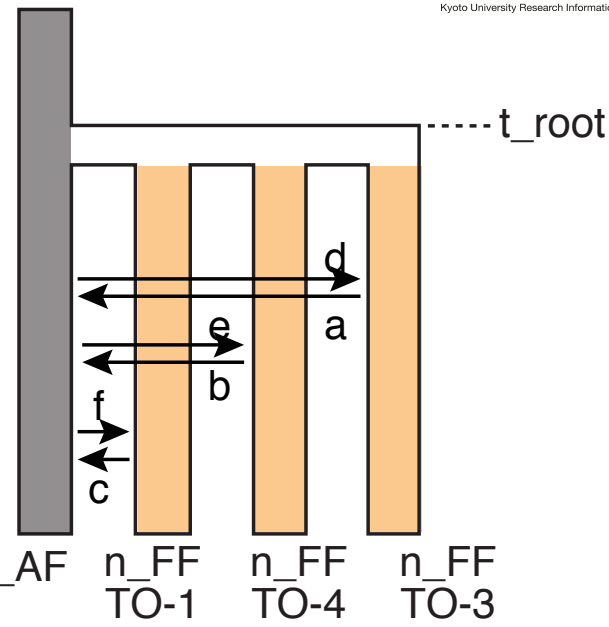

Model 2 (simultaneous divergence, gene flow)
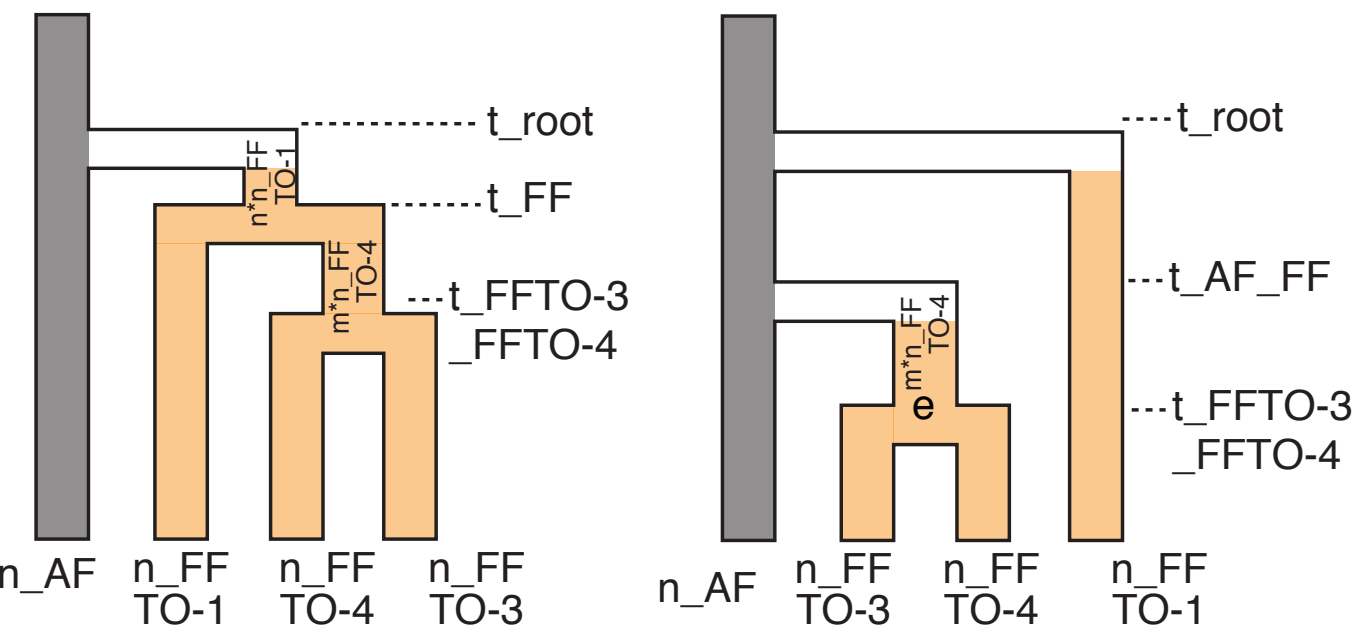

Model 6 (single origin, no gene flow)

Model 7 (parallel origin, no gene flow)

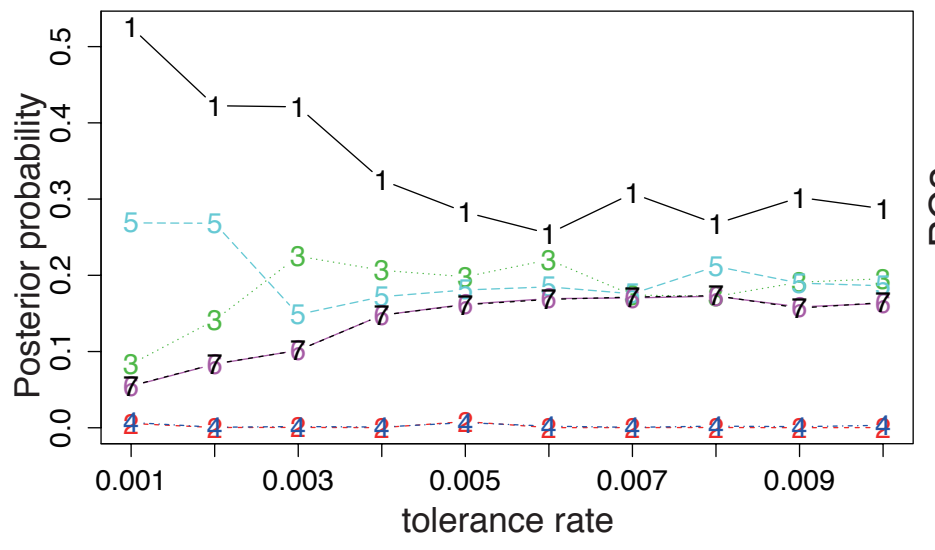

Posterior probability of models

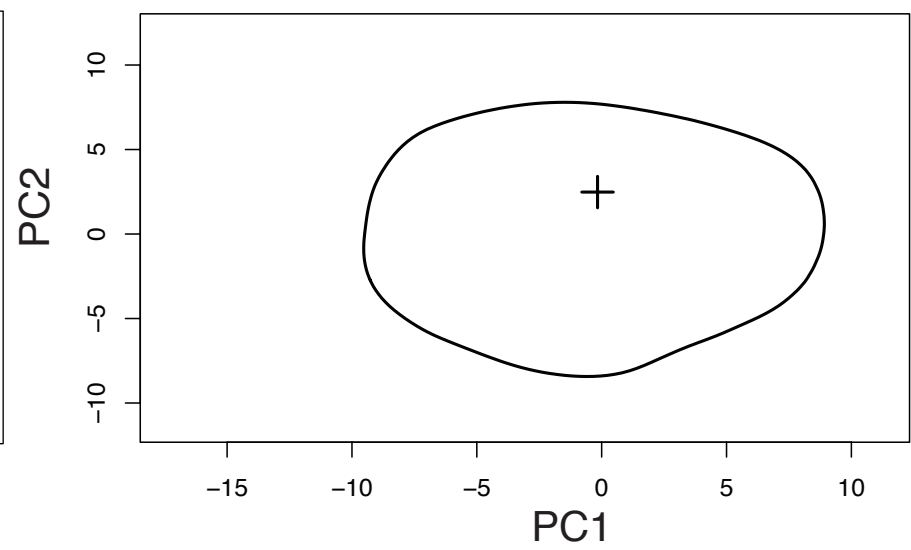

Posterior predictive check PCA 


\section{Okinawajima Is.}
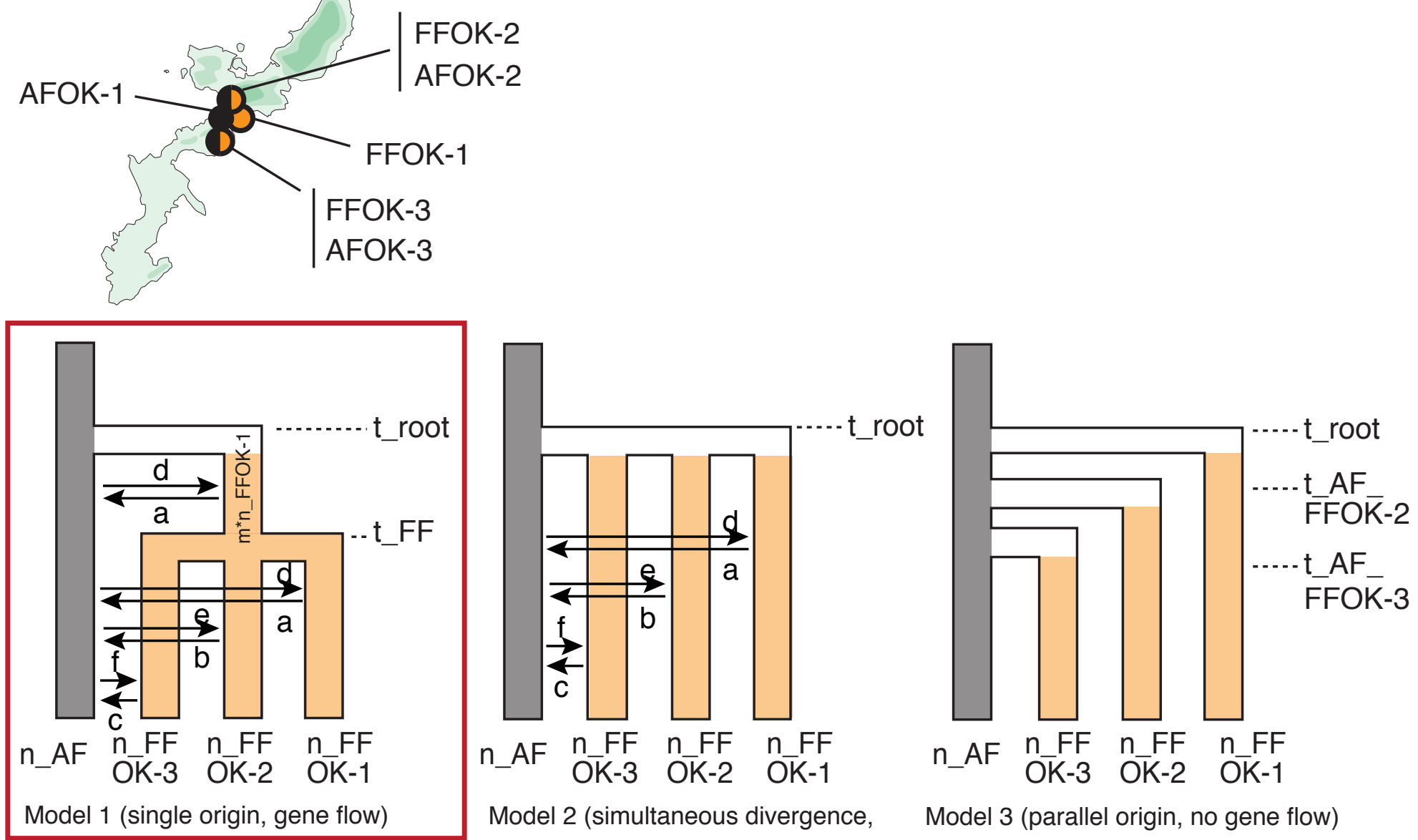

Model 2 (simultaneous divergence, Model 3 (parallel origin, no gene flow) gene flow)

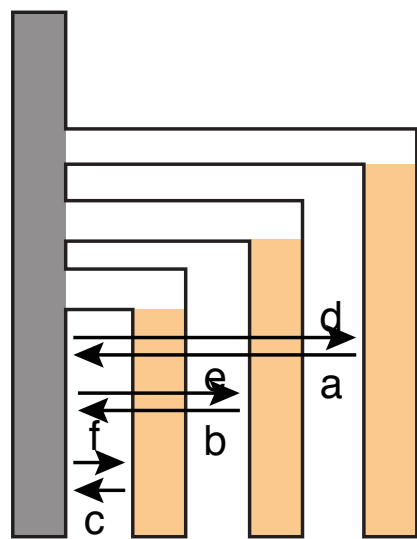

n_AF n_FF n_FF n_FF

_AF OK-3 OK-2 OK-1

Model 4 (parallel divergence, gene flow)

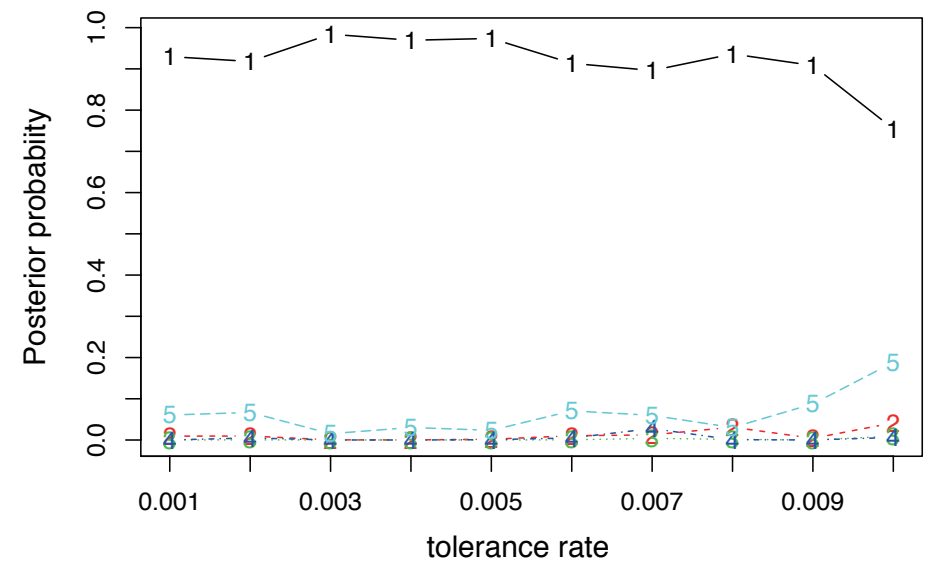

Posterior probability of models

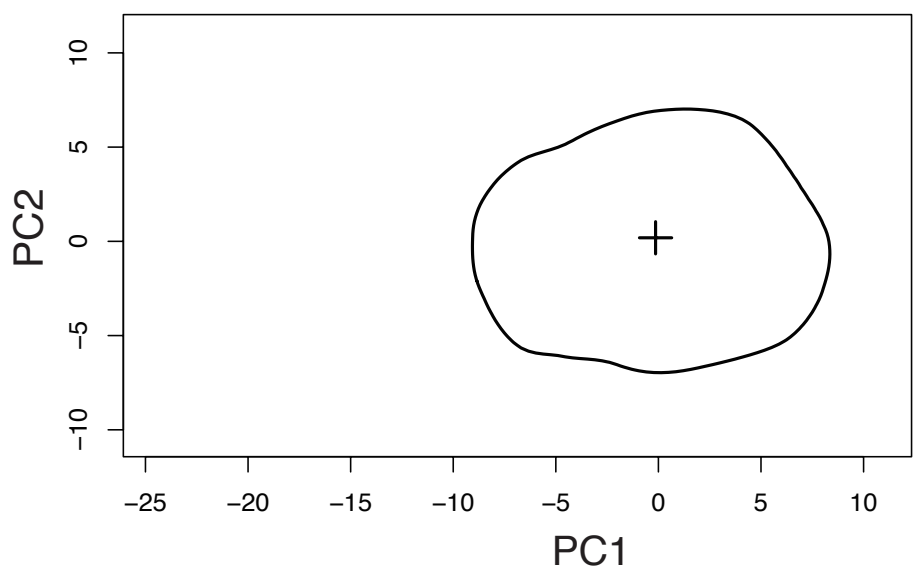

Posterior predictive check PCA

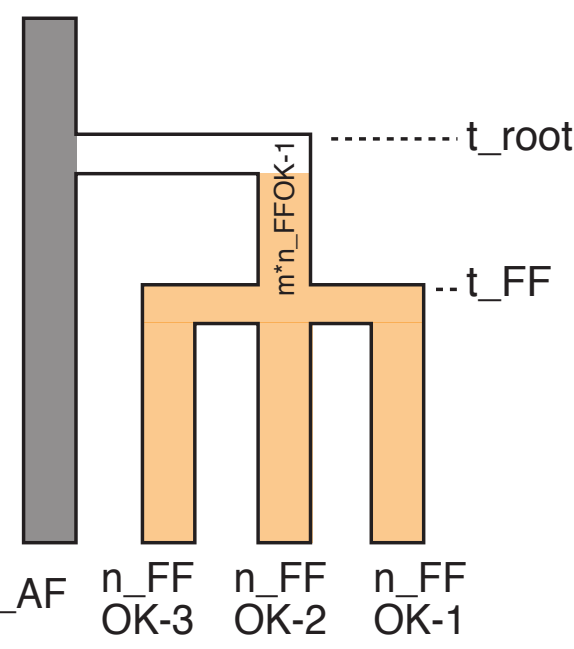

Model 5 (single origin, no gene flow) 
KYOTO

7. Kumejima Is.

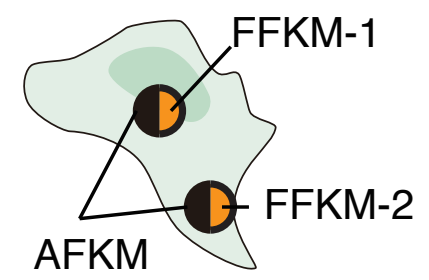

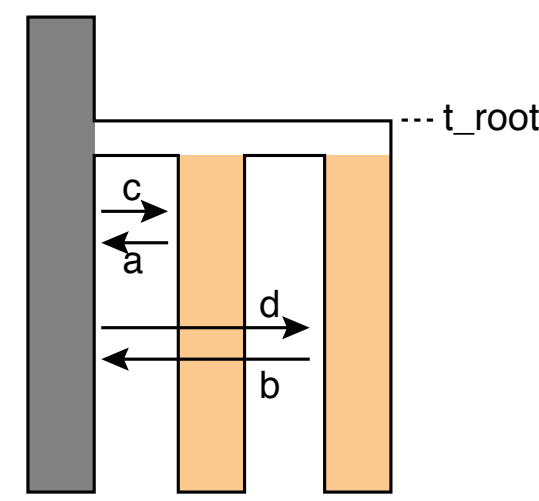

n_AFKM n_FFKM-1 n_FFKM-2

Model 1 (simultaneous origin, gene flow)

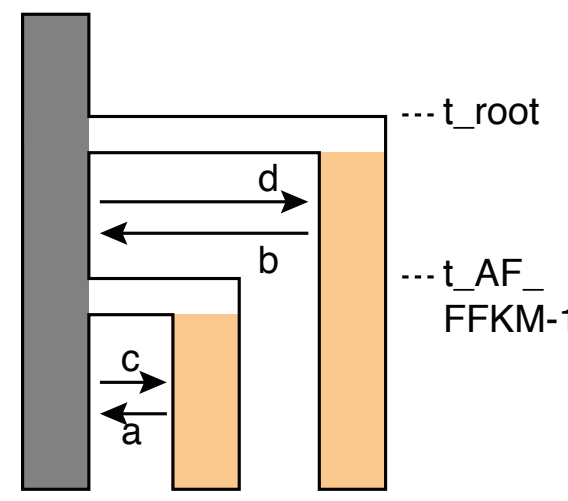

n_AFKM n_FFKM-1 n_FFKM-2 Model 2 (parallel origin, gene flow)

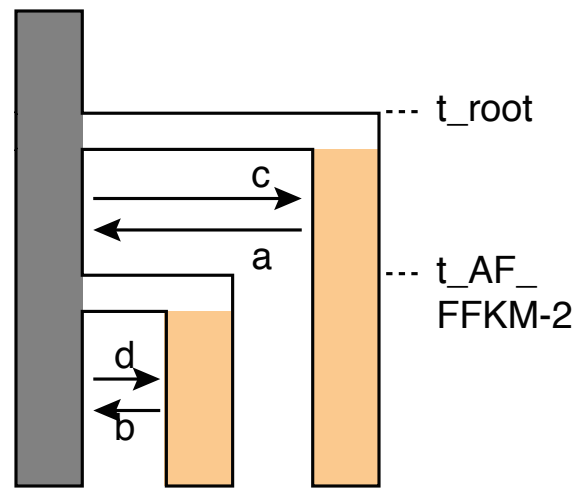

n_AFKM n_FFKM-2 n_FFKM-1

Model 3 (parallel origin, gene flow)

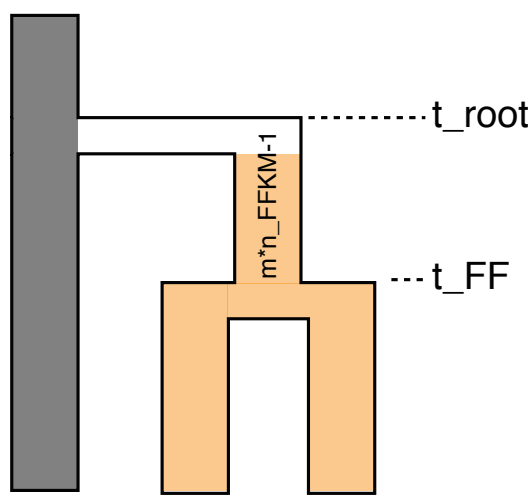

n_AFKM n_FFKM-1 n_FFKM-2

Model 4 (single origin, no gene flow)

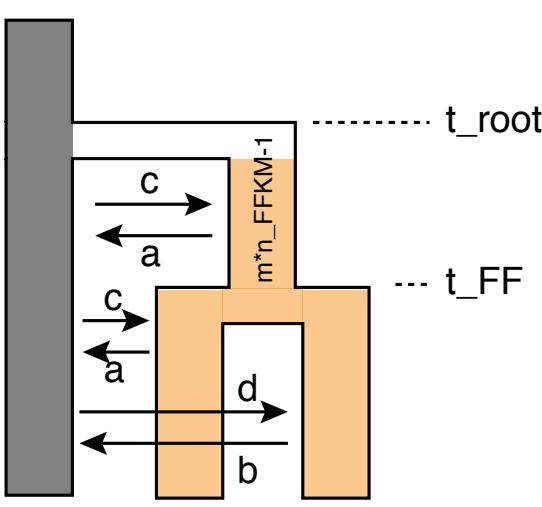

$\mathrm{n} \_$AFKM n_FFKM-1 n_FFKM-2

Model 5 (single origin, gene flow)

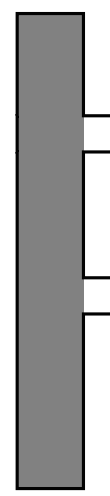

AFKM $n$ FFKM-2 n FFKM-1

Model 8 (parallel origin, no gene flow) n_AFKM n_FFKM-1 n_FFKM-2
Model 7 (single origin, gene flow)

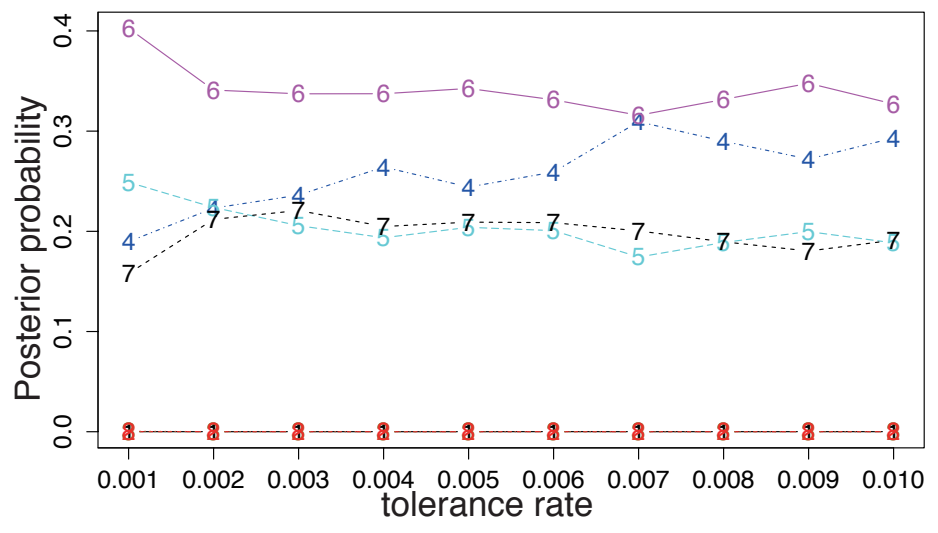

Posterior probability of models

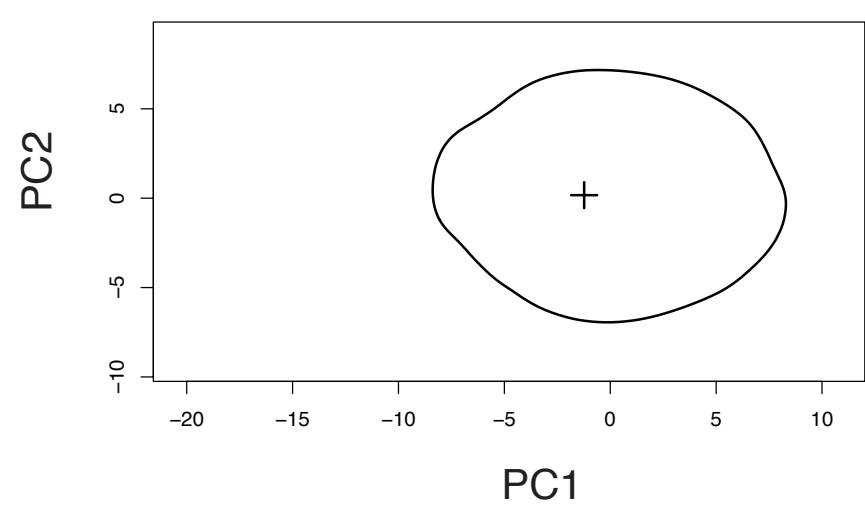

Posterior predictive check PCA

Figure S4 Continued 
9. Iriomotejima Is.

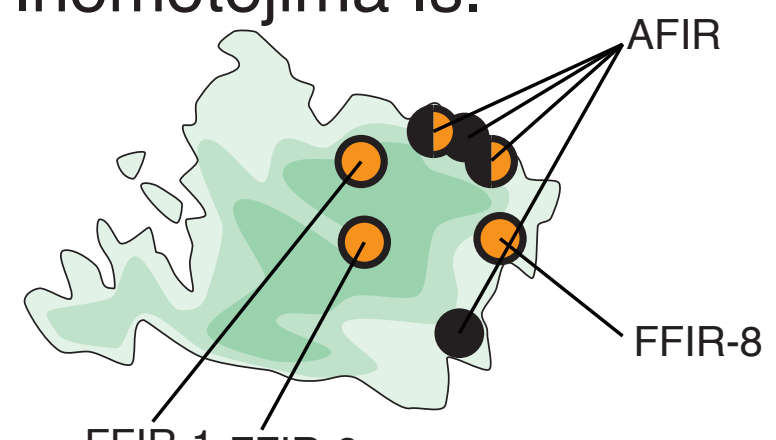

FFIR-1 FFIR-6

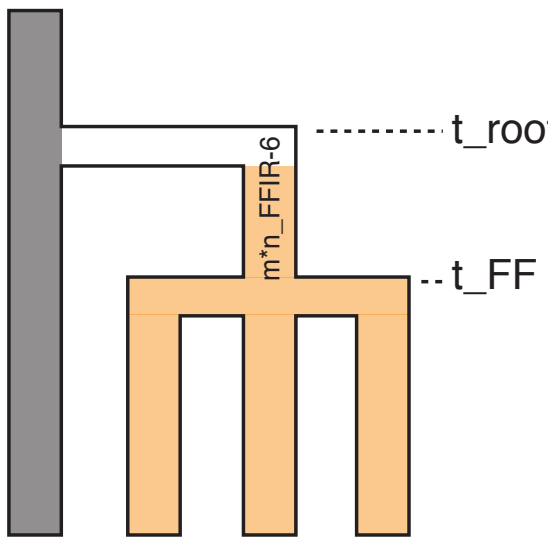

n_AFIRn_FF n_FF n_FF

IR-8 IR-1 IR-6

Model 1 (single origin, no gene flow)

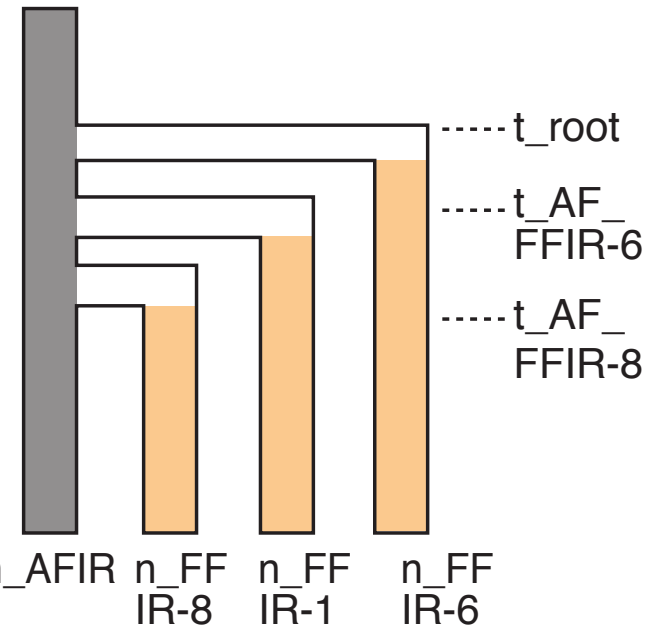

Model 2 (parallel origin, no gene flow)

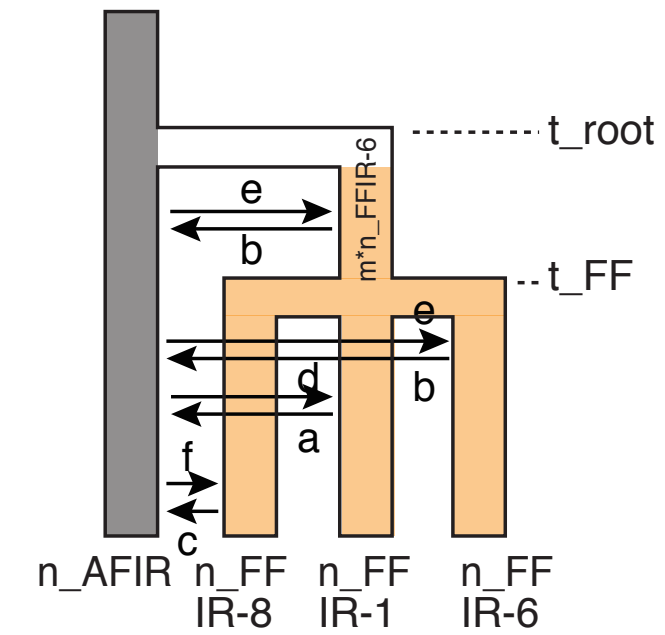

Model 3 (single origin, gene flow)

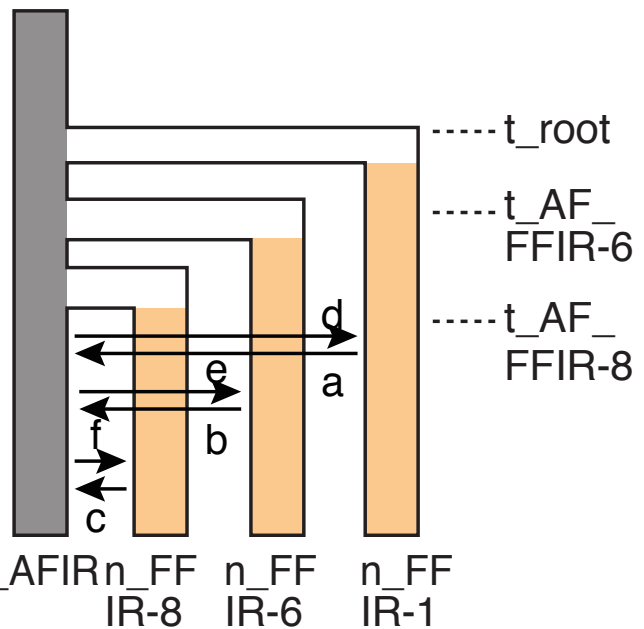

Model 4 (parallel origin, gene flow)

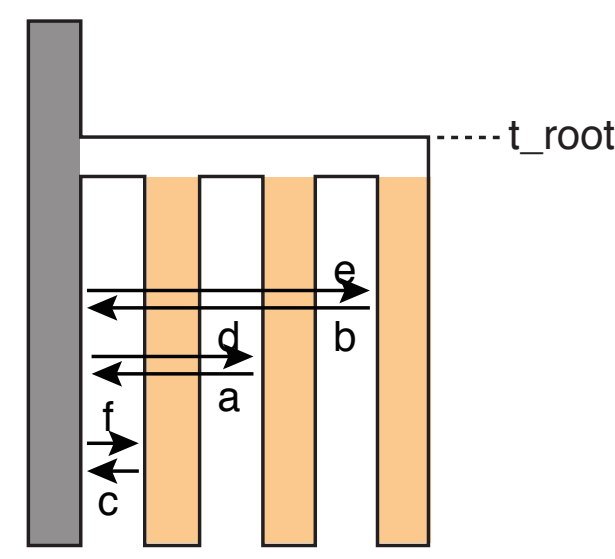

n_AFIR n_FF n_FF n_FF IR-8 I I $\bar{R}-1 \quad I \bar{R}-6$

Model 5 (simultaneous divergence, gene flow)

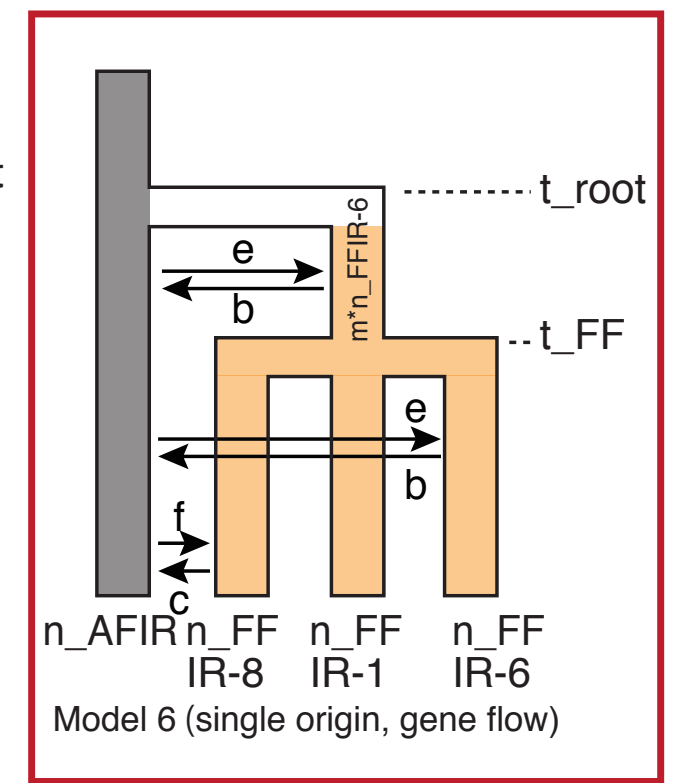

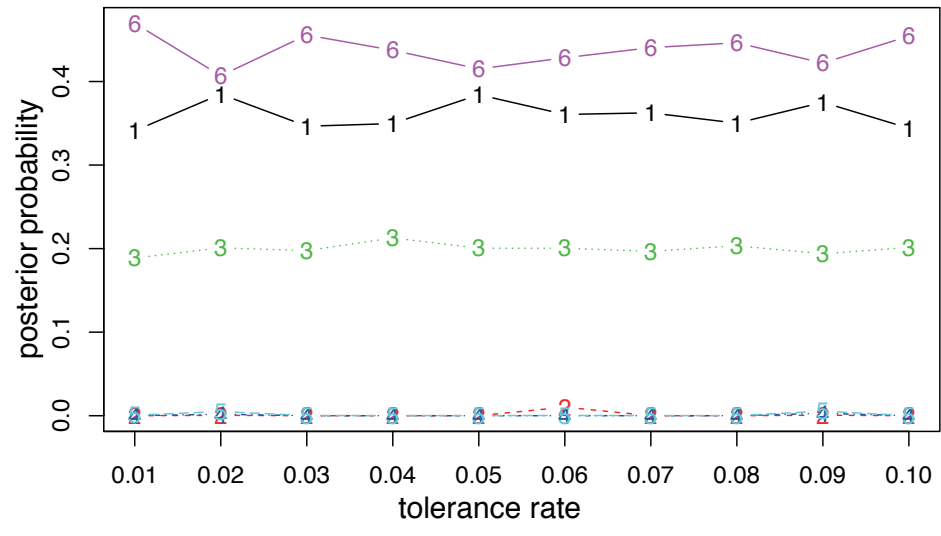

Posterior probability of models

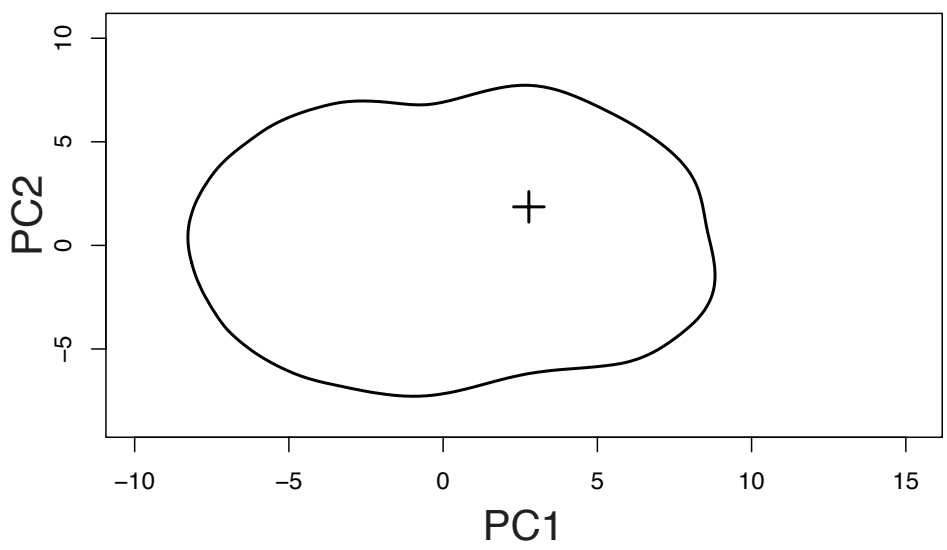

Posterior predictive check PCA

Figure S4 Continued 


\section{F \\ 4. Tokunoshima Is.- 5. Okinoerabujima Is.}
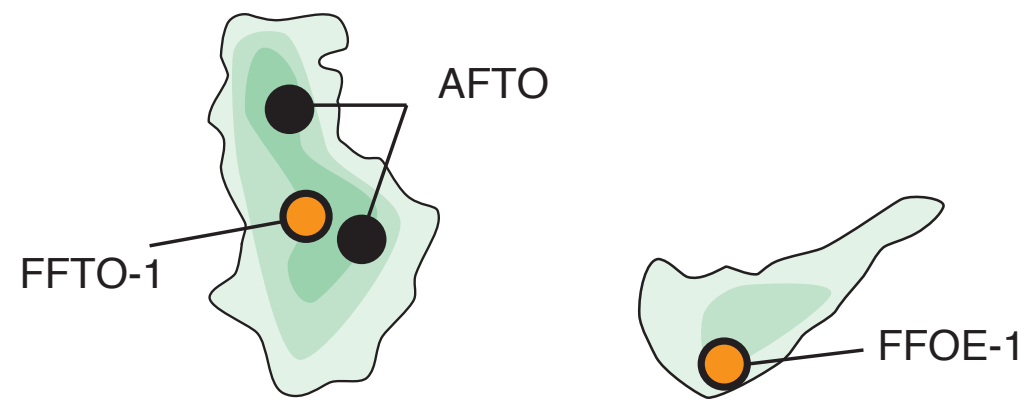

4. Tokunoshima Is.

5. Okinoerabujima Is.

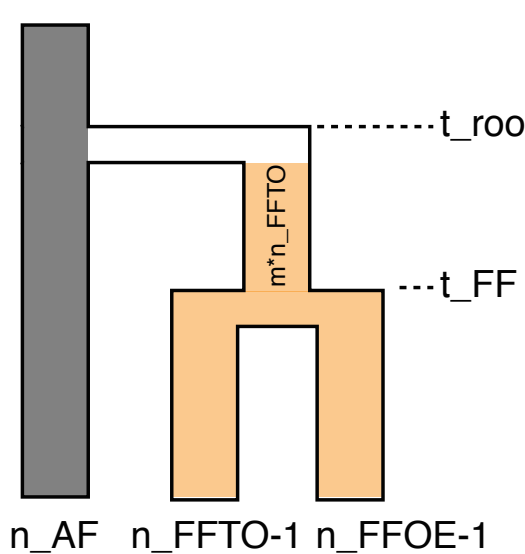

Model 1 (single origin, no gene flow)
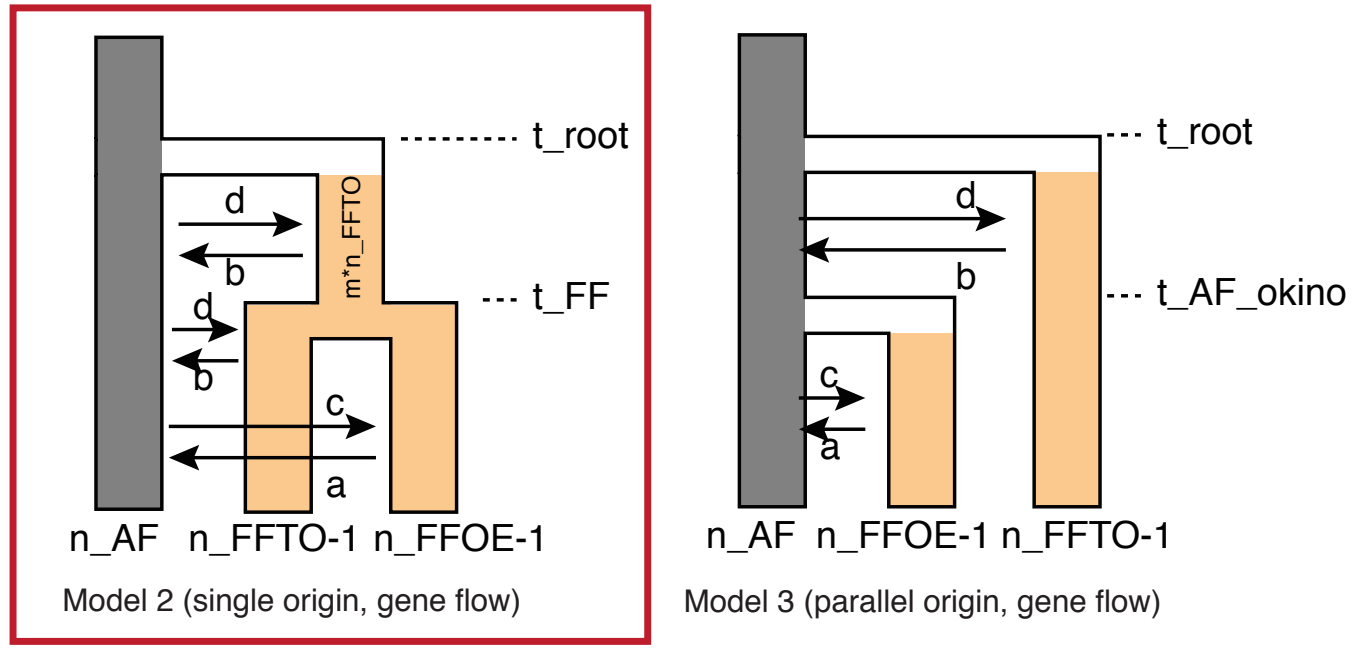

Model 3 (parallel origin, gene flow)

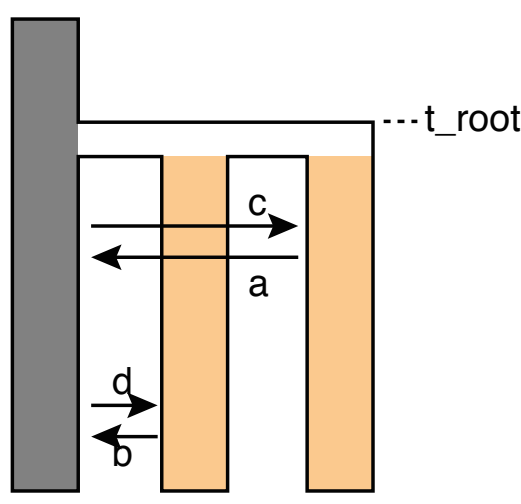

n_AF n_FFTO-1 n_FFOE-1

Model 4 (simultaneous divergence,

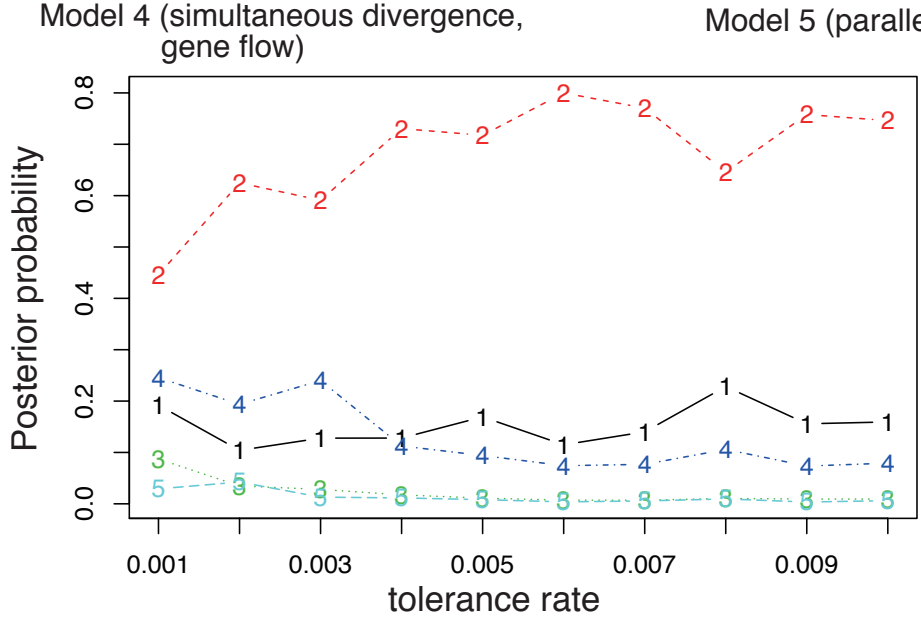

Posterior probability of models

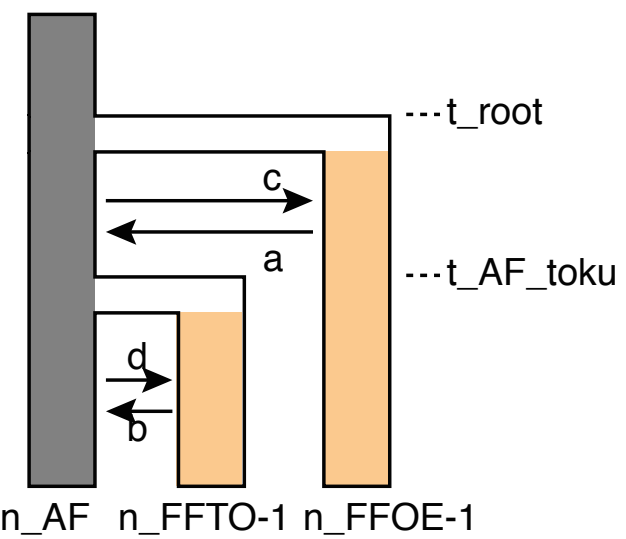

Model 5 (parallel origin, geneflow)

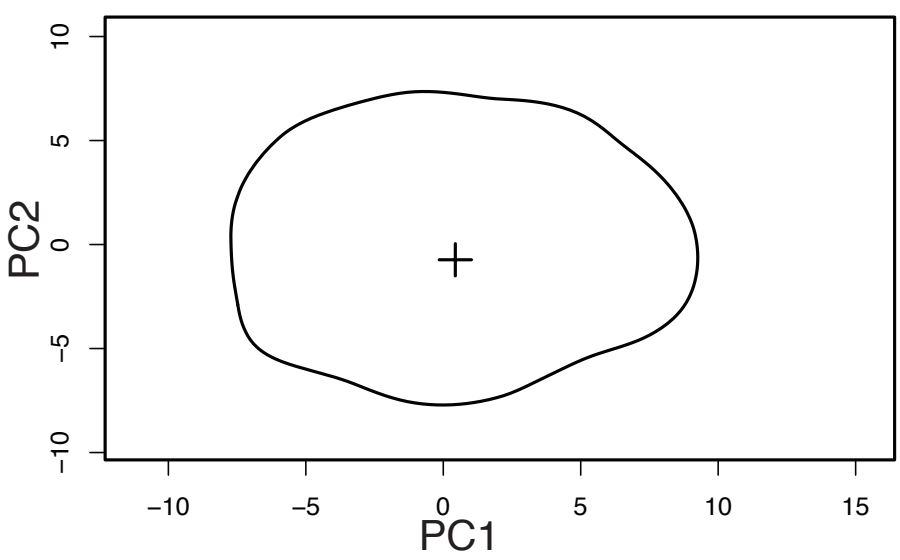

Posterior predictive check PCA

Figure S4 Continued 

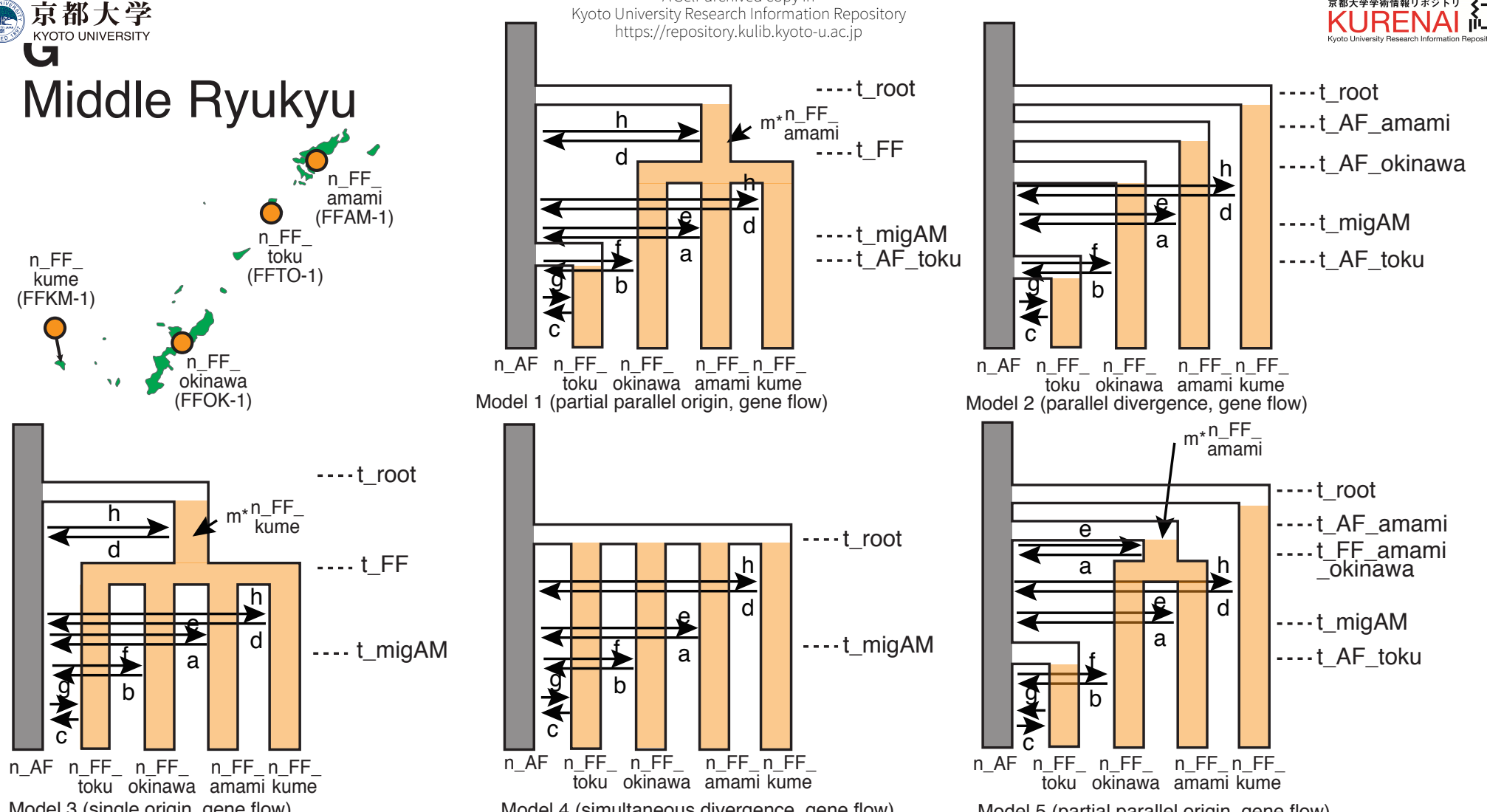

1 (partial parallel origin, gene flow)

Model 2 (parallel divergence, gene flow)

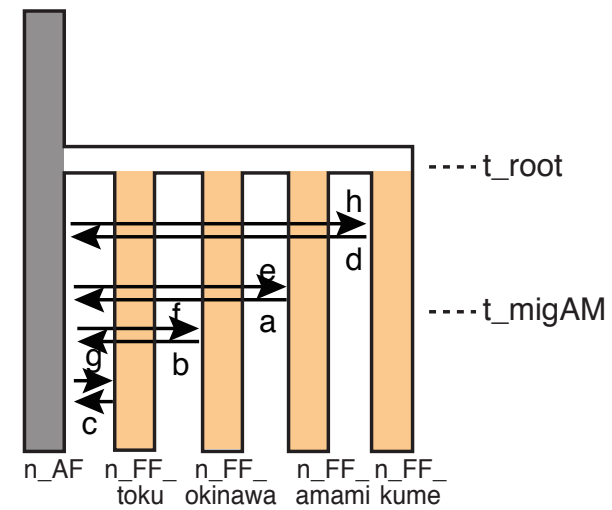

Model 4 (simultaneous divergence, gene flow)

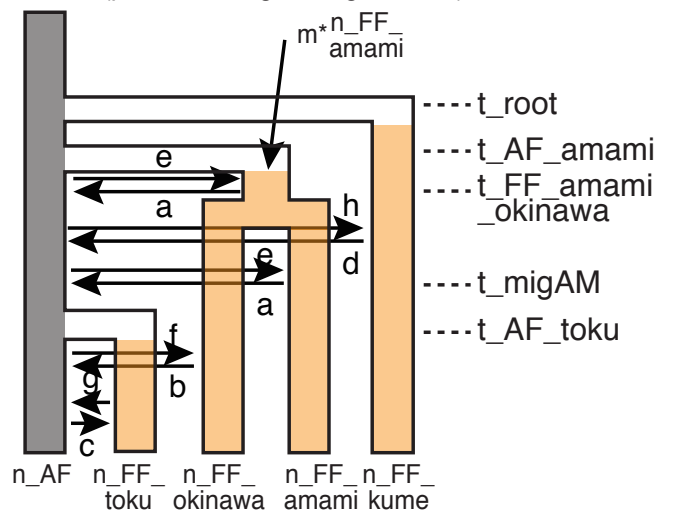

Model 5 (partial parallel origin, gene flow)
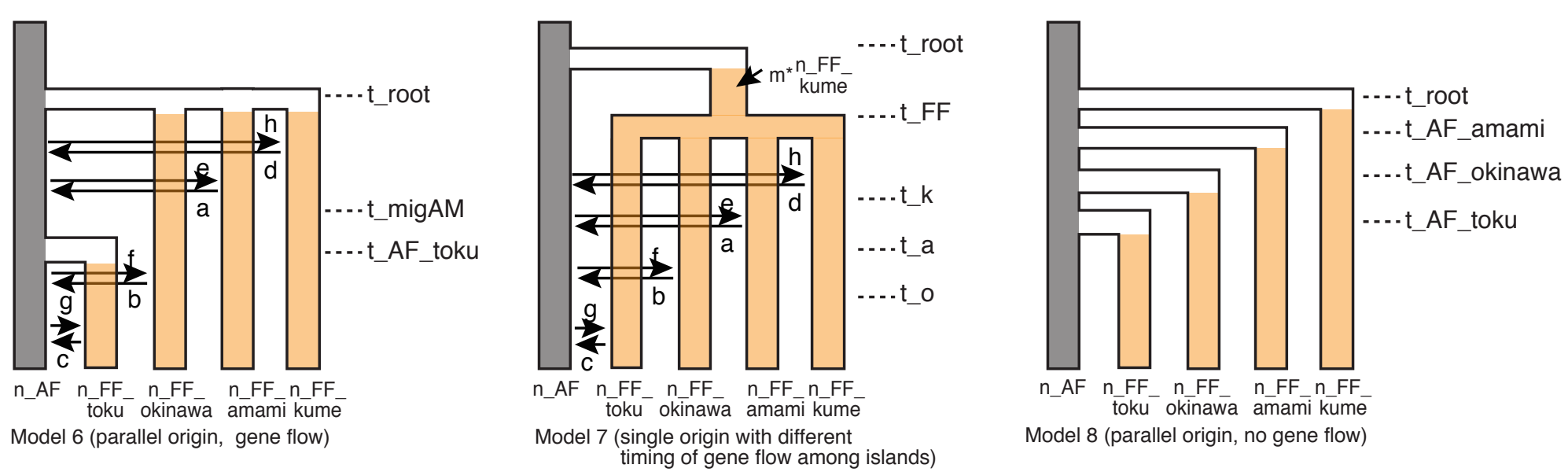
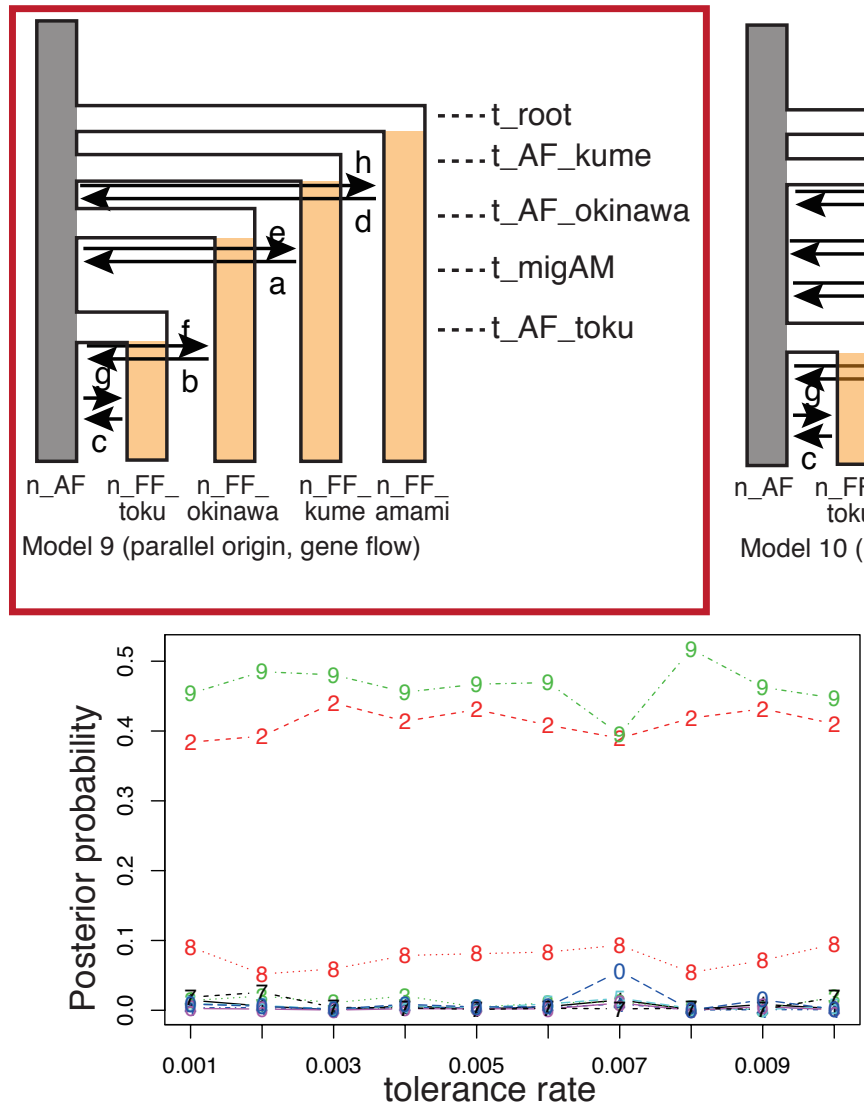

Posterior probability of models

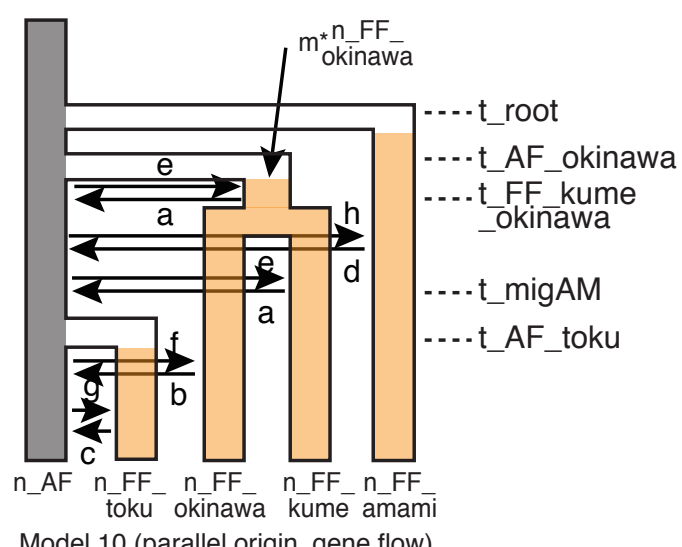

Figure S4 Continued

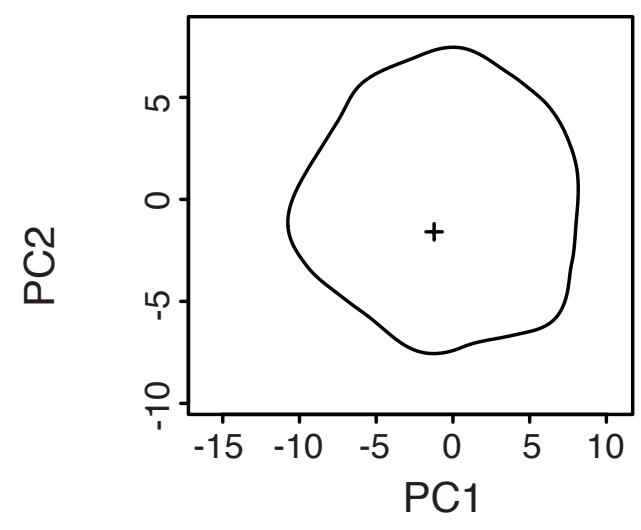

Posterior predictive check PCA 


\section{South Ryukyu}

n_FF

iriomote

(FFIR-6)
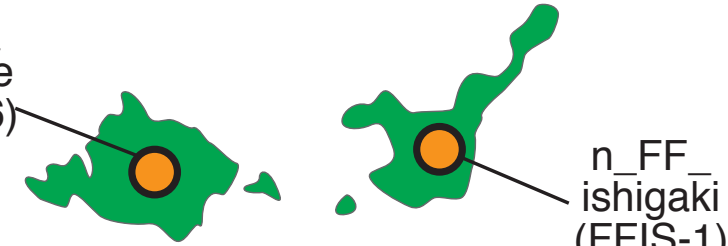

9. Iriomotejima Is. 8. Ishigakijima Is.

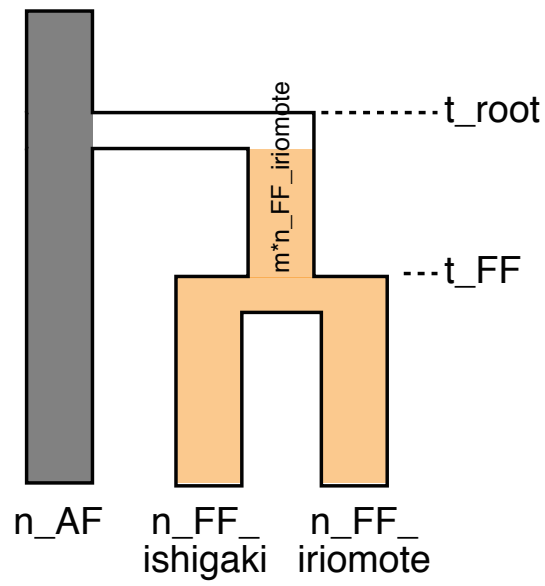

Model 1 (single origin, no gene flow)

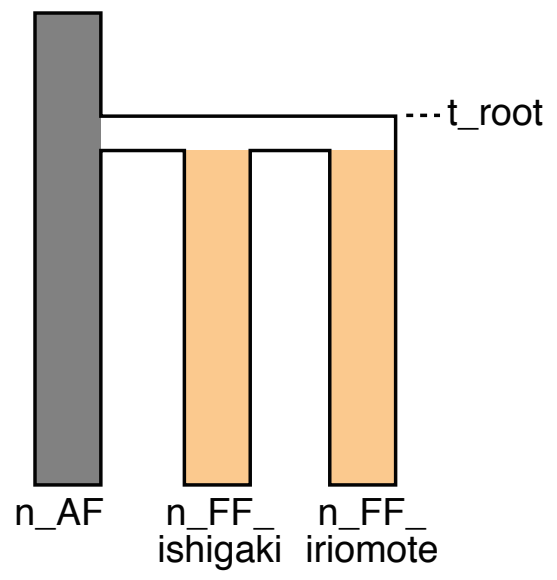

Model 2 (simultaneous divergence, no gene flow)

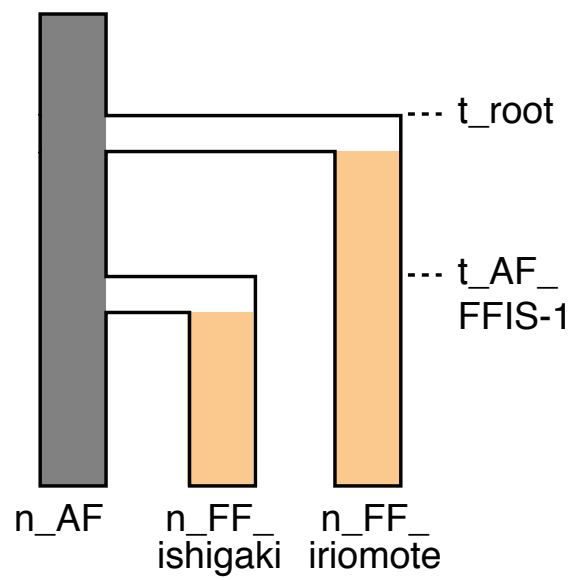

Model 3 (parallel origin, no gene flow)

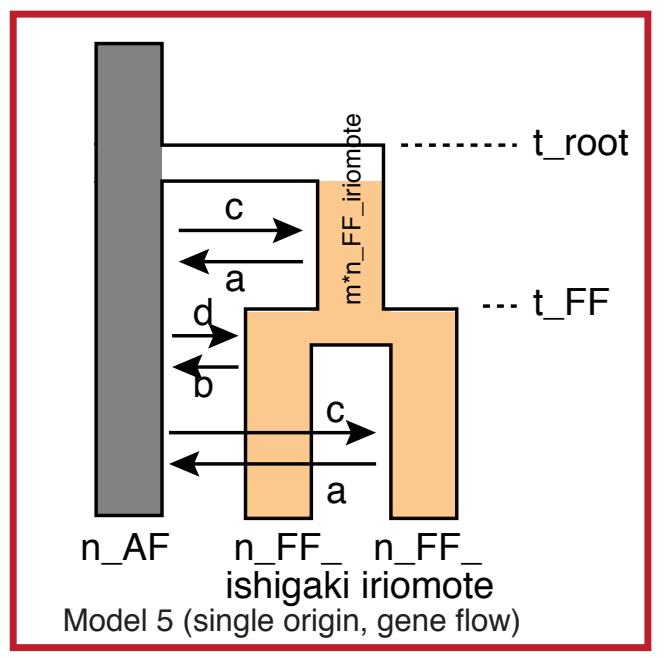

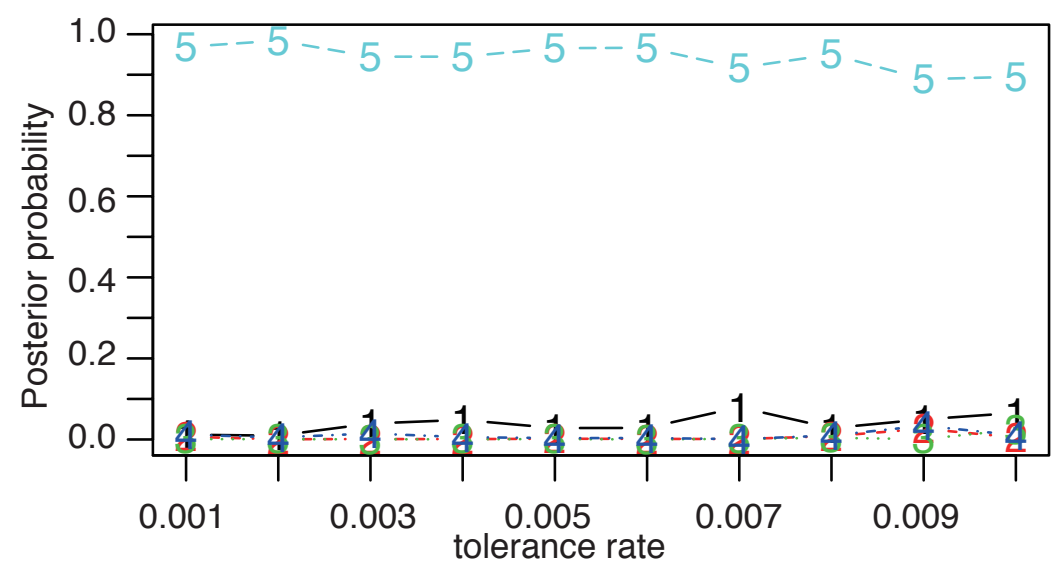

Posterior probability of models

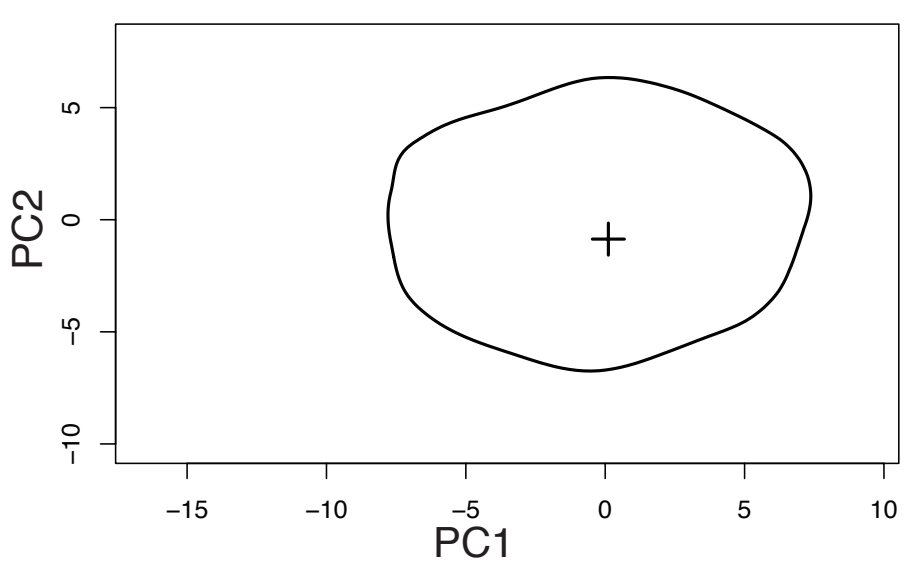

Posterior predictive check PCA

Figure S4 Continued 


\section{I \\ Ryukyu}
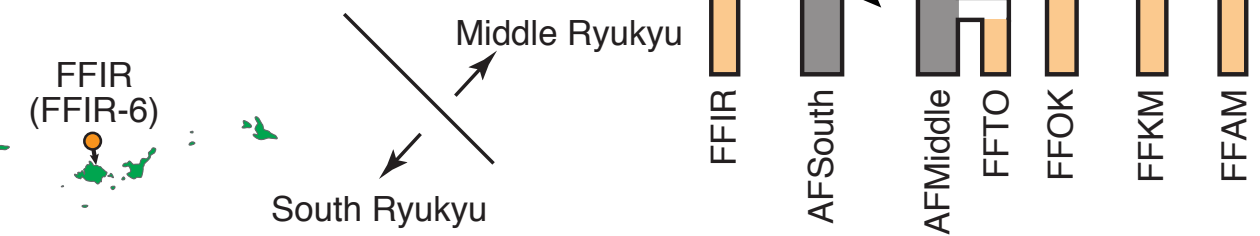

Model 1 (parallel origin between regions)
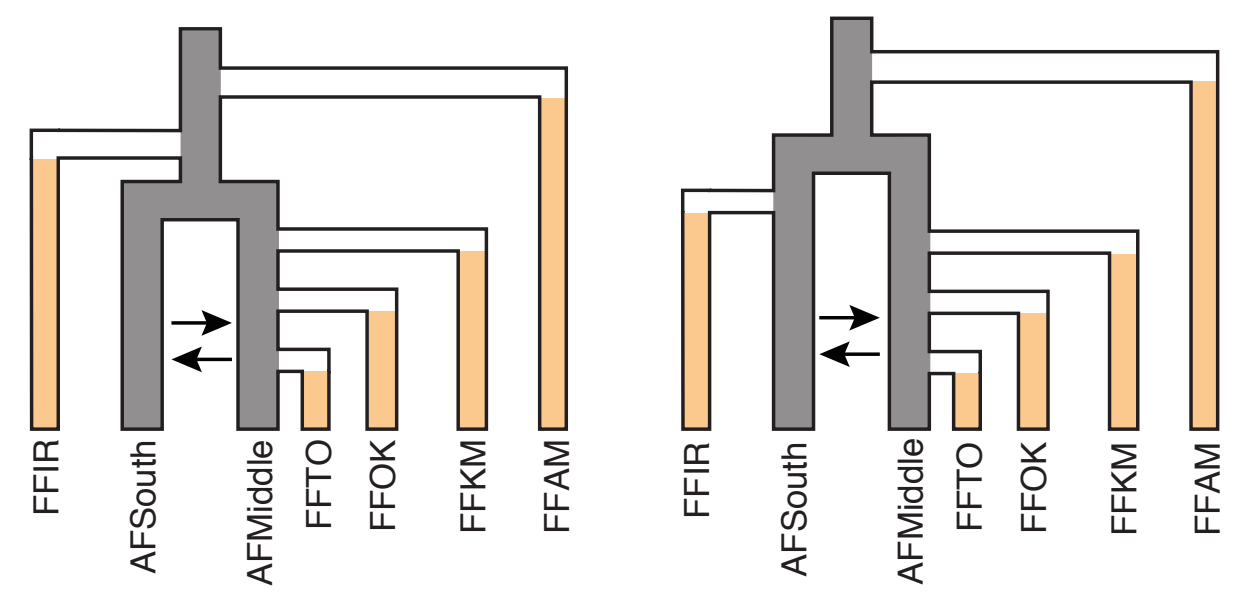

Model 3 (parallel origin between regions) Model 4 (parallel origin between regions)
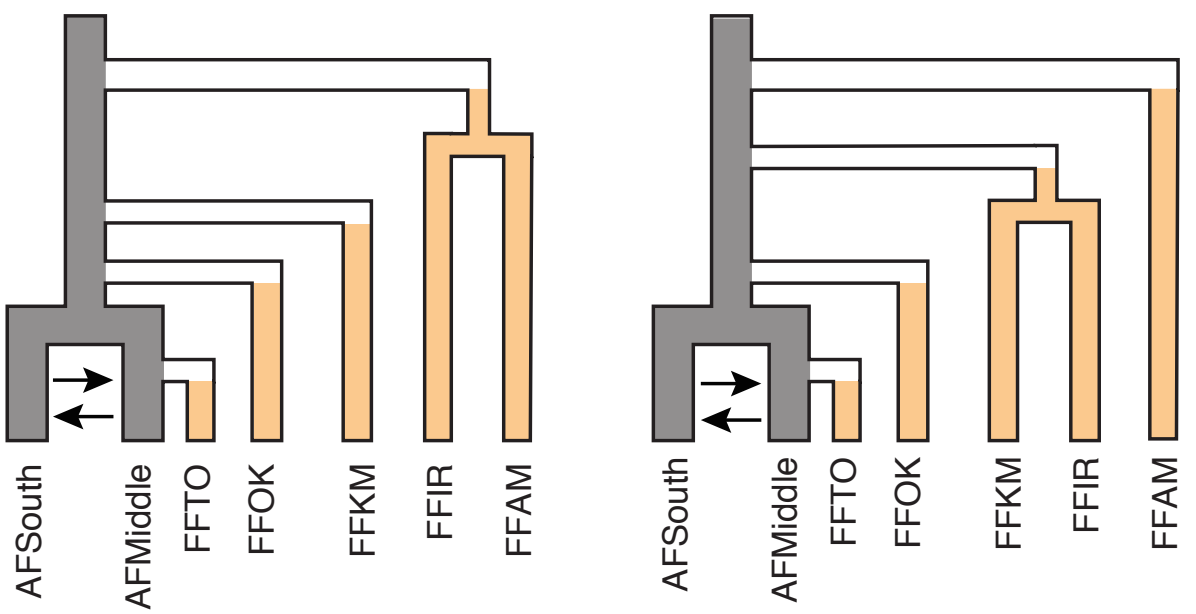

Model 6 (single origin between regions) Model 7 (single origin between regions)

Model 2 (single origin between regions)

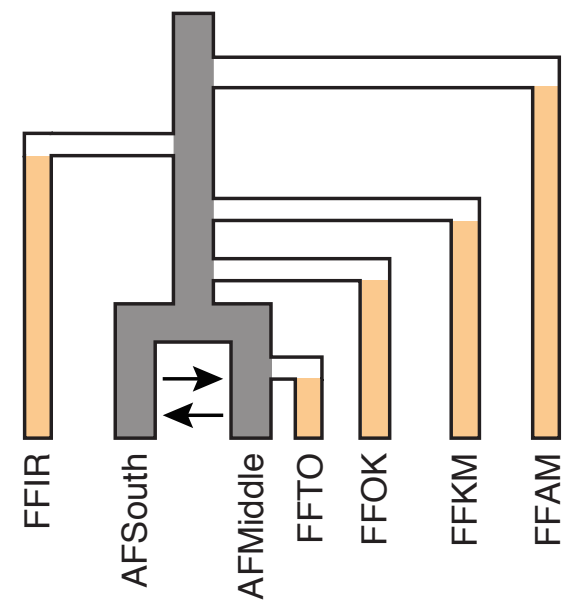

Model 5 (parallel origin between regions)

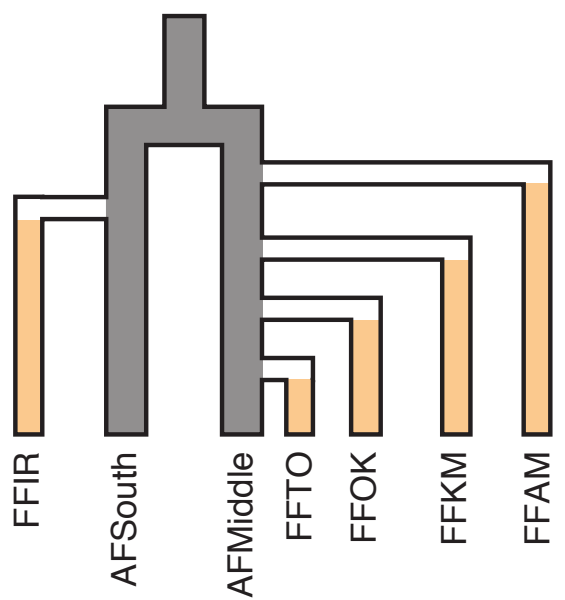

Model 8 (parallel origin between regions)
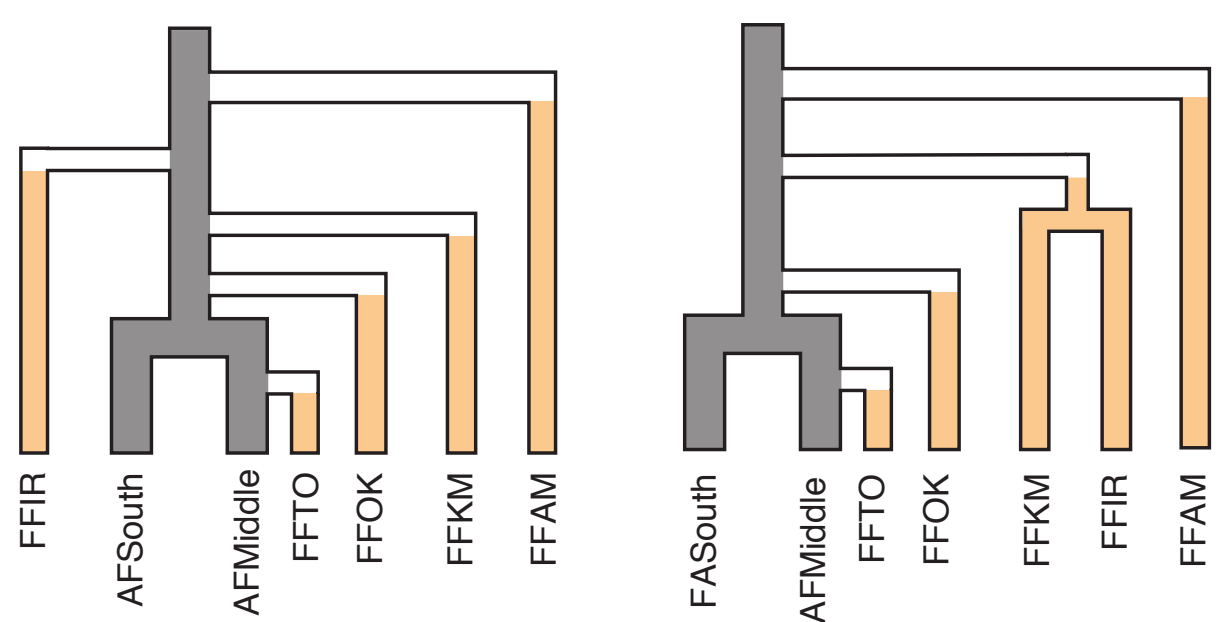

Model 9 (parallel origin between regions) Model 10 (single origin between regions)

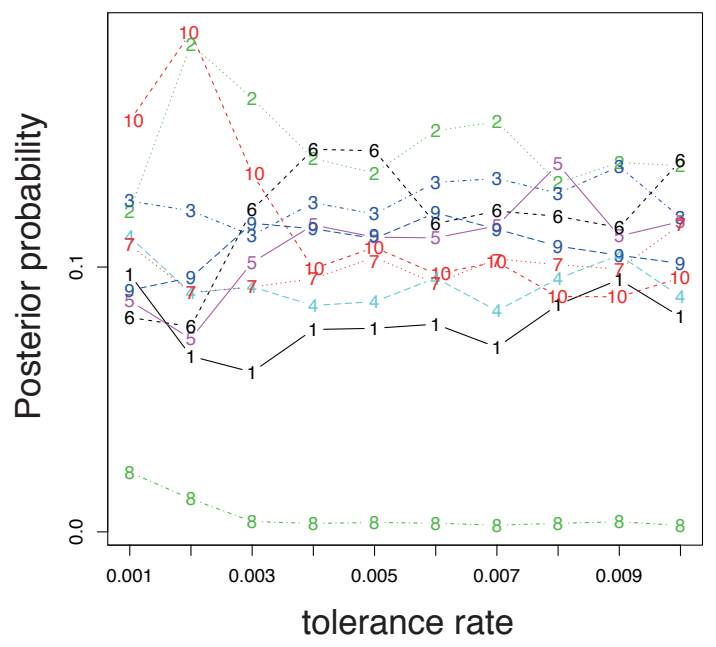

Parameters except gene flow between amphidromous form in Middle and South Ryukyu were omitted in this figure. 
A
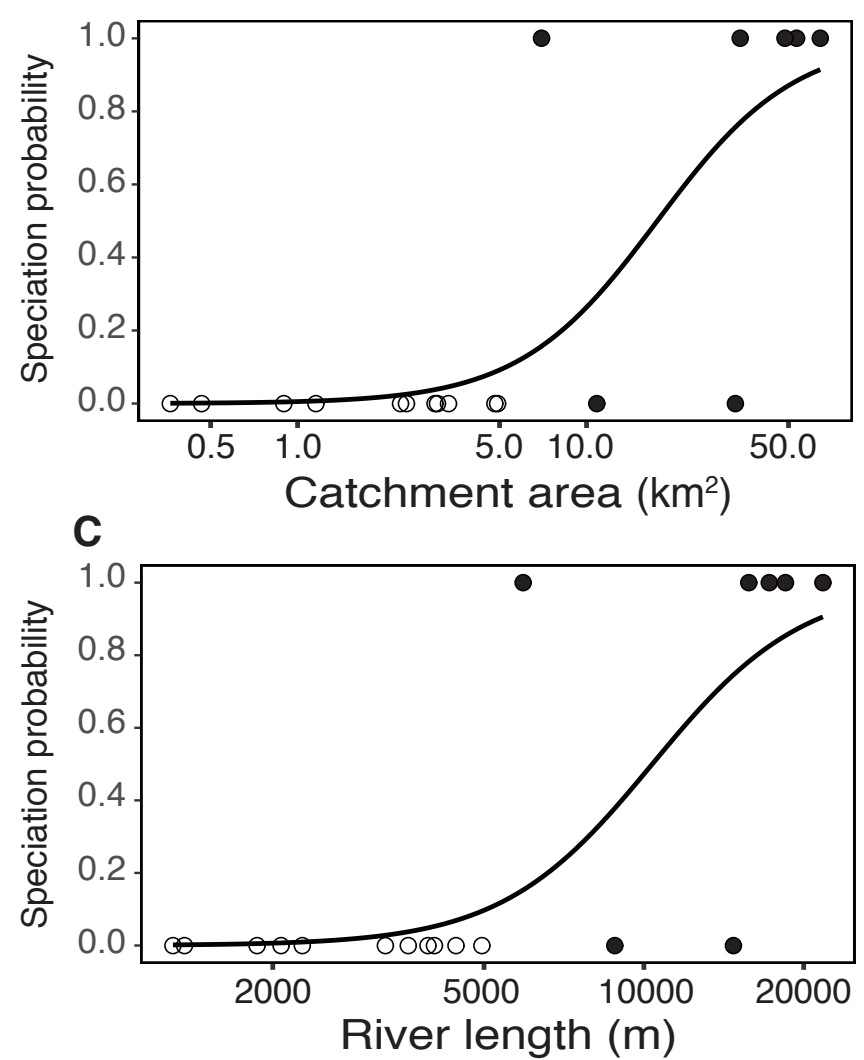

E

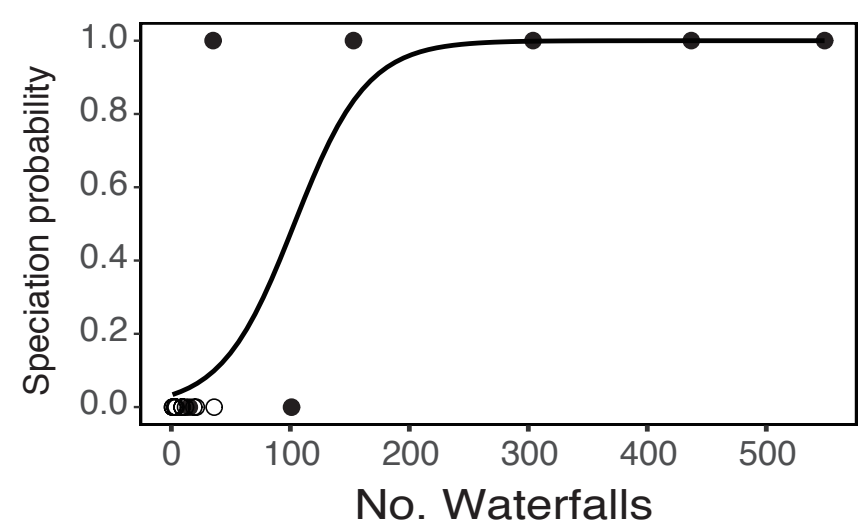

B
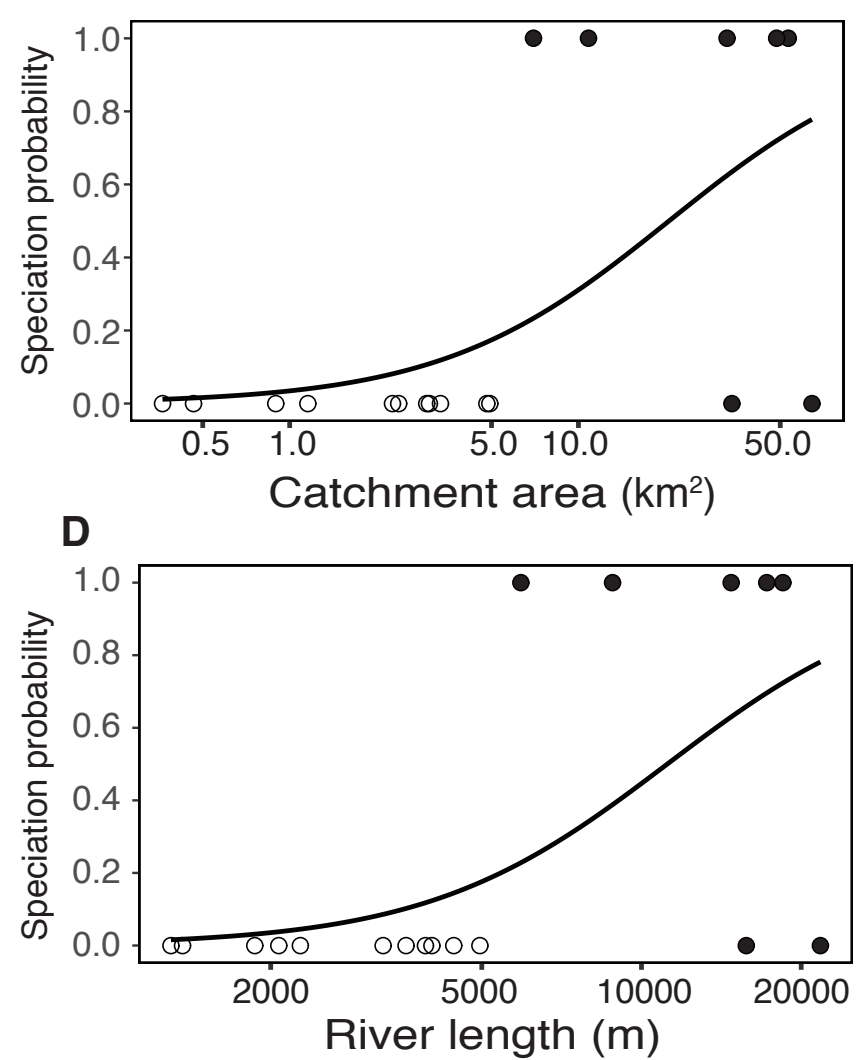

$\mathbf{F}$

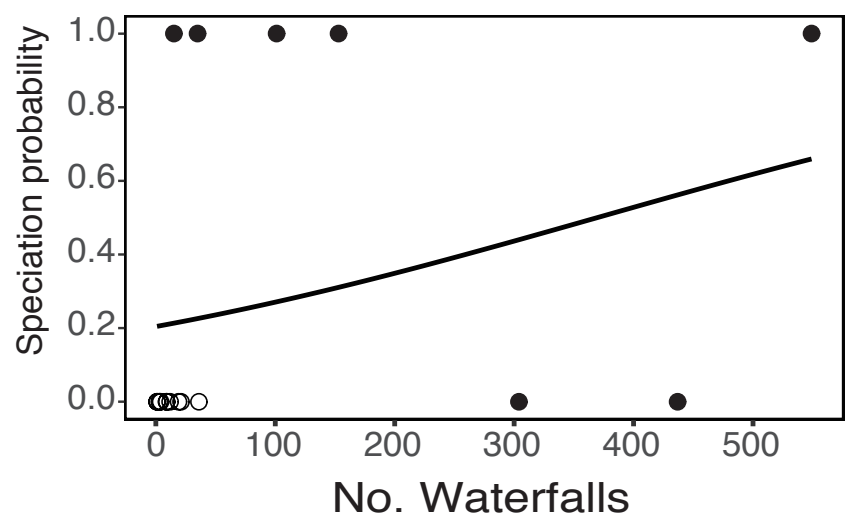

Figure S5 Results of logistic regression analysis between ecosystem size other than island size and speciation probability. Islands with the freshwater form (FF) are represented by filled circles, whereas those without FF are represented by open circles. Filled circles plotted on the x-axis (speciation probability $=0$ ) are for the islands with FF that was assumed to be of non-independent origin. Our $A B C$ analysis indicated that $F F$ in Tokunoshima Is. and Okinoerabujima Is., and Ishigakijima Is. and Iriomotejima Is. shared their origins. Plots in the left colomun $(A, C, E)$ assumed that the speciation of FF occurred in the larger island (Tokunoshima Is. and Iriomotejima Is.). Plots in the right colomun (B,D,F) assumed that speciation occurred in the smaller island (Okinoerabujima Is. and Ishigakijima Is.). 


\begin{tabular}{|c|c|c|c|c|c|c|c|c|c|c|c|c|}
\hline Region & Island & Form & River system & Point & Population Name & River length $\mathrm{m}$ & Catchment area ha & $\mathbf{N}$ & Ho & $\mathrm{He}$ & Rs & $\mathrm{ABC}$ \\
\hline \multirow{35}{*}{ Middle Ryuky! } & II Amami-Oshima & $\mathrm{FF}$ & Sumiyo & Sumiyo & FFAM-1 & 18478 & 4858 & 28 & 0.337 & 0.371 & 2.38575 & Amami-Oshima/Middle Ryukyu/Ryukyu \\
\hline & & & Akina & Akina & FFAM-2 & 9969 & 1135 & 16 & 0.228 & 0.235 & 2.6299 & Amami-Oshima \\
\hline & & & Kawauchi & Kawauchi & FFAM-3 & 12484 & 2817 & 31 & 0.239 & 0.234 & 1.65095 & Amami-Oshima \\
\hline & & & _Asado & Asado-2 & FFAM-4 & 13155 & 3238 & 30 & 0.128 & 0.181 & 2.77865 & \\
\hline & & $\mathrm{AF}$ & Asado & Asado-1 & AFAM-1 & 13155 & 3238 & 29 & 0.507 & 0.507 & 3.5093 & Amami-Oshima/Middle Ryukyu/Ryukyu \\
\hline & Kikaiijma & AF & Kikai-1 & Kikai-1 & AFKI-1 & 1859 & 69 & 11 & 0.495 & 0.514 & 3.3566 & - \\
\hline & & & Kikai-2 & Kikai-2 & AFKI-2 & 1825 & 56 & 10 & 0.438 & 0.489 & 3.5747 & \\
\hline & Tokunoshima & $\mathrm{FF}$ & Akirigami & Akirigami-1 & 1 FFTO-1-1 & 15754 & 3400 & 26 & 0.312 & 0.325 & 2.70765 & Tokunoshima/Tokunoshima-Okinoerabu/Middle Ryukyu/Ryukyu \\
\hline & & & & Akirigami-2 & 2FFTO-1-2 & & & 18 & 0.304 & 0.323 & 2.74675 & Tokunoshima/Tokunoshima-Okinoerabu/Middle Ryukyu/Ryukyu \\
\hline & & & & Akirigami-3 & 3FFTO-1-3 & & & 9 & 0.3 & 0.323 & 2.61145 & - \\
\hline & & & Oose & Oose & FFTO-2 & 8262 & 886 & 19 & 0.25 & 0.254 & 2.74265 & - \\
\hline & & & Uwanaru & Uwanaru 1 & FFTO-3 & 6791 & 403 & 24 & 0.253 & 0.262 & 2.68755 & Tokunoshima \\
\hline & & & Agon & Agon-1 & FFTO-4-1 & 6958 & 492 & 24 & 0.3 & 0.311 & 2.0111 & Tokunoshima \\
\hline & & & & Agon-2 & FFTO-4-2 & & & 16 & 0.256 & 0.287 & 1.78625 & Tokunoshima \\
\hline & & & Shikaura & Shikaura & FFTO-5 & 9038 & 1184 & 7 & 0.279 & 0.298 & 1.7933 & \\
\hline & & AF & Manda & Manda & AFTO-1 & 8817 & 1361 & 32 & 0.51 & 0.522 & 3.5405 & Tokunoshima/Tokunoshima-Okinoerabujima/Middle Ryukyu/Ryukyu \\
\hline & & & Kametoku & Kametoku & AFTO-2 & 9034 & 969 & 19 & 0.526 & 0.539 & 3.49895 & Tokunoshima/Tokunoshima-Okinoerabujima/Middle Ryukyu/Ryukyu \\
\hline & Okinoerabujima & $\mathrm{FF}$ & Amata & Amata & FFOE-1 & 8813 & 10.8 & 34 & 0.2 & 0.227 & 1.94955 & Tokunoshima-Okinoerabujima \\
\hline & Okinawaijma & $\mathrm{FF}$ & Sukuta & Sukuta-2 & FFOK-1 & 5573 & 369 & 28 & 0.294 & 0.289 & 2.4092 & Okinawajima/Middle Ryukyu/Ryukyu \\
\hline & & & Yofuke & Yofuke & FFOK-2 & 4442 & 403 & 31 & 0.098 & 0.121 & 2.2433 & Okinawajima \\
\hline & & & Okukubi & Okukubi & FFOK-3 & 8967 & 1682 & 33 & 0.262 & 0.274 & 2.14875 & Okinawajima \\
\hline & & & Hija & Hija-1 & FFOK-4-1 & 17218 & 5330 & 20 & 0.307 & 0.331 & 2.14305 & \\
\hline & & & 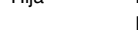 & Hija-2 & FFOK-4-2 & & & 8 & 0.296 & 0.293 & 2.07295 & - \\
\hline & & & Kyodafukuji & Kyodafukuj & j FFOK-5 & 6445 & 479 & 32 & 0.169 & 0.176 & 2.35485 & - \\
\hline & & & Kushiookawa & Kushi & FFOK-6 & 5299 & 662 & 32 & 0.133 & 0.144 & 1.92765 & - \\
\hline & & $\overline{\mathrm{AF}}$ & Sukuta & Sukuta-1 & AFOK-1 & & & 26 & 0.506 & 0.554 & 3.62115 & Okinawaijma/Middle Ryukyu/Ryukyu \\
\hline & & & Yofuke & Yofuke & AFOK-2 & & & 25 & 0.533 & 0.542 & 3.55845 & Okinawajima/Middle Ryukyu/Ryukyu \\
\hline & & & Okukubi & Okukubi & AFOK-3 & & & 27 & 0.477 & 0.523 & 3.6047 & \\
\hline & & & Hija & Hija-2 & AFOK-4 & & & 6 & 0.475 & 0.493 & 3.16775 & - \\
\hline & & & Sate & Sade & AFOK-5 & 7213 & 670 & 36 & 0.517 & 0.526 & 3.5023 & - \\
\hline & & & Yona & Yona & AFOK-6 & 7700 & 1179 & 33 & 0.482 & 0.518 & 3.5941 & - \\
\hline & Kumejima & $\mathrm{FF}$ & Shirase & Shirase & FFKM- 1 & 5925 & 699 & 31 & 0.241 & 0.274 & 1.9285 & Kumejima/Middle Ryukyu/Ryukyu \\
\hline & & & Suhara & Suhara & FFKM-2 & 3118 & 150 & 30 & 0.073 & 0.077 & 1.53105 & Kumejima \\
\hline & & $\overline{\mathrm{AF}}$ & Shirase & Shirase & AFKM-1 & & & 32 & 0.491 & 0.544 & 3.65115 & Kumejima/Middle Ryukyu/ryukyu \\
\hline & & & Suhara & Suhara & AFKM-2 & & & 32 & 0.494 & 0.52 & 3.5765 & Kumejima \\
\hline \multirow[t]{18}{*}{ South Ryukyl } & u Ishigakijima & $\mathrm{FF}$ & Miyara & Sokohara & FFIS-1 & 14750 & 3275 & 28 & 0.234 & 0.301 & 2.64575 & South Ryukyu \\
\hline & & $\mathrm{AF}$ & Arakawa & Arakawa & AFIS-1 & 2861 & 205 & 15 & 0.4 & 0.486 & 3.01515 & South Ryukyu/Ryukyu \\
\hline & & & _Nagura & Nagura & AFIS-2 & 8423 & 1604 & 24 & 0.505 & 0.496 & 3.02725 & South Ryukyu/Ryukyu \\
\hline & Iriomoteijma & FF & Pinai & Pinai & FFIR- 1 & 4705 & 361 & 24 & 0.152 & 0.202 & 1.5609 & Iriomotejima \\
\hline & & & Kura & Kura & FFIR-2 & 2937 & 160 & 24 & 0.094 & 0.104 & 1.21535 & \\
\hline & & & Geda & Geda-1 & FFIR-3-1 & 2885 & 131 & 24 & 0.083 & 0.106 & 1.2767 & . \\
\hline & & & & Geda-2 & FFIR-3-2 & & & 32 & 0.078 & 0.07 & 1.24555 & - \\
\hline & & & Yuchin & YuchinR-1 & FFIR-4-1 & 4266 & 498 & 13 & 0.233 & 0.248 & 2.6738 & \\
\hline & & & & YuchinR-2 & FFIR-4-2 & & & 42 & 0.24 & 0.238 & 2.2249 & - \\
\hline & & & & YuchinL & FFIR-5 & & & 24 & 0.103 & 0.118 & 1.62565 & \\
\hline & & & Urauchi & Urauchi & FFIR-6 & 21736 & 6437 & 24 & 0.329 & 0.39 & 3.0796 & Iriomotejima/South Ryukyu/Ryukyu \\
\hline & & & Arabara & Arabara & FFIR-7 & 3697 & 179 & 25 & 0.181 & 0.194 & 1.8484 & \\
\hline & & & Aira & Aira & FFIR-8 & 6130 & 557 & 46 & 0.289 & 0.305 & 2.9351 & Iriomotejima \\
\hline & & & Nishida & Nishida & FFIR-9 & 4759 & 476 & 9 & 0.3 & 0.299 & 2.74405 & - \\
\hline & & $\mathrm{AF}$ & Geda & Geda-2 & AFIR-1 & 4266 & 498 & 32 & 0.46 & 0.456 & 2.8527 & Iriomotejima/South Ryukyu/Ryukyu \\
\hline & & & Omija & Omija & AFIR-2 & 3395 & 227 & 24 & 0.508 & 0.502 & 3.1789 & Iriomotejima/South Ryukyu/Ryukyu \\
\hline & & & Yuchin & YuchinR-2 & AFIR-3 & 4266 & 498 & 24 & 0.437 & 0.46 & 2.7118 & \\
\hline & & & Nakama & Nakama & AFIR-4 & 15379 & 3355 & 27 & 0.437 & 0.466 & 2.9053 & \\
\hline \multirow[t]{3}{*}{ North Ryukyu } & Yakushima & $\mathrm{AF}$ & Takinokawa & Nunobiki-1 & AFYK-1-1 & 2000 & 70 & 34 & 0.426 & 0.457 & 2.97495 & - \\
\hline & & & & Nunobiki-2 & AFYK-1-2 & & & 27 & 0.417 & 0.456 & 3.07295 & - \\
\hline & & & Isso & Isso & AFYK-2 & 10521 & 1471 & 25 & 0.424 & 0.468 & 3.4101 & - \\
\hline \multirow[t]{3}{*}{ Honshu } & Honshu & $\mathrm{AF}$ & Esuno & Wakayama & AFHS-1 & & & 17 & 0.429 & 0.392 & 2.74215 & - \\
\hline & & & & Kagawa-1 & AFHS-2 & & & 5 & & 0.296 & 2.6938 & $\cdot$ \\
\hline & & & Yoshida & Kagawa-2 & AFHS-3 & & & 6 & 0.3 & 0.346 & 1.9406 & - \\
\hline Total & & & 42 river sys & i 50 points & 59 populations & & & 20 & & & & \\
\hline
\end{tabular}


Table S2 Primer pairs used in this study.

\begin{tabular}{|c|c|c|c|c|c|c|c|}
\hline Locus name & Motif & Forward primer sequence $\left(5^{\prime} \rightarrow 3^{\prime}\right)$ for microsatellite analysis. & Reverse primer sequence $\left(5^{\prime} \rightarrow 3^{\prime}\right)$ & Tm value & Fluorescent & Size range (bp) & No. of alleles \\
\hline \multicolumn{8}{|c|}{ Ohara et al (2004) } \\
\hline Rhi-3 & $(\mathrm{CA})_{5}(\mathrm{CA})_{4}(\mathrm{CA})_{10}$ & GGATATTCTGTCTCTGTT & АTCTATTCCCTTTCTGTTTGTCT & 53 & 6-FAM & $131-163$ & 9 \\
\hline Rhi-8 & $(\mathrm{CA})_{18}$ & ATACGCATAGTTTACCTTGA & CCTATGGTTTGAACTTGGGTGTG & 53 & HEX & $155-195$ & 8 \\
\hline Rhi-13 & $(\mathrm{TG})_{2}(\mathrm{TG})_{4}(\mathrm{GT})_{4}$ & GACTCGCCATCAAATACAAAAA & AGTCTCCTCCTCACCCGCACACC & 53 & NED & $99-132$ & 7 \\
\hline \multicolumn{8}{|c|}{ New loci (This study) } \\
\hline br_a_02 & $(\mathrm{AC})_{11}$ & (GCCTTGCCAGCCCGC)ACTCCTAGCCTACAGCTCACTCG & GCGTCAATGCAGCACTATATTACC & 63 & VIC & $82-126$ & 22 \\
\hline br_a_05 & $(\mathrm{AC})_{10}$ & (GCCTCCCTCGCGCCA)CCACTCAAGGCATTCTCCAGTTT & АTGTTTCCTCTCACAACAATCGC & 63 & $6-\mathrm{FAM}$ & $195-243$ & 14 \\
\hline br_a_06 & $(A C)_{9}$ & (GCCTTGCCAGCCCGC)AACGTCATTATCAGATCCGCTCC & СTCCTAACTTGGCAATCACATGG & 63 & VIC & $200-242$ & 17 \\
\hline br_a_07 & $(\mathrm{AC})_{12}$ & (CAGGACCAGGCTACCGTG)AGTTCATCGATCCATTCACCAGA & CGTGGAGCTCTAAACAAGAGGTG & 63 & NED & $174-226$ & 14 \\
\hline br_a_08 & $(\mathrm{AC})_{13}$ & (CGGAGAGCCGAGAGGTG)GTTCGTCTTCATCCATCACCAGT & TAAGATTTGTGCAGATGCGAAGG & 63 & PET & $194-252$ & 17 \\
\hline br_a_09 & $(\mathrm{AC})_{18}$ & (GCCTCCCTCGCGCCA)CCAGCTGAACATGGTGTAGCTTT & TCTCAGCTGCCAGTGAACTGAAC & 63 & $6-\mathrm{FAM}$ & $278-334$ & 29 \\
\hline br_a_10 & $(\mathrm{AC})_{11}$ & (GCCTTGCCAGCCCGC)CGCTGTCAATCACGGTAAGAGTT & СCTATAAGCACGACCTCCATGTG & 63 & VIC & $306-338$ & 15 \\
\hline br_b_05 & $(\mathrm{AC})_{12}$ & (GCCTCCCTCGCGCCA) GGAGCGGAGTTGTTGTGTCTTAC & TGTCCCAAGATAGTGCACAAATG & 63 & 6-FAM & $182-280$ & 45 \\
\hline br_b_06 & $(A C)_{11}$ & (GCCTTGCCAGCCCGC) ATCCTTAGGCCAACACAAAGCTC & TTAACCATATGCAAАССТСТССС & 63 & $\mathrm{VIC}$ & $190-243$ & 22 \\
\hline br_c_01 & $(\mathrm{AC})_{13}$ & (GCCTCCCTCGCGCCA) TGCAGTGGTTGTGTTGAAAGGTA & CCTTGCACAGATGTGTCTTAGCAT & 63 & $6-\mathrm{FAM}$ & $100-156$ & 20 \\
\hline br_c_02 & $(\mathrm{AC})_{10}$ & (GCCTTGCCAGCCCGC) GACAGCAGCACACTCCTAAGCTC & CAGATCCAGATCCTCTGTTGACAT & 63 & VIC & $111-135$ & 8 \\
\hline br_c_05 & $(A C)_{10}$ & (GCCTCCCTCGCGCCA) TGGCTCTAGAACTCTTGATGATGG & GCACAGTATAGACGCTCTGCACAT & 63 & 6-FAM & $212-286$ & 35 \\
\hline br_c_06 & $(\mathrm{AC})_{10}$ & (GCCTTGCCAGCCCGC) CTGAGCAGGACAGGAAGGAAATC & TGAATTGTTTGGACCATGAGACAG & 63 & $\mathrm{VIC}$ & $195-283$ & 39 \\
\hline br_c_07 & $(\mathrm{AC})_{14}$ & (CAGGACCAGGCTACCGTG) CCGTTTGACCGACTTCTTAAGGT & TTATCCTCACGСCTCCTTTCTTC & 63 & NED & $209-251$ & 17 \\
\hline br_c_08 & $(A C)_{10}$ & (CGGAGAGCCGAGAGGTG) TCTTGCATGACCACAATGTCAAC & AAGCTTGGTTTGTTTCCCTCTTG & 63 & PET & 222-258 & 15 \\
\hline br_c_09 & $(\mathrm{AC})_{10}$ & (GCCTCCCTCGCGCCA) TCCCACCAAACTAAGCCACAATA & GCTCCTCTGATGGTACTTGCTCA & 63 & 6-FAM & $334-386$ & 22 \\
\hline br_c_10 & $(\mathrm{AC})_{11}$ & (GCCTTGCCAGCCCGC) GACAGGAGCTCTGATCATCTCCA & ССАССАТССАССТСТАТААСТСТTТC & 63 & $\mathrm{VIC}$ & $340-380$ & 17 \\
\hline
\end{tabular}

The sequence in parentheses in forward primers indicate in tail sequence for universal fluorescent primers (Blacket et al., 2012). 
Table S3 List of summary statistics used in ABC analysis.

Summary statistics

Mean number of alleles over loci for each population

Standard deviation of Mean number of alleles over loci for each population

Mean number of alleles over loci and population

Standard deviation of mean number of alleles over loci and population

Mean total number of alleles over loci

Mean heterozygosity over loci for each population

Standard deviation of mean heterozygosity over loci for each population

Mean heterozygosity over loci and population

Standard deviation of Mean heterozygosity over loci and population

Mean total heterozygosity

Mean Graza-Williamson statistic over loci for each population

Standard deviation of mean Graza-Williamson statistic over loci for each population

Mean Graza-Williamson statistic over loci and population

Standard deviation of mean Graza-Williamson statistic over loci and population

Mean Graza-Williamson statistic over all populations

Mean modified Graza-Williamson statistic over loci for each population

Standard deviation of mean modified Graza-Williamson statistic over loci for each population

Mean modified Graza-Williamson statistic over loci and population

Standard deviation of mean modified Graza-Williamson statistic over loci and population

Global Fst

Global Fit

Pairwise Fst

Mean number of pairwise differences over populations

Mean delta mu-square

Mean allele range over loci for each population

Standard deviation of mean allele range over loci for each population

Mean allelic range over loci and populations

Standard deviation of mean allelic range over loci and populations

Mean total allelic range over loci and populations

Global Fis

Abbreviation
K_pop
Ksd_pop
MEAN_K
SD_K
TOT_K
H_pop
Hsd_pop
MEAN_H
SD_H
ALL_H
GW_pop
GWSD_pop
MEAN_GW
SD_GW
TOT_GW
NGW_pop
NGWSD_pop
MEAN_NGW
SD_NGW
FST
FIT
FST_pop1_pop2
PI_pop1_pop2
DMUSQ_pop1_pop2
R_pop
Rsd_pop
MEAN_R
MEAN_Rsd
TOT_R
FIS

Analysis the summary statistics used

All analysis

All analysis

All analysis

All analysis

All analysis

All analysis

All analysis

All analysis

All analysis

All analysis

All analysis

All analysis

All analysis

All analysis

All analysis

All analysis

All analysis

All analysis

All analysis

All analysis

All analysis

All analysis

All analysis

All analysis

Posterior predictive check only

Posterior predictive check only

Posterior predictive check only

Posterior predictive check only

Posterior predictive check only

Posterior predictive check only 


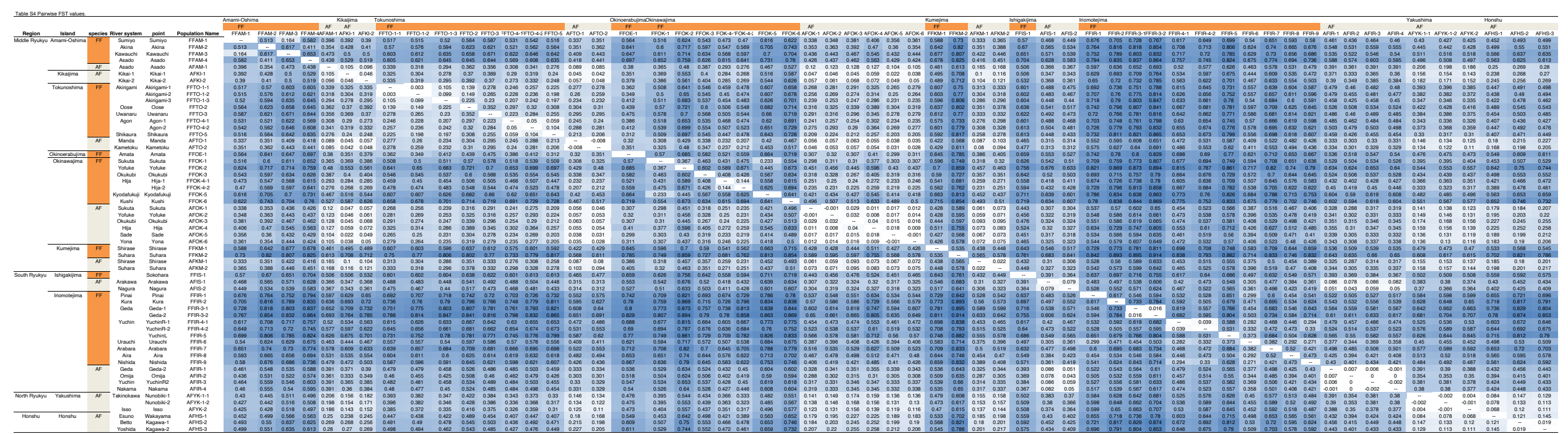




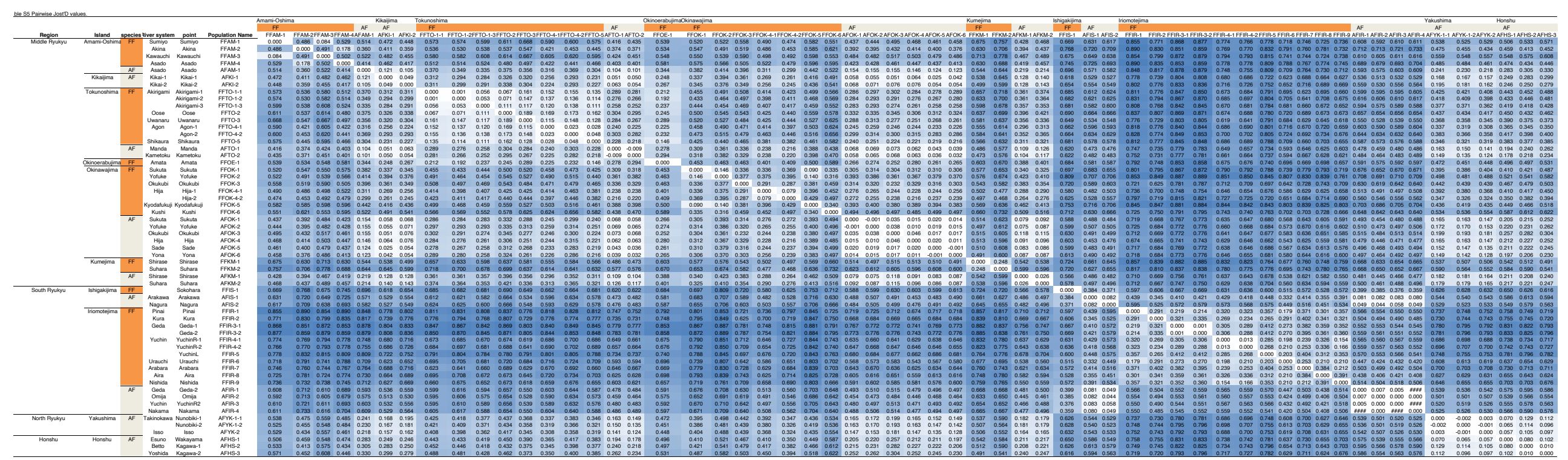


Table S6. Results of AMOVA analysis.

\begin{tabular}{|c|c|c|c|c|c|c|}
\hline Geographic scales & Form & Source of variation & \%var & Statistics & $F$ values & $P$ values \\
\hline \multirow[t]{16}{*}{ Among-islands within-regions } & \multirow[t]{8}{*}{ AF } & Within-individuals & 87.8 & FIT & 0.122 & - \\
\hline & & Among-individuals & 4.4 & FIS & 0.048 & 0.001 \\
\hline & & Among-rivers in Middle Ryukyu & 1.7 & FSC & 0.018 & 0.001 \\
\hline & & Among-islands in Middle Ryukyu & 6.2 & FCT & 0.062 & 0.001 \\
\hline & & Within-individuals & 91.8 & FIT & 0.082 & - \\
\hline & & Among-individuals & 2.8 & FIS & 0.03 & 0.016 \\
\hline & & Among-rivers in South Ryukyu & 1.7 & FSC & 0.018 & 0.001 \\
\hline & & Among-islands in South Ryukyu & 3.7 & FCT & 0.037 & 0.057 \\
\hline & \multirow[t]{8}{*}{$\mathrm{FF}$} & Within-individuals & 34.9 & FIT & 0.651 & - \\
\hline & & Among-individuals & 3.2 & FIS & 0.083 & 0.001 \\
\hline & & Among-rivers in Middle Ryukyu & 30.9 & FSC & 0.448 & 0.001 \\
\hline & & Among-islands in Middle Ryukyu & 31 & FCT & 0.31 & 0.001 \\
\hline & & Within-individuals & 29.4 & FIT & 0.706 & - \\
\hline & & Among-individuals & 3.3 & FIS & 0.101 & 0.001 \\
\hline & & Among-rivers in South Ryukyu & 36.5 & FSC & 0.527 & 0.001 \\
\hline & & Among-islands in South Ryukyu & 30.8 & FCT & 0.308 & 0.1 \\
\hline \multirow[t]{8}{*}{ Among-regions } & \multirow[t]{4}{*}{$\mathrm{AF}$} & Within-individuals & 68.1 & FIT & 0.319 & - \\
\hline & & Among-individuals & 4.1 & FIS & 0.057 & 0.001 \\
\hline & & Among-islands & 5.3 & FSC & 0.068 & 0.001 \\
\hline & & Among-regions & 22.5 & FCT & 0.225 & 0.002 \\
\hline & \multirow[t]{4}{*}{ FF } & Within-individuals & 26.7 & FIT & 0.733 & - \\
\hline & & Among-individuals & 22.5 & FIS & 0.457 & 0.001 \\
\hline & & Among-islands & 34 & FSC & 0.409 & 0.001 \\
\hline & & Among-regions & 16.8 & FCT & 0.168 & 0.038 \\
\hline
\end{tabular}




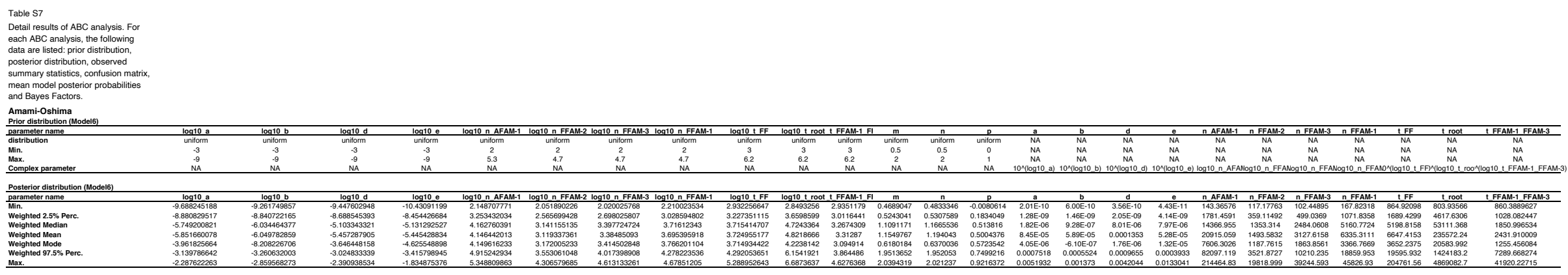

\begin{tabular}{|c|c|c|c|c|c|c|c|c|c|c|c|}
\hline 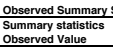 & 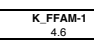 & $\frac{K_{-F F A M-2}}{23}$ & $\frac{K_{-F F A M-3}}{25}$ & $\begin{array}{l}\mathrm{K}_{7.5} \\
\end{array}$ & 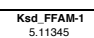 & 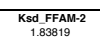 & $\begin{array}{c}\text { Ksd. FAM-3 } \\
1.9309\end{array}$ & 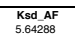 & 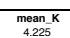 & 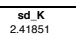 & $\begin{array}{l}\text { totk } \\
\text { i.t.5 }\end{array}$ \\
\hline 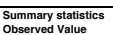 & 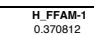 & $\begin{array}{c}\text { H.FFAM-2 } \\
\text { o. } 243667\end{array}$ & 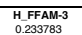 & $\begin{array}{l}\text { H.AF } \\
0.50722\end{array}$ & $\begin{array}{l}\text { Hsd FFAM-1 } \\
\text { o.3.319123 }\end{array}$ & 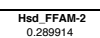 & $\begin{array}{c}\text { Hsd. FFAM-3 } \\
0.202524\end{array}$ & $\begin{array}{c}\text { HssdaF } \\
\text { os as781 }\end{array}$ & 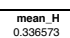 & 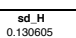 & $\begin{array}{l}\text { toth } \\
.03725\end{array}$ \\
\hline 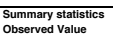 & 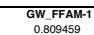 & 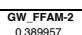 & 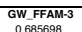 & 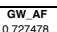 & $\begin{array}{l}\text { GWusd FFAM-1 } \\
0\end{array}$ & 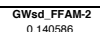 & 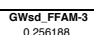 & $\begin{array}{c}\text { GWsd AF } \\
0.0252566\end{array}$ & 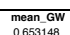 & $\begin{array}{c}\text { sdd GW } \\
\text { o1182036 }\end{array}$ & 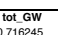 \\
\hline 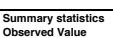 & 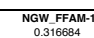 & $\begin{array}{l}\text { NGW, FFAM-2 } \\
\text { o. }\end{array}$ & $\begin{array}{l}\text { NGW.FFAM-3 } \\
\text { o. }\end{array}$ & $\begin{array}{l}\text { Now AF } \\
\text { o.5.5305 }\end{array}$ & 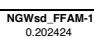 & 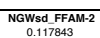 & 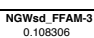 & $\begin{array}{l}\text { NoWsod AF } \\
\text { o. } 201813\end{array}$ & 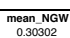 & $\begin{array}{l}\text { sdd NGW } \\
\text { o.1.1522233 }\end{array}$ & \\
\hline 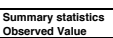 & 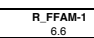 & 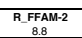 & 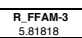 & 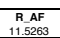 & 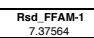 & 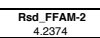 & 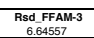 & 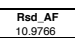 & 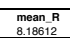 & $\begin{array}{c}\text { sd F } \\
2.55973 \\
\end{array}$ & $\begin{array}{c}\text { tot. } \\
14.5\end{array}$ \\
\hline $\begin{array}{l}\text { Summary statsistiss } \\
\text { osesered }\end{array}$ & 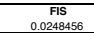 & $\begin{array}{c}\mathrm{FrT} \\
0.45506 \\
\end{array}$ & $\begin{array}{l}\mathrm{FHT} \\
0.40072\end{array}$ & & & & & & & & \\
\hline Summary tatalstics & FSTFFFAM-2FFA & TFFAM-3.FFACA & 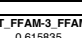 & 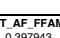 & FST_AFFFFAM-2 & FST-AFFFFAM-3 & & & & & \\
\hline & PILFFAM-2 FFA & FFAM-3. FAM & FFAM- FFAM & IAFFFAM & DAF FFAM-2 & AF FFAM-3 & & & & & \\
\hline 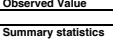 & MUSO.FFAM-2.F & SQ.FFAM-FF & LFAMM-1. & 2 CAF & & SSQAF FFAM. & & & & & \\
\hline
\end{tabular}

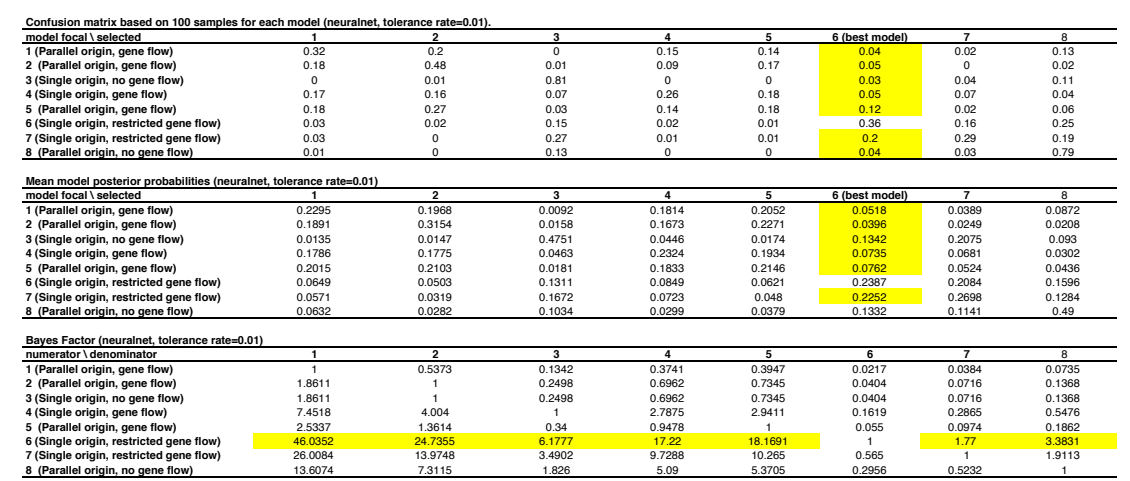




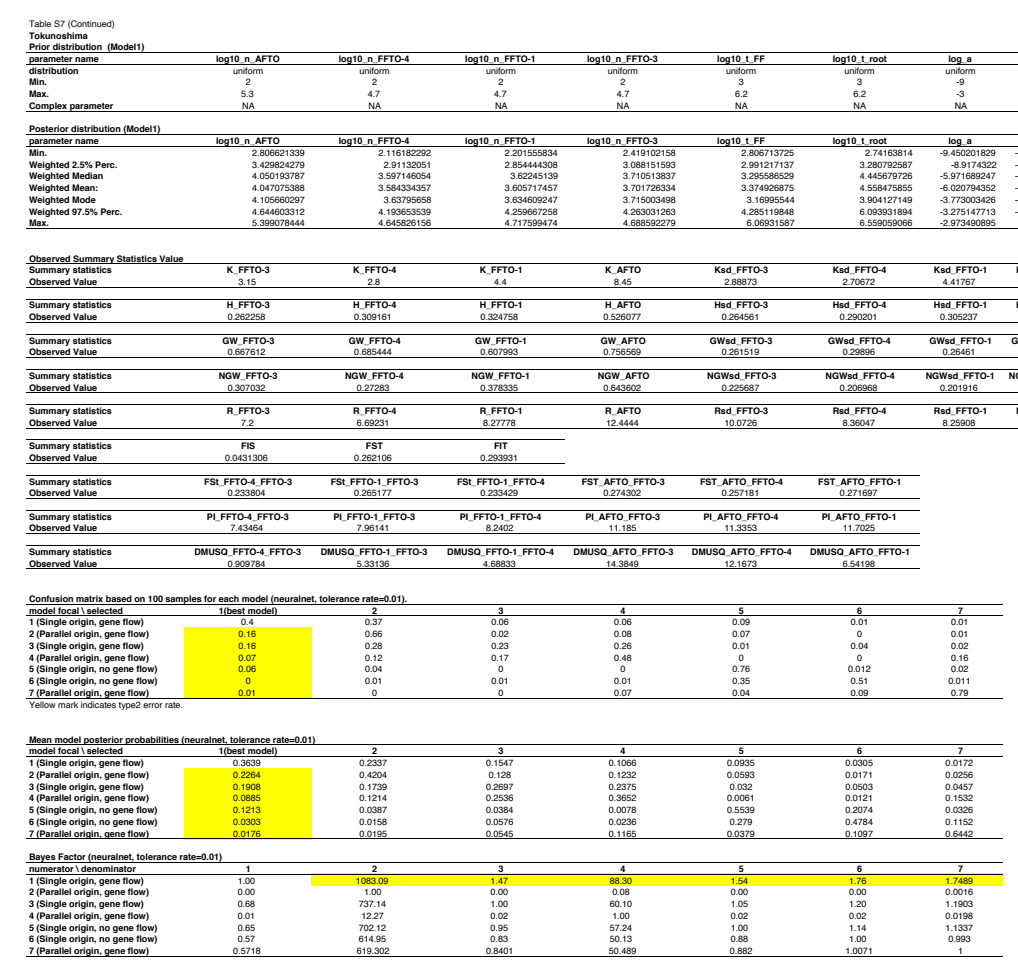




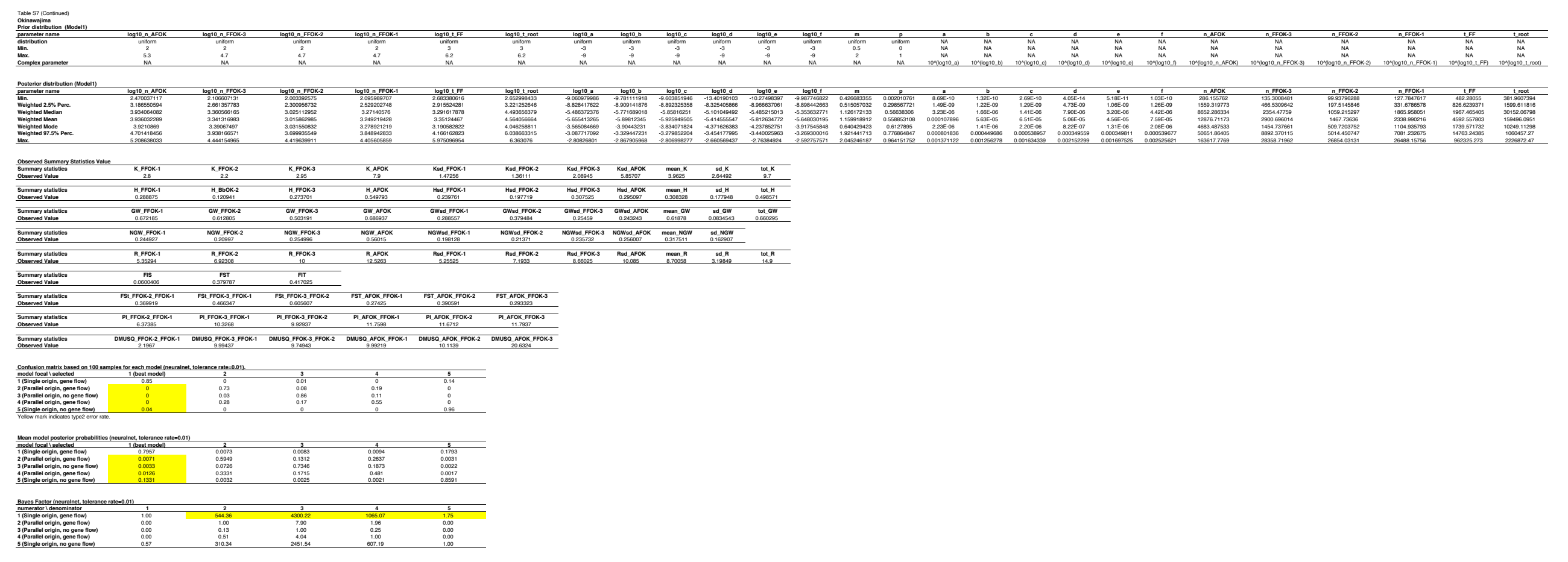


Table S7 (Continued)
Kumeilma

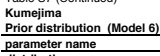

distributior name
Mini.
Max.
complex parameter
con

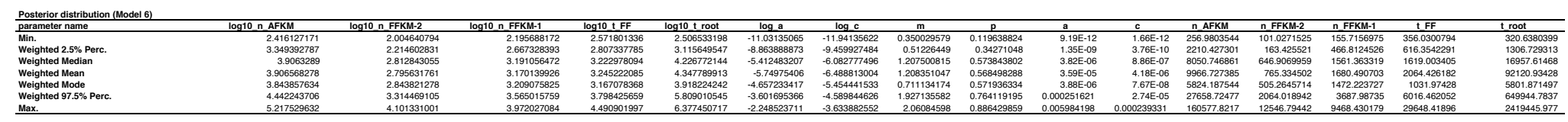

\begin{tabular}{|c|c|c|c|c|c|c|c|c|c|}
\hline 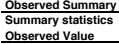 & 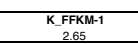 & 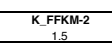 & 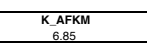 & $\begin{array}{l}\text { Ksd_FFFM-1 } \\
\text { 1.53125 }\end{array}$ & $\begin{array}{c}\text { Kss FFFM-2 } \\
0.688247\end{array}$ & 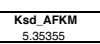 & 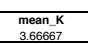 & $\begin{array}{l}\text { sd.k K } \\
2.81617 \\
\end{array}$ & $\begin{array}{l}\text { tot KK } \\
8.25 \\
x^{2}\end{array}$ \\
\hline $\begin{array}{l}\text { Summary statistics } \\
\text { Oobereved value }\end{array}$ & 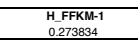 & $\begin{array}{l}\text { H.FFKM-2 } \\
0.0765779\end{array}$ & $\begin{array}{l}\text { H.AFKM } \\
0.537819 \\
\end{array}$ & $\begin{array}{c}\text { Hsd.FFKM-1 } \\
0.219506\end{array}$ & $\begin{array}{c}\text { Hsd.FFKM-2 } \\
0.148743 \\
\end{array}$ & $\begin{array}{l}\text { HsdA AFKM } \\
0.20866 \\
\end{array}$ & $\begin{array}{l}\text { mean H H } \\
0.296077 \\
\end{array}$ & $\begin{array}{l}\text { sd. H } \\
0.231424\end{array}$ & $\begin{array}{l}\text { tot H } \\
0.569533 \\
\end{array}$ \\
\hline $\begin{array}{l}\text { Sunmmary statistics } \\
\text { ofserend value }\end{array}$ & 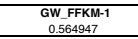 & $\begin{array}{l}\text { GW.FFKM-2 } \\
0.520009\end{array}$ & $\begin{array}{l}\text { GW.AFKM } \\
0.6717573\end{array}$ & 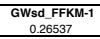 & 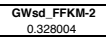 & $\begin{array}{l}\text { GWosd AfKM } \\
0.225523\end{array}$ & $\begin{array}{l}\text { mean - GW } \\
\text { O.5868176 }\end{array}$ & $\begin{array}{l}\text { sdd.GW } \\
0.07770009 \\
\end{array}$ & 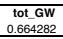 \\
\hline $\begin{array}{l}\text { Summary statisitics } \\
\text { Oosbered value }\end{array}$ & 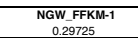 & 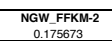 & 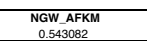 & $\begin{array}{l}\text { NaWsd FFKM-1 } \\
\text { No47376 }\end{array}$ & 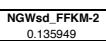 & 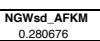 & 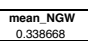 & $\begin{array}{c}\text { sdd NGW } \\
\text { o. } 187174\end{array}$ & \\
\hline $\begin{array}{l}\text { Summary ytatisics } \\
\text { observed Value }\end{array}$ & $\begin{array}{l}\text { R.FFKM-1 } \\
5.77778\end{array}$ & 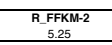 & $\begin{array}{l}\text { R.AFKM } \\
13.6471\end{array}$ & $\begin{array}{c}\text { Rsd.FFKM-1 } \\
5.07074\end{array}$ & $\begin{array}{c}\text { Rsd FFFM-2 } \\
3.99106 \\
\end{array}$ & $\begin{array}{l}\text { AsdA AFKM } \\
12.879\end{array}$ & 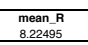 & $\begin{array}{l}\text { sd R } \\
4.7031 \\
\end{array}$ & $\begin{array}{l}\text { tot } \mathrm{R} \\
13.95 \\
\end{array}$ \\
\hline $\begin{array}{l}\text { Sunmerry statisics } \\
\text { Oossered value }\end{array}$ & 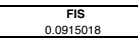 & $\begin{array}{ll}\mathrm{PST} \\
0.478775 \\
\end{array}$ & 0.052648 & & & & & & \\
\hline 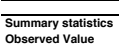 & 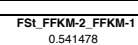 & 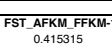 & $\begin{array}{l}\text { FST_AFKM_FFKM-2 } \\
0.514248\end{array}$ & & & & & & \\
\hline $\begin{array}{l}\text { Summarar statistics } \\
\text { Oobserved value }\end{array}$ & $\begin{array}{c}\text { Pl_FFKM-2 FFKM-1 } \\
7.49005\end{array}$ & $\begin{array}{l}P \perp A F K M=F F M-1 \\
14.3749\end{array}$ & $\begin{array}{l}\text { PI_AFKM_FFKM-2 } \\
14.2251\end{array}$ & & & & & & \\
\hline $\begin{array}{l}\text { Sunmmary statisicics } \\
\text { observed valut }\end{array}$ & $\begin{array}{l}\text { DMUSO_FFKM-2.FFM } \\
17.6762 \text {-FKM }\end{array}$ & musa AFKMFFKI & DMUSQ AAFMMFFKM-2 & & & & & & \\
\hline
\end{tabular}

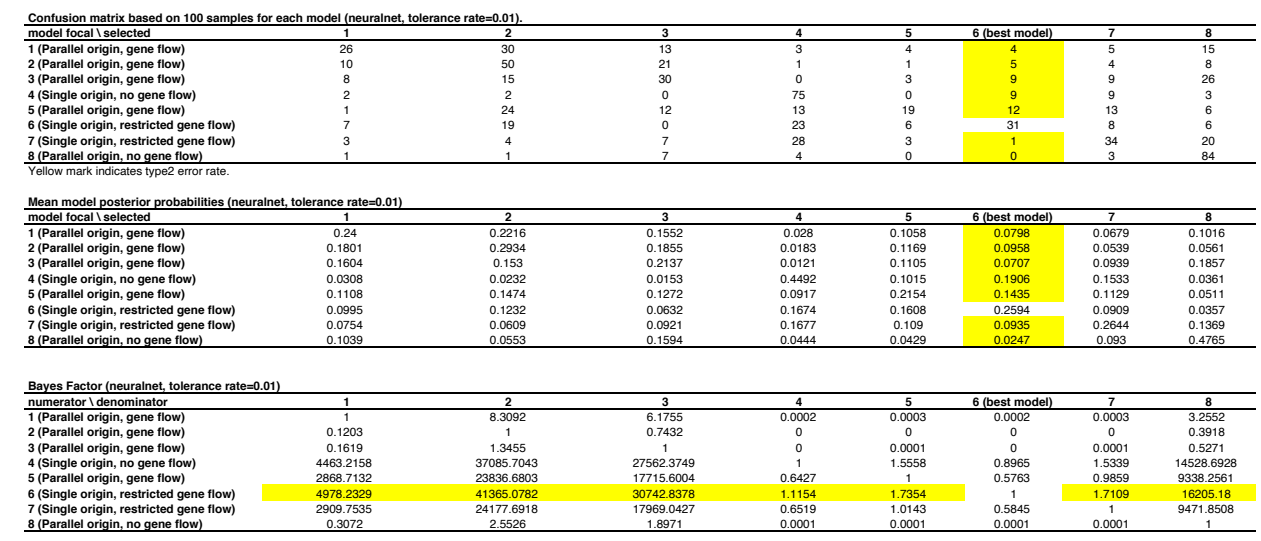




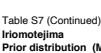

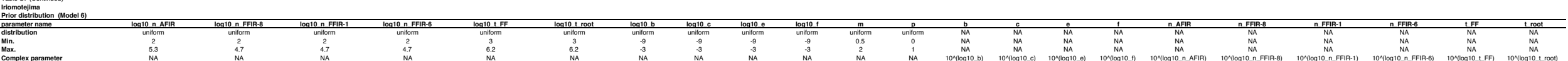

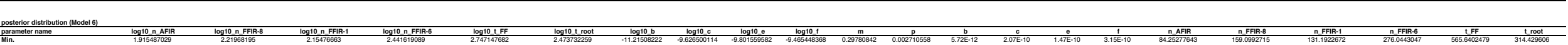

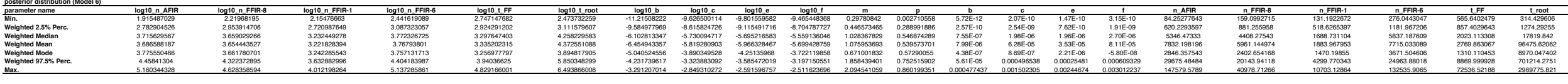

\begin{tabular}{|c|c|c|c|c|c|c|c|c|c|c|c|}
\hline 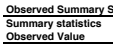 & $\begin{array}{l}K_{2,35} \text { FFF-1 } \\
25\end{array}$ & 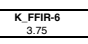 & 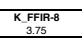 & $\begin{array}{l}\text { KAFAIR } \\
5.85 \\
\end{array}$ & 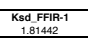 & 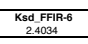 & 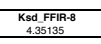 & 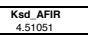 & $\begin{array}{l}\text { manan } \\
3.925 \\
\end{array}$ & 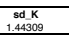 & $\begin{array}{l}100, \mathrm{~K} \\
8.95 \\
\text { 8.5 }\end{array}$ \\
\hline 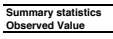 & $\begin{array}{l}\text { HFFFA-1 } \\
\text { O20201064 }\end{array}$ & 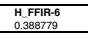 & 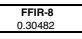 & 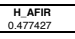 & 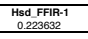 & 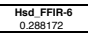 & 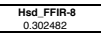 & 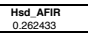 & $\begin{array}{l}\text { manan } \\
0.343023\end{array}$ & $\begin{array}{l}\text { sost } \\
\text { ofl17997 }\end{array}$ & 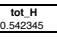 \\
\hline 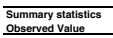 & 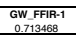 & 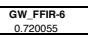 & 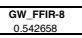 & 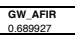 & 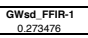 & 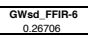 & 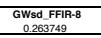 & 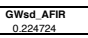 & 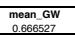 & 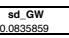 & 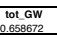 \\
\hline $\begin{array}{l}\text { minary statsistces } \\
\text { sered valute }\end{array}$ & 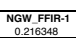 & 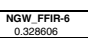 & 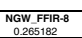 & 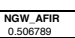 & 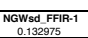 & 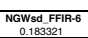 & 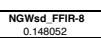 & 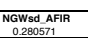 & $\begin{array}{c}\text { maan New } \\
\text { o.3020231 }\end{array}$ & 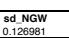 & \\
\hline $\begin{array}{l}\text { mary statsitics } \\
\text { reo valua }\end{array}$ & 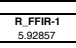 & 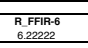 & 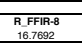 & $\begin{array}{l}\text { RAAFF } \\
8.63158 \\
\end{array}$ & 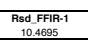 & 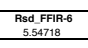 & 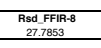 & $\begin{array}{c}\text { Resc AfFR } \\
629118 \\
62918\end{array}$ & $\begin{array}{l}\text { meann } \mathrm{B} \\
9.3879\end{array}$ & $\begin{array}{c}\text { solp } \\
\text { s.06789 }\end{array}$ & 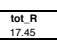 \\
\hline
\end{tabular}

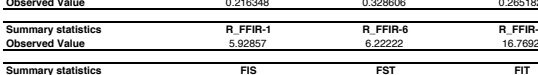

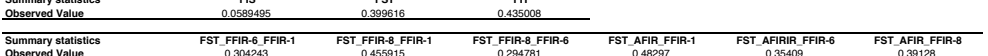

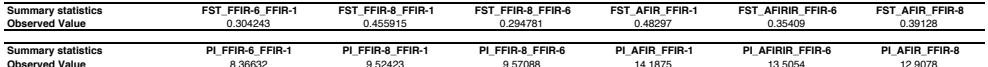

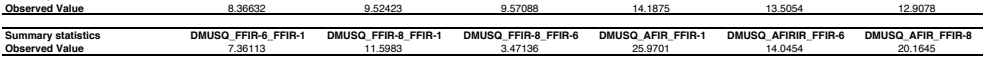
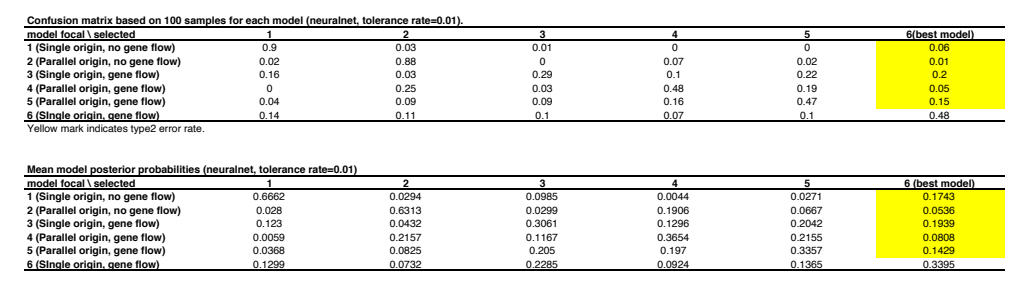

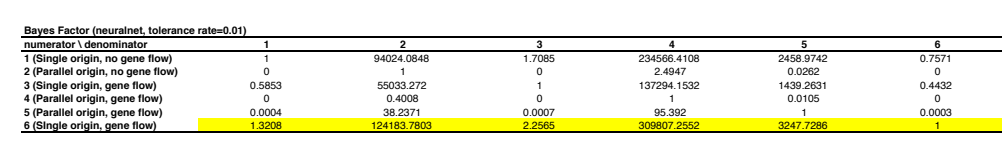




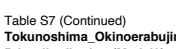

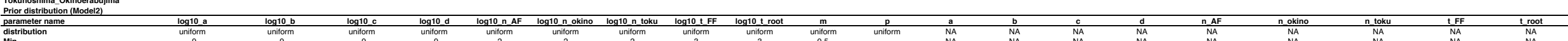

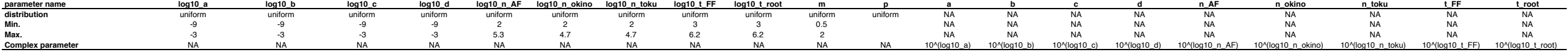

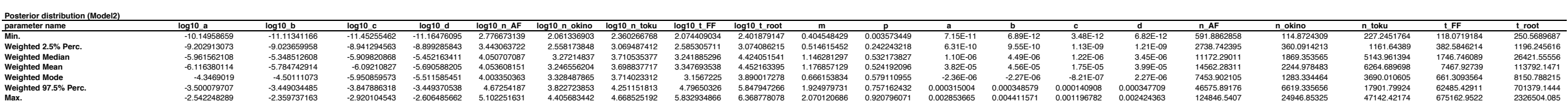

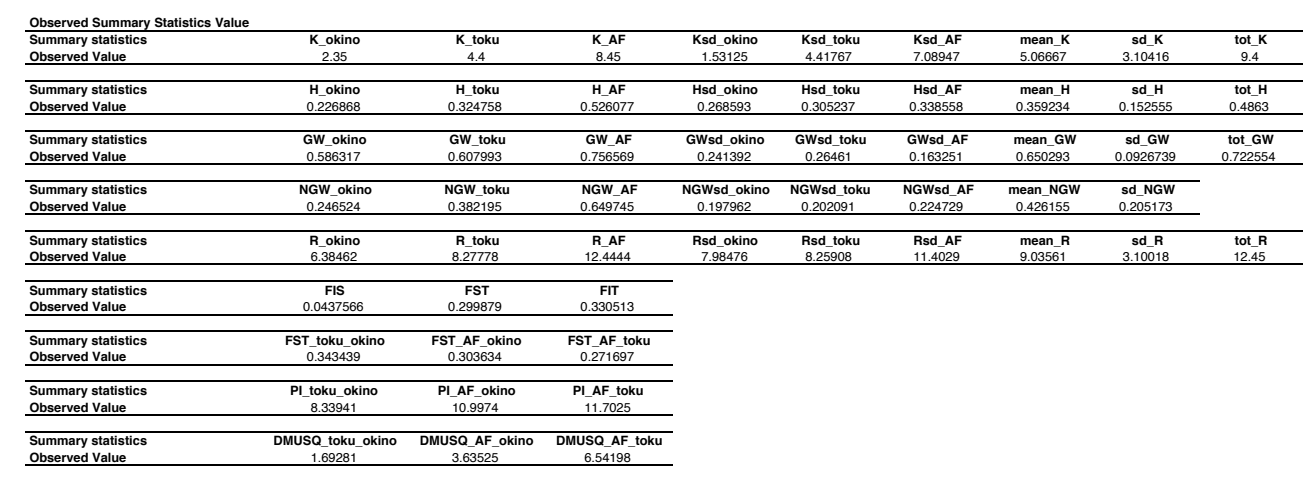
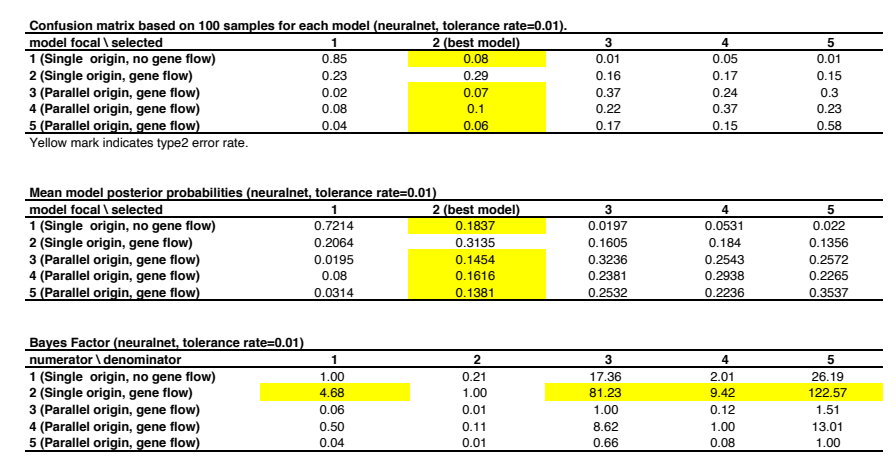


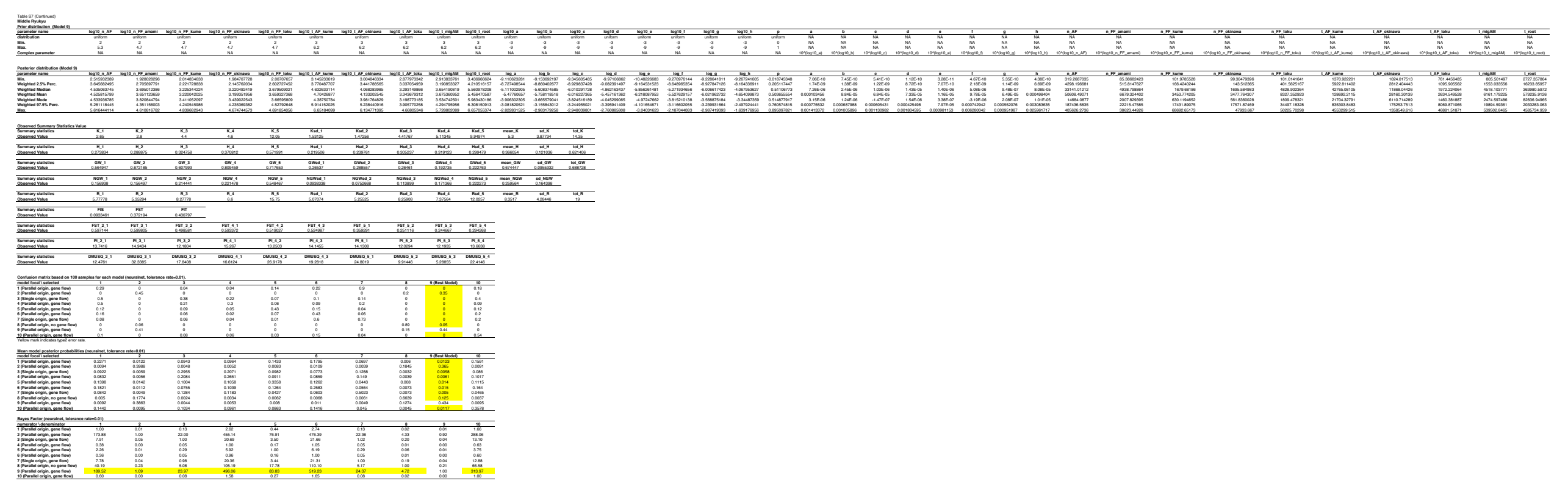




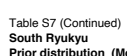

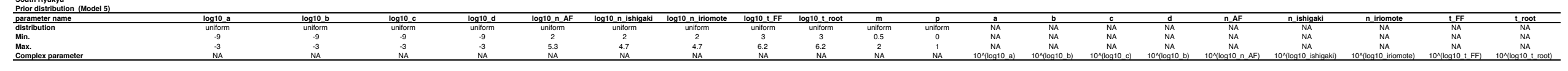

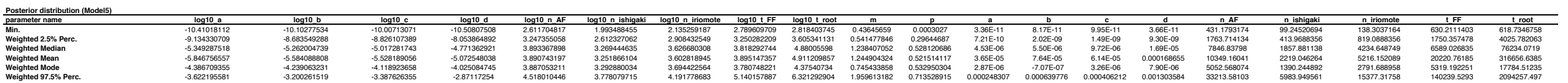

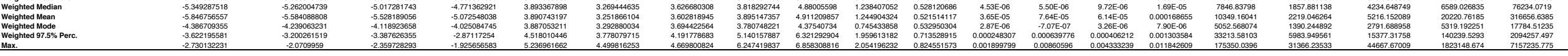

\begin{tabular}{|c|c|c|c|c|c|c|c|c|c|}
\hline 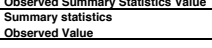 & $\begin{array}{l}\text { Kiritimomote } \\
3.75\end{array}$ & $\begin{array}{l}K_{\text {Ki-shigaki }} \\
3.1\end{array}$ & $\begin{array}{l}K_{7.3}^{K A F} \\
7\end{array}$ & 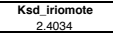 & $\begin{array}{l}\text { Ksd. sisigaki } \\
1.33377\end{array}$ & $\begin{array}{l}\text { Kss.AF } \\
\text { 4.780044 } \\
\end{array}$ & 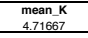 & $\begin{array}{l}\text { sdd K } \\
2.26072 \\
\end{array}$ & $\begin{array}{l}\text { toto } \mathrm{K} \\
8.8\end{array}$ \\
\hline $\begin{array}{l}\text { Summarry stititics } \\
\text { Observed a value }\end{array}$ & 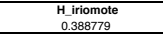 & 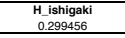 & $\begin{array}{l}\text { HAfA } \\
0.50118\end{array}$ & 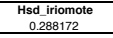 & 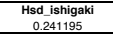 & $\begin{array}{l}\text { Hstaf AF } \\
0.200336\end{array}$ & 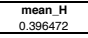 & $\begin{array}{l}\text { sdd H } \\
0.101081 \\
\end{array}$ & 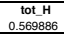 \\
\hline $\begin{array}{l}\text { Summary stititisis } \\
\text { Observed value }\end{array}$ & 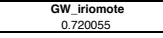 & 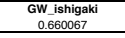 & $\begin{array}{l}\text { GWWA-AF } \\
0.653008\end{array}$ & 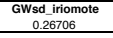 & 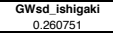 & $\begin{array}{l}\text { Gessd Af } \\
0.245748\end{array}$ & $\begin{array}{l}\text { mean GW } \\
0.67771\end{array}$ & 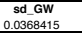 & 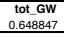 \\
\hline $\begin{array}{l}\text { Summary statistics } \\
\text { Oobserved avaue }\end{array}$ & \begin{tabular}{|l|} 
NGWW iniromote \\
0.324162
\end{tabular} & 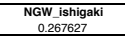 & $\begin{array}{l}\text { NGGWAF } \\
\text { N.5939343 } \\
\end{array}$ & $\begin{array}{l}\text { NGWwsdifiomote } \\
0.2216959\end{array}$ & 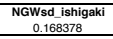 & 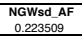 & $\begin{array}{l}\text { mean Naw } \\
\text { o. } 37770444\end{array}$ & 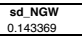 & \\
\hline $\begin{array}{l}\text { Summary stititisis } \\
\text { Observed Value }\end{array}$ & 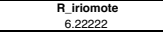 & 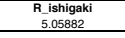 & 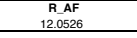 & 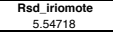 & 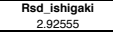 & $\begin{array}{l}\text { Rss.AF } \\
7.13733 \\
\end{array}$ & 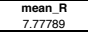 & $\begin{array}{l}\text { sd R } \\
3.77446 \\
\end{array}$ & $\begin{array}{l}\text { tot R } \\
\text { i3.35 }\end{array}$ \\
\hline $\begin{array}{l}\text { Summary statistics } \\
\text { observed Value }\end{array}$ & $\begin{array}{l}\mathrm{FIS} \\
0.0909702 \\
.\end{array}$ & $\begin{array}{ll}\text { FST } \\
0.349899 \\
0\end{array}$ & 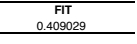 & & & & & & \\
\hline $\begin{array}{l}\begin{array}{l}\text { Summary statistics } \\
\text { Oobserved value }\end{array} \\
\end{array}$ & $\begin{array}{l}\text { FST_ishigaki iriomote } \\
0.501156\end{array}$ & $\begin{array}{l}\text { FST-AF-iriomote } \\
\text { 0.3.224191 }\end{array}$ & 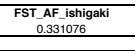 & & & & & & \\
\hline $\begin{array}{l}\text { Summary stititisis } \\
\text { Observed value }\end{array}$ & $\begin{array}{l}\text { PLishigigkiki irionote } \\
\text { 1344829 }\end{array}$ & 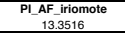 & 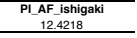 & & & & & & \\
\hline $\begin{array}{l}\text { Summary statistics } \\
\text { Observed Value }\end{array}$ & $\begin{array}{c}\text { DMUSO_ ishigaki iriomote } \\
13.1287\end{array}$ & 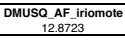 & $\begin{array}{l}\text { DMUSQAAF ishigaki } \\
7.11103 \\
\end{array}$ & & & & & & \\
\hline
\end{tabular}

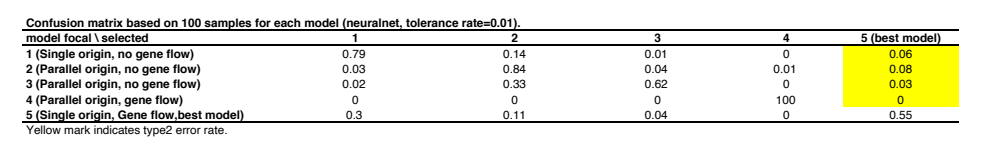

\begin{tabular}{|c|c|c|c|c|c|}
\hline 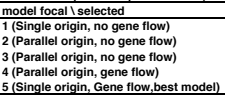 & 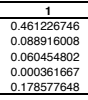 & 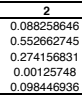 & 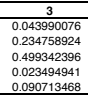 & 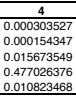 & 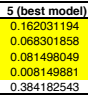 \\
\hline \multicolumn{6}{|c|}{$\begin{array}{l}\text { Bayes Factor (neurathet, tolerance rate }=0.01) \\
\end{array}$} \\
\hline 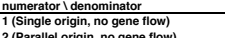 & & $\frac{2}{14.01}$ & 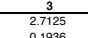 & $\frac{4.401}{6.1901}$ & 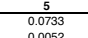 \\
\hline 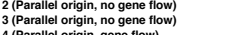 & $\begin{array}{l}0.0767 \\
0.3687\end{array}$ & 5.1649 & 0.1936 & $\begin{array}{l}0.4282 \\
2.282\end{array}$ & $\begin{array}{l}0.052 \\
0.027 \\
0.27\end{array}$ \\
\hline & 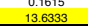 & $\begin{array}{l}21920300 \\
1900\end{array}$ & $\begin{array}{r}3458307 \\
30907\end{array}$ & 843915 & \\
\hline
\end{tabular}




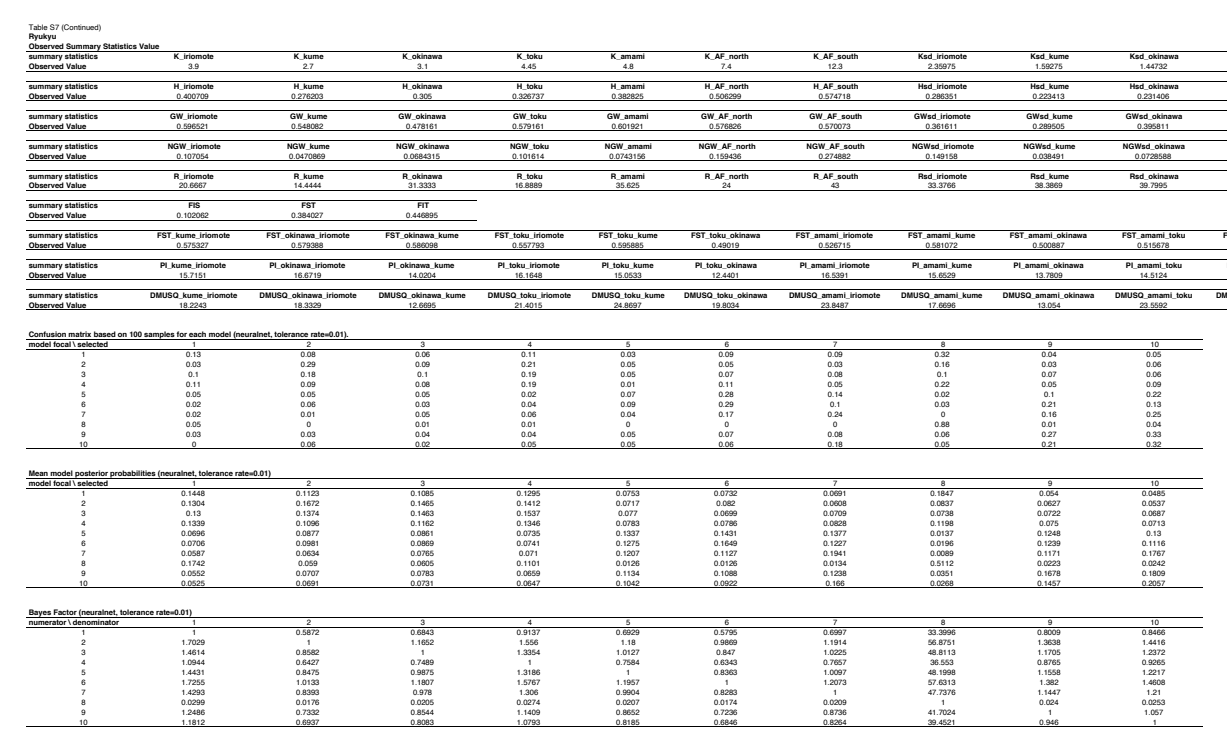




\begin{tabular}{|c|c|c|c|c|c|c|c|c|c|c|}
\hline Island Name & Freshwater form distribution & Latitude & Longitude & Area $\left(\mathrm{km}^{2}\right)$ & Area $\log 10$ & Catchment area $\left(\mathrm{km}^{2}\right)$ & Catchment area log10 & Length $(\mathrm{m})$ & Length log & No. Steep Slopes \\
\hline Okinawajima Is. & 1 & $26^{\circ} 35^{\prime}$ & $128^{\circ} 2^{\prime}$ & 1206.93 & 3.082 & 53.30 & 1.727 & 17218 & 4.236 & 152 \\
\hline Amami-Oshima Is. & 1 & $28^{\circ} 16^{\prime}$ & $129^{\circ} 20^{\prime}$ & 712.5 & 2.853 & 48.58 & 1.686 & 18478 & 4.267 & 548 \\
\hline Iriomotejima Is. & 1 & $24^{\circ} 20^{\prime}$ & $123^{\circ} 50^{\prime}$ & 289.6 & 2.462 & 64.37 & 1.809 & 21736 & 4.337 & 435 \\
\hline Tokunoshima Is. & 1 & $27^{\circ} 45^{\prime}$ & $128^{\circ} 57^{\prime}$ & 247.9 & 2.394 & 34.00 & 1.531 & 15754 & 4.197 & 304 \\
\hline Ishigakijima Is. & 1 & $24^{\circ} 24^{\prime}$ & $124^{\circ} 11^{\prime}$ & 222.2 & 2.347 & 32.75 & 1.515 & 14750 & 4.169 & 101 \\
\hline Okinoerabujima is. & 1 & $27^{\circ} 22^{\prime}$ & $128^{\circ} 35^{\prime}$ & 93.7 & 1.972 & 10.84 & 1.035 & 8813 & 3.945 & 15 \\
\hline Kakeromajima Is. & 0 & $28^{\circ} 7^{\prime}$ & $129^{\circ} 14^{\prime}$ & 77.3 & 1.888 & 2.99 & 0.475 & 3601 & 3.556 & 26 \\
\hline Kumejima Is. & 1 & $26^{\circ} 22^{\prime}$ & $126^{\circ} 46^{\prime}$ & 59.5 & 1.775 & 6.99 & 0.844 & 5925 & 3.773 & 35 \\
\hline Kikaijima Is. & 0 & $28^{\circ} 18^{\prime}$ & $129^{\circ} 57^{\prime}$ & 57.0 & 1.755 & 4.81 & 0.683 & 4957 & 3.695 & 5 \\
\hline Iheyajima Is. & 0 & $27^{\circ} 3^{\prime}$ & $127^{\circ} 58^{\prime}$ & 20.7 & 1.315 & 4.93 & 0.693 & 4428 & 3.646 & 2 \\
\hline Tokashikijima Is. & 0 & $26^{\circ} 11^{\prime}$ & $127^{\circ} 21^{\prime}$ & 15.3 & 1.185 & 3.33 & 0.522 & 4029 & 3.605 & 19 \\
\hline Izenajima Is. & 0 & $26^{\circ} 56^{\prime}$ & $127^{\circ} 56^{\prime}$ & 14.1 & 1.150 & 3.05 & 0.484 & 3918 & 3.593 & 3 \\
\hline Ukejima Is. & 0 & $28^{\circ} 1^{\prime}$ & $129^{\circ} 15^{\prime}$ & 13.3 & 1.125 & 2.38 & 0.377 & 2275 & 3.357 & 21 \\
\hline Yorojima Is. & 0 & $28^{\circ} 2^{\prime}$ & $129^{\circ} 9^{\prime}$ & 9.4 & 0.971 & 2.27 & 0.356 & 3257 & 3.513 & 12 \\
\hline Yagajijima Is. & 0 & $26^{\circ} 40^{\prime}$ & $128^{\circ} 0^{\prime}$ & 7.8 & 0.893 & 1.16 & 0.063 & 2072 & 3.316 & 0 \\
\hline Miyagijima Is. & 0 & $26^{\circ} 22^{\prime}$ & $128^{\circ} 0^{\prime}$ & 5.5 & 0.744 & 0.90 & -0.048 & 1867 & 3.271 & 2 \\
\hline Akajima Is. & 0 & $26^{\circ} 12^{\prime}$ & $127^{\circ} 17^{\prime}$ & 3.8 & 0.580 & 0.46 & -0.333 & 1364 & 3.135 & 4 \\
\hline Hamahigajima Is. & 0 & $26^{\circ} 19^{\prime}$ & $127^{\circ} 57^{\prime} 30^{\prime \prime}$ & 2.1 & 0.320 & 0.36 & -0.441 & 1297 & 3.113 & 0 \\
\hline
\end{tabular}




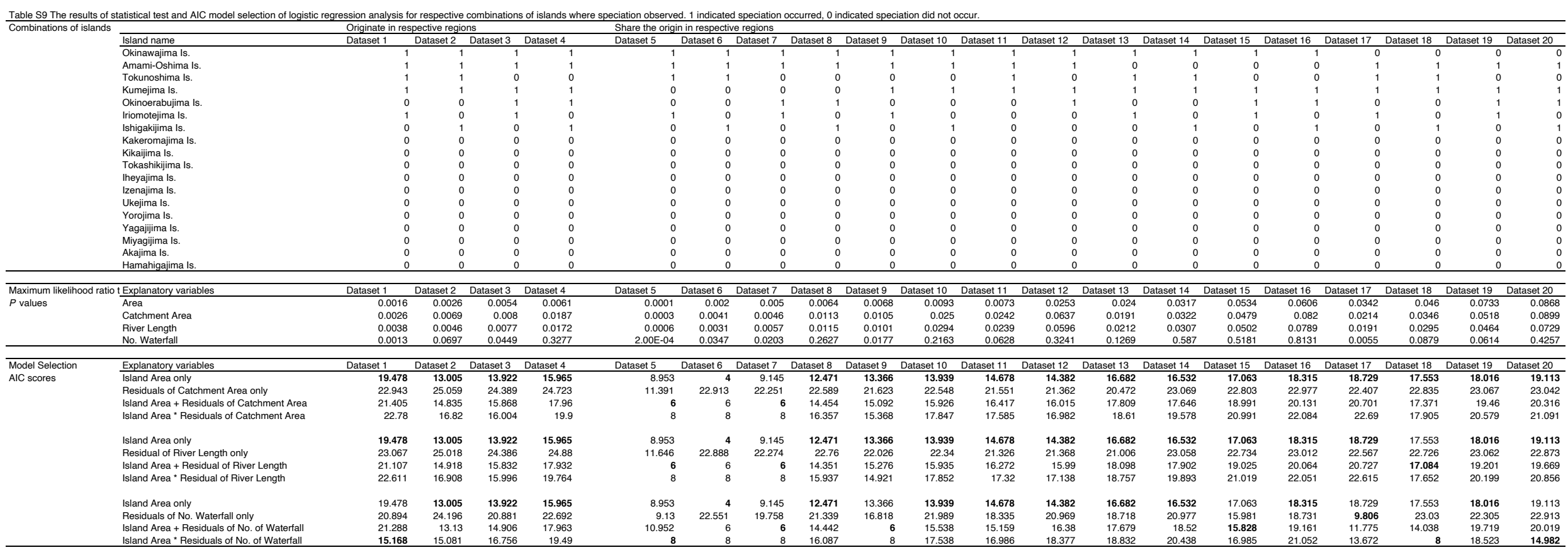

